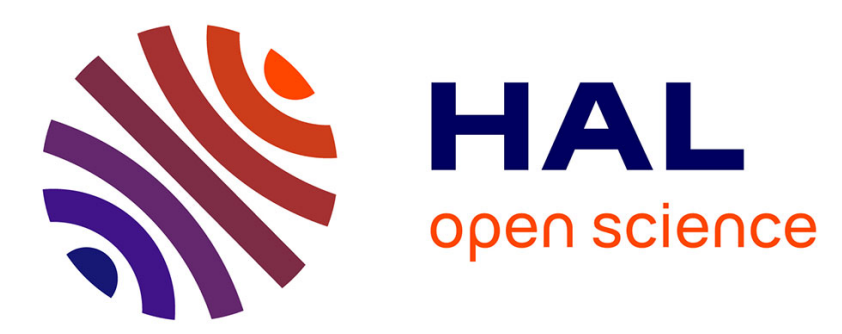

\title{
Dietary linseed and starch supplementation decreases methane production of fattening bulls
}

Maguy Eugène, Cécile Martin, Marie-Madeleine Mialon, Daniel Krauss, Gilles Renand, Michel Doreau

\section{- To cite this version:}

Maguy Eugène, Cécile Martin, Marie-Madeleine Mialon, Daniel Krauss, Gilles Renand, et al.. Dietary linseed and starch supplementation decreases methane production of fattening bulls. Greenhouse Gases and Animal Agriculture Conference, Oct 2010, Banff, Canada. hal-01193604

\section{HAL Id: hal-01193604 \\ https://hal.science/hal-01193604}

Submitted on 3 Jun 2020

HAL is a multi-disciplinary open access archive for the deposit and dissemination of scientific research documents, whether they are published or not. The documents may come from teaching and research institutions in France or abroad, or from public or private research centers.
L'archive ouverte pluridisciplinaire HAL, est destinée au dépôt et à la diffusion de documents scientifiques de niveau recherche, publiés ou non, émanant des établissements d'enseignement et de recherche français ou étrangers, des laboratoires publics ou privés. 


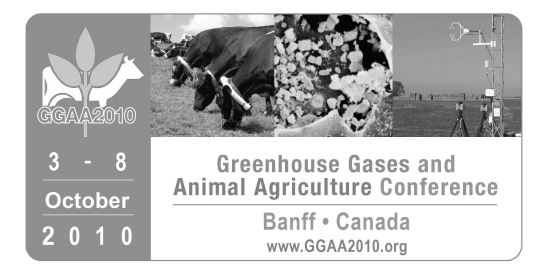

\title{
LISTING OF ABSTRACTS
}

\author{
to be presented at
}

GREENHOUSE GASES AND ANIMAL AGRICULTURE CONFERENCE

October 3-8, 2010

\author{
Banff, Canada
}

\section{TABLE OF CONTENTS}

Conference overview

Session 1: Oral abstracts

Poster abstracts

Session 2: Oral abstracts

Poster abstracts

Session 3: Oral abstracts

Poster abstracts

Session 4: Oral abstracts

Poster abstracts

Session 5: Oral abstracts

Poster abstracts

Session 6: Oral abstracts

Poster abstracts

Post-conference meeting and workshop 
CONFERENCE OVERVIEW

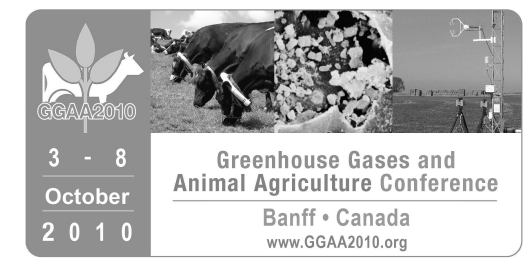

\begin{tabular}{|c|c|}
\hline Day & Event \\
\hline $\begin{array}{l}\text { Sunday } \\
\text { October } 3\end{array}$ & $\begin{array}{l}\text { Pre-conference workshops: } \begin{array}{l}\text { Workshop } 1(0900-1200 \mathrm{~h}) \\
\text { Workshop } 2(0900-1200 \mathrm{~h}) \\
\text { Workshop } 3(1400-1700 \mathrm{~h}) \\
\text { Workshop } 4(1400-1700 \mathrm{~h}) \\
\text { Workshop } 5(1400-1700 \mathrm{~h})\end{array}\end{array}$ \\
\hline $\begin{array}{l}\text { Monday } \\
\text { October } 4\end{array}$ & $\begin{array}{l}\text { Session } 1(0830-1200 \mathrm{~h}) \\
\text { Session } 2(1330-1700 \mathrm{~h}) \\
\text { Western Barbeque }(1830-2200 \mathrm{~h})\end{array}$ \\
\hline $\begin{array}{l}\text { Tuesday } \\
\text { October } 5\end{array}$ & $\begin{array}{l}\text { Session } 3(0800-1200 \mathrm{~h}) \\
\text { Session } 4(1315-1700 \mathrm{~h}) \\
\text { Happy Hour }(1700-1800 \mathrm{~h})-\text { Sponsored by PGgRc and NZAGRC, New Zealand }\end{array}$ \\
\hline $\begin{array}{l}\text { Wednesday } \\
\text { October } 6\end{array}$ & $\begin{array}{l}\text { Receding Glaciers and Climate Change Tour }(0745-1700 \mathrm{~h}) \\
\text { Reception and Gala Banquet }(1830-2200 \mathrm{~h})\end{array}$ \\
\hline $\begin{array}{l}\text { Thursday } \\
\text { October } 7\end{array}$ & $\begin{array}{l}\text { Session } 5(0800-1145 h) \\
\text { Session } 6(1315-1630 h) \\
\text { Session } 7(1635-1715 h)\end{array}$ \\
\hline $\begin{array}{l}\text { Friday } \\
\text { October } 8\end{array}$ & $\begin{array}{l}\text { Global Research Alliance (GRA Livestock) Open Forum (0900 -1200h) } \\
\text { Post Conference Workshop: } \\
\text { Greenhouse Gases and Sustainable Agriculture for Developing Countries (1300 - } 1740 \text { h) } \\
\text { Sponsored by: MAFF Japan, JIRCAS, Hokkaido University, Obihiro University of } \\
\text { Agriculture and Veterinary Medicine }\end{array}$ \\
\hline
\end{tabular}




\title{
SESSION 1: ORAL ABSTRACTS
}

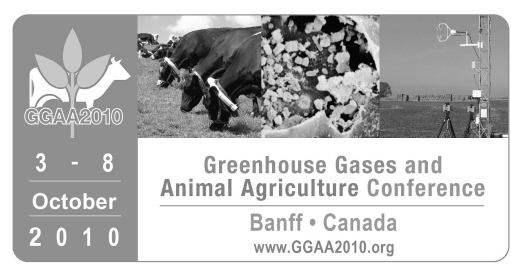

\section{PLEASE NOTE: Authors denoted with an asterisk are registered GGAA2010 delegates}

\author{
The significance of livestock as a contributor to global greenhouse gas emissions today and in the \\ near future \\ F.P. O'Mara*
}

\begin{abstract}
Animal agriculture is responsible for 8 to $10.8 \%$ of total global greenhouse gas (GHG) emissions when assessed on the basis of IPCC accounting. When assessed on the basis of a lifecycle analysis, the contribution of livestock is up to $18 \%$ of total global emissions. Asia is the source of most enteric methane emissions with Latin America, Africa, Western Europe and North America being significant sources also. These emissions are dominated by emissions from the cattle herd. When emissions are related to food production, the top four most efficient regions are Eastern and Western Europe, North America, and the non-EU FSU which together produced 46.1\% of ruminant meat and milk energy and only $25.5 \%$ of enteric methane emissions in 2005 . In comparison, the three least efficient producers (Asia, Africa and Latin America) produced an equivalent amount (47.3\%) of ruminant meat and milk energy and almost three times (69\%) as much enteric methane emissions in 2005. Livestock related emissions will increase as world population and food demand increases. For instance, enteric methane emissions are projected to grow by over 30\% from 2000 to 2020 . There are mitigation possibilities, but there is an imperative to develop new technologies, or ways to implement existing technologies in a more cost effective manner.
\end{abstract}

\section{What place for livestock on a re-greening earth? \\ H. Janzen*}

Ruminant livestock, globally, are a large and growing source of greenhouse gas emissions. As well, they have been implicated in other environmental stresses, many of which may intensify in decades ahead: waning freshwater supplies, depleting energy reserves, nutrient leaks to air and water, and land use changes like deforestation. Given these coming stresses, some have asked: how can we justify, ecologically, the widespread and expanded raising of livestock? The response, proffered here as working hypothesis, is this: that livestock have enduring benefits through their ties to the land, especially pastures and other lands vegetated with forage perennials. Such lands, spanning vast areas of the world, and a large share of agricultural areas, deliver many essential ecosystem services. If wisely managed, they hold large reserves of carbon, preventing its escape to the atmosphere; they give refuge to wildlife and help preserve biodiversity; they offer aesthetic value and recreational respite; they conserve quality of soils and filter water percolating through them; they yield countless other benefits, cultural and social, not easily quantified. Raising livestock, then, can be justified by their part in nurturing the land, a value seen long ago, but sometimes forgotten. But that does not mean, necessarily, that all ways of raising livestock are ecologically sound and defensible. And as pressures on landscapes intensify worldwide, scientists may want to ponder some adventurous questions about the place of livestock on a re-greening earth. What is the full and final effect of livestock practices on greenhouse gas budgets, based on life-cycle analysis including also removals and emissions from the land? How does the way we manage livestock affect a range of other ecosystem services, from biodiversity to human nutrition to aesthetic and other social values? How might prospective livestock practices look, ecologically, not just today, but in the altered world some decades from now? These questions and others like them might then lead us to develop new ways of raising livestock, more closely tuned to the needs and nuances of a re-greening world somewhat different from ours today. 


\title{
The potential of livestock-based offsets to reduce GHG emissions
}

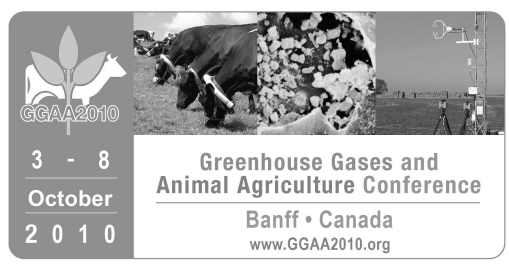

\author{
K. Baylis*, N. Paulson and P. Shaw
}

Methane from livestock accounts for $6.6 \%$ of total greenhouse gas (GHG) emissions in the United States. Methane is 23 times more potent than carbon dioxide $\left(\mathrm{CO}_{2}\right)$ in trapping heat in the atmosphere and is released into the air through common livestock and manure management practices. Livestock operators can qualify for carbon credits for the capture of methane by utilizing management technologies such as methane digesters, preventing methane emissions that would have otherwise been released into the atmosphere. Thus, livestock producers can play a large role in reducing GHG emissions while simultaneously earning carbon credits. In this paper, we explore the potential for livestock-based carbon offsets to reduce emissions. This paper has two related objectives. First, we explore the institutional framework in place for livestock-based GHG emissions and the source of uncertainties facing policymakers and the producers and consumers of offsets. Second, using farm-level data from the United States, we develop a simulation model of potential offset supply, with a focus on supply risk issues and how they might be mitigated. From these two objectives we hope to better understand the potential gains generated by methane-based offsets and characterize any institutional innovations which may be needed to allow this market to function efficiently. From 2004 through August 2009, over 1.4 million metric tons of $\mathrm{CO}_{2}$ equivalent from agricultural methane offset projects have been registered on the Chicago Climate Exchange. Offsets are issued on the basis of all methane collected and destroyed. Eligible collection/combustion systems include covered anaerobic digesters, complete-mix and plug-flow digesters. Participation in the program requires that producers demonstrate emissions reductions relative to a business as usual baseline and either be large or work with aggregators to pool enough offsets to be of interest to buyers. Offset markets pose substantial risk for producers, aggregators and consumers. One classic concern is the determination of the emissions baseline and how it affects early adopters. Second, a lag exists between the time aggregators register offsets with CCX and the time of actual sale (retirement) of these offsets, generating a potential price risk. Third, monitoring and enforcement is required to ensure that emissions reductions are real and substantial, while verification is imperfect and expensive. We explore these issues and ask how institutional changes can limit these risks and improve market efficiency. 


\title{
SESSION 1: POSTER ABSTRACTS
}

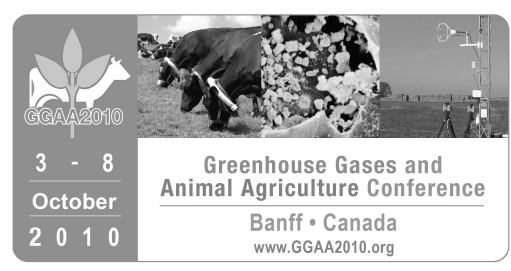

\section{PLEASE NOTE: Authors denoted with an asterisk are registered GGAA2010 delegates}

\author{
M01. Environmental and economic perspectives of milk production in feedlot and grazing systems \\ O. Alqaisi, A. Ndambi and T. Hemme*
}

\begin{abstract}
Dairy production systems involve large inputs and large outputs. In environmental and economic terms, this means dairying is potentially a large consumer of natural resources and a generator of large amounts of pollutants and waste as greenhouse gases (GHG) and manure. To ensure a sustainable milk production system, it becomes important to understand the environmental and economic aspects of feedlot and grazing dairy systems. The environmental and economic perspectives of six typical farms in different selected countries were compared using the TIPICAL (Technology Impact Policy Impact Calculations model). Three grazing farms from Argentina, Chile and New Zealand, and three feedlot farms from the USA, Spain and Jordan, were selected for this study. Milk production in the grazing system compared to the feedlot systems yielded 4.3 and 5.7 tons of milk year ${ }^{-1}$ in New Zealand and Argentina, respectively while it was higher in the USA and Spanish farms (10.6 and 8.9 tons year ${ }^{-1}$ ), respectively. Feed efficiency trends expressed as kg energy and protein corrected milk (kg milk kg ${ }^{-1}$ DM intake) were $0.96,0.80$ and 0.98 for Chile, New Zealand and the Argentinean farms, respectively, while it was higher in feedlot farms with FE of 1.25, 1.01 and 1.33 for Spain, Jordan and the USA farms, respectively. Dry matter concentrate intake per kg milk was: 675,699 and $447 \mathrm{~g} \mathrm{~kg}^{-1}$ in Jordan, Spain and the USA farms compared to 349 and $230 \mathrm{~g} \mathrm{~kg}^{-1}$ milk in Argentina and Chile and zero concentrate intake in the New Zealand farm. Enteric methane emissions were calculated using the equation from (Kirchgessner 1997) using the cow body weight and milk yield as variables. Results showed variations between both systems, as it was 130, 121 and $111 \mathrm{~kg} \mathrm{CH}_{4}$ cow $^{-1}$ year $^{-1}$ in the USA, Spain and Jordan, respectively, compared to 110, 101 and 92 $\mathrm{kg} \mathrm{CH}_{4}$ cow $^{-1}$ year $^{-1}$ in Chile, Argentina and New Zealand, respectively. Cost of milk production only was 57, 55 and $37 \$ / 100 \mathrm{~kg} \mathrm{ECM} \mathrm{milk} \mathrm{in} \mathrm{Spain,} \mathrm{Jordan} \mathrm{and} \mathrm{the} \mathrm{USA,} \mathrm{respectively,} \mathrm{compared} \mathrm{to} \mathrm{34,} 27$ and $28 \$ / 100 \mathrm{~kg}$ ECM milk in New Zealand, Chile and Argentina, respectively, showing a higher cost in the feedlot system compared to the grazing system. The study shows that the grazing system has lower production cost, and lower methane emissions. FE is higher in the feedlot production system which has higher methane emissions and higher production costs. Improving FE would lead to reducing the cost of milk production as well as reducing the methane emissions per cow or per $100 \mathrm{~kg}$ ECM milk either by reducing DM intake or by increasing milk yield cow $^{-1}$ year $^{-1}$.
\end{abstract}

\section{M02. The role of livestock production in greenhouse gases emissions in Ghana C. Antwi*, E.L.K. Osafo, D.S. Fisher, J. Baah and K. Oppong Anane}

Though livestock is not a major driving force of the global economy, it plays a crucial role in food security and supports the livelihoods of approximately 1.3 billion people. The livestock sector has extensive environmental impacts, and it is noteworthy that the activities of livestock contribute to about $18 \%$ of the anthropogenic greenhouse gases (GHG) emission. The livestock industry accounts for 9,37 and $65 \%$ of carbon dioxide, methane and nitrous oxide emitted, respectively, by human activities. The GHG emissions from animal agriculture in developing nations such as Ghana are lower than in more developed nations owing to relatively small livestock numbers. However, if the vision of a well developed, modernized, efficient and profitable 


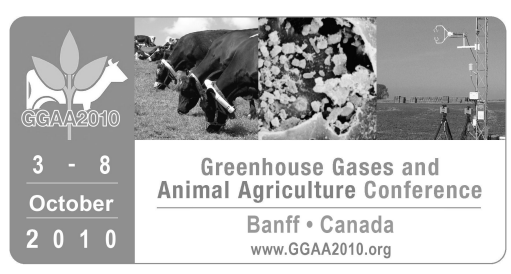

livestock industry that supports the livelihoods as well as ensuring poverty reduction and national growth is attained by 2015, it is anticipated that livestock production would increase along with a significant increase in the emissions of GHG. That is, the government of Ghana livestock policy seeks to supply meat, animal and dairy products from domestic production from the current aggregate level of 30 to $80 \%$ and contribute to the reduction of the incidence of poverty among food farmers (who are also livestock keepers) from 59 to $30 \%$ by the year 2015. That notwithstanding, the consumption patterns of livestock products in Ghana where meat, milk and eggs were consumed during festivities have considerably improved owing to urbanization, rising incomes and changes in lifestyle. The expansion of the livestock industry to meet the Government's goal and expanding demand of livestock products must be achieved while simultaneously reducing its environmental impact. It is possible to mitigate GHG emission levels in the years ahead by increasing the efficiency of animal agriculture. Improving the digestibility of fibrous feed commonly used in Ghana with processes such as urea, ammonia and fungal treatment of feed or supplementation with readily soluble carbohydrates, handling dry forms of manure other than conventional means of managing in liquid forms, and forest conservation in sequestering carbon are options in reducing the emission of GHG. Rigorous policies like 'polluter pays', etc., can be enforced to avert the danger posed by livestock to climate change. However, the fact that many people depend on livestock for their livelihoods may limit the policy options available for GHG emissions. The study therefore seeks to appraise the importance of livestock production in Ghana to changes in climate and potential approaches in alleviating their effects.

\section{M03. Comparison of methane production between temperate and tropical forage: A quantitative review \\ H. Archimède*, M. Eugène*, C. Marie-Magdeleine*, C. Martin, D. Morgavi*, P. Lecomte and M. Doreau}

It is generally admitted that ruminants fed on tropical forages produce more methane than ruminants fed on temperate ones. The presence of significant amounts of secondary compounds (e.g., tannins) in tropical legumes and the predominant C4 photosynthetic pathway in tropical grasses are known factors that can negatively influence fibre digestion and consequently methane production. However, information based on direct in vivo comparison of tropical and temperate forages is almost nonexistent in the literature. In this work a meta-analysis statistical approach was used to compare the effect on methane emissions of tropical and temperate forages of similar chemical composition. To be eligible for the database, only in vivo studies using forage feeds were considered. Information on methane production, intake, forage chemical composition, and total tract digestibility was available for all studies. The database contained 24 studies, 121 observations, 80 temperate (70 grasses and 10 legumes) and 41 tropical (32 grasses and 9 legumes) forages, respectively. For both tropical and temperate forages NDF content, CP content and DM total tract digestibility ranged from 400 to $800 \mathrm{~g} \mathrm{~kg}^{-1} \mathrm{DM}$, from 25 to $310 \mathrm{~g} \mathrm{~kg}^{-1} \mathrm{DM}$ and from 40 to $80 \%$, respectively. Mean value of CP content and DM total tract digestibility of legume diets was $187 \mathrm{~g} \mathrm{~kg}^{-1}$ and $55 \%$ against $140 \mathrm{~g} \mathrm{~kg}^{-1}$ and $62 \%$ for grass. The condensed tannin contents of the diets with legume ranged from 0 to $150 \mathrm{~g} \mathrm{~kg}^{-1} \mathrm{DM}$. An analysis of variance has been done. The main factors tested were fibre, nitrogen and tannin content of the diet, DM total tract digestibility and level intake of the diet, animal species, forage family and experiment effect. The preliminary results indicated that ruminants fed tropical forages produced more methane $(P<0.05)$ compared to those fed temperate ones: 15 to $21 \%$ expressed as $\mathrm{g} \mathrm{kg}^{-1} \mathrm{DM}$ intake or 15 to $26 \%$ as $\mathrm{g} \mathrm{kg}^{-1} \mathrm{DM}$ digested. Independently of the temperate or tropical origin, grasses produced more methane $(P<0.05)$ than legumes: 9 to $18 \%$ expressed as $\mathrm{g} \mathrm{kg}^{-1} \mathrm{DM}$ intake and 15 to $18 \%$ as $\mathrm{g} \mathrm{kg}^{-1} \mathrm{DM}$ digested. These differences were even higher when tropical grasses and legumes are compared alone. Tannins reduced $(P<0.05)$ methane production. In conclusion, the 


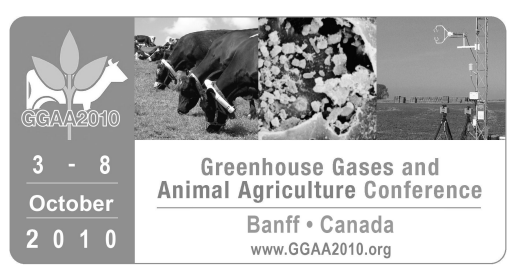

results confirm the existence of differences in methane production between animals consuming forage tropical versus temperate. They encourage the fitting of trials to compare these forages under similar experimental conditions.

\section{M04. The New Zealand livestock industry challenge of reducing Methane and Nitrous Oxide M. Aspin* and M. Leslie}

New Zealand is unique as a developed nation with $48 \%$ of its total GHG emissions coming from agriculture in the form of methane and nitrous oxide from livestock. As a signatory to the Kyoto Protocol it has a target to reduce its emission to 1990 levels, this represents a significant challenge for an export country that relies on agriculture to drive its economy. The Pastoral Greenhouse gas Research Consortium (PGgRc) is a partnership between New Zealand pastoral industries and the New Zealand Government. It was formed and set up by the industry to:

- identify, establish and develop on-farm technologies to improve production efficiency for ruminants,

- identify, establish and develop on-farm technologies for sheep, dairy, beef cattle, and deer, which lower methane emissions from New Zealand ruminants and nitrous oxide from grazing animal systems,

- exploit commercial opportunities arising from the science and technologies in a global market.

PGgRc has been a "centre of excellence" for pastoral-based agricultural greenhouse gas mitigation research both in New Zealand and internationally since 2002, and expects to continue its high-quality science programme into the foreseeable future. Over the past eight years the Consortium has invested over \$25M NZD in scientific programmes aimed at reducing agricultural greenhouse gases. Its investment has produced internationally acknowledged research on the production of methane and nitrous oxide from grazing livestock as part of the most comprehensive programme of its type in the world. The Consortium investment is jointly focused on reducing emissions while maintaining or improving livestock productivity. Productivity as a driver is well understood; enabling our pastoral farming businesses to thrive. The reduction in emissions is more difficult to value as direct measurement is not practical and there is no cost of carbon currently levelled against farm businesses, although New Zealand government policy will see this occurring through an emissions trading scheme in 2015. Both methane and nitrous oxide are products of complex biological systems operating within a livestock business, the scientific challenge is well acknowledged while the further challenge of how the solutions will eventually be adopted and use is still largely unknown. The consortium has developed its programme of activities to understand and develop cost effective solutions through science and has started the process of investigating the factors that will influence the commercialisation and application of these solutions. This paper will outline the progress the consortium has made towards achieving its goals across a broad science programme and focus on the remaining challenges from a livestock industry perspective striving to find solutions to reduce GHG emissions from extensive grazing systems.

\section{M05. Enteric methane emission factors for dairy and beef cattle in Argentina \\ L. Finster*, G. Berra*, R. Buala and S. Valtorta}

Enteric methane emission is the third main source category in Argentina, accounting for $20 \%$ of total country emissions. Dairy and beef cattle contribute $95 \%$ to such emissions. Dairy production systems are located in the Pampeana Region. These systems are very similar regarding feedstuffs use, differing only in their yields. Beef production is carried out all over the country and production systems vary widely. Due to the cropping area 


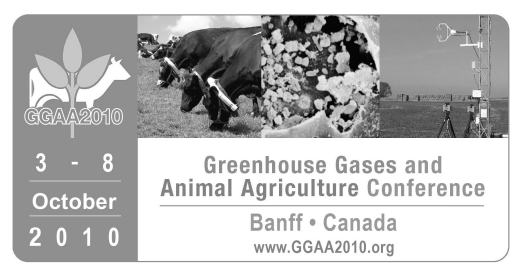

increase that took place over the last years, growing and fattening activities have intensified significantly, while breeding activity remained with a low efficiency index. In the present work, enteric methane emission factors for Argentine dairy and beef cattle were estimated using the IPCC Tier 2 method. A comprehensive characterization of cattle population was developed, following IPCC Good Practice Guidance. Uncertainty values were calculated applying the error propagation method. The estimated emission factors for Argentina were higher than the default factors given by IPCC for Latin America. The results showed that breeding herd accounts for $70 \%$ of methane emissions from cattle enteric fermentation and growing - fattening herd contributes $30 \%$. We concluded that, in countries with large livestock populations, country-specific emission factors need to be calculated and updated regularly to better reflect the sector circumstances and changes. In Argentina, breeding herds should be the target for mitigation measures tending to improve production efficiency.

\section{M06. The role of livestock in the agricultural sector emissions of Bolivia in 2002 and 2004}

E. Garcia-Apaza*, D. Cruz Choque and W. Angulo Veizaga

The greenhouse gas emissions from the Bolivian agriculture sector were estimated. The results showed that during 2002, Bolivian agriculture sector emitted $546.47 \mathrm{Gg}$ of methane, $2.27 \mathrm{Gg}$ of $\mathrm{N}_{2} \mathrm{O}, 8.24 \mathrm{Gg}$ of NOx and $428.99 \mathrm{Gg}$ of $\mathrm{CO}$. In 2004 the agriculture sector emitted $587.68 \mathrm{Gg}$ of methane, $2.63 \mathrm{Gg}$ of $\mathrm{N}_{2} \mathrm{O}, 13.43 \mathrm{Gg}$ of NOx and $728.18 \mathrm{Gg}$ of $\mathrm{CO}$. Taking into account the potential warming effects of methane and nitrous oxide as $\mathrm{CO}_{2}$ equivalent amounts, the agriculture sector is responsible for $12,568 \mathrm{Gg} \mathrm{CO}_{2}$ - eq of $\mathrm{CH}_{4}$ year ${ }^{-1}$ in 2002 and $13,516 \mathrm{Gg} \mathrm{CO}_{2}$-eq of $\mathrm{CH}_{4}$ year ${ }^{-1}$ in 2004. On the other hand, there were $464 \mathrm{Gg} \mathrm{CO}_{2}$-eq of $\mathrm{N}_{2} \mathrm{O}$ in 2002 and 546 $\mathrm{Gg} \mathrm{CO}_{2}$-eq of $\mathrm{N}_{2} \mathrm{O}$ in 2004. Enteric fermentation was the principal source of agriculturally derived methane accounting for $90.96 \%$ and $88.47 \%$ of the total in 2002 and 2004 , respectively. In contrast, agricultural soils accounted for $90.96 \%$ and $88.47 \%$ of the total $\mathrm{N}_{2} \mathrm{O}$ emissions from this sector in 2002 and 2004 , respectively. Apparently the trend emissions will not have a big difference in comparison to previous years. But the most important factor on those behaviours was the high correlation between the livestock population and the methane emissions among all years of inventories.

\section{M07. Systematic estimation of non- $\mathrm{CO}_{2}$ greenhouse gas emissions from global agricultural activities \\ T. Hasegawa* and Y. Matsuoka}

Animal agricultural activities are one of the GHG emission sources. However, the most comprehensive existing statistics on food and agriculture products includes outliers with inconsistent and missing values. In order to estimate and evaluate GHG emission and reduction potentials for the future, historical activity data with high reliability is necessary. Therefore, this study aims to analyze main driving forces on GHG emissions from agriculture by using more reliable activity data. In this study, Emission Accounting Table of Global Agricultural activities (EATGA), the high reliable data, is developed by improving outliers and missing values. EATGA provides time series and cross sectional data relating to transaction of agricultural products and money between economic entities from production to disposal in the world food market. In estimation of EATGA, a new robust methodology to improve outliers and missing values by using several international statistics is developed in order to obtain higher reliable data. As a result, it is confirmed the outliers and missing values are improved and the reliability of data is improved. By analyzing GHG emission factors focusing on livestock animals using EATGA, we found that it is required to reduce fertilizer in OECD countries and to reduce fertilizer 


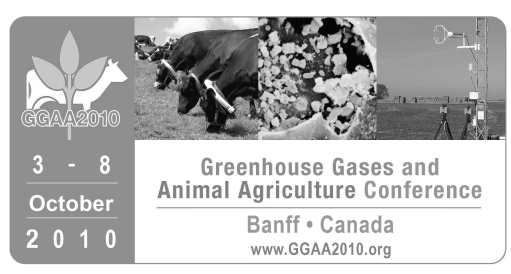

and animal numbers in non-OECD countries in order to achieve the reduction in world GHG emissions caused by agricultural activities.

\section{M08. Life cycle assessment of greenhouse gas emissions from Japanese pork production using feed from food residuals}

T. Hishinuma*, H. Kurishima and Y. Genchi

The purpose of this study was to assess the greenhouse gas (GHG) emissions of feed production from food residuals (FRs), from the viewpoint of the waste treatment and pork production using life cycle assessment method. We evaluated the GHG emissions at four cases of feed production from FRs using dehydration and liquid (mixture) systems, in order to compare with the emissions from incineration. Also, to confirm the role of feed production from FRs at the total GHG emissions in pork production, we evaluated the GHG emissions from scenario analysis of pork production system with typical pork production and pork production using feed from FRs. The model of pork production system included the following processes: incineration, feed production from FRs, concentrated feed production, pig production with livestock management and manure treatment, slaughter house and retail. The data of four feed production cases from FRs were collected by site investigations. The data of other processes for the model of pork production system was mainly based on literatures. The feed composition using feed from FRs was calculated from the values of TDN requirement from pigs. The functional unit was defined as "treatment of 1 ton FRs" for comparing GHG emissions between feed production from FRs and incineration. Also, the functional unit to assess GHG emissions from pork production system was defined as " $1 \mathrm{~kg}$ of pork distributed at a retail store". The GHG emissions from the two cases of feed production from FRs with dehydration were 230 and $360 \mathrm{~kg} \mathrm{CO}$-e/t-fr (fr:FRs). The GHG emissions from those cases were 110 and $220 \mathrm{~kg} \mathrm{CO}$-e/t-fr greater than that in incineration, because of the energy intensive drying process. The GHG emissions from liquid feed production from FRs were 16 and $50 \mathrm{~kg} \mathrm{CO}-\mathrm{e} / \mathrm{t}$-fr, which were 130 and $160 \mathrm{~kg} \mathrm{CO}$-e/t-fr less than that in incineration. The GHG emissions from typical pork production system totalled $6.4 \mathrm{~kg} \mathrm{CO}$-e/kg-pork, where manure treatment process $(35 \%)$, concentrated feed production process (31\%) and retail process (13\%) were large GHG emissions sources. The GHG emissions from the pork production system using dehydrated feed FRs was 6.5 to $6.8 \mathrm{~kg} \mathrm{CO}_{2}$-e/ $\mathrm{kg}$-pork, where the value was 0.4 to $6.2 \%$ higher than the values from a typical system. The GHG emissions from the pork production system using liquid feed FRs were 5.6 and $5.8 \mathrm{~kg} \mathrm{CO}_{2}$-e/kg-pork. The contribution to the total GHG emissions from liquid feed FRs was reduced by 9.5 to $13.1 \%$ compared with the values from typical production system.

\section{M09. Global Warming and Animal Agriculture Sector of India \\ P. Kataria, M. Wadhwa* and M.P.S. Bakshi}

Global warming today is an issue, about which the entire world is concerned. Global warming is the increase in average temperature of earth and oceans in recent times resulting in a continued increase in temperature in future. The gases like carbon dioxide, methane, ozone, nitrous oxide and sulphur hexafluoride as well as water vapours called greenhouse gases collect in the atmosphere like a blanket stopping the sun's heat and radiated off the earth's surface. Carbon dioxide is the most important greenhouse gas being added continuously to the atmosphere by human activity. Methane is the second most important greenhouse gas, accounting for onefifth of the global warming, after carbon dioxide, which is responsible for one half of the warming. The livestock are responsible for about $18 \%$ of global warming effect, even more than the contribution of the transportation 


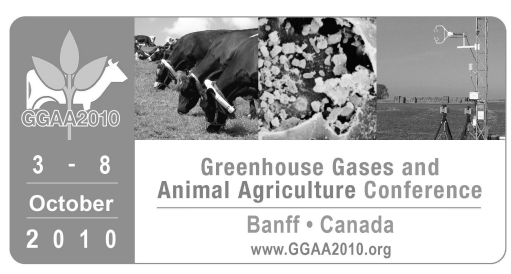

sector. The culprits are methane, the natural result of bovine digestion, and the nitrogen emitted by manure. The deforestation of grazing land adds to the effect. This phenomenon of climate change in its own right poses a challenge to the livestock sector, by way of marring its productivity. The mitigation and adaptation strategies are specifically crucial for the animal agriculture sector, which provides livelihoods to about 1.3 billion people and contributes about $40 \%$ to global agricultural output. The impact of animal agriculture sector on global warming and that of the ensuing climate change on livestock productivity, and the resultant economic implications, is so significant, that it needs to be addressed urgently. The present paper aims at addressing this issue for India, which is house to $16 \%$ of world's cattle, $54 \%$ of buffalo, $5 \%$ of sheep and $21 \%$ of the goat population and that too with only $2 \%$ of total geographical area of the world.

\section{M10. Possibility of biodegradable polymer as restoration technologies in semi-arid region}

A. Koike*, T. Honda, H. Kitano, T. Hara, C. Okamoto and K. Kabata*

The keywords in the 21st century are food and environment. Population growth, rising temperature and reduction of arable land per capita are a few examples. Especially, desertification has become a serious worldwide problem in recent years. This applies to dry zones (deserts, steppes and savannas) where ecosystems are unstable due to irregular weather such as frequent droughts and suffering from the condition of reckless overgrazing and over-cultivation. Furthermore, many of the developing nations in dry zones use firewood as fuel. This leads to wind and water erosion, which results in destruction of soil and lower productivity. This process is one of the most important causes of desertification. The livestock industry is considered to be the most appropriate industry in steppes and savannas areas of the world. Therefore, excluding grazing livestock is considered an alternative to restore vegetation in these areas. At the same time, an excellent measure would be to develop grassland, the cultivation of forage crops to supplement the roughage. The purpose of this paper is to describe a trial of biodegradable polymer, bridged poly ( $\hat{\mathfrak{l}}^{3}$-glutamic acid) (PGA) for revegetation in dry zones. Biodegradable hydro-gels prepared from natural polymers have been of attention for environmental preservation in recent years. "Natto" is a traditional non-salty fermented soybean food in Japan, which is grown by Bacillus subtilis (natto). We succeeded in synthesizing a cross-linked polymer, named as "Natto Jyushi" which shows high water absorption ability. Moreover, biodegradability based on ISO14855 of Natto Jyushi is more than $80 \%$ to $\mathrm{CO}_{2}$ at $30^{\circ} \mathrm{C}$ after 2 weeks, namely biodegradable polymer (BDP). We prepared the seed pellet which is used as Italian millet (Sataria italica) seed and consists of a variety of ratio mixtures of Natto Jyushi and cassava-pulp. We also measured the germination rate and the root growth of seed pellet. There was no difference at the germination rate of each seed pellet. However, the root growth of millet seed which was in seed pellet with $2 \%$ addition mixture Natto Jyushi and cassava-pulp (1:1) was significantly high compared with other pellets. Therefore, it was suggested the Natto Jyushi possibly contributes to the growth of the seed. In conclusion, these results suggest that the addition of BDP to seed pellets is one of the useful techniques. However, it is necessary to investigate further for practical use. 


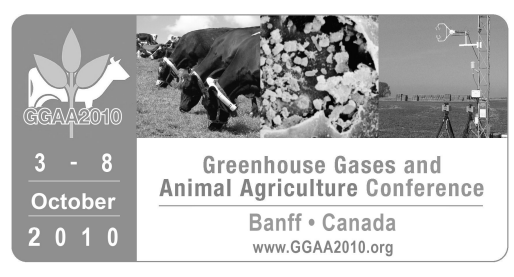

\title{
M11. More meat produced with greater production efficiency and less greenhouse gases
}

\author{
S. L. Kronberg*, M. A. Liebig and J. R. Hendrickson
}

Meat is a popular food world-wide. FAO estimates world food production will need to increase $70 \%$ by 2050 to feed 2.3 billion more people. Hungry people are a threat to social stability and national security, and provision of plant protein may not satisfy many who hunger for animal protein. Demand for fossil fuels may soon exceed supply, and production of bio-fuels may compete with food production. Research leading to production of more meat with less fuel and less GHG output is needed. We should encourage proactive social changes now within our traditions of meat production and consumption in order to eventually have more meat with less environmental impact in future decades. We should continue research on improving production efficiency and reducing environmental impact of ruminant production from less productive lands and with by-products from which it is impractical to produce efficient livestock. For our higher quality crop and pasture lands we should focus more of our efforts on improving production of more efficient small monogastric animals. A cow managed to produce less methane only produces one offspring per year and if her calf is also managed to produce less methane, it and its mother are still inefficient converters of forage or grain to muscle. Sheep are more efficient meat producers than cattle, but in contrast to ruminants, a rabbit doe produces many offspring per year and her offspring convert forage to muscle relatively efficiently. We estimated that a productive pasture on the northern Great Plains of North American grazed at a high stocking rate (typical for area) for 87 consecutive years had a net global warming potential of $-618 \mathrm{~kg} \mathrm{CO}_{2}$ equiv ha ${ }^{-1} \mathrm{yr}^{-1}$ when used to grow yearling cattle (28.3 kg gain ha ${ }^{-1} \mathrm{yr}^{-1}$ over 3-yr study; $-26 \mathrm{~kg} \mathrm{CO}_{2}$ equiv/ $\mathrm{kg}$ animal gain). Little information on methane and GHG production is available for rabbits, so we assumed pasture-based production of young rabbits would have similar GHG intensity as pasture-based cattle production. Forage quality would be adequate in this pasture for rabbit production from mid-May through June. With each rabbit consuming $150 \mathrm{~g}$ of forage $\mathrm{DM} / \mathrm{d}$ for $45 \mathrm{~d}$ until slaughter at $2.1 \mathrm{~kg}$ ( $35 \mathrm{~g} / \mathrm{d}$ gain), the same pasture could produce $431.7 \mathrm{~kg}$ of rabbit gain/ha; 15 times the cattle gain for the same pasture. This illustrates potential efficiency gains from utilizing fast-growing animals for meat production in a potentially climate-friendly system. Verification of GHG benefits from alternative forms of meat production is needed.

\section{M12. GHG emission profiles of the European livestock sectors}

J. P. Lesschen*, H.P. Witzke, M. van den Berg, H.J. Westhoek and O. Oenema

There are increasing concerns about the ecological footprint of global animal production. The expanding animal production sectors are implicated for their roles in the expansion of agricultural land and associated deforestation, the emissions of greenhouse gases (GHG), eutrophication of surface waters, and nutrient imbalances. Farm-based studies indicate that there are huge differences between farms in animal productivity and environmental performance. Comparisons at regional and country level have not been made yet. Here, we report on regional variations in dairy, beef, pork, poultry and egg production and related GHG emissions in the 27 Member States of the European Union (EU-27) for the year 2005. The analyses were made with the MITERRA-Europe model, which calculates nutrient flows and GHG emissions from agricultural sectors in EU-27 on annual basis. The main input data are derived from CAPRI (crop areas, livestock distribution and feed inputs), GAINS (animal numbers, excretion factors and $\mathrm{NH}_{3}$ emission factors), FAO statistics (crop yields, fertilizer consumption and animal products) and IPCC ( $\mathrm{CH}_{4}$ and $\mathrm{N}_{2} \mathrm{O}$ emission factors). The following sources of GHG emissions were included: enteric fermentation, manure management, direct and indirect $\mathrm{N}_{2} \mathrm{O}$ soil emissions, cultivation of organic soils and fertilizer production. The beef sector had the highest GHG emission in the EU-27 with an annual emission of 160 Mton $\mathrm{CO}_{2}$-equivalents, followed by the dairy sector with $140 \mathrm{Mton}$ 


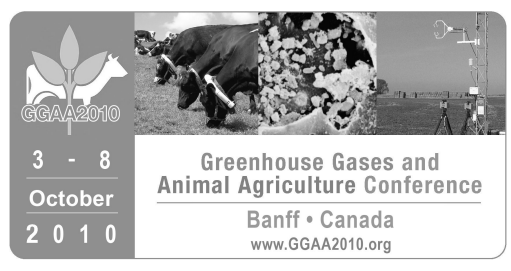

$\mathrm{CO}_{2}$-equivalents. Enteric fermentation was the main source of $\mathrm{GHG}$ emissions in the European livestock sector $(47 \%)$ followed by $\mathrm{N}_{2} \mathrm{O}$ soil emissions (32\%). On a product basis beef had by far the highest GHG emissions (19 $\mathrm{kg} \mathrm{CO}$-eq per $\mathrm{kg}$ product), followed by cheese $(6.5 \mathrm{~kg} \mathrm{CO}$-eq per $\mathrm{kg}$ product), pork (2.5 $\mathrm{kg} \mathrm{CO}$-eq per $\mathrm{kg}$ product) and poultry ( $0.9 \mathrm{~kg} \mathrm{CO}_{2}$-eq per $\mathrm{kg}$ product). Between countries a large variation in $\mathrm{GHG}$ emissions exists, which can be explained by differences in animal production systems, feed types, and nutrient efficiencies. The results of our study provide insight in the locations of stronger and weaker regions in Europe for animal production and form the basis for possible future development pathways towards more sustainable animal production.

\section{M13. Consumption of wood and economic payback for small scale digesters in Tanzanian villages R. B. Morrison*, K. Hartwig and C. Packer}

In Tanzania, the use of wood and charcoal for cooking fuel has contributed to a $37 \%$ loss of forest in the past 15 years. As an alternative, small-scale domestic digesters can use livestock manure and possibly the household waste stream to generate biogas. Additional benefits include reduced greenhouse gas emissions, reduced degradation of forests, reduced incidence of accidental burns in infants, improved indoor air quality, reduced time spent collecting or purchasing wood, and creation of jobs in a new biogas business sector. Despite these advantages, digesters are relatively uncommon in Africa. The objectives of this project were to determine the proportion of rural households in northern Tanzania burning wood for cooking fuel and estimate the payback time for a suggested design of a small scale digester. The University of Minnesota has partnered with Savannas Forever-Tanzania to create a long-term, comprehensive, village-level monitoring and evaluation program called the Whole Village Project. Data were collected from a sample of 14 villages in northern Tanzania. Approximately 71 households (SD 6.6) in each village were surveyed. The head of household was asked to identify the predominant source of fuel used for cooking and the number of cattle owned. The recommended digester model is a fixed dome, modified CAMARTEC design. Cost of materials and construction is approximately US\$900. Payback was calculated by comparing estimated construction costs to market value of wood burned per day. The Tanzania inflation rate for 2009 of $10.3 \%$ was used to project cost of wood. Approximately $96 \%$ of households (SD 3\%) burned primarily wood for cooking and an additional $2.1 \%$ (SD 2.2\%) burned charcoal. Within each village, $43 \%$ of households (SD 15\%) owned cattle. Of these, the average number of cattle per household was 7.3 (SD 5.3). Assuming a cost of wood of US\$0.37 per day, payback time was estimated to be 5.3 years. A US\$300 subsidy is available from SNV which lowered payback to 3.8 years. Payback time does not include the value of reduced risk of burns from a cooking fire, reduced incidence of chronic obstructive respiratory disease from smoke, reduced degradation of forests and increased time available for the householder. However, two obstacles inhibit adoption of biogas plants. First, the householder may be collecting wood instead of purchasing it and little value may be put on time. Second, the capital cost represents a significant amount for most households.

\section{M14. Livestock production in Brazil - A prospect for GHG emissions H.R.L. Neto*}

Livestock industry accounts for $40 \%$ of agricultural production globally and provides livelihood as well as food security to over a billion people. Additionally FAO estimates that the livestock industry alone represents $18 \%$ of all greenhouse gases (GHG) worldwide - more than the major oil consumer, the transport industry (13\%). 


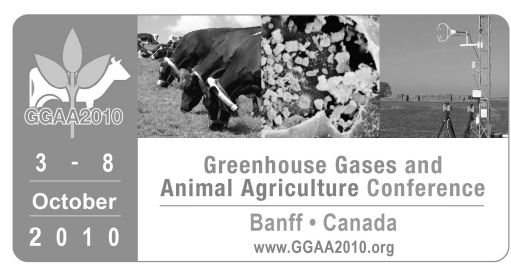

Brazilian agriculture was responsible for 78\% of methane emissions in that country in 1994 (First National Communication), where enteric fermentation from ruminants played an important role accounting for $92 \%$ of the total (Climate Change Aspects in Agriculture, 2009). Also the Brazilian Institution of Geography and Statistics estimated that about $74 \%$ of livestock from the Amazon region occupy previously forested lands. The figure could be even more overwhelming if we bear in mind that Brazil is the biggest beef producer in the world and the vast majority of its herd grazes in what was forest 100 years ago. However, mitigation is under target of animal scientists. Research has shown that agro-pastoral or agro-sylvo-pastoral systems integrating land for grazing livestock and/or forests have high carbon sequestration levels compared to traditional/degraded grassland areas. It does comprise a suitable alternative for many farms bearing better economical output/area. In addition, switching from traditional to organic fertilization methods seems to produce positive results with regard to tackling greenhouse gases emissions. Some data shows that organically enriched pastures can sequestrate more carbon. Changing livestock diet is proved to alter methane output and several studies suggest novel means of reducing GHG. Alternative feed additives can be used to select desirable microbes in the gut and then improve efficiency of the fermentation. Because of the vast amount of wild plants/shrubs in Brazilian ecosystems the possibility to develop similar or may be better "natural" ionophores is reasonable. Also, the species composition of pastures may offer solutions. Increasing the proportion of leguminous plants in the area provides different growth phases so that supply is more even and nutrition is more appropriate. Losses from fermentation are reduced due to a forage composition which allows better synchronism on nutrient breakdown. Methane emission is proven to reduce as a result. Finally the breeding programmes had been impacting the major Zebu breeds. Improved milk and meat production per animal has led to less methane emission per unit of product. In summary several strategies are being researched and developed to date in order to tackle greenhouse gas emissions from livestock in Brazil, especially with regard to grassland-based systems which are the backbone of its meat and milk production.

\section{M15. The value of extension for greenhouse gas communications in the Victorian livestock sector}

Z. Ritchie*, C. Gerbing and S. Holland-Clift

Livestock industries in Australia contribute $11 \%$ to the national greenhouse gas emissions. The Victorian Department of Primary Industries are responding to this by providing extension services for farmers and service providers of the livestock sectors to help prepare for them for climate and emissions challenge, under the Future Farming Strategy, 'Planning for Climate Change'. The key focus of this project is to build capability of industry service providers and department extension staff servicing the livestock and agricultural sectors. This is achieved through a team of industry experts across the beef, sheep and dairy sectors delivering local and industry specific information about climate and greenhouse gas emissions. Increasing the knowledge and skills of livestock industry service providers is essential for a unified approach to assist producers' understanding of greenhouse gas emissions and options for abatement. Sharing positive stories and approaches has enabled the project team to increase their capacity to respond and effectively disseminate information to livestock producers and service providers. The Farmers Taking Action case study series shows examples from throughout Victoria where positive actions have been taken to reduce emissions, adjust to changing seasonal climate variability and prepare for the impacts of climate change. Communicating to rural audiences using examples from within the local area assists in making complex issues meaningful and actions more achievable. Sharing such stories has been a significant step towards encouraging all Victorian agricultural businesses and industries to consider proven practice changes, by demonstrating that positive action can lead to positive outcomes. For example, Mark McKew is a livestock farmer in western Victoria who is calculating his on-farm greenhouse gas 


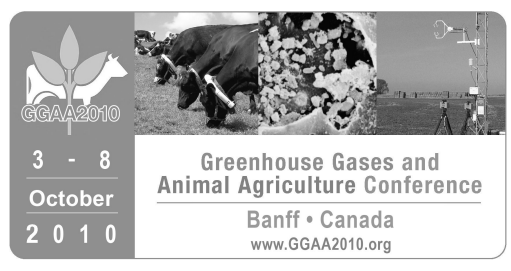

emissions and seeking opportunities for emissions reduction. He says "Being forewarned allows farmers to know what is coming and what can be done to offset it." The Carbon Toolkits in Agriculture Network has been established to keep farm businesses and farm service providers up to date with the latest events, training, news, resources and accounting tools relating to agricultural greenhouse gas emissions. A concise monthly update is disseminated to over 290 network members and training and extension services have been provided to farmers and service providers of the livestock industry to increase understanding and raise awareness of available tools and resources, such as the Dairy Greenhouse Gas Abatement Strategies Calculator. Information about 'Farmers Taking Action' case studies series, the Carbon Toolkits in Agriculture Network and available farm emissions tools can be found at www.dpi.vic.gov.au/climaterisk.

\section{M16. Carbon footprint due to dairying in India and mitigation measures}

\section{A. Saha}

The total emissions in $\mathrm{CO}_{2}$ Equivalent in the world was reported to be 29.6 billion tons in 1990. The share of India was 1.23 billion tons (approximately $4.15 \%$ of total global emissions). In 2003, methane from the livestock sector in India totaled 0.29 billion tons of $\mathrm{CO}_{2} \mathrm{e}$ accounting for approximately $24 \%$ of the total emissions. The present study shows the share of dairy animals in emissions in India to be 0.08 billion tons which means a share of around $7 \%$ of total carbon emissions in India. Hence, any program targeting emission reduction will have to look into the dairy sector emission. A $50 \%$ reduction in emissions level from the dairy sector by 2050 would mean reducing $40 \mathrm{Tg}$ of emissions. However, keeping the constraints of increasing demand for milk, the role of dairy as livelihood, a compromise solution is needed in a phased manner so that all stakeholders are satisfied. A simple calculation would mean reducing 40 million animals by 2050. Doubling the milk yield of local cows yielding less than $2 \mathrm{~L} \mathrm{day}^{-1}$ by adopting crossbreeding technology will also reduce methane emissions per $\mathrm{kg}$ of milk production by around $50 \%$. However, shifting from crossbred cows to buffaloes of similar body weight will increase methane emissions by around $50 \%$ per kg of milk produced. Crossbred cows yielding more than $5 \mathrm{~L}$ day $^{-1}$ produced methane at par with cows in the USA. High yielding indigenous cows with more than $4 \mathrm{~L} \mathrm{day}^{-1}$ and buffaloes yielding more than $6 \mathrm{~L} / \mathrm{cow}$ produce methane at par with countries in Western Europe. Hence efforts to upgrade the indigenous cows to more than $4 \mathrm{~L} \mathrm{day}^{-1}$ will enable the reduction of methane emissions as well as conservation of the indigenous cattle breeds in India. Similarly, efforts to upgrade the buffaloes yielding 3-6 $\mathrm{L} \mathrm{day}^{-1}$ to more than $6 \mathrm{~L}$ will also reduce carbon emissions significantly, as about $36.5 \%$ of animals represent this category.

\section{M17. Carbon Sequestration in Irrigated Pasture Soils}

\section{G. E. Shewmaker*, R. E. Sojka and J. A. Entry}

There is potential to sequester significant amounts of $C$ into soils of grazing lands, especially with irrigation. We measured organic and inorganic $C$ stored in southern Idaho soils having long term land use histories that supported native sagebrush vegetation (NSB) and irrigated pasture systems (IP). Inorganic C and total C (inorganic + organic $\mathrm{C}$ ) in soil was higher in IP than NSB. We use our findings to estimate the amount of possible organic, inorganic and total $C$ sequestration if irrigated pasture land was expanded by $10 \%$. If irrigated pasture land was expanded by $10 \%$, meaning NSB land was converted to IP, a possible gain of $1.17 \times 108 \mathrm{Mg}$ total C (1.7 $\%$ of the total $\mathrm{C}$ emitted in the next $30 \mathrm{yr}$ ) could be sequestered in soils world-wide. If irrigated agricultural land 


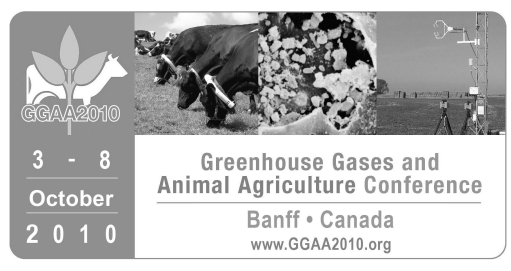

were expanded worldwide and NSB were converted to IP while an equal amount of less-productive rainfed agricultural land were returned to native grassland a possible gain of $6.8 \times 109 \mathrm{Mg}$ total C $(11.93 \%$ of the total $\mathrm{C}$ emitted in the next $30 \mathrm{yr}$ ) could be sequestered in soils. Altering land use to increase grazing land while selected less-productive rainfed agricultural land were returned to temperate forest or native grassland, there could be meaningful reductions in atmospheric $\mathrm{CO}_{2}$.

\section{M18. The relationship between methane observation from satellite and livestock populations}

\section{A. Takenaka*}

Methane contributes to around $20 \%$ of terrestrial greenhouse gases (GHGs), and $40 \%$ of methane is originated from agriculture. Main sources of agricultural methane gas are enteric fermentation of ruminant livestock and rice fields. The proportion of GHGs of agricultural origin in the total GHGs is higher in the developing countries compared to the developed countries, and accurate inventory data of GHG in the developing countries has not been shown recently. Data about the population of livestock is very important in order to estimate GHG inventory data, and this data has been reported by FAO every year. India and Brazil have exceeded numbers of cattle in the world according to the FAO database, and the population of cattle in both countries is more than 170 million. There are a lot of small ruminants such as sheep and goats in China, India, Pakistan and African countries. Also, $90 \%$ of the rice fields which are considered another methane source, are concentrated in Asian countries. These facts reveal that the methane production area has formed a belted region so called "methane belt". JAXA (Japan Aerospace Exploration Agency) has launched a greenhouse gas observation satellite named "Ibuki" in 2009, and the application of data from this satellite has been expected. The data from the satellite shows us that the methane concentrations change depending on the season. This fact reminds us that most of the methane is produced by methanogens (methane producing microorganisms), and the temperature affects the microbial activities. Also, the feed intake of the grazing livestock especially in these developing countries might be decreased during the winter season. The shape of the methane concentration map is roughly corresponded by "methane belt", but still there is a conflict. This conflict might be caused by the long life of methane and also the transportation of methane gas. In order to further analyze between top down from satellite data and bottom up inventory data, the accurate inventory data of these regions is needed. Most importantly research should be undertaken on the improvement of animal production in these countries, because it is quite possible to decrease the GHGs per product in these developing countries.

\section{M19. Agriculture in the New Zealand Emissions Trading Scheme \\ E. van Reenen*}

The New Zealand Emissions Trading Scheme (NZ ETS) is the domestic response to the country's obligations under the Kyoto Protocol. Unlike any other Emissions Trading Schemes in the world, the NZ ETS includes all gases and all sectors, including agriculture. The agriculture sector can begin voluntarily reporting its emissions from 1 January 2011. Reporting will be mandatory from 1 January 2012 with the sector being responsible for their emissions and beginning trading from 1 January 2015. Introducing agricultural greenhouse gas emissions into an ETS brings with it particular challenges, as well as opportunities, in a country that is reliant on exports of agricultural product for much of its income. Challenge 1: To identify who would be responsible for monitoring 


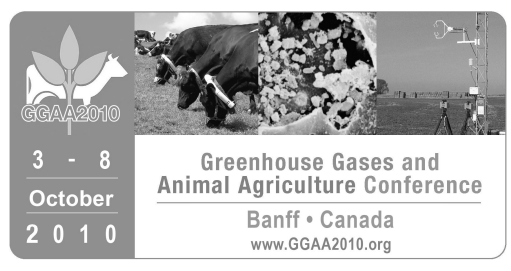

and reporting emissions and then surrendering New Zealand Units ${ }^{1}$ (NZUs) to cover these emissions. In general the scheme has up-stream points of obligation for the participants. For agriculture, this means the processor (e.g. meat and dairy processors) will be responsible for the emissions of methane and nitrous oxide that occur on farms. Challenge 2: Developing emission factors for the participants to use. The emission factors needed to be relatively simple, based on information already collected, such as tonnes of meat processed, and linked to outputs (e.g. carcasses, milk, fertiliser etc). They also needed to align with New Zealand's National Inventory, meaning they are based on robust, internationally peer reviewed science. Finally, the emission factors, and therefore emissions reported by participants, needed to be verifiable by Government. This has been achieved in the NZ ETS. Challenge 3: Allocating NZU's to participants, recognising that the agriculture sector is trade exposed due to $95 \%$ of New Zealand's agricultural product being exported. This allocation will start at $90 \%$ of a yet-to-be-determined baseline in 2015 , and will phase out by $-1.3 \%$ per annum thereafter. The allocation will be based on emissions per unit of product. The baseline is yet to be set, but will need to be carefully considered to ensure that the right incentives are produced. The New Zealand Ministry of Agriculture and Forestry is the lead agency bringing agriculture into the NZ ETS and is currently working to support the sector to begin its voluntary reporting in 2011.

${ }^{1}$ NZUs are the trading unit of the NZ ETS. They are equivalent to a Kyoto Unit.

\section{NOTES:}




\title{
SESSION 2: ORAL ABSTRACTS
}

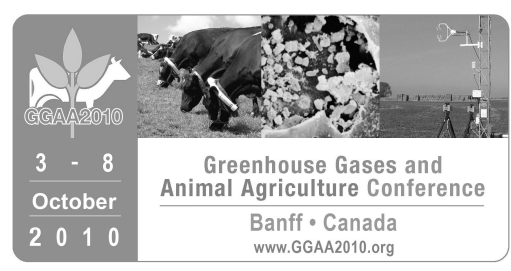

\section{PLEASE NOTE: Authors denoted with an asterisk are registered GGAA2010 delegates}

\author{
Manure management: Implications for greenhouse gas emissions \\ D. Chadwick*, S. Sommer*, R. Thorman, D. Fanguiero, L. Cardenas, B. Amon and T. Misselbrook*
}

Livestock manures are a source of both direct and indirect losses of nitrous oxide when applied to soil and also a source of methane and nitrous oxide emissions during storage. This is because they contain significant quantities of nitrogen, much of which is in the ammonium form, organic matter and carbon (with different degrees of microbial availability) and water - three essential factors controlling direct and indirect (e.g. ammonia emissions and nitrate leaching) losses of nitrous oxide and methane emissions. The direct emissions of nitrous oxide calculated using IPCC methodology (2009 submissions for the 2007 inventory) show the contribution from manure management can be significant, representing ca. $15 \%$ to ca. $40 \%$ of the total agricultural nitrous oxide emission from Austria, Denmark, Portugal, Spain and the UK. The other major sources are inorganic fertilisers, crop residues and urine returns from grazing livestock. The contribution of total agricultural methane emissions from manure management in these countries is also between ca. $15 \%$ and ca. $40 \%$, with the majority of methane arising from enteric fermentation in ruminants. Whilst manures are seen as a source of greenhouse gas emissions, it is the management strategies chosen by farmers that have the scope to influence the degree of gaseous losses, and indeed the potential to reduce those emissions. In this paper we review the latest information and understanding of how manure management influences direct nitrous oxide and methane emissions, as well as detailing how manure management controls indirect sources of nitrous oxide, at all stages of what might be termed the "manure management continuum"; viz. animal housing $\rightarrow$ yards $\rightarrow$ manure storage and treatment $\rightarrow$ land spreading. Manure management also offers the opportunity to reduce greenhouse gases indirectly, e.g., improved manure nutrient use efficiency should result in reduced production and use of manufactured inorganic fertiliser, and methane from stored manures can be used to generate biogas and thus heat and power reducing reliance on fossil fuels.

\section{Methane emissions from a southern High Plains dairy wastewater lagoon \\ R. W. Todd*, N. A. Cole*, K. D. Casey, R. Hagevoort and B. W. Auvermann}

Methane is a greenhouse gas with a global warming potential more than twenty times that of carbon dioxide. Animal agriculture is recognized as a significant source of methane to the atmosphere. The dairy industry has grown exponentially in the Texas Panhandle, with the number of dairy cows increasing from 5000 to more than 250,000 during the past decade. Dairies on the southern High Plains are typically open lot, and major sources of methane are the enteric emissions from cattle and emissions from wastewater lagoons. Uncovered anaerobic lagoons are identified by US Environmental Protection Agency (US EPA) as a major source of methane in dairy manure management systems. Our objective was to quantify methane emissions from the wastewater lagoons of a commercial dairy on the southern High Plains. Research was conducted during seven days in August, 2009 at a 2000-cow open lot dairy with flush alleys in eastern New Mexico. Methane concentration over three interconnected lagoons (total area $1.8 \mathrm{ha}$ ) was measured using open path laser spectroscopy. Background methane concentration was measured using a back-flush gas chromatography system with flame ionization located upwind in the direction of prevailing winds. Wind and turbulence data 


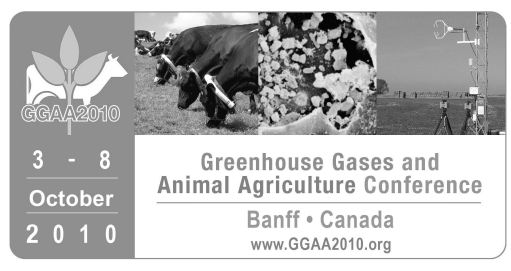

were measured using a three-axis sonic anemometer. Lagoon water was periodically sampled to quantify lagoon chemistry. Emissions were estimated using an inverse dispersion model. Data were filtered for quality, resulting in $60 \%$ retention of 15 -min observations over seven days. A thunderstorm with $29 \mathrm{~mm}$ of rain occurred on Day 3 of the study. Methane concentration over the lagoons ranged from 3.2 to $11.8 \mathrm{ppmv}$, and averaged $5.67 \mathrm{ppmv}$; background methane concentration averaged $1.77 \mathrm{ppmv}$. Methane flux density ranged from 165 to $1184 \mathrm{\mu g} \mathrm{m}^{-2} \mathrm{~s}^{-1}$. Mean methane flux density was $420 \mathrm{\mu g} \mathrm{m}^{-2} \mathrm{~s}^{-1}$, and mean methane emission rate was $666 \mathrm{~kg} \mathrm{~d}^{-1}$. Greatest methane flux occurred on the day after rain and subsequent heavy runoff into the lagoons. The mean emission rate of $666 \mathrm{~kg} \mathrm{~d}^{-1}$ would require that $52 \%$ of the manure of the dairy be partitioned to the uncovered anaerobic lagoon, according to US EPA inventory methodology. Uncovered anaerobic lagoons were a major source of methane emitted from this southern High Plains dairy, and results indicated that lagoons could be a significant control point for emission reduction.

\section{Direct and indirect strategies to mitigate $\mathrm{N}_{2} \mathrm{O}$ emissions from land-applied manure C. Wagner-Riddle*, A.C. VanderZaag*}

Nitrous oxide $\left(\mathrm{N}_{2} \mathrm{O}\right)$ is an important greenhouse gas and most $\mathrm{N}_{2} \mathrm{O}$ emissions come from microbial nitrification and denitrification processes in agricultural soil that has received nitrogen $(\mathrm{N})$ fertilizer or manure. Indirect emissions of $\mathrm{N}_{2} \mathrm{O}$ also occur when $\mathrm{N}$ is lost from a field (through ammonia volatilization or nitrate lost through leaching) and is subsequently converted into $\mathrm{N}_{2} \mathrm{O}$ in another location. These emissions represent an unproductive loss of $\mathrm{N}$ from agricultural systems. Reducing $\mathrm{N}_{2} \mathrm{O}$ emissions is therefore desirable for the purpose of GHG mitigation and to improve $\mathrm{N}$-use efficiency in agriculture. This paper reviews direct and indirect strategies for mitigating direct and indirect emissions of $\mathrm{N}_{2} \mathrm{O}$ from land-applied manure. The discussion will include strategies for both pasture-based and confined animal feeding systems, including: dietary changes and amendments, manure treatment, timing of manure application, manure application method, soil and crop management, and nitrification inhibitors.

\section{Greenhouse gas emissions from pig slurry during storage and after field application in northern Europe conditions}

L. Rodhe*, J. Ascue, M. Pell and A. Nordberg

In 2006, greenhouse gas (GHG) emissions from stored and field-applied manure comprised $12 \%$ and approximately $17 \%$, respectively, of total GHG emissions from Swedish agriculture (calculated using default values since national empirical data are limited). This study quantified emissions of GHG [methane $\left(\mathrm{CH}_{4}\right)$ and nitrous oxide $\left(\mathrm{N}_{2} \mathrm{O}\right)$ ] from pig slurry during storage and after spreading on soil, with and without measures to reduce ammonia emissions. GHG emissions from storage were measured twice per month for one year using a closed chamber technique in a pilot-scale plant with nine containers (height $1.5 \mathrm{~m}$, diameter $1.92 \mathrm{~m}$ ) provided with similar conditions as in full-scale storage (i.e., slurry temperature, climate, filling/empting routines). The experiment compared stored pig slurry: 1) without a cover, 2) with a straw cover, and 3) with a plastic sheet cover. In the field, pig slurry was band-spread either in spring or late summer before tillage, with or without immediate incorporation. Gas sampling took place during the following 7 weeks in order to determine $\mathrm{CH}_{4}$ and $\mathrm{N}_{2} \mathrm{O}$ emissions. Storage and field treatments were both organized in a randomized block design with three replicates. During the year-long pilot-scale study, $\mathrm{CH}_{4}$ emissions occurred from all types of storage, whereas 


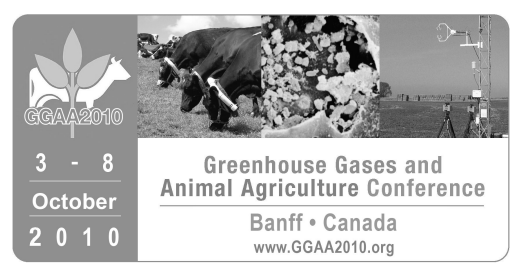

$\mathrm{N}_{2} \mathrm{O}$ emissions were very low except from the straw-covered slurry. In the summer period (May-Sept), plasticcovered slurry gave significantly lower $\mathrm{CH}_{4}$ emissions during storage than uncovered or straw-covered slurry. During winter (Oct-April), there were no significant differences between the storage treatments. Mean annual $\mathrm{CH}_{4}$ emissions ( $\mathrm{g} \mathrm{CH}_{4}-\mathrm{C}$ per $\mathrm{kg}$ VS) from stored slurry were 5.4 for uncovered, 5.8 for straw-covered and 3.0 for plastic-covered with corresponding methane conversion factors (MCF) of 2.6, 2.8 and 1.5\%, respectively. The $\mathrm{N}_{2} \mathrm{O}$ emissions from straw-covered slurry during storage were $35.9 \mathrm{~g} \mathrm{~N}_{2} \mathrm{O} \mathrm{m}^{-2} \mathrm{yr}^{-1}$, corresponding to a nitrous oxide emission factor (EFnit) $0.74 \%$ of total- $\mathrm{N}$ in slurry. The $\mathrm{N}_{2} \mathrm{O}$ emissions after field application of pig slurry varied depending on soil conditions, with dry conditions following application giving low emissions in early spring. However, there were emission peaks after subsequent rainfall. Incorporation of band-spread slurry reduced $\mathrm{N}_{2} \mathrm{O}$ emissions significantly in these conditions, with total $\mathrm{N}_{2} \mathrm{O}-\mathrm{N}$ losses of $1.35 \%$ of total- $\mathrm{N}$ in slurry for band spreading and $0.46 \%$ for band spreading plus harrowing. In the autumn, when conditions were wetter, the corresponding $\mathrm{N}_{2} \mathrm{O}-\mathrm{N}$ losses were 0.77 and $0.97 \%$, respectively. The soil generally acted as a sink for $\mathrm{CH}_{4}$, with higher consumption of atmospheric $\mathrm{CH}_{4}$ in control soil without slurry application.

\section{Greenhouse gases emissions from swine manure stored at different stack heights} H. Dong*, Z. Zhu*, Z. Zhou, H. Xin and Y. Chen

Swine manure storage is one of the major sources of greenhouse gas (GHG) emissions. This study attempts to quantify the GHG $\left(\mathrm{CO}_{2}, \mathrm{CH}_{4}\right.$ and $\left.\mathrm{N}_{2} \mathrm{O}\right)$ emissions from swine manure storage at different stack heights using dynamic chamber with in-situ multi-gas monitor methods. Three stack heights of 10,20 and $40 \mathrm{~cm}$ were examined under controlled a temperature $\left(25^{\circ} \mathrm{C}\right)$ and ventilation rate (20 air changes per hour), each replicated three times. The results showed that GHG emissions increased on the second to third day of storage followed by a decrease and became stable after 10-d storage. Manure stack height affected GHG emissions from the stored swine manure, with the lower stack height leading to higher $\mathrm{CO}_{2}$ and $\mathrm{N}_{2} \mathrm{O}$, but lower $\mathrm{CH}_{4}$ emissions per $\mathrm{kg}$ of initial manure weight. On the basis of 100-year global warming potential (GWP), cumulative emission was $0.31 \pm 0.02,0.22 \pm 0.02$ and $0.13 \pm 0.02 \mathrm{~kg} \mathrm{CO}_{2 \mathrm{e}}$ per $\mathrm{kg}$ initial manure, respectively, for the 10,20 and $40 \mathrm{~cm}$ stacks over the 6-week storage period. Data of the study will contribute to the improvement of the GHG inventory and best management practices for alleviating GHG emissions from swine manure storage.

\section{Ammonia and nitrous oxide interactions - The role of manure organic matter management}

S. Petersen* and S. G. Sommer*

Manure composition, management and climate determine emissions of $\mathrm{NH}_{3}$ and $\mathrm{N}_{2} \mathrm{O}$ during storage and after field application. The extent of, and balance between, these two gaseous losses is closely linked to the turnover of manure organic matter. There may be positive interactions between $\mathrm{NH}_{3}$ and $\mathrm{N}_{2} \mathrm{O}$ emissions, e.g., both emissions are stimulated by composting of solid manure and reduced by coverage during storage. The interaction may also be negative, e.g., $\mathrm{N}_{2} \mathrm{O}$ emissions can be stimulated due to denitrification following slurry injection to avoid $\mathrm{NH}_{3}$ losses. Livestock manure is potentially an important source of nutrients for crop production. The $\mathrm{N}$ use efficiency, however, will vary depending on manure type and management practice, and environmental losses are sources of agricultural GHG emissions. In terms of global warming potential it is currently assumed that emissions of $\mathrm{N}_{2} \mathrm{O}$ after deposition of $\mathrm{NH}_{3}$ are similar to those from manure $\mathrm{N}$ applied to soil, but $\mathrm{N}$ that is lost must be substituted by other $\mathrm{N}$ sources at the expense of energy for production and transport of fertilizer. Hence, the overall GHG balance of manure management will benefit from efforts to 


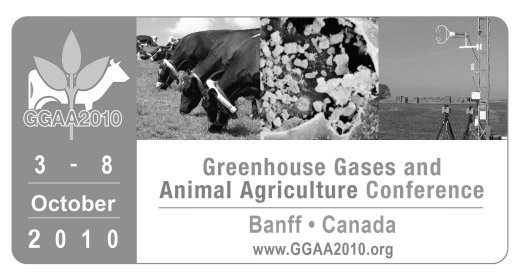

improve $\mathrm{N}$ use efficiency. In this context, feeding strategies which influence $\mathrm{NH}_{3}$ losses from the manure may be viewed as an integrated part of manure management. Ammonia and $\mathrm{N}_{2} \mathrm{O}$ emissions occur from liquid-air and oxic-anoxic interfaces, respectively. The coupling between these interfaces will depend on manure organic matter content and degradability, but $\mathrm{NH}_{3}$ and $\mathrm{N}_{2} \mathrm{O}$ abatement measures will likely affect both gases. For liquid manure (slurry), a wide range of treatment technologies have been developed for improved nutrient management, including chemical-mechanical separation, anaerobic digestion, and acidification. The resulting changes in slurry composition will significantly modify $\mathrm{C} / \mathrm{N}$ transformations and can in some situations increase the potential for $\mathrm{NH}_{3}$ and $\mathrm{N}_{2} \mathrm{O}$ emissions during storage and in the field. Simple models using organic matter and nitrogen composition as main drivers can visualize the effects of manure treatment and handling on $\mathrm{NH}_{3}$ and $\mathrm{N}_{2} \mathrm{O}$ losses, and the importance of management for the overall GHG balance. Such calculations indicate a significant scope for GHG mitigation via improved management, although the theoretical basis for parameterization is still very incomplete.

\section{An effective mitigation technology for reducing nitrous oxide emissions from grazed grassland H. J. Di* and K. C. Cameron}

In New Zealand, the predominant land use is grazed pastures where animals graze outdoor pastures all year round. Agriculture accounts for about $50 \%$ of New Zealand's greenhouse gas emissions inventory, of which two thirds are methane $\left(\mathrm{CH}_{4}\right)$ and one third is nitrous oxide $\left(\mathrm{N}_{2} \mathrm{O}\right)$. A major source of $\mathrm{N}_{2} \mathrm{O}$ is the nitrogen returned to the pasture in the animal excreta, particularly in the urine. This paper describes an effective mitigation technology for $\mathrm{N}_{2} \mathrm{O}$ emissions in grazed grassland involving the use of nitrification inhibitors. This technology involves spraying grazed pasture soil with the nitrification inhibitor dicyandiamide (DCD) shortly after grazing in the autumn and again in the spring. Real-time PCR and RT-PCR (Reverse Transcription-PCR) studies showed that the nitrification inhibitor dicyandiamide (DCD) worked by largely inhibiting the growth and activity of the ammonia oxidizing bacteria (AOB) in the urine patch soils. Studies have been conducted to determine the effectiveness of DCD in reducing $\mathrm{N}_{2} \mathrm{O}$ emissions from animal urine deposited on a range of soils, including: Horotiu soil in the Waikato, Taupo pumice soil in the Central North Island, Lismore and Templeton soils in Canterbury, Harihari soil from the West Coast of the South Island and Mataura soil from Southland. The water inputs (rainfall plus irrigation) in these studies varied from about 850 to $2200 \mathrm{~mm}$. Results show that the $\mathrm{N}_{2} \mathrm{O}$ emission factor (EF3) of the urine- $\mathrm{N}$ was decreased by an average of $68 \%$ with a standard error of 2.5 . In addition, nitrate leaching (a source of indirect $\mathrm{N}_{2} \mathrm{O}$ emissions) was decreased by an average of $64 \%$ with a S.E. of 3.6. Furthermore, significant increases in pasture yield have also been recorded. This nitrification inhibitor technology has therefore been proven to be highly effective in mitigating $\mathrm{N}_{2} \mathrm{O}$ emissions in a wide range of New Zealand grassland soils. It can serve as a valuable mitigation tool for $\mathrm{N}_{2} \mathrm{O}$ emissions from grazed grassland while at the same time increasing the $\mathrm{N}$ use efficiency by the pasture.

\section{Is on-farm biogas production the solution for reducing GHG emissions and for developing more sustainable livestock operations? \\ D. Massé*, G. Talbot and Y. Gilbert}

The intensification of the livestock sector contributes to climate change, air pollution, soil and water degradation, and biodiversity depletion. Livestock slurries are important sources of methane, nitrous oxide and ammonia emissions and of organic, chemical and biological contaminants. According to the Food and 


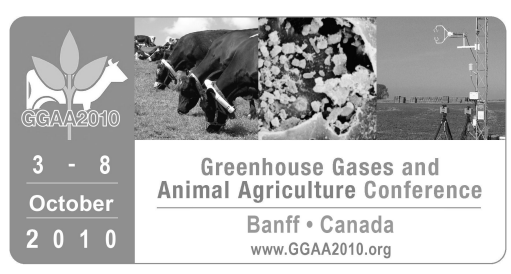

Agriculture Organization of the United Nations, the demand for animal food products is expected to double by 2050. If farming practices are not improved, the pressure on natural resources will drastically increase. Another reality is that the global energy demand is increasing rapidly while at the same time, the fossil fuel reserves are decreasing. These environmental and energy concerns are leading to a renewed interest in environmental biotechnologies that can produce renewable energy, minimize environmental impact and add value to livestock operations' by-products. The paper describes the potential contribution of on-farm biogas production by anaerobic digestion in reducing GHG emissions from livestock operation, either via the production of renewable energy to substitute fossil fuel and via the reduction in chemical fertilizer needs for livestock and cash crop productions. Anaerobic digestion (AD) biotechnologies produce biogas at rates ranging between 0.2 to $0.4,0.2$ to 0.3 and 0.35 to $0.6 \mathrm{~L} / \mathrm{g}$ VS from swine, cow and poultry slurries respectively. The biogas produced is of high quality with a methane concentration ranging between 60 and $80 \%$. AD facilitates the precipitation of phosphorous in the bioreactor and in digestate storages. The N/P ratio in bioreactor's digestate and storage supernatant is more balanced to meet the crop needs thus reducing the need for supplementary chemical fertilizers. Both the recovery of green energy and the reduced needs for chemical fertilizers will substantially decrease the carbon footprint of animal food products. Incentives for the adoption of AD on livestock operations go beyond renewable energy production and attenuation of GHG. Environmental, agronomic and social benefits should also be taken into consideration. The paper also addresses how on-farm biogas production can contribute to achieve more sustainable livestock operations by substantially reducing other environmental impacts related to manure management. AD has the potential to stabilize and deodorize animal wastes. It reduces the risk of water pollution associated with animal manure slurries (eutrophication) by removing 80 to $90 \%$ of the soluble chemical oxygen demand (COD). In addition, depending on operating conditions, some $A D$ processes are effective in eliminating populations of zoonotic pathogens, parasites and endocrine disruptors present in livestock manures. $A D$ also improves cohabitation in rural regions by reducing odour emissions by 70 to $95 \%$. The reduction in odour also allows more frequent land applications of manure to maximise nutrient uptake and minimize nutrient loss to the environment. The reduction in weed seeds during $A D$ process reduces the need for pesticides. The livestock producers will show more interest in $A D$ technology if the process is robust, very stable, easy to operate and requires minimum labour skills and energy input.

\section{The effect of anaerobic digestion of pig slurry on greenhouse gas and ammonia emissions under winter conditions}

W. Berg*, E. Dinuccio* and P. Balsari

The aim of the study was to investigate the effect of the anaerobic digestion of pig slurry on carbon dioxide $\left(\mathrm{CO}_{2}\right)$, methane $\left(\mathrm{CH}_{4}\right)$, nitrous oxide $\left(\mathrm{N}_{2} \mathrm{O}\right)$ and ammonia $\left(\mathrm{NH}_{3}\right)$ emissions during slurry management under winter conditions. Gaseous emissions during storage and after broadcast soil application of raw pig slurry and of pig digested slurry were investigated at laboratory scale and compared in term of greenhouse gas (GHG) emissions. Raw pig slurry was obtained from a commercial farm. The digested slurry was obtained by a laboratory batch fermentation of the raw slurry performed at mesophilic temperature $\left(35^{\circ} \mathrm{C}\right)$ for $35 \mathrm{~d}$. Four samples of each type of slurry (raw and digested, $1000 \mathrm{~cm}^{3}$ each sample) were stored in cylindrical glass jars $\left(1500 \mathrm{~cm}^{3}\right.$ capacity) for a period of $30 \mathrm{~d}$ in a climatic room kept at $5 \pm 0.5^{\circ} \mathrm{C}$. At the end of the storage period the replicates were used in the following application trials. Application trials were carried out for $5 \mathrm{~d}$ at $10 \pm 0.5^{\circ} \mathrm{C}$ using cylindrical glass jars $\left(1500 \mathrm{~cm}^{3}\right.$ capacity) filled with $1000 \mathrm{~cm}^{3}$ of a loamy sand soil. Slurries were broadcast applied to soil at a rate of $70 \mathrm{~kg} \mathrm{~N} \mathrm{ha}^{-1}$. Gaseous emissions were determined by dynamic chamber method using 


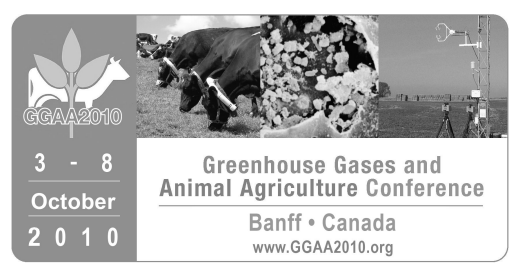

Infrared Photoacoustic Detection (IPD). During the storage period, $\mathrm{N}_{2} \mathrm{O}$ fluxes from raw pig slurry ranged from 0.01 to $0.07 \mathrm{mg} \mathrm{m}^{-2} \mathrm{~h}^{-1}$. No $\mathrm{N}_{2} \mathrm{O}$ was detected from digested pig slurry during the whole period of storage. On average, total emissions of $\mathrm{CO}_{2}, \mathrm{CH}_{4}$ and $\mathrm{NH}_{3}$ from digested slurry stores were, respectively, 33, 47 and $44 \%$ lower than that from raw slurry stores. After soil application, anaerobic digestion significantly reduced GHG emissions but increased total $\mathrm{NH}_{3}$ emissions by $17 \%$. Nevertheless, there was no effect of anaerobic digestion on nitrogen losses when total $\mathrm{NH}_{3}-\mathrm{N}$ losses were expressed as a percentage of total ammoniacal nitrogen (TAN) applied to soil. The combined GHG emissions from both storage and soil application of digested pig slurry were $\sim 70 \%$ lower compared to those from raw pig slurry.

\section{A new concept of biogas systems for sustainable animal agriculture}

O. Hamamoto*, J. Takahashi* and K. Umetzu

High performance digestion and following co-generation were studied for the improvement available to various types of biogas systems. There is still not little left to subjugate the defect of power generation instability caused by biogas quality fluctuations and environmental deterioration by excess nitrogen in digested manures. Biogas plants are characterized by two important functions of organic waste disposal for environmental protection and energy supply such as CHP (Combined heat and power) plants. And further advantages could be obtained by introducing biogas systems for the preservation of agricultural eco-systems from desertification and contamination of pesticide residue besides excess nitrogen by over fertilizing. A biogas conditioning process was developed for reliable and stable power generation by using a potentially controlled bioreactor which controls the concentration of methane for the uniformity of biogas quality, which is especially available to simplified digestion systems, such as closed type anaerobic ponds. The hyper-thermophilic digestion or the high temperature processing of digested manure, such as $60^{\circ}$ or $65^{\circ} \mathrm{C}$, is very effective to the pasteurization or inactivation of bacteria, viruses and seeds and also to the easy ammonia stripping from digested slurries. Biogas plants are in an advantageous position in the generation cost, compared with photovoltaic and wind turbine generations, since it is not necessary for biogas plants to have batteries for the energy storage, especially in case of stand alone application, too. 


\title{
SESSION 2: POSTER ABSTRACTS
}

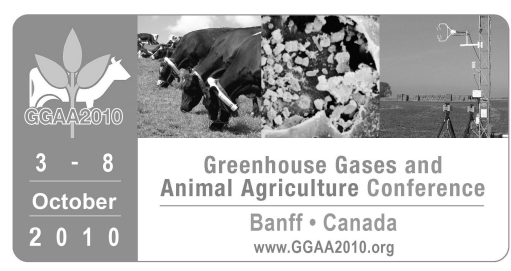

\section{PLEASE NOTE: Authors denoted with an asterisk are registered GGAA2010 delegates}

\author{
M20. Better prediction of impact of manure injection on nitrous oxide emissions \\ J. Agnew*, C. Lague and J. Schoenau
}

\begin{abstract}
A significant portion of anthropogenic nitrous oxide $\left(\mathrm{N}_{2} \mathrm{O}\right)$ emissions come from the land application of fertilizers and manure. Although $\mathrm{N}_{2} \mathrm{O}$ is naturally produced in soils, manure management practices such as slurry injection or solid manure incorporation have the potential to influence both the short-term and longterm emissions by changing the magnitude and pattern of the nitrogen cycle in the soil-plant system. Management practices also impact the magnitude of other nitrogen losses (ammonia, nitrate) which affect indirect $\mathrm{N}_{2} \mathrm{O}$ emissions. The effect of application method on the short- and long-term direct and indirect $\mathrm{N}_{2} \mathrm{O}$ emissions is required to better estimate national agricultural greenhouse gas (GHG) emissions. Collecting continuous GHG flux data from sites over several weeks or months is labour-intensive and does not always provide statistically distinguishable results. Therefore, a model that simulates the environmental conditions and nutrient transformations after manure application may allow a more reliable prediction of the effect of management practices on total GHG emissions. Numerous process based models exist for the estimation of regional and national GHG inventories. Two ecosystem models, DeNitrification DeComposition (DNDC) and DAYCENT, have been used to estimate $\mathrm{N}_{2} \mathrm{O}$ emissions as influenced by agricultural practices in Canada. These models simulate trace gas fluxes of carbon and nitrogen among the atmosphere, vegetation, and soil while submodels account for nitrogen gas emissions from nitrification and denitrification. However, these models do not account for enhanced denitrification that exists after slurry injection or manure incorporation, resulting in an underestimation of $\mathrm{N}_{2} \mathrm{O}$ emissions. The objective of this poster and short communication are to assess if manure application method impacts longer-term $\mathrm{N}_{2} \mathrm{O}$ emissions and to estimate the magnitude of the effects of manure application method on total direct and indirect $\mathrm{N}_{2} \mathrm{O}$ emissions. These results may be applied to modifications to the DNDC and DAYCENT models to better estimate $\mathrm{N}_{2} \mathrm{O}$ emissions from manure application practices.
\end{abstract}

\section{M21. Biogas and methane production of slurry from pigs fed with a biodiesel co-product from Jatropha curcas L.}

B. Berenchtein, A. L. Abdalla Filho, C. Goncales Shen, P. Barboza de Godoy, P. Pimental dos Santos, M. de Cássia Piccolo and A. L. Abdalla*

Methane $\left(\mathrm{CH}_{4}\right)$ is a greenhouse gas and recent inventories have suggested that livestock manure makes a significant contribution to global $\mathrm{CH}_{4}$ emissions if any treatment was made. However, by using controlled anaerobic digestion of animal manure, the $\mathrm{CH}_{4}$ emissions can be used as a substitute for fossil fuels, serving as a $\mathrm{CO}_{2}$-neutral energy source. The purpose of this work was to investigate the effects of dietary inclusion of detoxicated Jatropha curcas meal (DJCM), a biodiesel co-product, in the biogas and methane production from the slurry of finishing pigs for renewable energy production. Ten male finishing pigs $(70 \mathrm{~kg})$ were randomly allotted in metabolic cages and fed with basal diet (BD) or basal diet $+8 \%$ of DJCM (BD $+8 \%)$. The BD was formulated to meet all requirements for protein, amino acids, minerals and vitamins. In the other diet, $8 \%$ of 


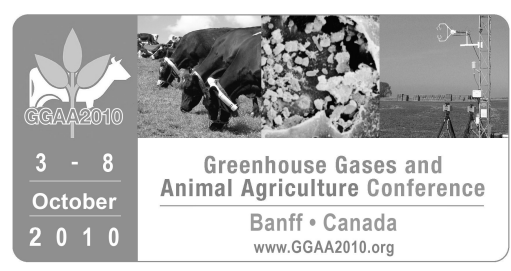

DJCM was included. The wastes were collected on the metabolic cages. The total solid (TS) content in the substratum was $5.2 \%$ composed by waste (feces and urine) diluted to water. A laboratory scheme was used, consisting of ten biodigesters whose total volume was $3.125 \mathrm{~L}$ and exposed to $39^{\circ} \mathrm{C}$. The departure phase analysis was based on the average accumulated biogas and methane yield during the 7 day period. Two groups formed by five of these biodigesters were exposed to slurry of two diets (BD and BD $+8 \%$ ). After each reading of the gas production, an aliquot of gas was stored in pipes of assay previously identified and submitted to the vacuum, where the determination of methane $\left(\mathrm{CH}_{4}\right)$ was made using a chromatograph of gaseous phase (model CG-2014 GAS CHROMATOGRAPHA, Shimadzu). The calibration of the equipment was made with the gas standard supplied for the company White Martins. Under these conditions, the accumulated biogas production (BP) (L and L/\%TS) and resultant accumulated methane volumetric production (MVP) (L and L/\%TS) were evaluated. The results showed $6.101 \mathrm{~L}$ and $1.201 \mathrm{~L} / \% \mathrm{TS}$ for $\mathrm{BD}, 6.036 \mathrm{~L}$ and $1.089 \mathrm{~L} / \% \mathrm{TS}$ for $\mathrm{BD}+8 \%$ of accumulated biogas production and $1.237 \mathrm{~L}$ and $0.247 \mathrm{~L} / \% \mathrm{TS}$ for $\mathrm{BD}, 1.206 \mathrm{~L}$ and $0.218 \mathrm{~L} / \% \mathrm{TS}$ for $\mathrm{BD}+8 \%$ of accumulated methane production. Addition of $8 \%$ of DJCM did not affect significantly $(P>0.05)$ the accumulated biogas production and resultant accumulated methane production. So, it is possible to use DJCM in pig diets without effects on renewable energy production.

\section{M22. Emissions of nitrous oxide after slurry application on dairy farm fields in coastal BC}

\section{S. Bittman*, D. E. Hunt, C. G. Kowalenko and A. Friesen}

Dairy farming in BC is characterized by high livestock densities and a long, wet growing season. Silage corn (Zea mays L.) and perennial grasses are grown for feed. High rates of winter-stored manure are applied in spring on perennial grass or on land that is either bare or in winter cover crop prior to corn planting. Previous work at the research centre had shown that nitrous oxide $\left(\mathrm{N}_{2} \mathrm{O}\right)$ emissions were lower when manure was applied on grass compared to bare land but no data exist on the emission rates from typical fields on commercial farms. The purpose of this study was to test the hypothesis that emissions can be reduced by applying manure on perennial grasses or cover crops rather than on bare land on commercial farms. The study was conducted on two farms in each of three years; 4 farms had sandy loam soil with about 3\% organic matter (OM) while 2 farms had silty clay loam with about $14 \%$ OM. Dairy slurry was broadcast at approximately $200 \mathrm{~kg} \mathrm{ha}^{-1}$ of total N in mid-March and corn was planted with conventional tillage in late April-early May. Perennial grass was orchardgrass (Dactylis glomerata L.) and cover crops were either Italian ryegrass (Lolium multiflorum Lam.) or winter wheat (Triticum aestivum L.). Emissions were monitored using vented chambers from mid-March to early-July when rates typically declined. In 5 of 6 trials emissions were significantly lower when manure was applied to grass than bare soil and emissions from cover crops were generally intermediate. Emissions were far greater from the high OM fine textured soils (150-3100 $\mathrm{g} \mathrm{N}_{2} \mathrm{O}-\mathrm{N}$ ha ${ }^{-1}$ ) than from the coarser low OM soils (97$830 \mathrm{~g} \mathrm{~N}_{2} \mathrm{O}-\mathrm{N} \mathrm{ha}^{-1}$ ). Applying manure to orchardgrass generally increased emission rates $2 \times$ on the sandy soil and $4 \times$ on the silty soil. In 4 of 6 fields, emissions from manured orchardgrass were no higher than emission from un-manured bare fields. In contrast, emissions from manured bare corn fields averaged over $5 \times$ emissions from unfertilized orchardgrass. Results suggest that to reduce emissions manure should be applied to grass or cover crops rather than bare soil, especially on soils with high emission potential. Although the measurement periods in this study were less than 4 months, the data indicate that the emission factor for manure application in coastal BC may be considerably less than the 1.25 value used by IPCC, especially for manure applied on grass on coarse textured soils. 


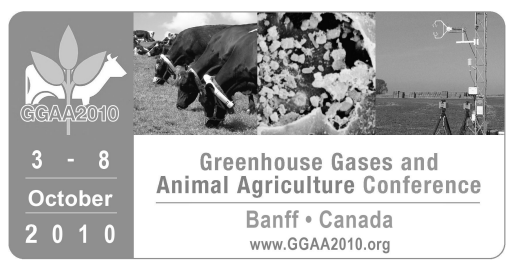

M23. Measurements of nitrous oxide and ammonia emissions from rooting areas in organic pig production: comparison between different substrates and two measuring methods

J. Botermans*, A.-C. Olsson, K.-H. Jeppsson*, M. Ngwabie Ngwa

Previous experiments have shown high nitrogen losses from outdoor areas in organic pig production. Therefore, two trials were conducted to compare the emissions of nitrous oxide $\left(\mathrm{N}_{2} \mathrm{O}\right)$ and ammonia $\left(\mathrm{NH}_{3}\right)$ from rooting areas in organic grower-finisher production. The pig house had 8 pens with 16 pigs in each pen. The pigs had access to $24 \mathrm{~m}^{2}$ inside area and $16 \mathrm{~m}^{2}$ outside area per pen. A part of the outside area was covered with a rooting material $\left(7 \mathrm{~m}^{2}\right)$. Two pens had peat (P), two pens wood shavings (WS), two pens peat plus some feed crumbs (PF) $(1 \mathrm{~kg} /$ pen/day) and two pens without rooting material (concrete) (C). Emissions of $\mathrm{N}_{2} \mathrm{O}$ were measured by using the closed chamber technique in combination with an infra-red photo acoustic multi gas analyzer or in combination with air sampling and gas chromatography. Ammonia emissions were measured with the ventilated chamber technique. Samples were taken with gas detection tubes (Kitagawa) when constant $\mathrm{NH}_{3}$ concentrations were reached. No differences in emissions of $\mathrm{N}_{2} \mathrm{O}$ or $\mathrm{NH}_{3}$ were detected between $\mathrm{P}$ and $\mathrm{PF}$ and therefore these two treatments were put together. The measurements of the $\mathrm{N}_{2} \mathrm{O}$ emissions were somewhat higher with the infra-red photo acoustic multi gas analyzer as compared to the measurements with the gas chromatography method. However, this difference was not statistically significant. Therefore, the gas chromatography method can be a good method for field studies. The emissions from the rooting material measured with the infra-red photo acoustic multi gas analyzer were $0.00,0.39$ and $0.08 \mathrm{mg} \mathrm{m}$ ${ }^{2} \mathrm{~h}^{-1} \mathrm{~N}_{2} \mathrm{O}$ for respectively $\mathrm{C}$, WS and $\mathrm{P} / \mathrm{PF}(\mathrm{P}=0.07)$. The corresponding measurements with the gas chromatography method were $0.00,0.32$ and $0.04 \mathrm{mg} \mathrm{m}^{-2} \mathrm{~h}^{-1} \mathrm{~N}_{2} \mathrm{O}(\mathrm{P}=0.10)$. The emissions of $\mathrm{NH}_{3}$ were 107, 211 and $16 \mathrm{mg} \mathrm{m}^{-2} \mathrm{~h}^{-1}$ for respectively $C, W S$ and $P / P F(P=0.02)$. It should be pointed out that all results from the present investigation should be used as relative measurements. So it is possible to compare different rooting materials with each other, but it is not possible to draw any conclusions with regard to the total emissions per produced pig. The main conclusions from the experiments were that peat as a rooting material has a good effect in reducing ammonia emissions as compared to no rooting material. However, emissions of $\mathrm{N}_{2} \mathrm{O}$ were higher. The use of wood shavings as a rooting material resulted in both a higher $\mathrm{NH}_{3}$ and $\mathrm{N}_{2} \mathrm{O}$ emissions.

\section{M24. Nitrous Oxide Emissions from Chernozemic Soils Amended with Anaerobically Digested Beef Cattle Feedlot-Manure: A Laboratory Study}

W.L. Chiyoka, X. Hao*, F. Zvomuya and X. Li

Biogas production from beef cattle (Bos taurus) feedlot manure results in the co-generation of anaerobically digested manure (ADM), a nutrient-rich substrate the solid fraction (SS) of which is often applied to cropland. Application of SS to cropland may result in lower nitrous oxide $\left(\mathrm{N}_{2} \mathrm{O}\right)$ emissions than raw manure due to biochemical changes occurring during anaerobic digestion. We tested this hypothesis using a laboratory incubation study in which $\mathrm{N}_{2} \mathrm{O}$ fluxes from two Alberta soils [a Dark Brown Chernozem clay loam (Typic Haploboroll) and a Black Chernozem silty clay (Typic Haplocryoll)] amended with fresh beef cattle feedlot manure, SS, pelletized SS (PSS), and urea + mono-ammonium phosphate (UMP) were measured over a 10-wk period. Amendments were applied at rates corresponding to 100 and $200 \mathrm{~kg} \mathrm{~N} / \mathrm{ha}$, with a $0 \mathrm{~N}$ control included for comparison. Amended soils were maintained near $70 \%$ of field capacity moisture content and incubated for $10 \mathrm{wk}$ at $22^{\circ} \mathrm{C}$. Gas samples were collected 0,3 and $7 \mathrm{~d}$ after the start of the incubation and at weekly intervals thereafter for $\mathrm{N}_{2} \mathrm{O}$ and $\mathrm{CO}_{2}$ analysis by gas chromatography. Analysis of variance (ANOVA) was done to determine the effect of soil, amendment and application rate on $\mathrm{N}_{2} \mathrm{O}$ and $\mathrm{CO}_{2}$ fluxes using Proc Mixed in SAS. 


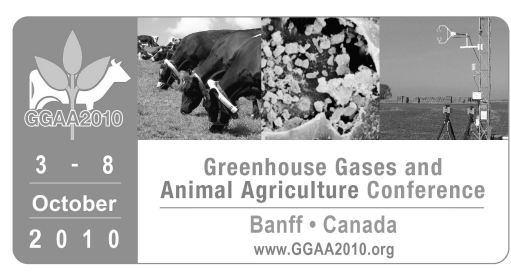

Our results showed that $\mathrm{N}_{2} \mathrm{O}$ fluxes differed significantly among amendments with the differences dependent on soil, amendment application rate, and time. Across amendment rates, mean cumulative emissions from SS(2.38 $\mathrm{mg} \mathrm{N} / \mathrm{kg}$ ) and UMP-amended soils $(0.59 \mathrm{mg} \mathrm{N} / \mathrm{kg})$ were not significantly different but were both significantly lower than emissions from PSS-amended soils $(10.7 \mathrm{mg} \mathrm{N} / \mathrm{kg})$ and those from the higher manure rate $(15.6 \mathrm{mg} \mathrm{N} / \mathrm{kg})$. The difference in cumulative $\mathrm{N}_{2} \mathrm{O}$ emissions between PSS and SS was only significant in the Black Chernozem. Microbial activity as indicated by cumulative $\mathrm{CO}_{2}$ fluxes was greatest in SS-amended $(6.7 \mathrm{~g}$ $\left.\mathrm{CO}_{2}-\mathrm{C} / \mathrm{kg}\right)$ and least in UMP-amended soils $\left(0.14 \mathrm{~g} \mathrm{CO}_{2}-\mathrm{C} / \mathrm{kg}\right)$. Post-incubation net mineral $\mathrm{N}$ content was greatest in manure-amended soils (144 mg N/ $\mathrm{kg}$ ), marginal in SS-amended soils $(23 \mathrm{mg} \mathrm{N} / \mathrm{kg}$ ) and lowest in PSS-amended soils that had net $\mathrm{N}$ immobilization $(-67 \mathrm{mg} \mathrm{N} / \mathrm{kg})$. We speculate that field application of SS in place of raw undigested manure will reduce $\mathrm{N}_{2} \mathrm{O}$ emissions.

\section{M25. Effects of dietary crude protein (CP) and rumen-degradable protein (RDP) level on microbial protein synthesis, ruminal fermentation characteristics, nitrogen balance, performance in lactating Holstein dairy cows}

K. L. Davies*, J. J. McKinnon, D. A. Christensen, and T. Mutsvangwa

Dairy cows capture only 25 to $35 \%$ of their dietary crude protein (CP) intake as milk protein, so large amounts of dietary nitrogen are excreted resulting in environmental pollution. The objectives of this study were to determine the effects of dietary CP and rumen-degradable protein (RDP) level on microbial protein synthesis, ruminal fermentation characteristics, nitrogen balance and milk production response in lactating dairy cows. Eight multiparous (BW: $711 \pm 21 \mathrm{~kg}$; DIM: $91 \pm 17$ days), lactating Holstein cows were used in a replicated $4 \times 4$ Latin square design with a $2 \times 2$ factorial arrangement of dietary treatments and 30-d experimental periods. Four cows in one square were fitted with rumen cannulas. Dietary treatments were 2 levels of CP (14.1 vs. $16.5 \%$ ) and 2 levels of RDP ( 63 vs. $69 \%$ of CP). Rumen-degradable protein levels were manipulated by varying inclusion levels of canola meal and heated canola meal. Diet adaptation (d 0-21) was followed by 2 days (d 2123) of rumen digesta collection every $6 \mathrm{~h}$ for $48 \mathrm{~h}$ to establish ruminal fermentation characteristics. Total collection of feces and urine was conducted for 4 days ( $\mathrm{d}$ 26-30) to estimate total tract nutrient digestibility and nitrogen balance. Milk samples were collected on 3 consecutive days (d 27-29). Nitrogen intake $(P=0.03)$, and both urinary $\mathrm{N}(P<0.001)$ and urinary urea-N $(P<0.001)$ output were greater for the high $\mathrm{CP}$ diets as compared to cows fed low CP diets. Ruminal ammonia- $\mathrm{N}$ concentration tended to be greater in cows fed high CP than those fed low CP diets ( 20.3 vs. $17.4 \mathrm{mg} / \mathrm{dL} ; P=0.06)$, and was greater in cows fed high RDP compared to those fed low RDP diets (21.5 vs. $16.2 \mathrm{mg} / \mathrm{dL} ; P=0.005)$. However, nitrogen balance, milk yield, milk composition and microbial $\mathrm{N}$ supply were unaffected $(P>0.05)$ by dietary treatment. Lowering the level of dietary CP had no affect on production parameters and reduced the urinary excretion of nitrogen, therefore increasing the efficiency of dietary nitrogen utilization and reducing the impact of environmental nitrogen pollution.

\section{M26. The effect of repeated use of the nitrification inhibitor DCD on reducing $\mathrm{N}_{2} \mathrm{O}$ emissions from cow urine \\ C.A.M. de Klein*, K.C. Cameron, H.J. Di*, G. Rys, R.M. Monaghan and R.R. Sherlock}

Urine patches deposited by grazing animals are the single largest source of nitrous oxide $\left(\mathrm{N}_{2} \mathrm{O}\right)$ emissions in New Zealand. In recent years, a nitrification inhibitor technology using dicyandiamide (DCD) has been 


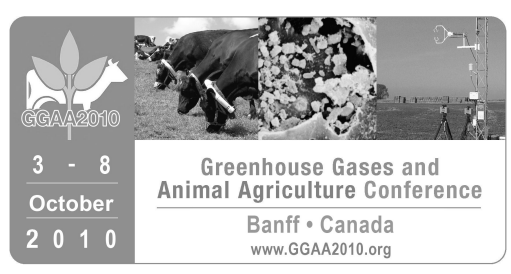

developed that can substantially reduce these emissions. However, uncertainty exists about the sustained effectiveness of repeated use of DCD on reducing $\mathrm{N}_{2} \mathrm{O}$ emissions from urine patches. The aim of this study was to determine if DCD application for 4 or 5 consecutive years alters its effectiveness to reduce the $\mathrm{N}_{2} \mathrm{O}$ emission factor from cow urine patches $\left(\mathrm{EF}_{3}\right)$. At 'repeated-DCD-use' sites and 'non-DCD' sites in Canterbury and Southland, $\mathrm{N}_{2} \mathrm{O}$ emissions were measured for 6 months in the following treatments: Control, Control+DCD, Urine and Urine+DCD. At the Canterbury site, $\mathrm{DCD}$ application significantly reduced $\mathrm{EF}_{3}$ by $61-70 \%(P<0.05)$. At the Southland site, DCD application reduced $\mathrm{EF}_{3}$ by $20-30 \%$ but this was not a significant effect $(P>0.05)$. The lack of significant reduction at the Southland site was probably a result of the extremely wet soil conditions encountered. Overall, the results showed that 4 or 5 years of DCD application did not significantly alter the effectiveness of DCD to reduce $\mathrm{N}_{2} \mathrm{O}$ emissions. A summary of 10 published New Zealand studies showed that, on average, DCD reduced $\mathrm{N}_{2} \mathrm{O}$ emissions by $57 \%$. Absolute reductions in $\mathrm{N}_{2} \mathrm{O}$ emissions were variable and ranged from 0 to around $30 \mathrm{~kg} \mathrm{~N}_{2} \mathrm{O}-\mathrm{N}$ ha ${ }^{-1}$. Under New Zealand's proposed emissions trading scheme farmers could receive carbon credits for reducing greenhouse gas emissions. If that happens, it is important to consider the absolute (i.e., $\mathrm{kg} \mathrm{N} \mathrm{N}_{2} \mathrm{O}-\mathrm{N}$ reduction per ha) rather than relative (\% of emission) benefit of the nitrification inhibitor technology, to ensure farmers can be provided with a value proposition for its use.

\section{M27. Seasonal variation methane emission from solid storage of cattle manures}

X. Z. Ding, R. J. Long*, J. D. Mi and X.D. Huang*

Methane $\left(\mathrm{CH}_{4}\right)$ is a potent greenhouse gas and animal manure makes a significant contribution to global $\mathrm{CH}_{4}$ emissions. Seasonal $\mathrm{CH}_{4}$ emission fluxes from solid storage of cattle manure were determined by dynamic chambers in northwestern China. Meanwhile, chemical properties of both fresh and stored manure were analyzed. Experimental results showed large spatial and seasonal fluctuations of $\mathrm{CH}_{4}$ emissions in solid manure. Manure $\mathrm{CH}_{4}$ emission rate in spring was significantly lower than that in summer $(P<0.05)$ and the emission rate during a 20-d storage periods was 1.8-15.3, 19.2-220.3 and 26.1-165.8 $\mathrm{g} \mathrm{CH}_{4} \mathrm{~kg}^{-1} \mathrm{~d}^{-1}$, as well as cumulative emission was $0.09-0.15,1.6-2.6$ and $2.1-3.5 \mathrm{~g} \mathrm{~kg}^{-1}$ in spring, summer and fall, respectively. Significant correlation observed between ambient air temperature and manure stack temperature $(P<0.05)$. The results indicated that effective manure management lead to a low manure heap temperature would achieve minimize emissions.

\section{M28. The effect of mechanical separation on GHG and ammonia emissions from cattle slurry under winter conditions}

E. Dinuccio*, W. Berg* and P. Balsari

The effect of cattle slurry mechanical separation on carbon dioxide $\left(\mathrm{CO}_{2}\right)$, methane $\left(\mathrm{CH}_{4}\right)$, nitrous oxide $\left(\mathrm{N}_{2} \mathrm{O}\right)$ and ammonia $\left(\mathrm{NH}_{3}\right)$ emissions during slurry management under winter conditions was investigated at a laboratory scale study. Gaseous emissions from storage and broadcast soil application of raw cattle slurry and its liquid and solid separated fractions were measured and compared in term of greenhouse gas (GHG) emissions. Investigations started after separation of $\sim 21 \mathrm{~kg}$ of fresh cattle slurry by means of a lab scale mechanical separator. The experiment was set up as a randomised block design with four replicates. Samples of $1000 \mathrm{~cm}^{3}$ of each investigated manure (raw cattle slurry and its liquid and solid fraction) were stored at $5 \pm$ $0.5^{\circ} \mathrm{C}$ for a period of 30 days in open vessels $\left(1500 \mathrm{~cm}^{3}\right.$ capacity). After storage, the tested manures were broadcast applied to a loamy sand soil, at a rate of $70 \mathrm{~kg} \mathrm{~N} \mathrm{ha}^{-1}$. Application trials were performed in a climatic 


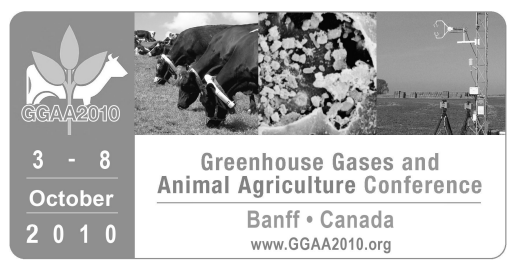

room kept at $10 \pm 0.5^{\circ} \mathrm{C}$. Open vessels ( $1500 \mathrm{~cm}^{3}$ capacity) filled with $1000 \mathrm{~cm}^{3}$ of soil were used. Each trial lasted for $168 \mathrm{~h}$. Flux measurements were performed by dynamic chamber method using infrared photoacoustic detection. Methane was the predominating GHG from stored slurries. Very low concentrations of $\mathrm{N}_{2} \mathrm{O}$, sometimes slightly above the background concentration, were measured from all materials over the storage period (30 days). During storage, ammonia fluxes were highest from the liquid fraction and lowest from the solid fraction. The solid fraction was the main source of $\mathrm{NH}_{3}$ emissions after land application: on average, $\sim 70 \%$ of total ammoniacal nitrogen (TAN) applied to soil were lost. Combining the losses during storage and after land application of both liquid and solid fraction, the total gas emissions measured in $\mathrm{CO}_{2}$-equivalents from both fractions together resulted $38 \%$ higher than that from raw cattle slurry.

\section{M29. Ammonia losses from storage and land application of raw and mechanical-chemical separated slurry \\ N. Dorno, E. Dinuccio*, F. Gioelli and P. Balsari}

The environmental performance of a slurry chemical-mechanical separator, in terms of ammonia $\left(\mathrm{NH}_{3}\right)$ emissions during pig slurry management, (storage and land application) was assessed. The separation process consisted of two phases: a chemical reaction between slurry and a flocculant polymer (polyacrilamide PAM), and a following mechanical separation, through a rotary separator and a filter press. Ammonia volatilization were determined during storage and after field application of raw pig slurry (RS) and its liquid (LF) and solid (SF) separated fractions, in summer and winter conditions. About $900 \mathrm{~m}^{3}$ of LF and $4 \mathrm{t}$ of SF obtained from chemical-mechanical separation of less than $1000 \mathrm{~m}^{3}$ of pig slurry have been stored in a tank of $1500 \mathrm{~m}^{3}$ (LF) and on a concrete platform (SF pile). The same amount $\left(900 \mathrm{~m}^{3}\right)$ of RS was stored in a tank of $1500 \mathrm{~m}^{3}$. Ammonia emissions were monitored for a period of $30 \mathrm{~d}$ by a set of three wind tunnels (WT) per each manure type. The air flow was adjusted to obtain an air speed of about $0.7 \mathrm{~m} \mathrm{~s}^{-1}$ over manure surface. Application trials were carried out on bare soil and on alfalfa (Medicago sativa L.) meadow. The three different manures were broadcast spread, on $10 \mathrm{~m}^{2}$ plots at a rate of $70 \mathrm{~kg} \mathrm{~N} \mathrm{ha}^{-1}$. Experiments on bare soil were performed by three open large dynamic chambers (OLDC), while a set of three WT was used to evaluate $\mathrm{NH}_{3}$ emissions after manure application on alfalfa meadow. Air speed over bare soil and alfalfa surface was arranged around $1.0 \mathrm{~m}$ $s^{-1}$.

M30. Measurement of potential methane oxidation rate and analysis of microbial community structure using DGGE in livestock slurry surface crusts

Y. Duan, S O. Petersen*, N. Boon and L. Elsgaard

During the storage of livestock slurry a surface crust may naturally form, which is sometimes reinforced with the addition of straw or wood chips. Previous studies have observed bacterial methane oxidation in this crust, suggesting a viable approach to reduce livestock methane emissions. This study investigated potential methane oxidation (PMO) rates and underlying microbial community structure in several crust materials (swine slurry natural crust, swine slurry straw crust, cattle slurry straw crust). Potential methane oxidation rates were measured by incubating crust materials with methane in the headspace. During the six hour incubation, strong methane oxidation was found in cattle slurry straw crust (up to $-0.173 \mu \mathrm{g}$ hour ${ }^{-1} \mathrm{~g}^{-1}$ sample), while net methane production instead of oxidation was observed in swine slurry straw crust (up to $0.106 \mu \mathrm{g} \mathrm{hour}^{-1} \mathrm{~g}^{-1}$ sample); no obvious activity of methane oxidation nor production occurred in swine slurry natural crust. DGGE band 


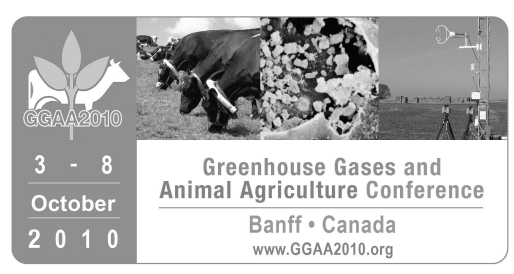

pattern analysis indicated varied structure of microbial communities, including general bacteria, type I and type II methanotrophs and methanogens, in all studied crust materials. In general, there was greater structure similarity within than between slurry types; however, in general bacterial community, especially in terms of richness of non-dominant species, swine slurry crust with straw addition was more similar to cattle slurry crust which also had straw addition than natural crust of the same slurry type. In the natural crust developed on swine slurry, differences in community structure of upper and lower layers were also observed. This study showed that both slurry type and the addition of straw influenced the development of microbial community in the surface crust, and this may have resulted in different manifestations of methanotrophic activity and net methane emission. The diversity of surface crust communities also indicated a potential to optimize methane oxidation.

\section{M31. Greenhouse gas emissions during composting of manure from cattle diets including corn dried distillers grains with solubles and condensed tannins}

X. Hao*, M. B. Benke, C. Li*, F. J. Larney, K. A. Beauchemin*, and T. A. McAllister*

Condensed tannins (CT) in ruminant diets improve $\mathrm{N}$ retention, but there is little research on how these phenolic compounds alter nitrogen metabolism during manure composting. This study investigated the effect of $\mathrm{CT}$ additives in cattle diets on $\mathrm{N}$ retention and greenhouse gas (GHG) emissions from feedlot manure during composting. The experiment consisted of two replications and three treatments: (1) manure from cattle fed a diet containing $86 \%$ barley grain, $9 \%$ barley silage and $5 \%$ supplement on a dry matter (DM) basis (Check, CK), (2) manure from cattle fed a diet similar to (1) with $400 \mathrm{~g} / \mathrm{kg}$ DM corn dried distillers grain with solubles (DDG) replacing barley grain, and (3) manure from cattle fed the diet described in (2) but with addition of Acacia mearnsii CT at $25 \mathrm{~g} / \mathrm{kg} \mathrm{DM} \mathrm{(DDG+CT).} \mathrm{After} 56 \mathrm{~d}$ of composting (Phase 1), windrows in each treatment were thoroughly mixed and divided into four portions. Two portions received additional mature compost ( $10 \%$ by weight) as a source of nitrite-oxidizing bacteria (NOB) and the other two portions received none. All portions were moved into individual bins for an additional 57-d (Phase 2) of composting, followed by 104-d (Phase 3) of curing. The ammonium $\left(\mathrm{NH}_{4}{ }^{+}\right)$content decreased $(\mathrm{P}<0.001)$ and total $\mathrm{N}(\mathrm{TN})$ content increased $(\mathrm{P}<0.001)$ in manure with $C T(D D G+C T)$ compared to manure without $C T(D D G)$. In the final compost higher $(P<0.001)$ contents of both $\mathrm{NH}_{4}{ }^{+}$and TN were observed in DDG+CT than DDG or CK. Adding mature compost had no $(P>0.05)$ effect on final compost properties and GHG emissions. Total cumulative nitrous oxide $\left(\mathrm{N}_{2} \mathrm{O}\right)$ emissions over 207- $d$ were affected $(P<0.001)$ by CT with emissions from DDG+CT $(0.109 \mathrm{~kg} \mathrm{~N} / \mathrm{Mg})>$ DDG $(0.090 \mathrm{~kg}$ $\mathrm{N} / \mathrm{Mg})>\mathrm{CK}(0.079 \mathrm{~kg} \mathrm{~N} / \mathrm{Mg})$, consistent with the trend of $\mathrm{NH}_{4}{ }^{+}$content in the compost. Total cumulative $\mathrm{CH}_{4}$ emissions were similar for $\mathrm{CK}(5.77 \mathrm{~kg} \mathrm{C} / \mathrm{Mg})$ and DDG $(5.84 \mathrm{~kg} \mathrm{C} / \mathrm{Mg})$, but both were higher $(\mathrm{P}<0.001)$ than from DDG+CT (4.49 kg C/Mg). Supplementation with $\mathrm{CT}$ in the DDG cattle diet led to a $23 \%$ reduction in $\mathrm{CH}_{4}$ emissions compared to DDG alone, suggesting $\mathrm{CT}$ in cattle diet could potentially reduce $\mathrm{CH}_{4}$ emissions during manure composting while higher $\mathrm{NH}_{4}{ }^{+}$and $\mathrm{TN}$ contents increase the value of compost as a fertilizer. However, increased $\mathrm{N}$ content also led to higher $\mathrm{N}_{2} \mathrm{O}$ emissions, thereby offsetting the reduction in $\mathrm{CH}_{4}$ emissions. This research demonstrates the importance of measuring all GHG when assessing manure management practices that are targeted at lowering overall GHG emissions. 


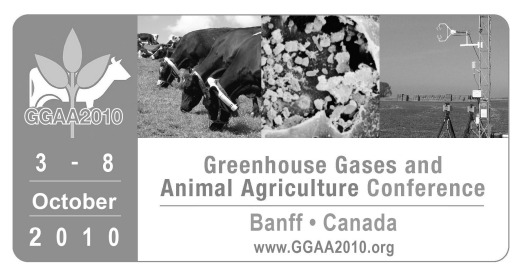

M32. Small-scale micrometeorological method for comparisonof nitrous oxide emissions from treated plots - assessing dicyandiamide (DCD) mitigation

\author{
M. Harvey*, A. McMillan, J. Laubach, S. Saggar, D. Giltrap, J. Singh, R. Martin, T. Bromley and M. Evans
}

Studies under well-controlled experimental conditions have advanced understanding of factors regulating nitrous oxide $\left(\mathrm{N}_{2} \mathrm{O}\right)$ emissions. In such studies, significant reductions in $\mathrm{N}_{2} \mathrm{O}$ emission have been achieved through the application of nitrification inhibitors. There is clearly a need to verify $\mathrm{N}_{2} \mathrm{O}$ emissions and their reduction potential in the "patchy reality" of the pastoral agricultural paddock, using non-intrusive techniques. Here we describe a micrometeorological system designed to test inhibitor efficacy on pasture grazed by cattle. The design allows for continuous and concurrent assessment of $\mathrm{N}_{2} \mathrm{O}$ emission from two treatment plots and two background plots in a "side-by-side" trial. An experimental site was selected with a relatively windy and strongly bi-directional regime. Cross-wind plots were established that ensured that there was minimal crosscontamination in the measurements. A single tuneable diode laser TGA-100A (Campbell Scientific) is used to make all concentration measurements with sequential gas source selection via a valve-switching manifold. Concentration differences between two heights are measured in the centre of each treatment plot and the flux-gradient technique is then used to derive $\mathrm{N}_{2} \mathrm{O}$ fluxes from each. The first trial of this technique was conducted on dairy-grazed pasture in Palmerston North in June 2009. The upwind paddock was not grazed for at least one month prior to this experiment. Two circular treatment plots, each $1250 \mathrm{~m}^{2}$, were grazed simultaneously, each by 20 cattle for $4 \mathrm{~h}$. The following day, dicyandiamide was applied to one of the plots at the standard rate of $10 \mathrm{~kg} / \mathrm{ha}$ in $800 \mathrm{~L}$ of water. Emissions from the experiment were then determined for $20 \mathrm{~d}$ with the flux-gradient method. Under very wet winter conditions of the experiment, nitrification appeared suppressed and the $\mathrm{N}_{2} \mathrm{O}$ emissions were generally very small (typically in the range 10 to $200 \mu \mathrm{g} \mathrm{N} \mathrm{O}_{2} \mathrm{~N} \mathrm{~m} \mathrm{~m}^{-2} \mathrm{~h}^{-1}$. This was confirmed independently by analysing air samples that were collected, every second day at midday, from 20 static chambers in each plot. The meteorological and laser equipment performed reliably and continuously and from this trial we have estimated the lower limits on inhibitor emission reduction that can be determined from this on-farm micrometeorological method.

\title{
M33. Treatment of effluent from an anaerobic digester fed with dairy manure for ammonium nitrogen removal using a divided electrochemical cell.
}

I. Ihara*, A. Nakayama, K. Toyoda and K. Umetsu

Electrochemical treatment of effluent from an anaerobic digester fed with dairy manure for ammonium nitrogen removal was investigated. In anaerobic digestion of livestock wastes, the effluent contains high concentration of ammonium nitrogen, and provides a potential to cause contamination of ground and rive water quality. Although electrochemical oxidation has good capabilities for removal of ammonium nitrogen $\left(\mathrm{NH}_{4}-\mathrm{N}\right)$ and refractory organic compounds, its main drawbacks are its consumption of electric power to purify wastewaters. For improvement of current efficiency and recovery of hydrogen gas, a divided electrochemical cell with an ion exchange membrane was developed for removal of $\mathrm{NH}_{4}-\mathrm{N}$ in digested effluent. In comparison of electrochemical cell performance, the order of the removal rates was divided cell with an anion exchange membrane > divided cell with a cation exchange membrane > common cell. When a divided cell was used with an anion exchange membrane, a high concentration of hydrogen gas was obtained from the cathode site during electrochemical oxidation of $\mathrm{NH}_{4}-\mathrm{N}$. The results presented that the divided cell with an anion exchange 


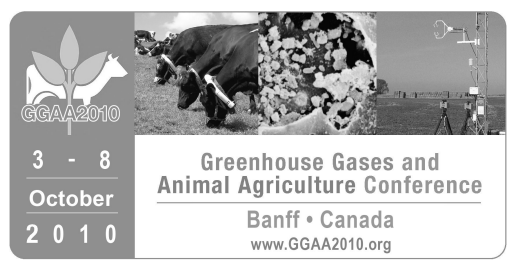

membrane has the lowest energy consumption for batch treatment of $\mathrm{NH}_{4}-\mathrm{N}$ in anaerobically digested effluent.

M34. How should we use the electricity from biogas plant for livestock manure in Hokkaido?

S. Ishikawa*, J. Matsuda*, S. Hoshiba, T. Ishida and S. Morita

The biogas plant with anaerobic digestion is receiving high attention as a facility for both livestock manure treatment and electric power generation. Until now, 47 biogas plants have been constructed to treat dairy cows' manure in Hokkaido, the most northern area in Japan. However, only 36 plants are operating at present in Hokkaido because running costs are too high for many farm households to maintain these plants. The reason for the problems with biomass energy in Japan is the lack of applications to consume or sell what is produced. In this study, the method of improving the biogas use in the on-site was examined in Japan without the system that efficiently sells the produced electricity. The basic data for the electricity utilization of the whole dairy farms (output, number of units and operation time of the main electricity use devices such as livestock manure discharge devices and milking devices) were investigated in the dairy farms that have individual biogas plants in Hokkaido. As a result of the investigation, it has been clear that electric power consumption in dairy farms raises very high when devices related to milking are operating at the milking time in the morning and in the evening. Although using energy within their own farms has great economic benefit for dairy farmers by, for example, reducing their electric costs and petroleum product use, one should have only low expectations for economic benefit through the off-farm sale of energy. Selling price of electricity from biogas plants in accordance with the RPS law is Yen4.5/kWh during 10 night time hours. By contrast, dairy farms buy electricity from the power company at the average rate of Yen14.5/kWh. The selling price of Yen $4.5 / \mathrm{kWh}$ is below the buying price, and some farmers bleed their biogas into the atmosphere. For dairy farms who utilized biogas plants, it was suggested that proportion of on-site use electricity generated from biogas be raised if such a peak electric power $w$ as able to be dropped and to achieve the levelling of utilization electricity. The use of electricity from biogas is useful for reduction of consumed fossil fuel. In addition, it is thought to be effective for the reduction of GHG emissions. The explanation for this is the concept of carbon neutrality.

\section{M35. Two-step Saccharification of rice straw with ammonia-stripping ammonia from the digested slurry of dairy manure in the biogas plant and Clostridium cellulovorans}

S. Kaneko*, A. Hirata, M. Araki, T. Yamashiro, H. Miyake, Y. Tamaru and J. Takahashi*

In Japan, $80 \%$ of the 91 million tons of manure produced from livestock sector every year are used as compost. Consequently, excess amounts of overdosed nitrogen pollute the soil and hydrosphere as nitrate nitrogen. Furthermore, emission of nitrous oxide from the manure contributes to global warming. Biogas plants for anaerobic treatment of livestock manure have become more common throughout the dairy industry. The biogas plant can reduce production of methane from the carbon in the manure, but it cannot abate nitrogen content. Ammonolysis is an effective pre-treatment for breakdown of holocellulose, to be followed with saccharification by microbes. Saccharification of holocellulose will be advantageous for producing bio-ethanol from non-edible cellulose biomass, which will not compete with human food or animal feed. The ammonia stripping from digested slurry of biogas plant can recycle ammonia, thereby reducing nitrogen content in the animal effluents. The present study deals with ammonolysis by ammonia stripped from digested slurry as a 


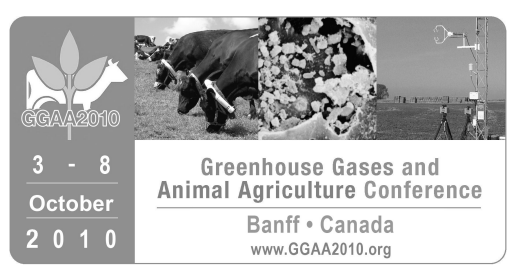

pre-treatment of saccharification of rice straw as a cellulose biomass and then with hydrolysis of holocellulose with the bacterium Clostridium cellulovorans. For ammonia stripping, $20 \mathrm{~L}$ of digested slurry from the dairy biogas was used for $400 \mathrm{~g}$ of rice straw. One cycle of ammonia stripping takes $12 \mathrm{~h}$. Within $12 \mathrm{~h}$, the ammonia concentration in the slurry was lowered to $1028 \mathrm{mg} / \mathrm{L}$ from $3072 \mathrm{mg} / \mathrm{L}$. This means $10 \%(\mathrm{w} / \mathrm{w})$ of the raw materials weight of ammonia was used for the ammonolysis. The ammonia-treated rice straw was held for 2 wk at room temperature. Then, the ammonia-stripping ammonia-treated rice straw and untreated rice straw as a control were incubated for $10 \mathrm{~d}$ at $37^{\circ} \mathrm{C}$ in the media containing subcultured $\mathrm{C}$. cellulovorans. No apparent change in the weight of holocellulose was observed with ammonia stripping treatment. However, crude protein content was substantially increased by ammonia stripping treatment. In consequence, cellulose content also substantially increased due to adding amide nitrogen by partial ammonolysis. The hydrolysis by $C$. cellulovorans in the next stage increased saccharification of rice straw in ammonia stripping treatment compared with non-treatment rice straw. In conclusion, the amide compounds added by ammonia stripping treatment as a microbial protein source contribute to the proliferation of $C$. cellulovorans.

\section{M36. Effects of residual hypochlorous acid on methane production during the anaerobic digestion of pig slurry \\ C.-H. Kim*, H. C. Kim, Y. Yoon and K. Ho So}

The hypochlorous acid is a widespread and a strong disinfecting agent that is used for the sterilization of pigpens in Korea. The hypochlorous acid that is spread into a bottom floor of a pigpen may remain as a small amount in the feedstock for anaerobic digestion. Also, the residual hypochlorous acid remaining in feedstock may inhibit the anaerobic microbial activity during the anaerobic fermentation for the biogas production. This study was carried out to investigate the effect on an anaerobic digestion of pig slurry by the presence of the residual hypochlorous acid. In order to investigate the effect on an anaerobic digestion by the presence of the residual hypochlorous acid, the batch and continuous anaerobic reactors were operated in the different residual concentrations of hypochlorous acid. The relationship of the volatile solid content and the residual hypochlorous acid was studied during the anaerobic fermentation. The effects on an anaerobic digestion by the presence of the residual hypochlorous acid were evaluated by the methane production rate, the degradation rate of volatile solid, etc. In the batch anaerobic fermentation for 6 days, the degradation rates of volatile solid showed $34.04,31.33,33.44,29.51$ and $24.42 \%$ at the residual hypochlorous acid concentrations of 5.23, 10.47, 15.70, 26.16 and $52.33 \mathrm{mg} \mathrm{L}^{-1}$, respectively. During the fermentation time of 20 days after putting on anaerobic batch reactor as the residual concentration of $52.33 \mathrm{mg} \mathrm{L}^{-1}$ of the hypochlorous acid, the degradation rates of volatile solid showed $27.3,19.3$ and $17.2 \%$ in the different volatile solid contents of input feedstock of 43,700 $( \pm 226), 26,235( \pm 148)$ and $9,890( \pm 651) \mathrm{mg} \mathrm{L}^{-1}$, respectively. The biogas production rate was gradually recovered at the reactors that have contained the high amount of volatile solid of $43,700( \pm 226) \mathrm{mg} \mathrm{L}^{-1}$ after 11 days. In the continuous anaerobic fermentation, the residual hypochlorous acid concentration of 5.23 and $15.70 \mathrm{mg} \mathrm{L}^{-1}$ did not affect the methane content in the produced biogas. However, the residual hypochlorous acid concentrations of 10.47 and $15.70 \mathrm{mg} \mathrm{L}^{-1}$ decreased the biogas production rate to 19.2 and $30.5 \%$. In the case of the hypochlorous acid input into the anaerobic reactor at the residual concentration of $52.33 \mathrm{mg} \mathrm{L}^{-1}$ continuously(three times every 6 hours), the methane content in the produced biogas did not show the significant variation, but the biogas production rate was reduced to $61 \%$. 


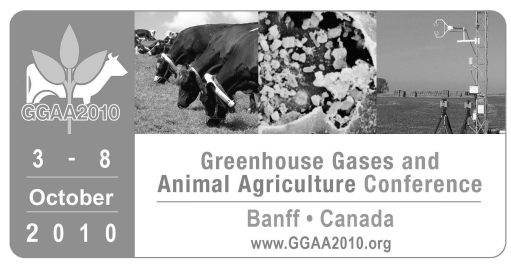

M37. The spatial distribution of $\mathrm{N}_{2} \mathrm{O}$ emissions from short-term measurements in sheep-grazed hill country pasture in New Zealand

S. Letica, R. Tillman, C. de Klein*, C. Hoogendoorn and R. Littlejohn

In New Zealand the major source of agricultural $\mathrm{N}_{2} \mathrm{O}$ emissions is from urine deposited directly onto pasture by grazing animals. In hill country nitrogen cycling is influenced by the unique topography, animal fertility transfer and resultant soil conditions. This limits the application of $\mathrm{N}_{2} \mathrm{O}$ emission data collected from trials conducted on flat land to hill country situations. The purpose of this short-term study was to measure $\mathrm{N}_{2} \mathrm{O}$ emissions from four distinct topographical land units in sheep-grazed hill country, on a poorly drained Mottled Fragic Pallic hill soil. We also aimed to describe the relationship between $\mathrm{N}_{2} \mathrm{O}$ emissions and topographical unit and a range of soil parameters. Two paddocks with a history of moderately intensively stocked sheep grazing were classified into low (campsites, $\left.0-12^{\circ}\right)$, medium $\left(13-24^{\circ}\right)$, steep $\left(>25^{\circ}\right)$ and gully (ephemeral drainage) areas. Within each paddock 12 plots $\left(2 \mathrm{~m}^{2}\right)$ were established: 3 camp, medium, steep and gully sites. Plots were sampled before and after rainfall events on 8 occasions over a16-day period in winter 2008. On each sampling occasion $\mathrm{N}_{2} \mathrm{O}$ emissions were measured over a $60-\mathrm{min}$ period at midday using a static chamber method. Following gas sampling, 3 soil cores were removed from the soil directly beneath chambers and analysed for mineral $\mathrm{N}\left(\mathrm{NO}_{3}-\right.$ $\mathrm{N}$ and $\mathrm{NH}_{4}-\mathrm{N}$ ), $\mathrm{pH}$ and soil moisture content. The degree of slope was also recorded at each site. The chambers were re-located within the plot areas and left to settle in preparation for the next sampling occasion. Soil variables and log-transformed daily $\mathrm{N}_{2} \mathrm{O}$ emissions $\left(\log \mathrm{N}_{2} \mathrm{O}-\mathrm{N}+1.965 \mathrm{~g} \mathrm{ha}^{-1} \mathrm{~d}^{-1}\right)$ were analysed by ANOVA. Averaged daily log-transformed $\mathrm{N}_{2} \mathrm{O}$ emissions were then analysed by stepwise regression on daily mean slope, soil mineral $\mathrm{N}$ and water filled pore space for each plot. The daily arithmetic mean and ranges of $\mathrm{N}_{2} \mathrm{O}$ emissions $\left(\mathrm{g} \mathrm{ha}^{-1} \mathrm{~d}^{-1}\right)$ were in the order campsites (37.3 and 2.2-312.7) > gullies $(6.7$ and -4.7-76.1) > medium (3.1 and 3.1-11.6) > steep slopes ( 0.1 and $-5.5-5.4)$. Mean log-transformed daily $\mathrm{N}_{2} \mathrm{O}$ losses $\left(\log \mathrm{N}_{2} \mathrm{O}-\mathrm{N}+1.965 \mathrm{~g} \mathrm{ha}^{-1} \mathrm{~d}^{-1}\right)$ were in the order campsites $(P<0.001)>$ gullies $>$ medium $>$ steep $(P<0.001)$ slopes. A strong relationship $(P<$ 0.001 ) was detected between $\mathrm{N}_{2} \mathrm{O}$ emissions and slope, but not with any of the soil parameters that were measured. The highly significant relationship between slope and $\mathrm{N}_{2} \mathrm{O}$ emissions suggests that topographical units may be used as a surrogate to estimate $\mathrm{N}_{2} \mathrm{O}$ emissions at larger scales for sheep-grazed hill country.

\section{M38. Greenhouse gas emissions from soil amended with cattle manure and compost - A controlled environment study}

C. Li*, X. Hao*, G. Yang*, J. Schoenau and T. A. McAllister*

The use of dried distillers' grains with solubles (DDGS) in diets for feedlot cattle (Bos Taurus) is increasing due to the expansion of the bio-ethanol industry. In Canada, wheat (Triticum aestivum L.) is the principal grain used for biofuel production. The objectives of this study were to investigate greenhouse gas emissions from soil either non-amended (Control), or following application of fresh or composted manure (Man, Comp) from cattle fed diets containing $85 \%$ barley grain (Hordeum vulgare L.; diet B) or $25 \%$ barley $+60 \%$ wheat-based DDGS (diet WDG). The soil (Dark Brown Chernozemic), manure and compost samples were collected at Lethbridge, $A B$, Canada. In a controlled environment chamber, $20 \mathrm{~g}$ soil samples $(n=6)$ were amended with $3.33 \mathrm{~g}$ of Manb, CompB, ManWDG or CompWDG, or left non-amended for Control, and were incubated for 3 mo at $22 \pm 1^{\circ} \mathrm{C}$ at a moisture content of $60 \%$ water holding capacity. During the incubation, $\mathrm{N}_{2} \mathrm{O}$ and $\mathrm{CO}_{2}$ emissions were measured at 1-wk intervals, using the static chamber method. Feeding DDGS to the cattle markedly increased $(P<0.05) \mathrm{N}_{2} \mathrm{O}$ emissions from manure and compost. After $72 \mathrm{~d}$, total $\mathrm{N}_{2} \mathrm{O}$ emission from ManDDGS and CompDDGS averaged $3.07 \mathrm{mg} \mathrm{N} \mathrm{kg}^{-1}$, compared with $0.52 \mathrm{mg} \mathrm{N} \mathrm{kg}^{-1}$ from ManB and CompB and $-0.49 \mathrm{mg} \mathrm{N} \mathrm{kg}^{-1}$ 


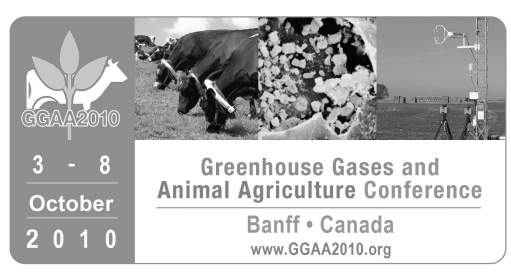

from Control. Emissions of $\mathrm{N}_{2} \mathrm{O}$ did not differ $(P>0.05)$ among $\mathrm{ManB}, \mathrm{CompB}$ and Control. Total $\mathrm{CO}_{2}$ emission was greater $(P<0.05)$ in each of the amendment treatments (ranging from 3.78 to $\left.9.04 \mathrm{~g} \mathrm{C} \mathrm{kg}^{-1}\right)$ than in the Control $\left(0.82 \mathrm{~g} \mathrm{C} \mathrm{kg}^{-1}\right)$, and was less $(P<0.05)$ from Comp treatments (average $\left.3.78 \mathrm{~g} \mathrm{C} \mathrm{kg}^{-1}\right)$ than Man $\left(8.40 \mathrm{~g} \mathrm{C}^{-1}\right.$ $\left.\mathrm{kg}^{-1}\right)$. Emissions of $\mathrm{CO}_{2}$ were similar $(P>0.05)$ between ManB and ManWDG, and between CompB and CompWDG. The higher $\mathrm{N}_{2} \mathrm{O}$ emission from DDGS treatment reflects a greater $\mathrm{N}$ input to soil due to the higher $\mathrm{N}$ content of DDGS-derived manure, while lower $\mathrm{CO}_{2}$ emission from compost- compared with manureamended soil reflects the lower degradability of $\mathrm{C}$ in the compost amendment.

\section{M39. Nitrous oxide emission from cattle manure compost}

K. Maeda*, S. Toyoda, R. Shimojima, T. Osada, D. Nanajima, R. Morioka and N. Yoshida

Nitrous oxide, a greenhouse gas, is emitted through the cattle manure composting process and requires mitigation. The aim of this study was to understand the mechanisms underlying $\mathrm{N}_{2} \mathrm{O}$ emission by determining the spatial distribution of $\mathrm{NOx}-\mathrm{N}$, analyzing the stable isotopes of $\mathrm{N}_{2} \mathrm{O}$ and the molecular microbiology of the bacterial community and measuring the denitrification potential of the compost surface in vitro. Dairy cattle manure was mixed with dried grass and formed into a pile $(1.8 \mathrm{~m}$ in height, $3.5 \mathrm{~m}$ in width and $3.9 \mathrm{~m}$ in width, 4 metric tons). Samples taken from the surface (to a depth of $30 \mathrm{~cm}$ ), core and bottom zones of the pile were used to test the denitrification potential by the acetylene block method. Overall and ammonia-oxidizing bacterial structures were analyzed by PCR-DGGE and real-time PCR assay. The nitrous oxide concentration was measured by an infrared photoacoustic detector or gas chromatograph with an electron capture detector, and then the bulk $15 \mathrm{~N} / 14 \mathrm{~N}$ isotope ratio and intramolecular $15 \mathrm{~N}$ distribution (site preference) in $\mathrm{N}_{2} \mathrm{O}$ were measured by gas chromatography-isotope ratio mass spectrometry. Nitrous oxide was actively emitted immediately after the turning of the pile, and stable isotope analysis data indicated its source as bacterial denitrification. Much nitrite and nitrate were detected from the surface samples, and significant Betaproteobacterial amoA gene copy numbers were also detected. The dominant bacteria of the core zone were unknown Bacillus and Crostridium species, especially in the initial stage of composting, while mesophilic bacteria belonging to class Bacteroidetes or Proteobacteria were dominant in the surface samples throughout the process. Although surface samples emitted significant $\mathrm{N}_{2} \mathrm{O}$ in vitro, the $\mathrm{NO}_{2}$ - $\mathrm{N}$-added core samples produced relatively little gas; its production rate was significantly lower than those of the surface samples. As the composting process progressed, both the $\mathrm{N}_{2} \mathrm{O}$ production rate and $\mathrm{N}_{2} \mathrm{O}$ reduction rate slowed. The $\mathrm{N}_{2} \mathrm{O}$ emission immediately after turning derived mainly from the bacterial denitrification of NOx-N accumulated in the compost surface zones. Betaproteobacterial ammonia oxidizers might contribute significantly to the nitrification actively occurring in the surface zones. The surface samples showed significant denitrification potential, while the core zone had relatively poor denitrification potential. The compost piles had significant spatial distribution of bacteria, and the bacterial community of the surface zones was considered to be primarily responsible for $\mathrm{N}_{2} \mathrm{O}$ emission.

\section{M40. Uncertain effect of nitrification inhibitor, DCD, on mitigation of $\mathrm{N}_{2} \mathrm{O}$ emission from anaerobically digested cattle slurry applied soil}

T. Matsunaka*, K. Goto*, K. Kinoshita and T. Sawamoto

We conducted several experiments to explore the effect of $D C D$ application with anaerobically digested cattle slurry (ADCS) to grassland soil surface on mitigation of $\mathrm{N}_{2} \mathrm{O}$ emission. The mitigation effect of DCD was 


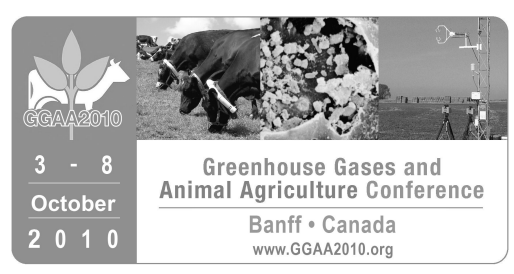

significant in a laboratory and pots experiments under controlled soil water conditions. The effect, however, was uncertain in a field experiment. The uncertain effect was probably due to uneven soil water conditions during the experiment. DCD application rate in all experiments was $10 \%$ of total $\mathrm{N}$ applied from ADCS. The results of the experiments were as follows. a) Laboratory experiment; Effect of DCD application method to soil was examined under no grass growing conditions. Soil water condition was maintained at WFPS $60 \%$. Two methods were compared; one was that DCD was mixed with soil prior to ADCS application to the soil surface. The other was that DCD was mixed with ADCS, and then the mixture was applied to the soil surface. The mitigation effect of DCD on $\mathrm{N}_{2} \mathrm{O}$ emission was significant in the both methods compared with no DCD application, although there was no significant difference in the effect between the methods. b) Pots experiment; Orchardgrass was grown in the pots in a glasshouse. Soil water condition in the pots was controlled at WFPS $60 \%$ by irrigation. The mitigation effect of DCD was very clear and the $\mathrm{N}_{2} \mathrm{O}$ emission from the ADCS with DCD applied soil was similar to that from no ADCS applied soil. $\mathrm{NH}_{4}-\mathrm{N}$ in the ADCS with DCD applied soil was higher level than $\mathrm{NO}_{3}-\mathrm{N}$ content until 2 weeks after the application because of the effect of DCD as a nitrification inhibitor. c) Field experiment; Timothy and alfalfa grassland was used. The ADCS application with DCD was carried out both at middle of October (autumn application) and the following early May (spring application) at the rate of $30 \mathrm{Mg} \mathrm{ha}^{-1}$ each time. The DCD showed clear mitigation effect on $\mathrm{N}_{2} \mathrm{O}$ emission in both grasslands after the autumn application. The spring application of DCD, however, did not show a significant mitigation effect in the both grasslands. Soil water condition in the grasslands following the ADCS with DCD application was clearly different between autumn and the following spring. WFPS of the soil after the autumn application ranged from 60 to $70 \%$, although that during a month after the spring application was almost less than $60 \%$, meaning very dry conditions.

\section{M41. A field study on ammonia and nitrous oxide emissions following land-application of pig manure}

G. Meade, T. McCabe, K. Pierce, J. O' Doherty, G. Lanigan*, C. Mueller

Pig manure can be a valuable nutrient source in crop production but significant nitrogen $(\mathrm{N})$ loss may occur through denitrification and ammonia $\left(\mathrm{NH}_{3}\right)$ volatilisation, reducing its economic value and causing environmental pollution. Agriculture in Ireland contributes to a high proportion of greenhouse gas (GHG) and $\mathrm{NH}_{3}$ emissions; therefore, strategies to reduce GHG and transboundary gas emissions must be investigated. The effect of dietary crude protein (CP) concentration and timing of application on gaseous emissions of $\mathrm{NH}_{3}$ and nitrous oxide $\left(\mathrm{N}_{2} \mathrm{O}\right)$ from land application of pig manures were examined in a field trial study on a winter wheat crop ( $c v$. Alchemy). One hundred and sixty finisher pigs were randomly assigned to one of two diets; a high CP $\operatorname{diet}(230 \mathrm{~g} / \mathrm{kg})$ producing a high $\mathrm{N}(\mathrm{HN})$ manure; or a low CP diet $(160 \mathrm{~g} / \mathrm{kg})$ producing a low $\mathrm{N}(\mathrm{LN})$ manure. In a $2 \times 3$ factorial design with 3 replications, the two manure products were applied to individual plots $(30 \times 24$ $\mathrm{m}$ ) with applications timed at three different stages of crop growth. Using a 6-m band spread applicator, manure was applied (30,000 L/h) at: growth stage 25 (mid-tillering; T1), growth stage 30-31 (stem elongation, T2) or growth stage 37-39 (flag leaf emergence; T3). Ammonia emissions were measured at 1, 3, 6, 24, 48, 96 and $168 \mathrm{~h}$ after each application using the micrometeorological mass balance technique with passive flux samplers placed at $0.2,0.4,0.8,1.5$ and $3.0 \mathrm{~m}$ above ground level. $\mathrm{N}_{2} \mathrm{O}$ fluxes from the soil surface were measured using the closed chamber technique at 3- to 4-d intervals for $4 \mathrm{wk}$ post-manure application. Greater $\mathrm{N}_{2} \mathrm{O}(P<0.03)$ and $\mathrm{NH}_{3}(P<0.04)$ emissions were measured from the $\mathrm{HN}$ manure treatments than from $\mathrm{LN}(15.75$ vs. $12.95 \mathrm{~g} \mathrm{~N}_{2} \mathrm{O}-\mathrm{N} / \mathrm{ha}$ per day and 6.97 vs. $6.03 \mathrm{~kg} \mathrm{NH}_{3}-\mathrm{N} / \mathrm{ha}$, respectively). Manure spreading date impacted both $\mathrm{N}_{2} \mathrm{O}(P<0.02)$ and $\mathrm{NH}_{3}(P<0.001)$ emissions, with $\mathrm{T} 1$ generating highest total emissions $(7.62 \mathrm{~kg} \mathrm{~N} / \mathrm{ha}$ as 


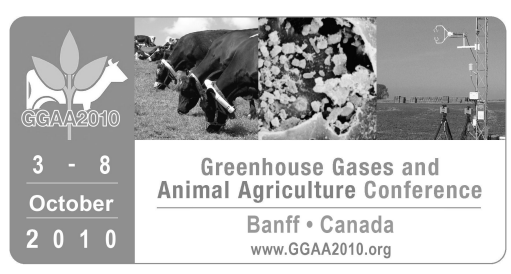

$\mathrm{NH}_{3}, 15.91 \mathrm{~g} \mathrm{~N}_{2} \mathrm{O}-\mathrm{N} /$ ha per day) compared to T2 (5.88 kg N/ha as $\mathrm{NH}_{3} ; 11.79 \mathrm{~g} \mathrm{~N}_{2} \mathrm{O}-\mathrm{N} / \mathrm{ha}$ per day) and T3 (5.95 $\mathrm{kg} \mathrm{N} /$ ha as $\mathrm{NH}_{3} ; 15.36 \mathrm{~N}_{2} \mathrm{O}-\mathrm{N} /$ ha per day $)$. Sampling time influenced $\mathrm{NH}_{3}(P<0.0001)$ and $\mathrm{N}_{2} \mathrm{O}(P<0.04)$ emissions, with the highest $\mathrm{NH}_{3}$ concentrations measured $1 \mathrm{~h}$ post manure application, and 92 to $95 \%$ of emissions released within the first $24 \mathrm{~h}$ after application. Losses as $\mathrm{NH}_{3}$ emissions varied from 6.61 to $10.61 \%$ of the total ammoniacal $\mathrm{N}$ applied depending on application timing and manure type. These data indicate that dietary manipulation and application of manure at more advanced growth stages are useful methods of reducing gaseous emissions from land-spreading of pig manure.

\section{M42. Anaerobic co-digestion of synthetic waste and dairy cattle manure}

Y. Moriya*, T. Yamashiro, M. Iwasaki, L.S. Adekunle and K. Umetsu

Anaerobic fermentation treatment of organic wastes using biogas plant has been spreading all over the world as a renewable methane energy resource. There are two major issues to the use of organic wastes as the materials for methane fermentation. The low-input collection system should be established to maintain the effective management of anaerobic fermentation in the biogas plant using the wastes. Another issue is the characteristics of materials. In general, the materials such as kitchen wastes, food processing wastes etc. contain poor population of methanogen. Furthermore, for those materials, the relatively higher density of methanogen in effluents of the anaerobic fermentation than that in influents has been demonstrated. The density of methanogen in the digester of biogas plant gradually decreases due to the increase in flow rate of methanogen to the effluent in these materials. Thus, larger flow rate of methanogen to the effluents than the proliferation rate of methanogen inhibit stable methane fermentation in the biogas plant. Livestock manures contain high density of methanogen. Therefore, the co-digestion of these materials with livestock manures should be recommendable to maintain the stable methane fermentation in biogas plant. To simulate the codigestion of both organic wastes the sham trials were examined using food and paper wastes as the synthetic waste (SW) and dairy cattle manure (DCM) at high organic loading rate (OLR). The digestion processes were carried out in two-phase digesters. Acidogenesis of SW alone was performed in the first-stage digester to promote organic acids production as the precursors of acetotrophic methanogenesis. The liquids are added to the effluents in two other separate reactors for methanogenesis (R1 and R2) as substrates of methane. The R1 was a reactor to digest SW alone and the R2 was a reactor for co-digestion of SW with DCM. The total inputs into R1 for 196 days and R2 for 205 days were $52905 \mathrm{~g}$ and $70615 \mathrm{~g}$ respectively. The OLR used in the experiment were $4.2 \mathrm{~g}-\mathrm{VS} / \mathrm{L} \bullet$ day in R1 and $6.3 \mathrm{~g}-\mathrm{VS} / \mathrm{L} \bullet$ day in R2. Relatively lower biogas generation rate and methane concentration in R1 was observed compared to R2. Methane production per organic matter in SW was higher in R2 than R1. In conclusion, anaerobic co-digestion of organic waste and dairy cattle manure would be a suitable technology to treat such wastes, obtaining a renewable source of energy from biogas.

\section{M43. Manure pad composition and greenhouse gas emissions from Australian beef feedlots} S. Muir*, D. Chen*, D. Rowell and J. Hill*

Feedlot operations are significant point sources of greenhouse gas (GHG) emissions from enteric fermentation and manure decomposition. Feedlots consist of multiple pens, each holding more than 100 animals for several months. This results in a build up of manure, a source of methane and nitrogenous gases. Despite this, limited 


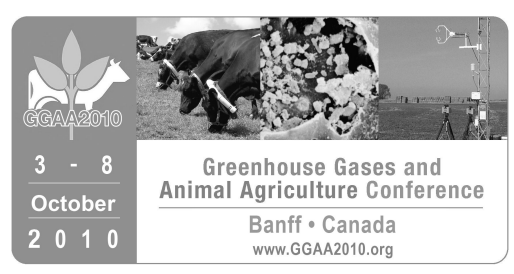

studies report emissions directly from the manure pad. Rations and manure management, as well as environmental factors may influence emissions. An investigation of manure composition and GHG emissions was undertaken on two sites representative of Australian feedlot production. These were located in the southern state of Victoria $\left(36.6^{\circ} \mathrm{S}, 143.4^{\circ} \mathrm{E}\right)$ and the northern state of Queensland $\left(27.1^{\circ} \mathrm{S}, 151.2^{\circ} \mathrm{E}\right)$. The objective of this study was to characterise manure pad composition, and evaluate emissions of methane $\left(\mathrm{CH}_{4}\right)$, nitrous oxide $\left(\mathrm{N}_{2} \mathrm{O}\right)$ and carbon dioxide $\left(\mathrm{CO}_{2}\right)$. A single pen in each feedlot was selected for static chamber measurements. Three locations were selected to capture spatial variation within the pen and examine the effect of manure enrichment: unshaded (A) shaded (B) within the pen and external soil (no manure) (C). Fluxes were expressed as $\mathrm{mg} \mathrm{m}^{-2}$ and the average of the soil area (C) subtracted from the enriched areas (A and B) to determine flux associated with manure enrichment. Concentrations $\left(\mathrm{mg} \mathrm{m}^{-2}\right)$ were plotted against sample time to estimate flux and Logistic curves were fitted. At the northern site there was no significant difference $(P>0.05)$ between shaded and unshaded areas in $\mathrm{CH}_{4}$ concentration. Furthermore, concentration was not significantly different from zero $(95 \% \mathrm{Cl}$ included 0$)$ over the sampling period. Concentration of $\mathrm{CH}_{4}$ measured in the soil area was as expected for an area with no manure enrichment, and not significantly different from 0. No flux of $\mathrm{N}_{2} \mathrm{O}$ was detected at the northern site. $\mathrm{CO}_{2}$ flux was equivalent to $1.10 \mathrm{~g}_{\text {animal }}{ }^{-1} \mathrm{~d}^{-1}$ in unshaded and $0.97 \mathrm{~g}$ animal ${ }^{-1} \mathrm{~d}^{-1}$ in shaded areas. At the southern site, shade had no effect $(P>0.05)$ on $\mathrm{CH}_{4}$ emissions. $\mathrm{CH}_{4}$ flux rate at the southern site was $0.028 \mathrm{mg} \mathrm{m}^{-2} \mathrm{~min}^{-1}$ or $0.65 \mathrm{~g}$ animall ${ }^{-1} \mathrm{~d}^{-1} . \mathrm{N}_{2} \mathrm{O}$ concentration was significantly affected by shade $(P<0.05)$. Flux rates were $0.033(A)$ and $0.032(B) \mathrm{mg} \mathrm{m}^{-2} \mathrm{~min}^{-1}$. $\mathrm{CO}_{2}$ fluxes equated to $1.16(\mathrm{~A})$ and 1.44 (B) $\mathrm{g}_{\text {animal }}{ }^{-1} \mathrm{~d}^{-1}$. Differences in substrate composition between the two sites related to moisture content, manure management practices and environmental temperature. These factors appear to have significantly affected emissions. This study suggests that environmental and management factors need to be considered in the development of emissions factors.

\section{M44. Potential reduction of $\mathrm{N}_{2} \mathrm{O}$ emission from swine manure by using a low-protein diet supplemented with synthetic amino acids}

T. Osada*, R. Takada* and I. Shinzato

Although the effects of dietary protein reduction on nitrogen excretion are well documented, the potential of protein reduction to decrease greenhouse gas emissions has not been examined. We performed nitrogen balance trials in growing swine to assess the effect of a low-protein diet supplemented with amino acids on nitrogen retention and urinary excretion. The feces and urine obtained were used to evaluate greenhouse gas emissions from composting and wastewater treatment processes. Five crossbred barrows (mean weight about $38 \mathrm{~kg}$ ) were used. The crude protein contents in the control (CONT) and low-protein (LOW) diets were 17.1 and $14.5 \%$, respectively. The low-protein diet was supplemented with lysine, threonine, methionine and tryptophan at levels sufficient to meet each requirement. Crossover trial for the feeding experiment was performed. Feces and urine were each collected separately and used for the subsequent experiment. Manure from swine fed the control or low-protein diet was placed in an experimental composting apparatus with forced aeration, and greenhouse gas emissions were measured after 5 week periods. Two bench-scale activated sludge units were used for wastewater treatment. Under a hydraulic retention time of 5 days and biochemical oxygen demand loading rate of $0.4 \mathrm{~kg} \mathrm{~m}^{-3} / \mathrm{day}^{-1}$ both sets of wastewater were performed during 6 weeks. Two 5-day measurements of GHG emissions were compared between CONT and LOW. There were no significant differences in daily weight gain and nitrogen retention between the control and low-protein groups. However, urinary nitrogen excretion per unit feed intake $\left(5.5 \mathrm{~g} \mathrm{~kg}^{-1}\right)$ and total nitrogen excretion per unit feed intake $\left(10.1 \mathrm{~g} \mathrm{~kg}^{-1}\right)$ were significantly lower in the low-protein than in the control $\left(8.9\right.$ and $13.7 \mathrm{~g} \mathrm{~kg}^{-1}$, 


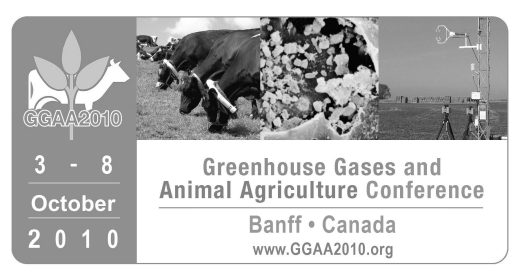

respectively). The total amount of nitrogen excreted in feces and urine was reduced by $28.7 \%$ in the lowprotein group. The reduction in the manure's global warming potential was even higher, with a $39.1 \%$ reduction of greenhouse gases by weight in manure from the low-protein group. About $0.5 \%$ of the influent nitrogen was emitted as $\mathrm{N}_{2} \mathrm{O}$ gas $\left(\mathrm{N}_{2} \mathrm{O}-\mathrm{N}\right)$ from compost and about $1.8 \%$ was emitted as $\mathrm{N}_{2} \mathrm{O}-\mathrm{N}$ from wastewater. Six times more $\mathrm{N}_{2} \mathrm{O}$ was emitted through the wastewater treatment than from composting. In the manure treatment experiments, there was no significant difference in the $\mathrm{N}_{2} \mathrm{O}$ emission factors $\left(\mathrm{g} \mathrm{N} \mathrm{N}_{2} \mathrm{O}-\mathrm{N} / \mathrm{g}\right.$ total $\mathrm{N}$ ) between control and low-protein manure. Feeding swine a low-protein diet is an effective means for reducing greenhouse gas emissions from intensive livestock producing areas, where wastewater treatment is commonly used.

\section{M45. Low greenhouse gas emissions during composting of swine solid manure}

K.-H. Park*, D.-Y. Choi, J.-H. Kwag and H.-S. Kang

Methane $\left(\mathrm{CH}_{4}\right)$ and nitrous oxide $\left(\mathrm{N}_{2} \mathrm{O}\right)$ emissions during swine solid manure (manure) composting were studied in Korea. Three aeration, forced aeration (FA), meshed wire (MW), and turnover (TO) and one no aeration (NA) methods were simultaneously conducted from June to October, 2009. Manure was collected from a swine research barn by a scraper system in National Institute of Animal Science and mixed with sawdust which was used as a bulking agent. Manure and sawdust mixture was placed on linear low-density polyethylene (LLDPE) containers $[135 \mathrm{~cm}(\mathrm{~L}) \times 145 \mathrm{~cm}(\mathrm{~W}) \times 100 \mathrm{~cm}(\mathrm{H})]$ for each composting method. FA used a container having a $100 \mathrm{~mm}$ diameter hole on the wall where $100 \mathrm{~mm}$ PVC pipes with holes on the surface for the aeration passed and were connected to the blower which was used to supply air into the composting pile above. The container used for MW had a $100 \mathrm{~mm}$ diameter hole on the wall and chicken wire which was tied on steel angle support $(135 \times 145 \mathrm{~cm})$ was placed above the height of the hole in order to supply air thorough the hole during composting with chimney effect. For TO, the composting pile was turned over by manpower. NA was never disturbed after manure and straw mixture had piled up. In order to measure $\mathrm{CH}_{4}$ and $\mathrm{N}_{2} \mathrm{O}$ emissions during composting with each method, a steady-state chamber $[180 \mathrm{~cm}(\mathrm{~L}) \times 180 \mathrm{~cm}(\mathrm{~W}) \times 200 \mathrm{~cm}$ $(\mathrm{H})$ ] covering each container was designed to eliminate the effect of temporal and spatial heterogeneous fluxes during composting. Air samples from inhaled and exhausted air of each chamber were analyzed 10 times per second for $15 \mathrm{~s}$ every $2 \mathrm{~min}$ by TGA100A (Campbell Scientific Inc., Logan, UT). During the research period, $\mathrm{CH}_{4}$ emissions from FA, MW, TO and NA were 8.8, 4.3, 6.9 and $45.1 \mu \mathrm{g} \mathrm{m}^{-2} \mathrm{~s}^{-1}$, respectively. Nitrous oxide emissions from FA, MW, TO and NA were 1.3, 2.6, 6.7 and $9.6 \mu \mathrm{g} \mathrm{m}^{-2} \mathrm{~s}^{-1}$, respectively. Carbon dioxide equivalent $\left(\mathrm{CO}_{2}\right.$-eq.) based on global warming potentials of $\mathrm{CH}_{4}(23)$ and $\mathrm{N}_{2} \mathrm{O}$ (296) from FA, MW, TO and NA were 587.2, 868.5, 2141.9 and $3878.9 \mathrm{\mu g} \mathrm{m}^{-2} \mathrm{~s}^{-1}$, respectively. MW which did not use electricity would be the possible method to reduce greenhouse gas emissions during manure treatment as FA uses electricity for the aeration which causes greenhouse gas emissions from power plants. Further research on the full-scale composting system and life cycle assessment will be required in the future.

M46. Testing methanotrophs in on-farm biofilters to reduce methane emissions in New Zealand C. Pratt*, K. R. Tate*, A. S. Walcroft, D. J. Ross, M. H. Hills and R. Roy

Methane $\left(\mathrm{CH}_{4}\right)$ is New Zealand's major agricultural greenhouse gas, mainly sourced from enteric fermentation (85-95\%) and dairy farm effluent ponds (5-15\%). Nationally, $\mathrm{CH}_{4}$ represents about $37 \%$ of our total emissions 


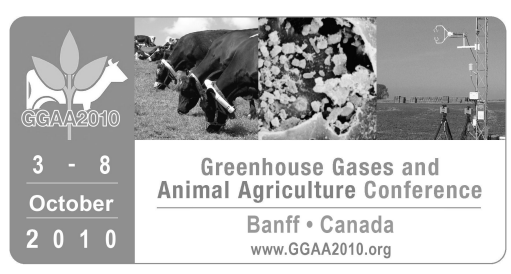

on a $\mathrm{CO}_{2}$-equivalent basis, and effective mitigation options have yet to be developed for the agriculture sector. Methane biofilters, in which methanotrophic bacteria convert $\mathrm{CH}_{4}$ to $\mathrm{CO}_{2}$, are being increasingly used to reduce $\mathrm{CH}_{4}$ emissions from landfills and coal mines. We are developing a biofiltration technology to reduce New Zealand's dairy farm $\mathrm{CH}_{4}$ emissions from effluent ponds and housed animals. Volcanic landfill cap soils containing highly active methanotroph populations form the basis for our prototype biofilter. Automated laboratory chamber experiments have revealed that the soils are able to consume $65 \mu \mathrm{g} \mathrm{CH}_{4} \mathrm{~g}^{-1}$ soil/h (approximately $40 \mathrm{~L} \mathrm{CH}_{4} / \mathrm{m}^{3}$ soil/h), which is in the upper range of $\mathrm{CH}_{4}$ consumption reported in the literature. Analysis of methane oxidation in similar soils sampled away from the landfill indicated rapid adaptation of methanotrophs to high $\mathrm{CH}_{4}$ concentrations. Molecular analysis of pmoA and mmoX genes showed that mainly Type II methanotrophs (Methylocystis sp.) appear to be involved in oxidizing the elevated $\mathrm{CH}_{4}$ concentrations in the chambers and this is further supported by successful enrichment of mostly Type II methanotrophs from the soils using a nitrate-mineral salt medium. The most active landfill soil, mixed with an inert support medium, has been incorporated in a prototype biofilter that has been operating for 8 months on a Massey University dairy farm effluent pond. Maximum $\mathrm{CH}_{4}$ uptake rates in this filter $\left(62 \mu \mathrm{CH}_{4} \mathrm{~g}^{-1}\right.$ soil/h) are comparable with those observed in the laboratory chamber trials. Average $\mathrm{CH}_{4}$ consumption rates exhibited by this field experiment, and from an ongoing laboratory trial, indicate that a modestly sized biofilter $\left(90 \mathrm{~m}^{3}\right)$ could remove approximately $85 \%$ of $\mathrm{CH}_{4}$ emitted from a typical New Zealand dairy effluent pond (average emission rates are $30-40 \mathrm{~L} / \mathrm{m}^{2} /$ day). We are currently quantifying $\mathrm{CH}_{4}$ concentration profiles inside dairy cattle housings. This information will be used to determine the feasibility of developing a suitable biofilter using a methanotroph population best suited to this low-concentration high-flow application.

\section{M47. Whole farm impact of biogas generation and use on a New York dairy farm C. A. Rotz* and S. Hafner}

The dairy industry in the United States has set the goal of reducing greenhouse gas emissions $25 \%$ by 2020 . Many mitigation strategies are required to meet this goal, but an important component may be the use of anaerobic digesters for biogas production. Anaerobic digestion removes a major portion of the volatile solids from manure, which reduces the potential for methane and carbon dioxide production during manure storage and following land application. The biogas produced can be used to generate electricity and heat water, both of which reduce secondary emissions contributing to the carbon footprint of the farm. As manure moves through a digester, nitrogen and phosphorus forms change, potentially affecting ammonia emissions, nitrate leaching losses, and phosphorus runoff. An anaerobic digester component was added to the Integrated Farm System Model to obtain a tool for comprehensive evaluation of these various effects on dairy farms. An 1100-cow dairy farm in New York was simulated for 25 years of weather with and without the use of a digester. Farm records were used to verify simulated feed production and use, milk production, biogas production, and electric generation and use. Employing the digester had relatively small effects on feed production. Ammonia emission from stored manure increased $5 \%$, which caused a small reduction in the yield and protein content of the corn silage produced on the farm. The solubility of phosphorous in the manure was increased, but because manure was incorporated immediately after application, this had little effect on phosphorous runoff. Methane emission from the manure storage was reduced $60 \%$, which reduced the whole farm emission by $15 \%$. Energy saved in water heating and purchased electricity reduced combustion and secondary carbon dioxide emissions by 10 and $50 \%$, respectively. Over all farm sources and sinks, the digester reduced the net greenhouse gas emission and carbon footprint by $22 \%$. When the producer bore the full cost of the $\$ 1,300,000$ investment in 


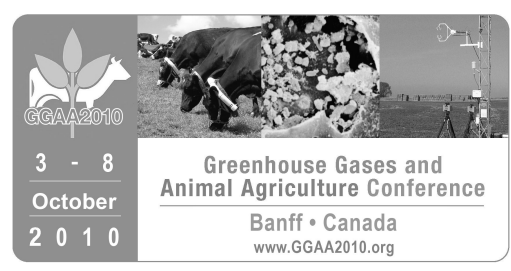

the digester and associated equipment, annual farm profit was reduced by $\$ 50 /$ cow or $\$ 0.001 / \mathrm{kg}$ of milk produced. The anaerobic digester system could be owned and operated with no reduction in farm profit on this farm if biogas production and use were increased by $20 \%$. Data reported for other digesters indicate that improvements in efficiency may be obtained as start up issues are resolved. Whole-farm simulation provides a useful tool for evaluating and comparing management options to reduce the carbon footprint of dairy production systems.

\section{M48. Nitrous oxide losses after application of anaerobically digested dairy manure under laboratory conditions}

O. Saunders*, A.M. Fortuna, J. Harrison*, L. Whitefield and C. Cogger

There is interest among dairy farmers to anaerobically digest manure because of its potential to provide energy, enhance mineral nitrogen content, and reduce pathogen loading. However, potential gaseous losses after field application and fertilizer value have not been sufficiently quantified. In this study we compared rates of nitrous oxide $\left(\mathrm{N}_{2} \mathrm{O}\right)$ emissions, ammonia $\left(\mathrm{NH}_{3}\right)$ volatilization, and plant available nitrogen from soil fertilized with two types of dairy manure or synthetic fertilizer. Applications of anaerobically digested dairy manure (AD) $150 \mathrm{~kg} \mathrm{~N}$ ha-1, or non-digested dairy manure (non-AD) $122 \mathrm{~kg} \mathrm{~N} \mathrm{ha}^{-1}$, were applied by either subsurface deposition (SSD) or surface broadcast (SB). Synthetic urea fertilizer was surface applied at $144 \mathrm{~kg} \mathrm{~N} \mathrm{ha}^{-1}$. Nitrous oxide emissions, $\mathrm{NH}_{3}$ volatilization and inorganic nitrogen were monitored during a $30 \mathrm{~d}$ laboratory incubation to determine the fate of nitrogen. A Puget silty clay loam soil was fertilized and incubated at $25^{\circ} \mathrm{C}$ for two months in glass jars. Head spaces of the jars were sampled every 24-hr. Rates of $\mathrm{N}_{2} \mathrm{O}$ production were calculated using the graceNET trace gas protocol (Parkin et al., 2003). Samples were run on a gas chromatograph with an electron capture detector. A duplicate set of microcosms were sampled for inorganic nitrogen with $1 \mathrm{M} \mathrm{KCl}$ extracts run on an OI Analytical ALPKEM Flow Solution IV Auto-Analyzer autoanalyzer and $\mathrm{NH}_{3}$ volatilization using acid traps soaked in $30 \mathrm{~g} \mathrm{~L}^{-1}$ oxalic acid in acetone. The data showed that $A D$ manure produced more total $\mathrm{N} 2 \mathrm{O}$ (5.58 and $4.60 \mathrm{~kg} \mathrm{~N}_{2} \mathrm{O}-\mathrm{N} \mathrm{ha}^{-1}$ for SB and SSD) over 30 days than non-AD manure (0.866 and $0.610 \mathrm{Kg} \mathrm{N}_{2} \mathrm{O}-\mathrm{N} \mathrm{ha}{ }^{-1}$ for SB and SSD) and synthetic urea fertilizer (0.865 kg N $\mathrm{N}_{2} \mathrm{O}-\mathrm{N} \mathrm{ha}^{-1}$ ). Nitrogen mineralization data demonstrated an increase in inorganic nitrogen over 30 days in soils fertilized with urea, while the manure treatments declined. Inorganic $\mathrm{N}$ in urea treatments remained higher throughout the incubation, which may have been the result of a salt effect on soil microorganisms. Ammonia losses were not significantly different where $A D$ and non- $A D$ manures were applied, and significantly higher in the urea treatment. Greater available carbon in the non-AD manure stimulated nitrogen immobilization potentially reducing $\mathrm{N}_{2} \mathrm{O}$ emissions. Incorporation of manures reduced $\mathrm{NH}_{3}$ and $\mathrm{N}_{2} \mathrm{O}$ losses although it was not always statistically significant Our findings indicate that $A D$ manure has similar inorganic nitrogen content after 30 days as non- $\mathrm{AD}$ manure, lower potential for $\mathrm{NH}_{3}$ volatilization (17\% of $\mathrm{N}$ applied) and greater $\mathrm{N}_{2} \mathrm{O}$ emissions (<5\% N applied). 


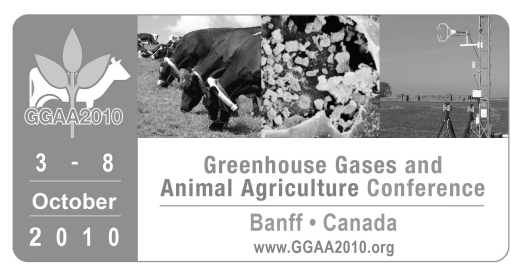

\section{M49. Effect of antibiotics on methane production in the anaerobic digestion of pig manure slurry} J.-C. Shi, X.-D. Liao*, Y.-B. Wu and J.-B. Liang*

Laboratory-scale digesters were used to study the effects of tetracycline (TC) and sulfamethoxydiazine (SMD), the two antibiotics commonly used in pig diets in China, on methane production in anaerobic fermentation of pig manure slurry. Tetracycline and SMD were added at different concentrations $\left(0,25\right.$ and $\left.50 \mathrm{mg} . \mathrm{I}^{-1}\right)$ as treatments. The results showed a clear delay in initial production of methane gas and lower daily methane production peaks for the treatment groups as compared to the control. Cumulative methane volumes (CMV) for all treatments within 20 days were significantly lower than the control, suggesting the presence of TC and SMD in manure slurries adversely effecting methane production. Furthermore, at the early stage of anaerobic process decreased in liquor $\mathrm{pH}$, ammonium- $\mathrm{N}$ and total solid degradation rates of the fermentation material were detected when TC and SMD were added at different concentrations, indicating that these two antibiotics inhibit biogas production in pig slurry and the rate of inhibition varied with dosage of antibiotics added. In a separate supporting experiment concentration of TC and SMD were shown to decline rapidly in the anaerobic system with more than $50 \%$ of the antibiotics disappearing within the first $12 \mathrm{~h}$ and leaving very little of the drugs in the system after the first 2 to 3 days.

M50. Feasibility estimation of a farm-scale biogas bio-desulfurization system for small pig farms in Taiwan

J.-J. Su*, Y.-J. Chen, Y.-C. Chang, S.-C. Tang, I.-T. Yu, and K.-C. Chang

This work aims improvement of the bottleneck of biogas utilization in pig farms, promotion of biogas use, and reduction of greenhouse gas emission. The biogas bio-desulfurization system (BBS), instead of conventionally adopted water scrubbing systems, was developed and tested. A farm-scale BBS (working volume $=0.73 \mathrm{~m}^{3}$ ) mainly packed with expanded clay beads as bio-carriers was installed at a 1,000-head pig farm in Miaoli, Taiwan. Experimental results showed that removal efficiency of hydrogen sulfide in biogas was higher than $90 \%$ after $21 \mathrm{~d}$ and became steady after $35 \mathrm{~d}$. Daily treatment amount of biogas was $72 \mathrm{~m}^{3}$ at flow $=50 \mathrm{~L} / \mathrm{min}$. Relative humidity of the BBS's outlet was higher than $85 \%$ after $21 \mathrm{~d}$. By the way, the inoculated bio-carriers can provide optimal humidity for sulfur-oxidizing bacteria to form bio-film on the surface of bio-carriers and removal efficiency of hydrogen sulfide became steadier after $35 \mathrm{~d}$. However, when excessive elemental sulfur accumulated on biocarrier surfaces, removal efficiency decreased. At this point, effluents from piggery wastewater treatment facilities were used to flush the BBS and provide $\mathrm{N}$ and $\mathrm{P}$ nutrients for sulfide oxidizers. The $\mathrm{pH}$ and the sulfate concentrations of water dropping from the BBS were $1.54 \pm 0.17$ and 27,086 $\pm 3,956$ $\mathrm{mg} / \mathrm{L}$, respectively, according to ion chromatography. The $\mathrm{pH}$ and sulfate concentrations in the effluent after flushing the BBS were $2.25 \pm 0.84$ and $5,704 \pm 2,701 \mathrm{mg} / \mathrm{L}$, respectively. In addition, elemental sulfur identified in the extraction solvent of flushing effluents taken from the BBS revealed that hydrogen sulfide was oxidized to elemental sulfur and sulfate by sulfur oxidizers. Hopefully, the biogas bio-desulfurization system can be applied to pig farms. Increased ratios of both biogas purification and utilization can help achieve waste recycling goals and enhance sustainability and cost efficiency in the livestock industry. 


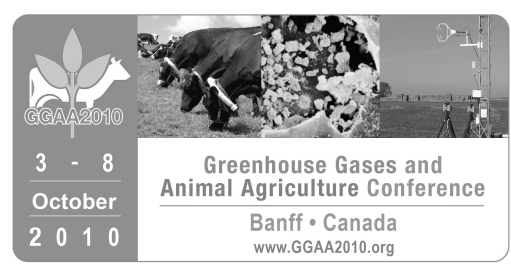

\title{
M51. The effect of feeding ensilages of poultry litter with bread left over on the body weight of Barka cattle
}

\author{
T. A. Tewoldebrhan* and G. Asghedom
}

Litters from replacement birds, layers and broilers were collected; sun dried and analyzed for the content of crude protein (CP), crude fiber (CF), ash and fat. The CP content (\% DM) for the replacement, layer and broiler litter was $21.15,18.59$ and 18.03 , respectively while the ash content (\% DM) was $14.54,38.56$ and 16.79 for the respective litters. The litters were ensiled with bread left over in a ratio of 45.5:54.5 by weight in plastic containers for a minimum of 21 days. The process of ensiling resulted in a product that had a higher CP content. The CP content (\% DM) for the initial mixtures of bread left over with the replacement, layer and broiler litter was 16.44, 15.27 and 15.02, respectively. This was elevated to 21.36, 19.47 and 17.94, respectively, after ensiling. The ensilages were of wholesome appearance, palatable and safe and were used in a feeding trial on Barka cattle. A trial was conducted to examine the effect of ensiled different kinds of poultry litters with bread left over on the body weight of cattle. Sixteen Barka cattle were divided into groups of four cattle in each treatment and a 90 day trial was conducted. The treatments consisted of a control diet (T1) consisting of a commercial type ration made up of $30 \%$ wheat bran, $36.3 \%$ bread left over, $2.4 \%$ fish meal, $30.3 \%$ taff straw and $1 \%$ salt. The other three treatments consisted of ensilages of $30 \%$ replacement litter (T2), layer litter (T3) or broiler litter (T4) with bread left over 36.3\%, fishmeal $2.4 \%$, taff straw $30.3 \%$ and salt $1 \%$. The feeding system was restricted and all the groups consumed all the feed that was offered to them $(7.44 \mathrm{~kg}$ of DM per cattle per day). Average body weight gains (ABG) for T1, T2, T3 and T4 were 1.093, 1.019, 0.673 and $0.966 \mathrm{~kg} \mathrm{day}^{-1}$, respectively. ABG for T1, T2 and T4 were not significantly different $(P>0.05)$, whereas cattle fed on T3 were significantly different $(P<0.05)$ from ABG of T1, T2 and T4. Wheat bran can be completely replaced by replacement and broiler litters in rations for Barka cattle. The ensiling process is an effective, simple and low cost technique. Feeds containing poultry silage can improve the cost of feed for farmers engaged in fattening of cattle.

\section{M52. Physical vs. biological processes driving methane fluxes from surface and subsurface filled dairy slurry storages}

J. D. Wood*, R. J. Gordon, C. Wagner-Riddle*, K. Dunfield and A. Madani

Methane $\left(\mathrm{CH}_{4}\right)$ fluxes from animal slurry storages are the net result of production, consumption and transport processes. Production and consumption are predominantly biological while transport occurs by physical processes. We characterized the relative contribution of biological and physical processes to $\mathrm{CH}_{4}$ fluxes from dairy slurry storages over a six week period in 2009. Six pilot-scale storages (6.6 $\mathrm{m}^{2}$ each) in Bible Hill, Nova Scotia were filled with slurry from August 28 through October 2. Each week, $\sim 1 \mathrm{~m}^{3}$ of slurry was added to each of the storages over a 30 to 75 min period. Three of the storages were subsurface filled through buried pipes, while the others had slurry deposited on the surface. Flow-through dynamic chambers were permanently situated over the entire surface of each of the storages, allowing for quasi-continuous measurement of $\mathrm{CH}_{4}$ fluxes. Flux events were observed during the storage period. These events were confined to the periods during which, and shortly after slurry was added to the storages; and were caused by mixing and disruption of the surface. On the first day that slurry was added, the ratios of the event flux to the total daily flux were 0.74 and 0.64 for the surface and subsurface filled storages, respectively. By the last day that slurry was added, these ratios had decreased to 0.24 and 0.14 for the surface and subsurface filled storages, respectively. This decrease was caused by higher background $\mathrm{CH}_{4}$ fluxes, as mean event fluxes were similar within treatments for the last 


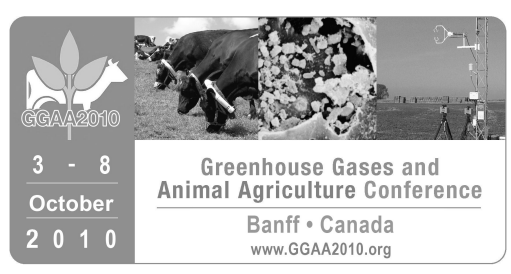

five weeks of the study. These results suggest that physical factors are more important early in the storage period and that biological production of $\mathrm{CH}_{4}$ becomes the driver of fluxes as storage time increased. This research also showed that more intense flux events can be expected from surface filled storages.

\author{
M53. Methane emissions from stored liquid dairy manure in a cold climate \\ A.C. VanderZaag*, C. Wagner-Riddle*, K.-H. Park* and R.J. Gordon
}

Climate change has been linked to increasing concentrations of greenhouse gases including methane $\left(\mathrm{CH}_{4}\right)$, which has a global warming potential 25 times greater than carbon dioxide over a 100 year time horizon. Stored liquid animal manure is an important source of $\mathrm{CH}_{4}$ globally and in Canada. As part of the ongoing efforts to mitigate these emissions it is beneficial to obtain field-scale flux estimates that can be used to verify emission factors. The objective of this study was, therefore, to measure $\mathrm{CH}_{4}$ fluxes from a liquid dairy manure storage tank and compare measured fluxes with predicted values using the USEPA methodology. Fluxes were measured from a circular concrete tank (11.25 m diameter) storing liquid dairy manure in Bright, Ontario, Canada. Measurements were conducted semi-continuously from January through July 2003, using a tunable diode laser and the non-interfering micrometeorological mass balance method. The monthly average $\mathrm{CH}_{4}$ flux ranged from $11 \mu \mathrm{g} \mathrm{m}^{-2} \mathrm{~s}^{-1}$ in June (after the tank had been emptied) to $153 \mathrm{\mu g} \mathrm{m}^{-2} \mathrm{~s}^{-1}$ in July. Large bubble flux events were observed in February and March that coincided with surface thawing. Predicted emissions using the USEPA approach revealed a large overestimation unless a substantial correction factor was used or carryover of volatile solids from month to month was ignored.

\title{
M54. A study of using different plant sources in association with pig manure for in vitro biogas production in the Mekong delta of Vietnam
}

N. Van Thu*

Anaerobic fermentation of animal wastes and plant materials for producing biogas could mitigate the World energy crisis and green house gas (GHG) emission. This study, therefore, aimed to evaluate the potential biogas production by using different forms of plant materials associated with pig manure. The Exp 1 was the complete randomized design with 6 treatments and 3 replicates by using the 10 liter-flasks. The treatments were the water hyacinth juice (WHJ) replacing pig manure at the levels of $0,20,40,60,80$ and $100 \%$ (DM basis). The experiment last 42 days, while the WHJ and manure were daily supplied for 21 days with around $5 \mathrm{gOM}$ per day. The Exp 2 was a factorial design. The first factor was plant materials (rice straw, water hyacinth (Eichhornia crassipes) and Para grass (Brachiaria mutica)) and the second factor was replacement levels of plants to pig manure of 10, 20, 30, 40 and 50\% (DM basis). The experimental period was 60 days. The results showed that in Exp 1 biogas production from day 8 to day 21 was significantly different $(P<0.01)$ among the treatments with the accumulated values of $0.439,0.378,0.327,0.317,0.283$ and $0.251 \mathrm{~m}^{3} / \mathrm{kgOM}$ for the treatments of $0,20,40,60,80$ and $100 \%$ WHJ replacing the pig manure, respectively. Similarly the Methane production was $0.261,0.223,0.201,0.190,0.171$ and $0.155 \mathrm{~m}^{3} / \mathrm{kgOM}(\mathrm{P}<0.001)$ for the above treatments, respectively. In Exp 2 the biogas production at day 60 was significantly different $(P<0.001)$ and it was 0.296 , 0.323 and $0.0867 \mathrm{~m}^{3} / \mathrm{kgOM}$ for rice straw, water hyacinth and para grass, respectively. This value was significantly different $(\mathrm{P}<0.001)$ and was $197,181,225,270$ and $304 \mathrm{~m}^{3} / \mathrm{kgOM}$ for 10, 20, 30, 40 and 50\% pig manure replaced by plant materials, respectively. The methane concentration of rice straw at the day 37 reached to methane concentration standard of biogas of $61.6 \%$ while water hyacinth and Para grass were 58.2 


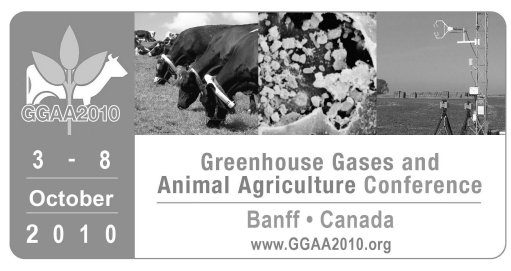

and $16.6 \%$. It was concluded that juice from pressed water hyacinth could be potentially used for replacing the pig manure for biogas production. However, the biogas and methane production were proportionally reduced by increasing the juice to replace the manure. Potential biogas production of rice straw and water hyacinth were higher than Para grass, and replacement of plant level at 50\% to pig manure was the highest biogas and methane production.

\section{M55. Effects of land use and amendment on greenhouse gas emission of farm land} G. Yang*, X. Hao* and Y. Li

Following land policy reform in the 1980's in China, land use has become more diverse and intensive, and disposal of agricultural waste is becoming an emerging issue. The use of agricultural wastes and land use changes could have profoundly impacted on greenhouse gas (GHG) emission from soil. The objectives of this study were to investigate how the land use type and organic amendment affect GHG emission. Surface soil (0$20 \mathrm{~cm}$ ) was collected near Kunming, Yunnan Province, from three dominant land use types: (1) rice-legume production in a two-crop, one-year rotation (Rice); (2) vegetable production in open fields (Veg); and (3) recent ( $<3$ years) conversed from open fields to plastic covered intensive vegetable and flower production (VegC). There were two amendments: rose (Rosa rugosa Thunb.) residual and cattle manure. Organic amendments (at $5 \%$ by weight) and soil samples were incubated at $60 \%$ water holding capacity moisture for three months under $22 \pm 1^{\circ} \mathrm{C}$. During the incubation, rate of greenhouse gas emission was determined once a week using static chamber method. The preliminary results indicated that there were little $\mathrm{CH}_{4}$ emissions and $\mathrm{N}_{2} \mathrm{O}$ emissions did not differ $(P>0.05)$ among all treatments. Amendment application significantly increased $\mathrm{CO}_{2}$ emission with the value from rose residue addition highest ( 5078 to $7216 \mathrm{mg} \mathrm{kg}^{-1}$ ), followed by cattle manure addition (2162 to $3581 \mathrm{mg} \mathrm{kg}^{-1}$ ); both were significantly $(P<0.05)$ higher than the non-amended Control (535 to $971 \mathrm{mg} \mathrm{kg}^{-1}$ ). Our study demonstrates that application of organic waste to soil could significantly increase $\mathrm{CO}_{2}$ emission from agricultural land.

\section{M56. The anaerobic co-digestion of swine manure and food waste in a Korean swine farm} Y. Yoon, H. C. Kim, J. S. Yoo, S. H. Kim, J. K. Park and C.-H. Kim*

Generally the pig slurry discharged from most Korean pig farmhouses has a high fluctuation in organic content since many pigpens have been adopting a slurry storage tank without the solid/liquid separation equipment. The organic contents generated from the pig farmhouse had a high fluctuation by season. The solid content increased in winter season, and on the other hand, decreased in summer due to an increase of water use at the pigpen. The fluctuation of organic contents in pig slurry discharged from the farmhouse may cause "wash-out" such that methane-producing bacteria are lost in anaerobic digester which disturbs the microbial community of the anaerobic digester and consequently methane yield decreases steeply. Therefore, the co-digestion system is more adaptable to Korean pig farmhouse because co-digestion can manage more stably the farm scale anaerobic digester. In order to assess the performance of co-digester using pig slurry and food waste at a farmscale biogas production facility, the anaerobic facility that adopts the one-stage plug and flow reactor (PFR) of 5 $\mathrm{m}^{3} \mathrm{~d}^{-1}$ input scale was designed and installed under the conditions of the organic loading rate (OLR) of $2.33 \mathrm{~kg}$ $\mathrm{m}^{-3} \mathrm{~d}^{-1}$ and a hydraulic retention time (HRT) of 30 days in a pig farmhouse. Several operation parameters were monitored for the operation of process performance. The anaerobic facility was operated in three stages to 


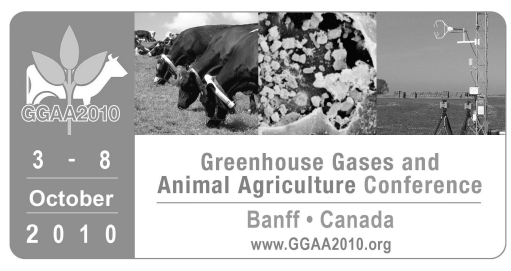

compare the performance of the anaerobic co-digester. Stage I was the case of the input in the 7:3 ratio (the designed input plan) of pig slurry to food waste. Stage II was the case of input in the 6:4 ratio of pig slurry to food waste, and Stage III was the case of input of pig slurry only. In the Stage I, average biogas yield showed $252 \mathrm{~m}^{3} \mathrm{~d}^{-1}$ (at STP) and methane content was $67.9 \%$. This facility was capable of producing electricity of 626 $\mathrm{kWh} \mathrm{d}^{-1}$ and heat recovery of $689 \mathrm{Mcal} \mathrm{d}^{-1}$. In Stage II, total solid (TS) content of the input materials of the mixture of $60 \%$ pig slurry and $40 \%$ food waste showed $6.9( \pm 1.9) \%$, and OLR was 1.22 to $3.524 \mathrm{VS} \mathrm{kg} / \mathrm{m}^{3}$ per day. The TS content of digestate was increased to $3.0( \pm 0.3) \%$. In Stage III, TS content of the pig slurry was 3.6\%

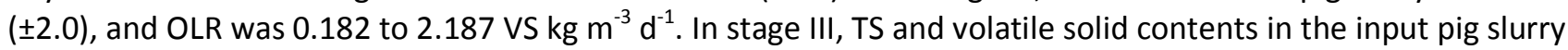
were in high variations, and also input volatile fatty acids and alkalinity values that affect the performance of anaerobic digester were highly changed during the operation. The biogas yields in stage III ranged between 11.3 and $170.0 \mathrm{~m}^{3} \mathrm{~d}^{-1}$, which were more variable than those of 222.5 to $330.2 \mathrm{~m}^{3} \mathrm{~d}^{-1}$ in Stage II.

\section{NOTES}




\section{NOTES:}




\title{
SESSION 3: ORAL ABSTRACTS
}

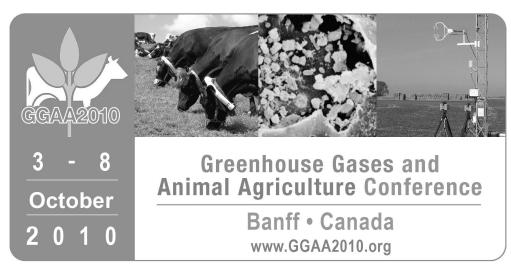

\section{PLEASE NOTE: Authors denoted with an asterisk are registered GGAA2010 delegates}

\author{
Animal vs. measurement technique variability in enteric methane production - is the measurement \\ resolution sufficient? \\ H. Clark*
}

The finding that individual ruminant animals appear to differ in the quantity of methane $\left(\mathrm{CH}_{4}\right)$ they produce when consuming the same quantity and quality of feed suggests that understanding and exploiting these differences could be a promising mitigation route. However, although the differences between individual animals within a group have been found to vary by a factor of three identifying consistently low $\mathrm{CH}_{4}$ emitting phenotypes presents a stern challenge. Two technologies for measuring $\mathrm{CH}_{4}$ emissions from individual animals are in common use; respiration calorimetry and the $\mathrm{SF}_{6}$ tracer technique. Studies comparing group mean $\mathrm{CH}_{4}$ emissions suggest that there is good agreement between the two techniques although New Zealand studies indicate that, when expressed as emissions per unit of feed consumed $\left(\mathrm{g} \mathrm{CH}_{4} \mathrm{~kg} \mathrm{feed}^{-1}\right)$, the variability of results obtained from calorimetry are approximately half of those obtained from $\mathrm{SF}_{6}$ tracer studies. The reasons for this are not fully elucidated but the performance of $\mathrm{SF}_{6}$ permeation tubes seems to be a major factor. Further, the correlation between emissions values obtained from individual animals is low and the repeatability of values obtained using $\mathrm{SF}_{6}$ technique is low. Taken together these findings suggest that using the $\mathrm{SF}_{6}$ tracer technique is not suitable for identifying low emitting phenotypes. However, using respiration calorimetry has its own challenges. The number of animals that can be measured is often restricted compared with the number that can be measured using the $\mathrm{SF}_{6}$ tracer technique and confining animals in calorimeters means that animals are measured in a highly artificial environment. Therefore this would appear to suggest that a choice has to be made between measuring a small number of animals accurately and a larger number of animals with less accuracy. However, the New Zealand experience suggests that for practical purposes the size of the difference between individual animals and variability and lack of repeatability of the $\mathrm{SF}_{6}$ technique is such that for the accurate identification of low emitting animals the only choice at present is to measure as large a number of animals as accurately as possible using calorimetry methods.

\section{Validation of a short-term methane measurement as a predictor of daily methane production in sheep: Development and proving of portable chambers for field testing \\ J. Goopy, R. Woodgate and R. S. Hegarty*}

There is increasing demand for technologies to measure daily $\mathrm{CH}_{4}$ production (DMP) of ruminant livestock in developing and verifying strategies for methane mitigation. Studies of genetic variation in DMP particularly, require emissions to be measured on 1000s rather than scores of animals. Short term emission measures had previously been observed to correlate with DMP, so a study was conducted to verify the usefulness of 1 and $2 \mathrm{~h}$ emission measures in predicting DMP. On day 1 Merino sheep $(n=14)$ fed twice daily were measured for DMP over $22 \mathrm{~h}$ by open circuit calorimetry; on day 2 methane output was measured for 1 and $2 \mathrm{~h}$ in static chambers. On day 3 , sheep were fed then fasted for $1 \mathrm{~h}$ before $\mathrm{CH}_{4}$ output was again measured over 1 and $2 \mathrm{~h}$. DMP measured on day 1 correlated well with $2 \mathrm{~h} \mathrm{CH}_{4}$ emission measures on day 2 and day $3\left(r^{2}=0.58-0.59\right)$ and $1 \mathrm{~h}$ measures $\left(r^{2}=0.51\right)$. Portable static respiration chambers were designed for $1-2 \mathrm{~h} \mathrm{CH}_{4}$ emission capture. The 


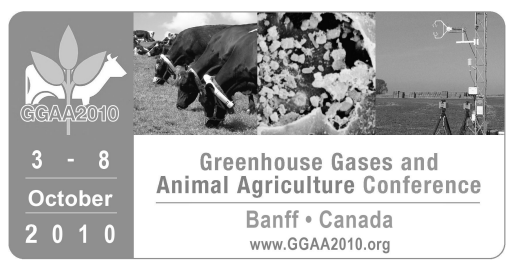

polycarbonate static chambers retained $98-99 \%$ of tracer gas after 90 min showing gas loss was minimal. With a sheep inside a chamber, $\mathrm{CO}_{2}$ concentration reached $2.2 \%$ after $2 \mathrm{~h}$, but animals showed no discomfort and $\mathrm{pO}_{2}$ saturation remained above $97 \%$, being safe for animal health. It is concluded that $1-2 \mathrm{~h}$ measures of methane output in static chambers can provide a useful estimate of DMP. As for full day measures, repeat measures are likely to be required to characterize an animal's DMP phenotype.

\section{Extending the collection length of breath samples for methane emission estimation using the $\mathrm{SF}_{6}$ tracer technique}

C. S. Pinares-Patiño*, J. I. Gere, K. E. Williams, R. Graton, M. P. Juliarena, G. Molano*, M. Fernandez, S. MacLean, E. Sandoval, G. Taylor and J. P. Koolaard

Conventionally, the sulphur hexafluoride $\left(\mathrm{SF}_{6}\right)$ tracer technique for the estimation of methane $\left(\mathrm{CH}_{4}\right)$ emissions involves sample collections over $24 \mathrm{~h}$ repeated across 5-7 days. This schedule may not be practical under extensive grazing systems with low carrying capacity of grasslands. Here, we explored the possibility of a single sample collection over extended periods ( 5 and 10 days) as an alternative to daily sample collections. Eight rumen-fistulated non-lactating cows were housed in a facility enabling both natural and artificial ventilation and fed commercial silage to achieve a fixed and common daily feed intake of $6.4 \mathrm{~kg}$ dry matter per cow. Each cow was deployed with a fresh $\mathrm{SF}_{6}$ permeation tube and after a 10-day diet acclimatization, breath collections were conducted for $\mathrm{CH}_{4}$ emission estimation using the $\mathrm{SF}_{6}$ tracer technique. Eight sample lines were fitted to the collection harness, ensuring that a common mix of breath sample was available to each sampling line. Half of the sample lines collected breath samples into stainless steel cylinders using a steel bearing ball flow regulator (UNICEN-Argentina system, ARG), and half collected samples into PVC yokes using a capillary system as flow regulator (AgResearch-New Zealand system, NZL). Within each system and within the 10-day timeframe, common-source breath samples were collected either daily (ARG-1 and NZL-1), across two 5-day periods (ARG 1-5, ARG 6-10, NZL 1-5, NZL 6-10) or one 10-day period (ARG 1-10, NZL 1-10). Both the ARG 1-10 and NZL 1-10 collections were conducted in duplicate. Thus, within each system, 14 breath samples were collected from each cow, and following the 10-day tracer period, emissions of $\mathrm{CH}_{4}$ were measured using respiration chambers. Overall, the NZL system had larger sample collection success than the ARG system. Further, the NZL system yielded more consistent $\mathrm{CH}_{4}$ emissions than the ARG system. However, both systems yielded much lower $(P<0.05) \mathrm{CH}_{4}$ emissions than the respiration chambers. Compared with the NZL system, the ARG system yielded better relationships between the tracer estimates and the chamber values. It is concluded that sample collection length can be successfully extended, but mismatch between tracer estimates and chamber values of $\mathrm{CH}_{4}$ emission remains.

\section{Micrometeorological techniques for measurement of greenhouse gas emissions from ruminant animal production}

L. A. Harper*, T. K. Flesch* and J. D. Wilson*

Methane $\left(\mathrm{CH}_{4}\right)$, because of its high radiative forcing property in the atmosphere, is targeted for reduced emissions in industries worldwide. Methane emissions from animal production are a small but significant proportion of total anthropogenic emissions. The evaluation of these emissions represents a challenge to the animal industry to determine accurately both enteric and waste-management emissions. In addition to the 


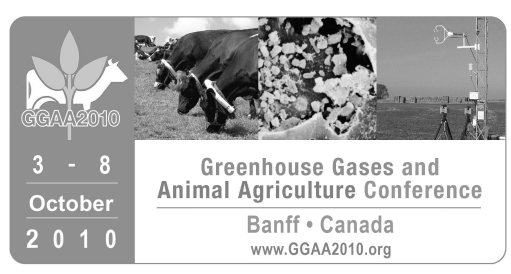

production of radiatively-active gases, enteric $\mathrm{CH}_{4}$ emissions also represent a significant loss of gross energy consumed by ruminant animals. It is particularly difficult to evaluate accurately the respiratory emissions from animals. Enclosed chambers and permeation tube techniques are common measurement approaches but their use inevitably changes animal diet, behaviour, and stress levels. A "non-interference" technique that does not infringe on the animal or its surroundings is a more appropriate approach. Two types of limited-interference micrometeorological techniques have been used in animal studies. A micrometeorological mass difference (MMD) technique has been used to study animal emissions in paddocks; however, it requires substantial instrumentation and is practical only for small paddocks. Inverse dispersion analysis is a more flexible technique that has been used to evaluate treatment differences in small paddocks, but it has also been used to make whole-farm measurements. Both the MMD and inverse dispersion techniques have been shown sensitive enough to test for treatment differences, but also sensitive enough to detect emissions differences between feeding and resting periods by the animals. The purpose of this presentation is to discuss the advantages and disadvantages of these techniques and give examples of their applications.

\section{Recognizing the strength and weaknesses of chamber nitrous oxide measurements P. Rochette* and N. Bertrand}

Chamber techniques have been used to estimate soil $\mathrm{N}_{2} \mathrm{O}$ fluxes for more than eight decades and remain the most commonly used approach. They permit measurement of very small fluxes, are relatively inexpensive to build and use, and can be adapted to a wide range of field conditions and experimental objectives. However, chambers are not exempt from methodological problems, and in this presentation we will review known sources of chamber-induced errors in soil $\mathrm{N}_{2} \mathrm{O}$ flux estimates. We will discuss how the presence of the chamber on the soil surface modifies environmental factors that in turn influence gas exchange. Finally, we will propose how adequate gas sample handling and analysis as well as proper chamber design (dimensions, materials) and deployment methodology (placement, duration, flux calculation) can minimize biases in flux estimates.

\section{Greenhouse gas emissions from Australian beef cattle feedlots \\ D. Chen*, D. Rowell, J. Hill*, D. W. T Griffith, O. T. Denmead* and S. M. McGinn*}

In Australia, agriculture is the second largest source of greenhouse gas emissions, accounting for $16.3 \%$ of the national total. Beef cattle account for an estimated $40 \%$ of agricultural sector emissions, of which $2.4 \%$ was attributed to beef cattle feedlots. Although a minor source, the feedlot production results in a concentrated source of gas emissions to the atmosphere. Here, we report the first Australian study to measure greenhouse gas emissions from beef cattle feedlots using open-path spectroscopy and atmospheric dispersion modelling. The nitrous oxide $\left(\mathrm{N}_{2} \mathrm{O}\right)$, ammonia $\left(\mathrm{NH}_{3}\right)$ and nitrogen oxides $\left(\mathrm{NO}_{\mathrm{x}}\right)$ measured by combination of open- and closed-path techniques were reported in the companion paper (Denmead et al.) and the greenhouse gas $\left(\mathrm{CH}_{4}\right.$, $\mathrm{N}_{2} \mathrm{O}$ and $\mathrm{CO}_{2}$ ) emissions from manure pad, measured with static chambers, were reported in the companion paper (Muir et al.). Gas concentration measurements were made with an open path Fourier-transform infrared (FTIR) spectrometer (for $\mathrm{CH}_{4}, \mathrm{NH}_{3}, \mathrm{~N}_{2} \mathrm{O}$ and $\mathrm{CO}_{2}$ ) and four open-path lasers $\left(\mathrm{CH}_{4}\right.$ and $\mathrm{NH}_{3}$ ). The WindTrax program, computer software of backward Lagrangian Stochastic model, was used to calculate emissions fluxes. Subsequent to the campaigns, supplementary, long-term measurements of $\mathrm{NH}_{3}$ and oxides of nitrogen (NOx) were carried out using a self-contained system of rack-mounted trace gas analysers. Emissions measured by the open-path methodology were compared with currently-used biophysical animal models. The average $\mathrm{CH}_{4}$ 


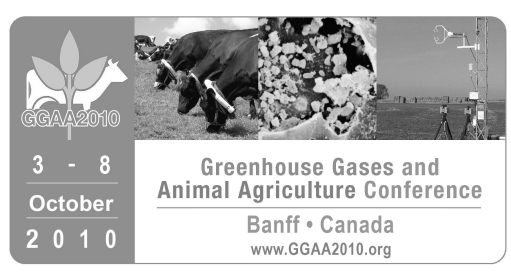

emission was $113 \mathrm{~g}_{\text {animal }}{ }^{-1} \mathrm{~d}^{-1}$, approx. 40\% lower than estimates generated using the standard Moe and Tyrrell model, but close to average estimates using the IPCC Tier II model. Thus, results support the use of IPCC Tier II for modelling $\mathrm{CH}_{4}$ emissions in beef cattle feedlots. Average $\mathrm{NH}_{3}$ emission was $176 \mathrm{~g}$ animal ${ }^{-1} \mathrm{~d}^{-1}$ (nearly three times IPCC Tier II-modelled estimates), while average nitrous oxide $\left(\mathrm{N}_{2} \mathrm{O}\right)$ emission was $3.3 \mathrm{~g}$ animal ${ }^{-1} \mathrm{~d}^{-1}$ (half that of IPCC-modelled emissions). This suggests that the greater-than-expected volatilisation of $\mathrm{NH}_{3}$ may have resulted in less-than-expected nitrogen remaining available for $\mathrm{N}_{2} \mathrm{O}$ production via nitrificationdenitrification. The indirect $\mathrm{N}_{2} \mathrm{O}$ emissions (derived from deposited $\mathrm{NH}_{3}$ and $\mathrm{NOx}$ ) are substantial, accounting for more than half as much (in terms of $\mathrm{CO}_{2}$-e) as the emissions of $\mathrm{CH}_{4}$ from feedlots. Average $\mathrm{CO}_{2}$ emission was $12.9 \mathrm{~kg}$ animal ${ }^{-1} \mathrm{~d}^{-1}$. This is somewhat higher than modelled estimates, although livestock-respired $\mathrm{CO}_{2}$ is not considered a net anthropogenic greenhouse gas emission.

\section{A study of the variability in ammonia and greenhouse gas emissions from seven identical compartments of a mechanically ventilated pig house}

N. Peiren*, P. Demeyer, B. Sonck, N. Van Ransbeeck and D. De Brabander

The objective was to compare the emissions of ammonia $\left(\mathrm{NH}_{3}\right)$ and greenhouse gasses from seven identical constructed compartments in a commercial pig house. To conduct comparative feeding experiments on emission reducing feed rations and/or feed additives in a pig house, the climate conditions and gas emissions of all compartments should be comparable under the same management conditions. The pig house was built in 1995 and has seven compartments with each containing 8 fully-slatted pens and separate manure pits. The pig house has an indirect air inlet in the side-alley. Via a ventilation channel in the floor of the side-alley the fresh air enters the compartments. Each compartment has an axial fan. The ventilation rate was temperature controlled and continuously monitored with a free-running impeller. Ammonia, $\mathrm{CH}_{4}, \mathrm{~N}_{2} \mathrm{O}$, and $\mathrm{CO}_{2}$ were measured in each compartment every $30 \mathrm{~min}$ in the exhaust channels with an infrared photo acoustic detector during two fattening periods: the first period from mid January until the beginning of June 2009 and the second period from mid June until the end of October 2009. The data of the two outer compartments with three outside walls were not considered, because the indoor climate was more influenced by the outdoor climate than that of the other compartments. The average temperature for the first and the second period was $22.9 \pm$ $0.1^{\circ} \mathrm{C}$ and $24.0 \pm 0.4^{\circ} \mathrm{C}$, respectively. The average ventilation rate was $2130 \pm 230$ and $3010 \pm 420 \mathrm{~m}^{3} \mathrm{~h}^{-1}$, respectively. Within each period a lot of variation in the total emission between the five compartments was noticed. For the first period there was a difference between the highest and lowest total emissions of 63,44 , 197 and $20 \%$ for $\mathrm{NH}_{3}, \mathrm{CH}_{4}, \mathrm{~N}_{2} \mathrm{O}$ and $\mathrm{CO}_{2}$, respectively. For the second period there was a difference between the highest and lowest emissions of $15,64,81$ and $21 \%$. All the outliers were caused by two compartments. By eliminating these two the percentages are 11, 21, 29 and $1 \%$ for the first period and 15, 47, 25 and $8 \%$ for the second period. There are indications that there may be problems with the manure pits of these two compartments. The variations between the other compartments can not be explained. Moreover, relative differences between the compartments are not consistent for the different gases. We conclude that before planning comparative experiments in (commercial) pig houses, the compartments should be checked for construction errors even in the manure pits and should be measured before incorporating additional variables. 


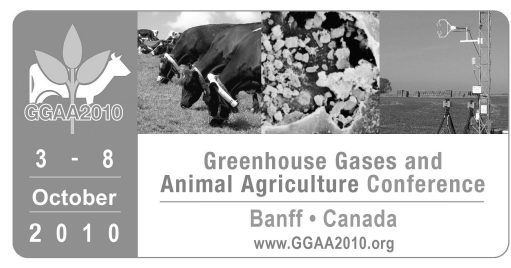

\section{Methane and nitrous oxide emissions from two dairy freestall barns with flush and scrape manure collection systems}

L. D. Jacobson*, B. P. Hetchler, E. Cortus*, A. J. Heber and B. W. Bogan

Real time methane $\left(\mathrm{CH}_{4}\right)$ and nitrous oxide $\left(\mathrm{N}_{2} \mathrm{O}\right)$ emission measurements were made from two commercial dairy buildings located in Midwestern (Wisconsin) U.S. during periods of 2008 and 2009. The two cross-flow mechanically ventilated dairy buildings (approximately 300 and 400 cow capacities) were part of the National Air Emissions Monitoring Study (NAEMS), which collected hazardous gas (ammonia $\left(\mathrm{NH}_{3}\right)$ and hydrogen sulfide $\left(\mathrm{H}_{2} \mathrm{~S}\right)$ ) and particulate matter (PM) emission data from various dairy, pig, and poultry buildings in the U.S. Additional research funds were secured to install $\mathrm{CH}_{4}$ and $\mathrm{N}_{2} \mathrm{O}$ gas analyzers in the environmentally-controlled trailer located adjacent to the two dairy buildings monitored for the NAEMS project. Methane was primarily measured by a Model 55C Direct Methane, Non-Methane Hydrocarbon Analyzer (Thermo Environmental Instruments, Franklin, MA) while nitrous oxide was measured with a Model 320EU (Teledyne API, San Diego, CA). As part of the original NAEMS project, airflow rates from both dairy buildings were measured by recording run times of the barn's exhaust fans (a total of 59 and 66 fans, respectively). All exhaust fans were the same model (belt driven, $127 \mathrm{~cm}$ diameter with $1 \mathrm{hp}$ motor). Airflow measurements of a representative number of the similar exhaust fans in both buildings were done in situ at the start and halfway through the two year monitoring project with a special fan measurement device, the Fan Assessment Numeration System (FANS). Therefore, hourly $\mathrm{CH}_{4}$ and $\mathrm{N}_{2} \mathrm{O}$ emission rates were calculated for both dairy buildings over approximate 18 and 6 month time periods, respectively. Methane emissions varied between 400 and $600 \mathrm{~g}^{2}$ animal ${ }^{-1} \mathrm{~d}^{-1}$ from both buildings. There seems to be no statistical seasonal effect, however, there may be a trend of higher rates during cooler vs. warmer temperatures. The above per animal rates translates to single barn emissions of between 100 and $150 \mathrm{~kg} /$ day. Nitrous oxide emissions were quite low, varying between 1 and $2 \mathrm{~g} \mathrm{animal}^{-1} \mathrm{~d}^{-1}$ which would translate to between 0.5 and $1 \mathrm{~kg} \mathrm{~d}^{-1}$ barn $^{-1}$. Also, in the fall of 2009 both barns' manure collection system was switched from a flush (using manure storage effluent as flush water) to a tractor scrape system. Little variation is seen in methane emission rates before and after this key manure management change, probably suggesting that most of the methane emissions are enteric losses directly from the dairy cows. 
SESSION 3: POSTER ABSTRACTS

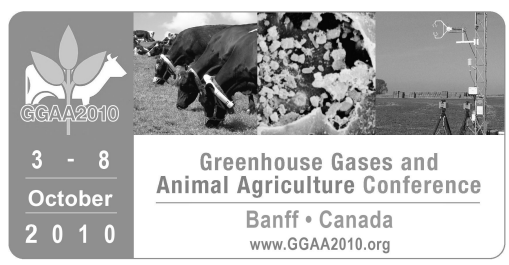

\title{
PLEASE NOTE: Authors denoted with an asterisk are registered GGAA2010 delegates
}

\author{
T01. The effect of dietary alfalfa silage to corn silage ratio on lactating cow performance and \\ methane emission \\ C. Arndt*, M. A. Wattiaux*, J. M. Powell* and M. J. Aguerre*
}

The objective was to determine the effect of varying alfalfa silage (AS) to corn silage (CS) ratio in a total mixed ration on performance of lactating cows and methane $\left(\mathrm{CH}_{4}\right)$ emission. Sixteen multiparous Holstein cows (mean $\pm S D ; 77 \pm 35$ days in milk and $640 \pm 84 \mathrm{~kg}$ body weight) housed in a modified tie-stall barn with four airflow controlled chambers designed to accommodate four cows per chamber were fed diets with 20:80 (AS20), 40:60 (AS40), 60:40 (AS60), and 80:20 (AS80) CS:AS ratio in a 55:45 forage:concentrate ratio (DM basis) diet in a balanced $4 \times 4$ Latin square. Methane was measured in inlet and outlet air samples with a photo-acoustic multi-gas monitor (Innova Model 1412) for about $17 \mathrm{~h} / \mathrm{d}$ on three consecutive days of each period. The aNDFom content of diet DM averaged 27.1, 27.3, 27.6, and 27.8\% and NFC content of diet DM averaged 46.4, 44.9, 43.5, and 42.0 for AS20, AS40, AS60, and AS80, respectively. No effect was observed for DMI (26.6 \pm 0.3 $\mathrm{kg} / \mathrm{d}$ ), milk yield (41.0 $\pm 0.4 \mathrm{~kg} / \mathrm{d})$, feed efficiency ( $\mathrm{kg}$ milk yield $/ \mathrm{kg} \mathrm{DMl} ; 1.56 \pm 0.02)$, fat content $(37.8 \pm 0.58 \mathrm{~g} / \mathrm{kg}$ ), MUN $(16.2 \pm 0.2 \mathrm{mg} / \mathrm{dL})$, and $\mathrm{CH}_{4}$ per energy corrected milk (ECM) $(17.5 \pm 0.5 \mathrm{~g} / \mathrm{kg})$. A quadratic response $(\mathrm{P}<0.05)$ was observed for $\mathrm{ECM}$ and milk fat yield, which averaged 41.2, 42.7, 42.0, and $41.2 \mathrm{~kg} / \mathrm{d}$ and 1.51, $1.61,1.57$, and $1.53 \mathrm{~kg} / \mathrm{d}$ for AS20, AS40, AS60 and AS80, respectively. True milk protein content and yield decreased linearly $(P<0.05)$ from $30.3 \mathrm{~g} / \mathrm{kg}$ in AS20 to $28.9 \mathrm{~g} / \mathrm{kg}$ in AS80 and $12.2 \mathrm{~g} / \mathrm{d}$ in AS20 to $11.7 \mathrm{~g} / \mathrm{d}$ in AS80. Estimated $\mathrm{CH}_{4}$ emission averaged $711,764,749$, and $698 \mathrm{~g} / \mathrm{d}$ and estimated $\mathrm{CH}_{4}$ per DMI averaged 26.1, $27.7,27.0$, and $25.0 \mathrm{~g} / \mathrm{kg}$. A quadratic response $(\mathrm{P}<0.05)$ was observed for the above emission rates with the greatest response for 40AS and the lowest $80 \mathrm{AS}$ with a difference of $7 \%$ for $\mathrm{CH}_{4} \mathrm{~g} / \mathrm{d}$ and $10 \%$ for $\mathrm{CH}_{4}$ per DMI between extremes. In contrast greatest ECM was observed for 40AS and lowest for 80AS with a difference of $4 \%$. Our results suggest that large substitutions between AS and CS in the diet impact methane emission and cow performance quadratically. However, the ratio of AS and CS does not seem effect methane emitted per $\mathrm{kg}$ ECM produced.

T02. Effects of replacing barley in feedlot diets with increasing levels of glycerol on in vitro methane production

J. Avila Stagno*, A.V. Chaves, L.M. Hernandez-Calva, K.A. Beauchemin*, S.M. McGinn* and T.A. McAllister*

The increasing availability of glycerol from the biodiesel industry has led to its use as an energy source for ruminants in replacement of cereal grains. Its effects on ruminal fermentation patterns are not clear and the literature shows no report of methane $\left(\mathrm{CH}_{4}\right)$ production as affected by glycerol inclusion. The aim of this study was to assess in vitro ruminal fermentation and $\mathrm{CH}_{4}$ production from diets containing increasing levels of

glycerol. Glycerol was used as replacement of barley grain to obtain inclusions of $0,7,14$ and $21 \%$ in the dry matter (DM) of diets containing $50 \%$ barley grain and $50 \%$ barley silage. Each dietary treatment was dried and 


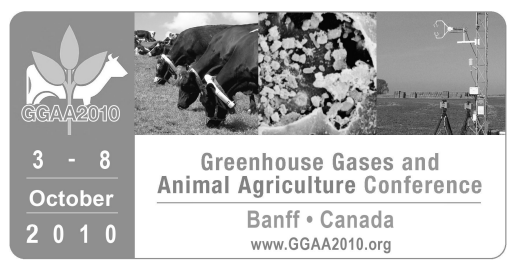

ground through a 1-mm screen and incubated twice $(n=10)$ in ANKOM ${ }^{\circledR}$ bags in $50-\mathrm{mL}$ sealed batch culture flasks ( $0.5 \mathrm{~g}$ substrate $+25 \mathrm{~mL}$ media). Ratio of buffer:rumen liquor was 3:1. The rumen liquor was obtained from cows fed a diet containing $71 \%$ barley silage, $5 \%$ barley grain and $4 \%$ concentrate (DM basis). Gas production was measured at 3, 6, 12, 24, 36 and $48 \mathrm{~h}$ post inoculation. Volumes corrected for gas released from 15 negative controls (no substrate) were used to estimate cumulative gas production. Gas samples collected at 24 and $48 \mathrm{~h}$ were analyzed for $\mathrm{CH}_{4}$ concentration. In vitro DM disappearance (IVDMD) and culture $\mathrm{pH}$ were measured at $48 \mathrm{~h}$. Cumulative gas production $(\mathrm{mL} / \mathrm{g}$ incubated $\mathrm{DM})$ and IVDMD were similar $(\mathrm{P}>0.05)$ among treatments. Culture $\mathrm{pH}$ was higher $(\mathrm{P}<0.001)$ in the $21 \%$ glycerol diet compared to other treatments. Total $\mathrm{CH}_{4}$ production $(\mathrm{mg})$ did not differ $(\mathrm{P}=0.31)$ among treatments. However, $\mathrm{CH}_{4}$ expressed as $\mathrm{mg} \mathrm{CH}_{4} / \mathrm{g}$ digested $D M$ decreased linearly $(P=0.02)$ from 12.5 to 11.3 as the level of glycerol increased from 0 to $21 \%$. Results suggest that replacing barley grain with glycerol reduces methane production as a function of digested DM.

\section{T03. Measurement of bovine enteric methane emission: an on-line recording technique} G. Berra*, R. Bualo, L. Finster* and S. E. Valtorta

Six Holstein steers (average initial weight $368+/-36 \mathrm{~kg}$ ) were utilized at the Enteric Methane Emissions Unit, INTA Castelar (Argentina), between December $12^{\text {th }} 2008$ and February $18^{\text {th }} 2009$, to assess enteric methane emissions, using an on-line recording technique. Animals were housed in individual boxes. They received a diet consisting of $3.6 \mathrm{~kg}$ alfalfa pellets and $6.4 \mathrm{~kg}$ concentrate, offered once a day, at $1100 \mathrm{~h}$, right before connecting the measuring equipment. Water was available ad libitum. Three daily enteric methane emission data were obtained from each steer, over a one and a half month period, following a 1-month adjustment period. An on-line technique to record ruminal gasses production was utilized. Rumen gasses were collected through a microfistula. A cannula was introduced through the fistula in the gaseous portion of the rumen. The other end of the cannula was connected to a one-way valve to prevent the gasses from returning to the rumen. Then, the gasses were circulated through a flow meter, connected to an electronic module that digitalized the flow value and transformed it into a volume datum. This module also had a cellular communication device, which utilized the GPRS network to send the signal, via internet, to a central server. The server stored the information in a data-base. Thus, data could be seen in real time, on-line, from any computer. Six times a day, gas samples were taken and analyzed with a methane detector. Since accumulated volumes every 10 seconds were available, total ruminal gas and methane emission curves, as a function of time post-feeding, could be drawn. Data were subjected to a one-way analysis of variance. Average daily gain was $8901+/-10 \mathrm{~g} / \mathrm{d}$. Total ruminal gas and methane emissions over a 24-hour period were $555+/-140 \mathrm{~L}_{\text {animal }}{ }^{-1} \mathrm{~d}^{-1}$ and $115+/-33 \mathrm{~L}$ animal $^{-1} \mathrm{~d}^{-1}$, respectively. Methane concentration was $20.6+/-2.2 \%$. Significant differences $(P<0.001)$ were observed between animals for both, total rumen gas and methane, volumes. The animals presenting higher total rumen gas volumes did not necessarily coincide with the ones showing higher methane emission volumes, since there was also a significant difference among methane concentration levels $(P<0.01)$. Total rumen gas production curves were drawn for the first $12 \mathrm{~h}$ after feeding. All the resulting curves could be fitted to exponential curves, consistent with feedstuffs incubation in situ. It was concluded that this measuring technique a promising tool to be utilized to determine the emissions of this greenhouse gas by cattle. 


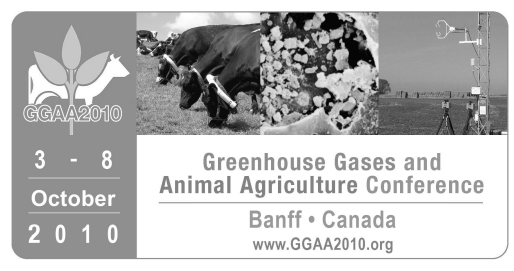

T04. In vitro measurement of gas production from Mediterranean tree and shrub leaves

\author{
A.G. Boubaker*, S. Ben Saïd, R. Mosquera-Losada* and A.R. Rodriguez
}

The objective of this study was to determine effects of polyethylene glycol 6000 (PEG) on deactivation of tannins in Mediterranean tree and shrub leaves (i.e., Arbutus unedo, Calycotum villosa, Erica arborea, Phillyrea angustifolia, Pistacia lentiscus, Myrtus communis, Quercus suber) by assessing changes in methane production and in vitro gas production (IVGP) parameters. Estimated organic matter digestibility (OMD) and metabolizable energy (ME), with or without PEG addition, were determined. Calibrated glass syringe containing $200 \mathrm{mg}$ of sample tested and $30 \mathrm{ml}$ of buffered rumen fluid ( $10 \mathrm{ml}$ sheep rumen fluid $+20 \mathrm{ml}$ culture medium) were incubated with or without addition of $200 \mathrm{mg}$ of PEG at $39^{\circ} \mathrm{C}$ for $24 \mathrm{~h}$. After incubation, $\mathrm{pH}$, gas and methane production were recorded. Browses varied in their crude protein (CP: $55-221 \mathrm{~g} \mathrm{~kg}^{-1} \mathrm{DM}$ ) and neutral detergent fibre (360-551 $\mathrm{g} \mathrm{kg}^{-1} \mathrm{DM}$ ) contents. High levels of total condensed tannins (TCT) were observed in $P$. lentiscus, and the lowest levels were in $C$. villosa and $P$. angustifolia. There were significant differences among species in terms of methane and gas production. The PEG addition significantly increased the methane and total gas production and some estimated parameters of shrub and tree leaves. However, species showed variable responses to PEG treatment. Amongst the chemical constituents, neutral detergent fibre had a high correlation $(r=0.86)$ with methane concentration. There was a negative relationship between total phenol, total tannins or tannin activity and methane concentration. The improvement in gas production, organic matter digestibility (OMD) and metabolizable energy (ME) with PEG emphasizes the negative effect of tannins on digestibility.

\title{
T05. Validation and further development of different air volume flow measurement methods for livestock buildings \\ W. Buescher*, B. Diekmann, C. Nannen, E. Rosenthal, P. Lodomez, P. Roesmann and J. Henseler
}

To determine the emission mass flow from livestock buildings, it is necessary to measure the concentration of the target substance and the air volume flow. Simple and precise methods are available for measurements in forced-ventilated livestock houses (e.g., by means of calibrated measuring fans). For naturally ventilated buildings tracer gas methods are useful, which can be used to determine the air volume flow based on the dilution of the tracer gas concentration. Energy- and $\mathrm{CO}_{2}$-balance methods are also used to calculate air volume flow, but these methods are not very accurate. Radioactive tracer methods guarantee high precision but are mostly not accepted by researchers and residents. Consequently, validation and further development of existing methods in the context of getting realistic greenhouse gases emission factors are urgently needed. In different studies of our working group measuring fans in forced-ventilated buildings and tracer gas $\left(\mathrm{SF}_{6}\right)$ for free-ventilated buildings have been used. Previously, the following methodical questions have been addressed to enhance the accuracy and long-term applicability: a) influence of the position of the measuring fans and the dust deposit on the blades on accuracy and recalibration time, b) validation of tracer gas method in comparison to measuring fan in different housing types in relation to mass- and energy-balance method and c) further development of $\mathrm{SF}_{6}$-tracer gas method into an automatic continuous working system to consider daily and seasonal effects on air exchange and emission level. Results include: dust deposit has only small effects on the long term characteristics of measuring fans. After six months the divergence was lower than $5 \%$. Due to position effects the calibration of the fan in the same way as in the measuring situation is necessary. Additionally, tracer gas method leads to almost identical results if the dilution of tracer in the building is installed carefully. Automation of the tracer gas $\left(\mathrm{SF}_{6}\right)$ method was successfully achieved at a frequency of 30 min. Considering wind speed and wind direction, it was possible to get a reliable data base for simulating the air exchange rate of a free-ventilated cow house to predict the emission flow over the year. 


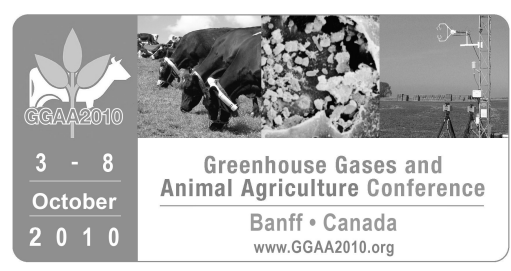

\title{
T06. Effect of release rate of the SF6 tracer on methane and carbon dioxide emission estimates based on ruminal and breath gas samples
}

\author{
M. Cécile, J. Koolaard, Y. Rochette, H. Clark*, J.P. Jouany, C.S. Pinares-Patiño*
}

Release rate (RR) of $\mathrm{SF}_{6}$ tracer appears to be positively associated with $\mathrm{CH}_{4}$ emission estimates. Gas samples of breath and of ruminal head space were collected simultaneously in order to evaluate the hypothesis that transactions of $\mathrm{SF}_{6}$ in the rumen are the source for this relationship. Six non-lactating dairy cows fitted with rumen cannulae were subdivided in two groups and randomly assigned in a two-period cross-over design to permeation tubes with low ( $L R R=1.577 \mathrm{mg} / \mathrm{d}$ ) or high $(H R R=3.147 \mathrm{mg} / \mathrm{d}$ ) release rate (RR). Each period consisted of 3-d gas sampling. The cows were limited fed on maize silage ( $80 \%$ ad libitum) and split into two meals (40\% at 0800 and $60 \%$ at 1600$)$. Ruminal gas samples (50 mL) were withdrawn throughout the cannula equipped with stoppers avoiding to open the cannula, immediately before the morning feeding and then each hour over $8 \mathrm{~h}$. Simultaneously, 8-h integrated breath gas samples were collected on the same period. Ratios of concentration of $\mathrm{CH}_{4} / \mathrm{SF}_{6}, \mathrm{CO}_{2} / \mathrm{SF}_{6}$ and $\mathrm{CO}_{2} / \mathrm{CH}_{4}$ and emission estimates of $\mathrm{CH}_{4}$ and $\mathrm{CO}_{2}$ were calculated for each sample source using the $\mathrm{SF}_{6}$ tracer technique principles. As expected, the LRR treatment yielded higher $(P<0.001)$ ruminal $\mathrm{CH}_{4} / \mathrm{SF}_{6}$ (by 1.84 times) and $\mathrm{CO}_{2} / \mathrm{SF}_{6}$ (by 1.87 times) ratios than the HRR treatment, but these differences were lower than the 2.0 times difference expected from the RR between the LRR and HRR. Consequently, the LRR treatment was associated with lower $(P<0.01)$ ruminal emissions of $\mathrm{CH}_{4}$ over the 8-h collection period than with the HRR treatment (101 vs. $114 \mathrm{~L}$, respectively), a difference also confirmed by the breath samples (110 vs. $123 \mathrm{~L}$, respectively). RR treatments did not differ $(P=0.53)$ in ruminal or breath $\mathrm{CO}_{2}$ emissions. Relationship between rumen and breath sources for $\mathrm{CH}_{4}$ emissions were better for LRR than for $\mathrm{HRR}$ treatment, suggesting that tracer performance is better at lower RR of $\mathrm{SF}_{6}$. Hypothesis is discussed in regards to the mechanism responsible for the relationship between RR and emission estimates. The use of permeation tubes with small range in release rates appears essential in animal experiments.

\section{T07. Nitrous oxide emissions from grassland in animal agriculture production systems in Uruguay} V. S. Ciganda*, J. Sawchik, A. Fontaine and L. Berger

In Uruguay, there is a growing awareness among scientists and the society about the impacts of grazing animals on nitrous oxide $\left(\mathrm{N}_{2} \mathrm{O}\right)$ emissions due to the importance of the bovine meat production sector in the national economy. The national inventory estimated that agricultural activities are responsible for more than $90 \%$ of $\mathrm{N}_{2} \mathrm{O}$ emissions being the animal agriculture sector is the main contributor with more than $80 \%$. These estimations are based on the Tier 1 or Tier 2 methodologies using IPCC default emission factors. However, it is well known that $\mathrm{N}_{2} \mathrm{O}$ emissions are very dependable on local factors such as type of pasture, soil properties, and climatic conditions. The general objective of the present study is to quantify $\mathrm{N}_{2} \mathrm{O}$ emissions from grassland systems in Uruguay and to compare the measured data with estimations using IPCC factors. The specific objectives are: 1 ) to quantify the effect of seasonal climate and pasture type on $\mathrm{N}_{2} \mathrm{O}$ emissions from bovine urine in Uruguay; and 2) to develop country specific $\mathrm{N}_{2} \mathrm{O}$ emission factors for bovine urine. Experiments are conducted on two sites, one on an exotic pasture (experiment 1 , with $>18 \%$ protein) and the other one on a native pasture (experiment 2 , with $<8 \%$ of protein). Stainless steel chambers were installed at each field site one month prior to treatment application. Chambers are $40 \mathrm{~cm}$ in diameter and are inserted $10 \mathrm{~cm}$ into the soil surface. A 25-cm-high stainless steel headspace cover with a thermal membrane insulation is used to form the chamber headspace. Two treatments were applied in March 2010, urine application and control, arranged in a complete randomized block design with four repetitions. Urine was collected from meat cows grazing the same 


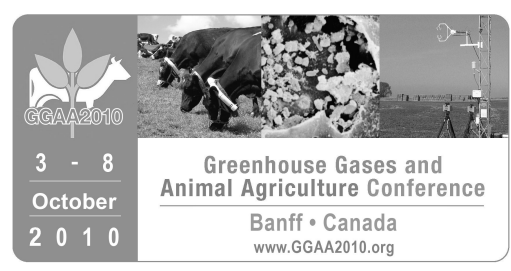

pasture where each experiment was installed. After treatment applications, gas samples were obtained from each chamber, and from ambient air, 22 and 18 times during 49 and 36 days in experiments 1 and 2, respectively. Gas samples were taken using a glass syringe at three 15 -min intervals. Pasture and soil $\mathrm{N}$ content as well as soil temperature and moisture were monitored on small plots besides each chamber during the sampling period. Gas samples were analyzed using a gas chromatograph. Results are in progress and will be presented and discussed in the poster.

\title{
T08. Can the $\mathrm{SF}_{6}$ tracer gas technique be used to accurately measure methane production from ruminally cannulated cattle?
}

\author{
T. Coates*, B. Farr*, K.A. Beauchemin* and S.M. McGinn*
}

An experiment was conducted to determine whether using ruminally cannulated cattle increases the variability associated with using the sulphur hexafluoride (SF6) tracer gas technique to measure methane $\left(\mathrm{CH}_{4}\right)$ emissions from cattle. Twelve beef cattle were surgically fitted with ruminal cannula (Bar Diamond, Parma, ID); $2 \mathrm{C}$ models (outer and inner flanges with opposite curvature; high leakage) were assessed and then the cannulas were replaced with $9 \mathrm{C}$ models (outer and inner flanges with the same curvature; minimum to moderate leakage) and the measurements were repeated (for a total of 45 cow-day measurements). A permeation tube containing $\mathrm{SF}_{6}$ was placed in the rumen of each animal several weeks before the measurement period. The air from around the nose/mouth of each animal was drawn through tubing into an evacuated canister (head). A second sample of air was drawn from outside the rumen, but near the cannula, into another canister (cannula). The canisters were removed daily, sampled, and analyzed for $\mathrm{SF}_{6}$ and $\mathrm{CH}_{4}$ concentrations. The $\mathrm{CH}_{4}$ emission was estimated following standard procedures (uncorrected), which assumes all the $\mathrm{SF}_{6}$ exits via the nose/mouth. The permeation $\mathrm{SF}_{6}$ release rate was then partitioned based on the proportion of the $\mathrm{SF}_{6}$ concentration measured in head versus cannula cannisters. The $\mathrm{CH}_{4}$ emissions at each site were calculated using the two release rates and the two $\mathrm{CH}_{4} / \mathrm{SF}_{6}$ concentration ratios. The head and cannula emissions were summed to obtain the total emission (corrected). The difference (corrected - uncorrected) in $\mathrm{CH}_{4}$ emission was attributed to the differences in $\mathrm{CH}_{4} / \mathrm{SF}_{6}$ ratio at the two exit locations. Estimates of uncorrected $\mathrm{CH}_{4}$ emissions were $\pm 10 \%$ of corrected emissions for $51 \%$ of the cow-day measurements, while $69 \%$ of the measurements were within \pm $20 \%$ of the corrected emissions. We concluded that using cannulated cattle introduces more variability into the $\mathrm{SF}_{6}$ technique; a technique that is already highly variable. In addition, in poorly ventilated barns, high $\mathrm{SF}_{6}$ background concentration results in the net $\mathrm{SF}_{6}$ concentration approaching zero and causes the $\mathrm{CH}_{4}$ emission to be over-inflated. Aerobic instability from cannula leakage can also affect methanogenesis in the rumen. Thus, use of cannulated animals when using the $\mathrm{SF}_{6}$ technique is not recommended. If cannulated cattle are used, the cannulas need to be tight fitting to minimize leakage and large animal numbers are needed to overcome the additional variability.

\section{T09. Evaluation of greenhouse gas monitoring equipment for a freestall dairy barn E. Cortus*, L. D. Jacobson*, B. Hetchler and A. J. Heber}

During the course of a two-year multi-pollutant monitoring study, we had the opportunity to evaluate simultaneous measurements of two major greenhouse gases, methane $\left(\mathrm{CH}_{4}\right)$ and nitrous oxide $\left(\mathrm{N}_{2} \mathrm{O}\right)$, using various gas analyzers. The in-field monitoring data, calibration results and equipment operation notes provide 


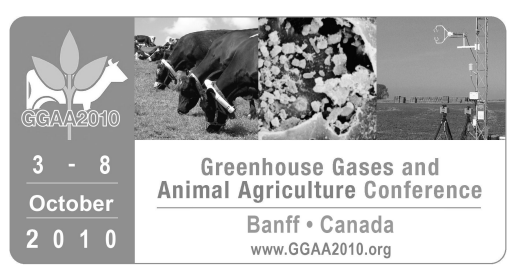

valuable insights into the value and applicability of these instruments for greenhouse gas measurements from freestall dairy barns. The INNOVA 1412 Photoacoustic Multigas Analyzer (Ballerup, Denmark) and Model 55C Direct Methane Non-Methane Hydrocarbon Analyzer (Thermo Environmental Instruments, Franklin, MA) provided side-by-side measurements of $\mathrm{CH}_{4}$ for over 16 mo. The INNOVA $1412 \mathrm{CH}_{4}$ calibration results showed a stable response of the analyzer over the monitoring period with the standard deviation of zero and span checks less than $5 \%$ of the applied span, but the accuracy reflected different internal factory calibration settings over time. The $55 \mathrm{C}$ calibration also showed a stable response over time, with the standard deviation of zero and span checks less than $3 \%$ of the applied span. For both instruments, we corrected the instrument output based on the instrument calibration records post-processing; thus, the accuracy of the instruments based on the calibration data was made nearly identical. During measurements in the freestall dairy barn, the difference between the two measurements was compared in conjunction with water vapor and other gases. The impact of the analyzer on the total methane emission rate estimation is presented. The INNOVA 1412 also measures nitrous oxide, and a side-by-side comparison was performed with the Model 320E (Teledyne API, San Diego, $\mathrm{CA})$ for over $3 \mathrm{mo}$. In-field and calibration data revealed the range of the 320E was too high for the near ambient $\mathrm{N}_{2} \mathrm{O}$ measurements in the freestall dairy barn. A Model 320EU (Teledyne API, San Diego, CA) was installed concurrently with the INNOVA 1412 for over 6 mo and showed significantly improved results over the Model 320E for this application. The INNOVA $1412 \mathrm{~N}_{2} \mathrm{O}$ measurement shows high stability during calibration. The 320EU shows some drift over time, but as with $\mathrm{CH}_{4}$, correcting both instruments' output based on the calibration data can result in nearly identical calibration data. During measurements of the freestall dairy barn air, differences in the output of the two analyzers were compared, especially as a function of carbon dioxide. For $\mathrm{N}_{2} \mathrm{O}$, a discussion is provided on the analyzer sensitivity required to capture differences between barn and ambient measurements (in conjunction with airflow rates) from a regulatory standpoint.

\section{T10. A simple method for pre-calibration storage of $\mathrm{SF}_{6}$ permeation tubes}

M.H. Deighton*, B.M. O'Loughlin, F. Buckley and T.M. Boland*

The long term storage of sulphur hexafluoride $\left(\mathrm{SF}_{6}\right)$ permeation tubes used for the ERUCT technique is desirable to increase the flexibility of post-manufacture tube handling. To be effective such storage must decouple the date of tube manufacture from the date of subsequent expiration due to gas loss. We hypothesise that release of $\mathrm{SF}_{6}$ gas could be effectively inhibited by freezing tubes at $-80^{\circ} \mathrm{C}$ without affecting their subsequent performance. Thirty permeation tubes with mean $\mathrm{SF}_{6}$ content of $3.081 \mathrm{~g}$ were blocked by $\mathrm{SF}_{6}$ weight and randomly allocated to treatment; i) immediate incubation at $39^{\circ} \mathrm{C}$, or ii) incubation at $39^{\circ} \mathrm{C}$ following 75 days storage at $-80^{\circ} \mathrm{C}$. The $\mathrm{SF}_{6}$ permeation rate at $39^{\circ} \mathrm{C}$ of all tubes was determined by weighing over a 50 day period. Storage of permeation tubes at $-80^{\circ} \mathrm{C}$ effectively inhibited the release of $\mathrm{SF}_{6}$ yet had no significant effect upon subsequent permeation rate at $39^{\circ} \mathrm{C}$. Deep frozen storage offers researchers improved flexibility in their handling of $\mathrm{SF}_{6}$ permeation tubes for the ERUCT technique.

\section{T11. Gaseous nitrogen emissions from Australian cattle feedlots}

O.T. Denmead*, D. Chen*, D. Rowell, Z. Loh, D.W.T. Griffith, T. Naylor*, M. Bai

Agriculture ranks second to stationary energy as a source of greenhouse gas emissions in Australia accounting for $16.3 \%$ of the national total. It is the main contributor of methane $\left(\mathrm{CH}_{4}\right)$ and nitrous oxide $\left(\mathrm{N}_{2} \mathrm{O}\right)$. The national inventory notes that the present growth in $\mathrm{N}_{2} \mathrm{O}$ emissions in Australia is driven in part by increased 


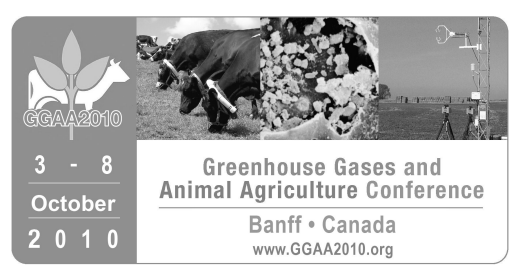

emissions from the manure of intensively managed livestock. At any one time, $2.4 \%$ of Australia's beef cattle are raised intensively in feedlots. Here, we report emissions from feedlots of the direct greenhouse gas $\mathrm{N}_{2} \mathrm{O}$ and the indirect greenhouse gases, ammonia $\left(\mathrm{NH}_{3}\right)$ and nitrogen oxides $\left(\mathrm{NO}_{\mathrm{x}}\right)$. Line-averaged concentrations of $\mathrm{N}_{2} \mathrm{O}$ and $\mathrm{NH}_{3}$ in the feedlots were measured continuously in campaigns of approximately $10 \mathrm{~d}$ in summer and winter at two feedlots in each of 2007 and 2008, using open-path laser systems and an open-path Fourier transform infrared spectrometer. In 2008, the summer campaign at one feedlot was extended for a further 6 months through autumn and winter by using a closed path chemiluminescence analyser to measure concentrations of $\mathrm{NH}_{3}$ and $\mathrm{NO}_{x}$. Emissions of the various gases were inferred through a software package, WindTrax (Thunder Beach Scientific), which simulates trajectories of "particles" backwards from the sensor using a backward Lagrangian stochastic dispersion model. Fluxes are calculated from the numbers of particle touchdowns inside and outside the source area. The overall mean of the $\mathrm{N}_{2} \mathrm{O}$ emissions and its standard deviation were $1.30 \pm 1.65 \mathrm{~kg} \mathrm{~N}_{2} \mathrm{O}-\mathrm{N} \mathrm{ha}^{-1} \mathrm{~d}^{-1}$. The corresponding figures for $\mathrm{NH}_{3}$ were $95 \pm 36 \mathrm{~kg} \mathrm{NH}_{3}-\mathrm{N} \mathrm{ha}^{-1} \mathrm{~d}^{-1}$, and for $\mathrm{NO}_{x}, 1.20 \pm 0.58 \mathrm{~kg} \mathrm{NO}_{x}-\mathrm{N} \mathrm{ha}^{-1} \mathrm{~d}^{-1}$. Mosier et al. (1998) suggest that about $1 \%$ of the $\mathrm{NH}_{3}$ and $\mathrm{NO}_{x}$ released into the atmosphere is eventually converted to $\mathrm{N}_{2} \mathrm{O}$ after deposition. Using that figure and the above emission data, we estimate a net contribution of $\mathrm{N}_{2} \mathrm{O}$ to the atmosphere from Australian cattle feedlots through emissions of $\mathrm{NH}_{3}, \mathrm{NO}_{x}$ and $\mathrm{N}_{2} \mathrm{O}$ itself of $0.42 \mathrm{t} \mathrm{CO}_{2}-\mathrm{e}, 75 \%$ of which comes from the indirect greenhouse gases $\mathrm{NH}_{3}$ and $\mathrm{NO}_{\mathrm{x}}$. These direct and indirect $\mathrm{N}_{2} \mathrm{O}$ emissions are substantial, more than half as large in terms of $\mathrm{CO}_{2}$-e as the emissions of $\mathrm{CH}_{4}$ from feedlots. Further whole-year studies are needed. As well, the ecological impact of the $99 \%$ of the deposited $\mathrm{N}$ remaining after emission as $\mathrm{NH}_{3}$ and $\mathrm{NO}_{\mathrm{x}}$ requires investigation.

\section{T12. Validation of Regional Methane Emission Estimates using Aircraft-based Flux Measurements} R. Desjardins*, M. Mauder, R. Srinivasan, E. Pattey*, D. Worth, X. Verge and D. Worthy

Agricultural methane emissions reported in Canada's national inventories are mainly from enteric fermentation and from manure storage systems. These emissions are presently calculated using a methodology developed by the Intergovernmental Panel on Climate Change but adapted to conditions in Canada. The methodology requires information on the number of animals, the type of animals, their diet, their age, the type of manure storage system, as well as many other ancillary data. Verification of methane emissions using standard micrometeorological techniques is sometimes done at the farm level, but these techniques frequently present some challenges because of complex wind conditions and geometry around the sources. A top-down methodology which is based on aircraft-based flux measurements of methane emissions will be presented. Methane flux measured at an altitude of $150 \mathrm{~m}$, along several flight tracks 8-20 km long located in the Prescott-Russell County in Ontario agreed within the measurement error to footprint adjusted flux estimates based on a bottom-up approach. With the new sensors that are now available for measuring methane concentration measurements it should be possible to improve the accuracy of the methane flux measurements. This should become an excellent tool to verify methane emission inventories.

\section{T13. Comparison of prediction of enteric methane production from lactating cows in Pennsylvania}

\section{J. D. Ferguson*, R. Munson, L. Baker, Z. Wu and Z. Dou}

Sixty-two dairy farms participated in a precision feeding project over a 1 to 3 year period. The project investigated control of $\mathrm{N}$ and $\mathrm{P}$ in feeding management. Herds were visited quarterly and samples of forages, feeds, TMR and feces were collected for the lactating dairy cows and analyzed for DM, CP, SP, ADFCP, NDFCP, 


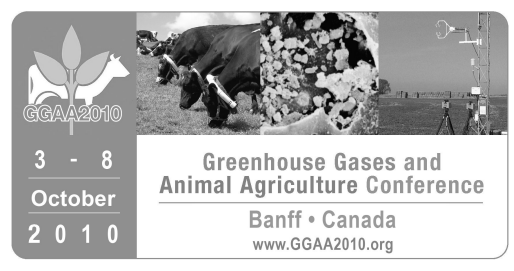

NDF, ADF, Sugar, Starch, Lignin, Fat, Ash, $\mathrm{Ca}, \mathrm{P}, \mathrm{Mg}, \mathrm{K}, \mathrm{Na}$ and $\mathrm{Cl}$. Production records were obtained through Dairy Records Management Services, Raleigh, NC. TMR and fecal data were merged with cow test day records to construct a data base which contained dietary and production information. Herds were composed of Jersey ( 3 herds) and Friesan Holstein ( 59 herds) breeds. Herd size ranged from 43 to 1165 cows, and production ranged from 5,100 kg to $13,000 \mathrm{~kg}$ of milk per cow per year. Models published in the literature were used to predict daily methane production per cow using test day production and dietary composition. Models used were those published by Blaxter and Clapperton (Br. J. Nutr. 19:1965), Moe and Tyrell (J. Dairy. Sci. 62:1979), Giger-Reverdin et. al. (Livest. Prod. 82:2003), Ellis et al. (7 prediction equations, J. Anim. Sci. 87:2009) and Dong et al. (IPCC Tier II, IPCC Guidelines for National Green Inventories). In addition a presumptive predictive model based on apparent diet digestibility and composition from rumen stoichiometry was explored. The model published by Moe and Tyrell was chosen as a comparison model based on work by Ellis et al. (Global Change Biology 2010). Mean model prediction across herds for cow/day enteric emission (moles/d):

\begin{tabular}{llllll} 
Model & Mean $\mathrm{CH}_{4}$ & $\mathrm{SD}$ & Min-Max & $\% \mathrm{GE}$ & SD \\
\hline Moe and Tyrell & 26.27 & 1.79 & $20.37-30.97$ & 5.78 & 0.22 \\
IPCC & 28.20 & 2.10 & $22.23-34.44$ & 6.20 & 0.26 \\
Giger-Reverdin & 40.16 & 3.05 & $27.44-45.21$ & 8.93 & 0.09 \\
Blaxter et al. & 28.99 & 1.28 & $22.79-31.03$ & 6.38 & 0.22 \\
Ellis_1 & 47.01 & 4.40 & $34.75-60.51$ & 17.78 & 1.17 \\
Ellis_2 & 17.78 & 1.17 & $13.91-20.23$ & 3.91 & 0.13 \\
Ellis_3 & 19.49 & 1.24 & $15.45-22.52$ & 4.29 & 0.17 \\
Ellis_4 & 22.81 & 1.55 & $16.26-25.35$ & 5.00 & 0.12 \\
Ellis_5 & 26.87 & 2.17 & $20.29-32.47$ & 5.91 & 0.26 \\
Ellis_6 & 18.41 & 2.81 & $9.77-23.15$ & 4.05 & 0.57 \\
Ellis_7 & 21.75 & 1.48 & $15.38-23.75$ & 4.78 & 0.07 \\
VFA_CH & 30.42 & 3.06 & $21.80-39.40$ & 6.69 & 0.49
\end{tabular}

Models sensitive to dietary composition and feed intake appear to be the preferred models for estimating enteric methane production from dairy herds. These predictions should be adjusted for the distribution of cow DIM and level of production to provide the most robust estimates.

\section{T14. Estimation of methane emission by dairy cows according to NIRS prediction of feces composition}

E. Froidmont*, C. Delfosse*, F. Dehareng, C. Martin, V. Decruyneaere, N. Bartiaux-Thill and P. Dardenne

Two groups of 4 dairy cows $\left(19.8 \pm 3.9 \mathrm{~L} \mathrm{~d}^{-1}\right)$ in the middle of their lactation $(180 \pm 30 \mathrm{~d})$ received two iso-NE

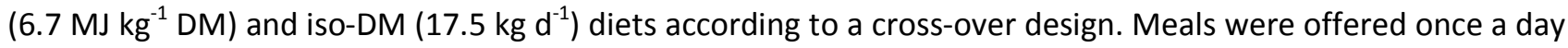
and milking occurred at 06:30 and 16:30. The first diet (' $G$ ') contained fresh grass ( $55 \%, 7$ weeks old), sugar beet pulps ( $20 \%)$, soya hulls $(10 \%)$, soybean meal $(15 \%)$ and minerals. The second one ('M') was composed by maize silage $(41 \%)$, meadow hay $(20 \%)$, ground maize $(13 \%)$, rapeseed meal $(15 \%)$, coconut meal $(5 \%)$, soybean meal (5\%), oil (1\%, coco/flaxseed: $50 / 50)$ and minerals. Both periods were composed by 21 -d for adaptation to diets, and 7-d for methane measurement, feces and urine collection. Methane emission was measured according to the $\mathrm{SF}_{6}$ method and reported to the milk production. Chromic sesquioxyde $\left(50 \mathrm{~g} \mathrm{~d}^{-1}\right)$ was used as DM tracer to estimate DM, N and NDF digestibilities. The feces composition (DM, Protein, NDF, ADF, Cellulose, 


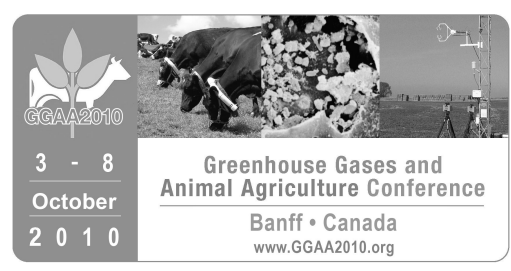

ADL) was analyzed by NIRS analysis (Rapid Contain Analyser XDS, FOSS, Denmark) after freeze-drying and grinding. On average, the methane emission was similar for $G$ and $M\left(29 \mathrm{~L} \mathrm{~kg}^{-1}\right.$ milk) but differed widely between animal $\times$ period (from 19 to $52 \mathrm{~L} \mathrm{~kg}^{-1}$ milk). The linear regression $\left(R^{2}=0.68, \mathrm{~s}=6.3\right.$ ) expressing the methane emission according to the feces components was as follows: Estimated $\mathrm{CH}_{4}\left(\mathrm{~L} \mathrm{~kg}^{-1}\right.$ milk $)=-367-1.19$ Milk production $\left(\mathrm{kg} \mathrm{d}^{-1}\right)+5.2$ Fecal protein (\%) + 10.3 Fecal NDF (\%) - 11.8 Fecal ADF (\%) + 9.12 Fecal ADL (\%). Moreover, it was possible to improve the precision of this estimation by adding a curvilinear tendency $\left(R^{2}=\right.$ 0.73), taking into account the fact that the feces composition did not allow to discriminate the animals producing more than $40 \mathrm{~L} \mathrm{~kg}^{-1}$ milk of $\mathrm{CH}_{4}$. The nutrient digestibilities did not improve the methane estimation. The relation should be confirmed in other feeding schemes but appeared as a good opportunity to predict the methane emission for lactating animals, in addition to the milk composition (see Delfosse et al., GGAA, 2010), but also for non lactating animals such as heifers or meat cattle. This project was subsidized by the 'Service public de Wallonie, Direction de la Recherche, Namur, Belgium', under the reference D31-1200.

\section{T15. The $\mathrm{SF}_{6}$ tracer technique for methane emission estimation: The normalized mixing ratio of $\mathrm{SF}_{6}$ across days of breath sampling}

J.I. Gere, K.E. Williams, R. Gratton, M.P. Juliarena and C. Pinares-Patiño*

The $\mathrm{SF}_{6}$ tracer technique is widely used for estimating methane $\left(\mathrm{CH}_{4}\right)$ emissions, yet the mechanisms by which $\mathrm{SF}_{6}$ mixes with fermentation gases and is released from the rumen are not clear. In particular, short time-scale irregularities in $\mathrm{SF}_{6}$ release seem to occur. This issue is investigated here, where data from an experiment involving daily and extended (across 5 and 10 days) breath sample collection periods were analysed concerning the mixing ratios of $\mathrm{SF}_{6}$. Eight rumen-fistulated non-lactating cows were housed in a facility enabling both natural and artificial ventilation and fed commercial silage to achieve a fixed and common daily feed intake of $6.4 \mathrm{~kg}$ dry matter per cow. Each cow was deployed with a fresh $\mathrm{SF}_{6}$ permeation tube and after a 10-day diet acclimatization, breath collections for $\mathrm{CH}_{4}$ emission estimation using the $\mathrm{SF}_{6}$ technique were conducted. Eight sample lines were fitted to collection harnesses ensuring that a common mix of breath sample was available to each sampling line. Four lines collected breath samples into stainless steel cylinders using a steel bearing ball flow regulator (UNICEN-Argentina system, ARG), while the remaining 4 lines collected samples into PVC yokes using a capillary system as a flow regulator (AgResearch-New Zealand system, NZL). Within each system and within the 10-day timeframe, common-source breath samples were collected either daily (ARG-1 and NZL-1), across two 5-day periods (ARG 1-5, ARG 6-10, NZL 1-5, NZL 6-10) or one 10-day period (ARG 1-10, NZL 1-10). Both the ARG 1-10 and NZL 1-10 collections were conducted in duplicate. It was assumed that during extended sample collection periods, the time-averaging of micrometeorological and other conditions influencing gas mixing ratios near the animal's snouts reduced the uncontrollable external variations. $\mathrm{As}^{\mathrm{SF}_{6}}$ release rates from each permeation tube are known and assumed to continue at the same rate in the rumen, a 'normalized' $\mathrm{SF}_{6}$ mixing ratio (NR) was found by subtracting the background mixing ratio from the observed values and dividing the difference by the release rate of each permeation tube. The NR for the ARG and NZL correlated well and the NR for the 5-day and 10-day extended sample collection periods were similar to those of average consecutive 5 and 10 daily sample collections, respectively. The between-animal variability of NR averaged over 10 days was larger than the within-animal variability of NR (35 vs. 10\%). This suggests that some factors related to individual animals may affect NR. However, the effects of pathways and release rates of $\mathrm{SF}_{6}$ from the animal could not be excluded, but if present, their effects should have been largely smoothed out by the timeaveraging effect of the extended sample collection periods. 


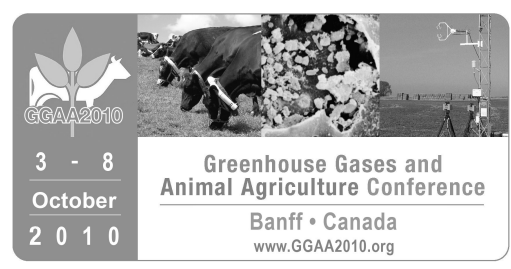

T16.Effect of Brachiaria dyctioneura replacement by the Acacia mangium arborea Acacia mangium on its in vitro ruminal fermentation and methane production

\author{
L. A. Giraldo V.*, M.J. Ranilla, M.L. Tejido and M.D. Carro
}

We analyzed the in vitro ruminal fermentation of four diets composed only by brachiaria grass (Brachiaria dictyoneura) (B100) or blended with acacia (Acacia mangium) in proportion 80:20 (B80), 70:30 (B70) and 60:40 (B60). $400 \mathrm{mg}$ of each diet with a mixture of buffer and rumen fluid have been incubated for $12 \mathrm{~h}$ and $24 \mathrm{~h}$ to determine the main fermentation parameters. After 12 hours of incubation, the final $\mathrm{pH}$ was higher $(\mathrm{P}<0.05)$ for diets B80, B70 and B60 regarding the one composed only by brachiaria (B100). There were no differences observed $(P>0.05)$ among diets in gas and methane production, ammonia concentration and total AGV production. Propionic acid production was higher $(P<0.05)$ with $B 60$ diet than with the rest of the diets, but butyric acid production was higher in the diet without acacia (B100) than in the others. After 24 hours of incubation, differences between diets were also observed. The final $\mathrm{pH}$ of incubation was lower $(\mathrm{P}<0.05)$ for $\mathrm{B} 100$ diet compared with the other diets, which agrees with the higher gas production $(P<0.05)$ for this diet. A decrease in methane production $(P<0.05)$ in all diets that included acacia was observed. This decrease was $5 \%, 10 \%$ and $14 \%$ for diets B80, B70 and B60, respectively. No effects of the inclusion of acacia in the diet on the acetic acid production were observed $(P>0.05)$, but there was a lower amount $(P<0.05)$ of butyric acid in the diet B60. Replacing bracharia by acacia caused an increase $(P<0.05)$ in the ammonia concentration, independent of the percentage of acacia inclusion, but also reduced DMO and DFND $(P<0.05)$ in comparison with the diet composed only by bracharia (B100). Depending on the type of diet, changes occur in the kinetics and in the extension of the in vitro ruminal fermentation. Including acacia in the diets composed by brachiaria could have potential in reducing methane production, but it also causes unfavorable changes in ruminal fermentation, such as degradability reduction of the diet due to the tannin contents.

T17. In vitro ruminal fermentation and methane assessment in various forage diets used in milk production in Colombia

\author{
L. A. Giraldo V.*, M.J. Ranilla, M.L. Tejido and M.D. Carro
}

We analyzed the in vitro ruminal fermentation of five diets composed only by kikuyu grass (K), Pennisetum clandestinum or by kikuyu grass mixed in 80:20 ratio with a commercial concentrated (KC), with black wattle (KA), Acacia decurrens, with maralfalfa grass (KM), Pennisetum sp, or with a mixture of $50 \%$ acacia and maralfalfa (KAM). $400 \mathrm{mg}$ were incubated with a mixture of butter and ruminal fluid for 12 and 24 hours. Then, the main fermentation parameters were identified. After 12 hours of incubation, the DMS was higher $(P<0.05)$ for KC treatments, followed by KM, KAM, and $\mathrm{K}$ and lower for KA. On the other hand, 24 hours after the incubation, the DMS was higher $(P<0.05)$ for $K M$ treatment compared to $K C$, $K$ and $K A M$. On the contrary, $K A$ treatment had the lowest DMS. For DFND after 12 hours of incubation, KC treatment caused an increase $(P<0.05)$ in 4 percentage units for $K$ treatments; 5.8 for KM, 3.5 for KAM and 9.4 for KA. When fermentation was extended to 24 hours, the observed increase in FDN degradation was more pronounced for the KC treatment, but KM treatment showed the same increase, followed by $\mathrm{K}$ and KAM. KA treatment had the lowest DFND. No differences among diets $(P>0.05)$ in the final $\mathrm{pH}$ of the incubation among treatments were observed, except for $K C$, which was more acid $(P<0.05)$. The gas amount was higher $(P<0.05)$ for $K C$ compared to the other treatments. KAM and KM treatments produced an increase $(\mathrm{P}<0.05)$ in $\mathrm{NH}_{3}$ concentration after 12 hours of incubation, and lower $\mathrm{NH}_{3}$ concentrations were found in $\mathrm{K}$ and $\mathrm{KC}$ treatments. The effects changed after 24 


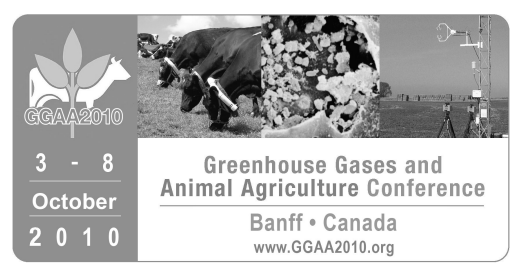

hours of fermentation, like this: the $\mathrm{pH}$ was higher $(\mathrm{P}<0.05)$ for treatments with acacia (KA, KAM). KC and KM treatments produced an increase in the volume of gas produced by fermentation $(P<0.05)$, which was reflected in AGV total production and in the proportion of the three main acids (acetic, propionic and butyric) but these AGV increases did not affect the relation acetic/ propionic. The treatment producing the lowest volume of gas, the lowest AGV total levels and the lowest concentration of the three main fatty acids, and methane was the one containing black wattle (KA), due to its tannin contents.

\section{T18. Measurement of greenhouse gas emissions from an anaerobic dairy waste lagoon using a backward Lagrangian Stochastic Model}

R. H. Grant* and M. T. Boehm

Greenhouse gas emissions from agricultural activities is a topic of increasing environmental importance. The objective of the study was to determine the variability in emissions of carbon dioxide $\left(\mathrm{CO}_{2}\right)$, nitrous oxide $\left(\mathrm{N}_{2} \mathrm{O}\right)$ and methane $\left(\mathrm{CH}_{4}\right)$ from a dairy waste lagoon across a range of air temperatures. Measurements of emissions were made during the Fall of 2009. Field measurements utilized a synthetic open-path sampling system with samples analyzed via color wheel correlation $\left(\mathrm{N}_{2} \mathrm{O}\right)$, flame ionization detection gas chromatography $\left(\mathrm{CH}_{4}\right)$ and non-dispersive infrared spectrometry $\left(\mathrm{CO}_{2}\right)$. These path-integrated concentration measurements and simultaneous 3-D sonic anemometer measurements were used as inputs to a backward Lagrangian stochastic (bLS) emissions model. Temporal variability in the emissions is related to weather conditions and farm operations. Results showed emissions of $\mathrm{CO}_{2}$ correlates with air temperature and is likely occurring in the aerobic zone of the lagoon. In general, $\mathrm{N}_{2} \mathrm{O}$ emissions were negligible, however emissions did occur when the lagoon levels were very low. In terms of effective $\mathrm{CO}_{2}$ equivalents, the $\mathrm{CH}_{4}$ emissions dominated the lagoon emissions.

\section{T19. Measuring methane emissions from cattle feedlots using Open-Path Eddy Covariance}

J. Ham* and K. Johnson*

Methane emissions from cattle feedlots in the High Plains of the United States could represent a large component of agriculture's greenhouse gas inventory. An eddy covariance system was used to quantify penscale $\mathrm{CH}_{4}$ fluxes from a commercial beef feedlot near Greeley, CO, USA, in the summer of 2010. A LI-7700 open path $\mathrm{CH}_{4}$ analyzer (Li-Cor Biosciences, Lincoln, NE, USA) was co-deployed with a sonic anemometer and open path $\mathrm{CO}_{2} / \mathrm{H}_{2} \mathrm{O}$ analyzer on an 8-m tower. Livestock weight, feed consumption, and pen surface conditions were also monitored in pens within the sampling footprint of the tower. Fluxes of ammonia were also measured using relaxed eddy accumulation. The performance of the $\mathrm{LI}-7700 \mathrm{CH}_{4}$ instrument and methods for computing fluxes from the time series were evaluated. Methane fluxes from the cattle pens were compared to existing $\mathrm{CH}_{4}$ emissions models for enteric and manure sources within cattle feedlots. 


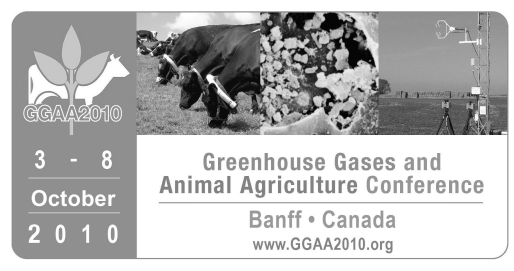

T20. System for quantitative measurements of methane emission from dairy cattle in Denmark A.L. Frydendahl Hellwing*, P. Lund*, M. Johannes* and T. Hvelplund

The methane emission from the digestive tract of cattle in Denmark accounts for $45 \%$ of the total methane emissions based on the assumption that $6 \%$ of the gross energy is metabolized to methane. There is a lack of newer experimental data available for Danish cattle; therefore, we have built a unit for quantitative measurements of methane, based on the principles for an open circuit system for indirect calorimetry. The chambers are transparent (polycarbonate) and open in the bottom, the inlet air is coming from the barn, and air-conditioning is a simple radiator to cool and condense for dehumidifying the chamber air. The system constitutes four chambers, flow meters and gas sensors for measuring methane, oxygen and carbon dioxide. The outside measurements of chambers are approximately $1.45 \times 3.9 \times 2.45 \mathrm{~m}$. Inside there is a platform to give the cows a comfortable laying area, space for the feeding bin and water bowl and draining of urine and feces. The air flow out of the chambers can be controlled individually by a motor controller. The outlet is in the top of the chambers through a filter box to reduce the dust content before the flow meter (Teledyne Hastings, delivered by Columbus instruments, Ohio, USA), which can measure flow rates up to 3000 standard liters per minute. After the air has passed the flow meter an air sample is drawn. A manifold, drying system, oxygen sensor, carbon dioxide sensor, methane sensor, and data program for management were delivered by Columbus instruments (Ohio, USA). Methane and carbon dioxide are measured by infra red sensors and oxygen by a paramagnetic sensor. The system has five channels; one for each chamber and one for measuring the background in the barn. Each measuring cycle takes $12.5 \mathrm{~min}$, flushing for two minutes and measuring a half minute. The recoveries of methane and carbon dioxide have been checked and found to be $100 \% \pm 10 \%$ ( $\mathrm{min}$ max). As chambers are placed in the barn the background level may vary and needs to be considered. The system has been working for four months and although we still work on improving the system, it seems to fulfill our expectations for a system for exact measurements of methane emission in dairy cows at the production level under close to natural in barn conditions, where cows' behavior can be expected to be natural.

\section{T21. Greenhouse gas emissions from naturally-ventilated dairy cow barns}

K.-H. Jeppsson*, N. M. Ngwabie, S. Nimmermark and G. Gustafsson

Emissions of greenhouse gases from two commercial dairy barns ( $A$ and $B$ ) with natural ventilation and daily manure removal systems were investigated. Barn A housed 164-195 Holstein dairy cows in a cubicle system with a conventional milking system. The cows in barn A produced 31-33 kg milk cow ${ }^{-1} \mathrm{~d}^{-1}$ and were fed on a mixed ration of grass silage, corn silage, straw, beet pulp, wheat, and protein premix. Barn B housed 108 Holstein dairy cows in a cubicle system with an automatic milking system. The cows in barn B produced $31.6 \mathrm{~kg}$ milk day ${ }^{-1}$ cow $^{-1}$ and were fed on a mixed ration of grass, straw and corn silage, with wheat and protein premix in concentrate feeders. Barn A had a slatted concrete floor and the manure gutters were scraped twice a day (0900 and 2100) into a storage tank outside the building. In barn B, the manure alley was a solid concrete floor which sloped towards a central urine gutter. The manure in this barn was scraped every hour during the daytime and every second hour at nighttime to a central gutter which was emptied twice a day (0600 and 1700). Continuous measurements were carried out in barns $A$ and $B$ from December to March and from February to May, respectively. The concentrations of $\mathrm{CH}_{4}, \mathrm{~N}_{2} \mathrm{O}$ and $\mathrm{CO}_{2}$ were measured using a photo acoustic multi-gas analyzer 1412 and a multiplexer 1309 (Lumasense Technologies SA, Ballerup, Denmark). The ventilation rates in the barns were calculated using $\mathrm{CO}_{2}$ mass balance. The activity of the cows in barn $\mathrm{B}$ was 


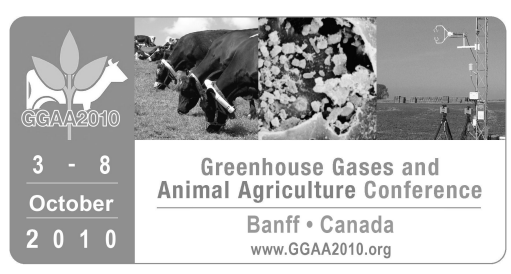

measured using passive infrared detectors and an analogue signal interface. The $\mathrm{CH}_{4}$ emissions were $12.0 \pm 4.5$ $\mathrm{g} \mathrm{LU}^{-1} \mathrm{~h}^{-1}$ in barn A and $10.8 \pm 2.3 \mathrm{~g} \mathrm{LU}^{-1} \mathrm{~h}^{-1}$ in barn $\mathrm{B}$ ( $\mathrm{LU}=500 \mathrm{~kg}$ animal weight). In both barns the $\mathrm{CH}_{4}$ emission showed a diurnal variation with two maxima coinciding with the periods of manure removal. The magnitude of the diurnal variations was 0.13-4.21 and 0.56-1.96 of the diurnal mean in barns $A$ and $B$, respectively. The emission of $\mathrm{CH}_{4}$ was highly correlated to the animal activity $\left(\mathrm{R}^{2}=0.87\right)$, where $\mathrm{R}^{2}$ is the coefficient of determination. The concentrations of $\mathrm{N}_{2} \mathrm{O}$ were mostly below the detection limit in both barns.

\section{T22. Methane production in growing and finishing pigs in Southern China}

Z.-y. Ji, Z. Cao, X.-d. Liao*, Y. -b. Wu, J. B. Liang* and B. Yu

Methane from enteric fermentation and manure decomposition as the result of extensive livestock production has been blamed to cause enormous damage to the environment. Research on methane production from enteric fermentation has mainly focused on ruminant livestock. On the other hand, due to its huge global population, methane production from enteric fermentation in pigs cannot be neglected. This experiment estimated methane production from enteric fermentation of growing and finishing pigs in Guangdong Province, China. Five $60 \mathrm{~kg}(59.58 \pm 1.15 \mathrm{~kg})$ and five $90 \mathrm{~kg}(89.55 \pm 0.85 \mathrm{~kg})$ female pigs (Duroc $\times$ Landrace $\times$ Large Yorkshire) randomly selected from a commercial farm in Shenzhen, Guangdong, China were used in this experiment. The pigs were transferred into individual respiration cages $(2.0 \mathrm{~m} \times 1.0 \mathrm{~m} \times 1.2 \mathrm{~m})$ located in the same farm and continued to receive either the commercial grower or finisher diets, similar to those for the non-experimental animals in the farm. After 3 days of adaptation in the respiration cages, measurements of gaseous exchange were made for the 10 pigs simultaneously. The air in each chamber was extracted by an electrical pump at a known speed (measured using a flow meter) and a portion of the extracted air was collected into a 3-cubic meter gas collection bag (Nanjing Shenglu Scientific Co. LTD.). At $4 \mathrm{~h}$ intervals, $1 \mathrm{~L}$ of the collected air was sampled into the gas sampling bag. The process was repeated 6 times to determine the total volume of air extracted per day. Methane concentration of the sampled air was determined using Gas Chromatography. The above procedure was carried out over three days as three replications for each animal. The results showed that the average methane production was $1.13 \pm 0.44 \mathrm{~g}$ and $2.01 \pm 0.60 \mathrm{~g} \mathrm{day}^{-1}$, equivalent to 18.97 and $22.45 \mathrm{mg} \mathrm{day}^{-1} \mathrm{~kg}^{-1} \mathrm{BW}$, respectively, for the $60 \mathrm{~kg}$ grower and $90 \mathrm{~kg}$ finisher. Based on the above values, the estimated annual methane production from each $60 \mathrm{~kg}$ and $90 \mathrm{~kg}$ pig was $0.41 \mathrm{~kg}$ and $0.73 \mathrm{~kg}$, respectively.

\section{T23. Characterization of daily variation of stable isotope ratio of methane from ruminant}

T. Kondo*, K. Yamada, I. Nonaka, O. Enishi, K. Higuchi, T. Shinkai* and N. Yoshida

Enteric methane $\left(\mathrm{CH}_{4}\right)$ formations in ruminants are considered as a major contribution to the global anthropogenic $\mathrm{CH}_{4}$ [e.g. Steinfeld et al., 2006]. The isotopic analysis of $\mathrm{CH}_{4}$ is useful to estimate global $\mathrm{CH}_{4}$ budgets [e.g. Levin et al., 1993]. For studies applying the isotopic information to the budget estimation, determination of an accurate global average of isotopic value for each $\mathrm{CH}_{4}$ source (a representative source signature) is an important step. For the ruminant source, several studies on the carbon isotope ratio $\left(\delta^{13} \mathrm{C}\right)$ of $\mathrm{CH}_{4}$ have reported to be -65 -75\%o [Rust 1981; Levin et al., 1993; Schulze et al., 1998; Bilek et al., 2001; Klevenhusen et al., 2010]. A few studies on the hydrogen isotope ratio $(\delta D)$ of $\mathrm{CH}_{4}$ have reported to be -290 360\% [Wahlen et al., 1989; Levin et al., 1993; Bilek et al., 2001]. These broad isotopic values make it difficult to 


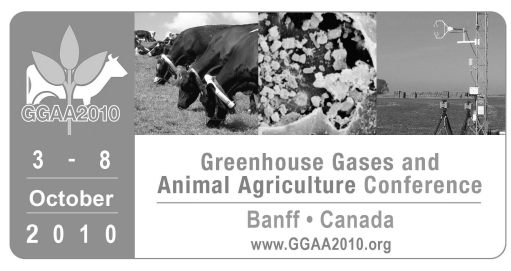

determine the representative source signature of ruminant source. Therefore additional systematic measurements are needed along with study of the processes that control the isotopic values of $\mathrm{CH}_{4}$ emitted from ruminant source. The purpose of this study is to obtain additional isotopic data and the knowledge about factors controlling isotope ratios of $\mathrm{CH}_{4}$ by monitoring of $\mathrm{CH}_{4}$ from ruminants for 24 hours using the open circuit respiration chamber in National Institute of Livestock and Grassland Science. Four Holstein heifers (initial body weight $=196 \mathrm{~kg})$ were kept under constant temperature $\left(30^{\circ} \mathrm{C}\right)$ and relative humidity $(60 \%)$ from September to December 2009. We set up 3 treatment periods that fed a certain amount of Concentrate pellet and a full feeding of three kinds of different quality Italian ryegrass on 10:00 and 16:30 each day. We put heifers in the open circuit respiratory chamber and got the gas samples for 24 hours. We measured the concentration of $\mathrm{CH}_{4}, \mathrm{CO}_{2}$ and hydrogen gases, and $\delta^{13} \mathrm{C}$ and $\delta \mathrm{D}$ of $\mathrm{CH}_{4}$ and feeds and $\delta \mathrm{D}$ of drink water. Temporal variation of $\delta^{13} \mathrm{C}$ of $\mathrm{CH}_{4}$ was $\sim 10 \%$ or 24 hour sampling periods. This variation might be related to ? ${ }^{13} \mathrm{C}$ and degradation rate of components of feeds such as soluble protein, carbohydrate, especially cellulose. Temporal variation of $\delta \mathrm{D}$ of $\mathrm{CH}_{4}$ was $\sim 15 \%$ for 24 hour sampling periods.

\section{T24. Enteric methane emission rates determined by the $\mathrm{SF}_{6}$ tracer technique: Temporal patterns and averaging times}

K. R. Lassey*, C. S. Pinares-Patiño*, R. J. Martin, G. Molano* and A. M. S. McMillan

The $\mathrm{SF}_{6}$ tracer technique has been widely applied to determine methane $\left(\mathrm{CH}_{4}\right)$ emission rates by ruminant animals since its development in the mid-1990s. It remains the only viable method for determining emission rates from individual animals while freely grazing. Essential ingredients of the method are, for each participating animal: (1) pre-insertion into the rumen of a source of sulphur hexafluoride $\left(\mathrm{SF}_{6}\right)$ with known release rate; and (2) collection of a "breath" sample near the nose and mouth into a pre-evacuated canister carried by or hung near the animal, to be analysed off-line for $\mathrm{CH}_{4}$ and $\mathrm{SF}_{6}$. Breath samples are accumulated over an "averaging time" of usually $24 \mathrm{~h}$, so that $\mathrm{CH}_{4}$ emission rates are daily averages. The choice of $\mathrm{SF}_{6}$ as a tracer is motivated by its biological inertness and its physical properties that result in very low detection limits (better than $1 \mathrm{SF}_{6}$ molecule per $10^{12}$ ), enabling release rates of a few tens of microlitres per hour to be sustained for many months by an initial $\mathrm{SF}_{6}$ charge of order $1 \mathrm{~g}$. It has been argued that any variability in retention times of $\mathrm{SF}_{6}$ in the digestive tract could result in non-uniform $\mathrm{SF}_{6}$ collection rates in the breath sample, thereby introducing a source of variability into inferred $\mathrm{CH}_{4}$ emission rate. Such technique-induced variability has the potential to explain reports of a greater variability in $\mathrm{CH}_{4}$ emission rates deduced with this technique when compared with the variability based on whole-animal enclosure techniques. In this study a novel automated gas chromatography system continuously samples the breath of each of nine housed sheep for six days, isolating successive 20-minute breath accumulations and analysing them for $\mathrm{SF}_{6}$ and $\mathrm{CH}_{4}$. We find that not only is $\mathrm{SF}_{6}$ not excreted into the breath stream at a uniform rate, but its daily pattern of excretion is strongly correlated with that of $\mathrm{CH}_{4}$, suggesting that some $\mathrm{SF}_{6}$ is retained within the digestive tract to be later ventilated with the fermentation gases following feeding. By combining data in different ways $\mathrm{CH}_{4}$ emission rates are estimated over successive averaging times ranging from three hours to six days, enabling the role of averaging time to be assessed. Emission rate estimates are surprisingly consistent among successive periods and across all averaging times, but inter-period variability is highest for sub-day averaging times as expected. 


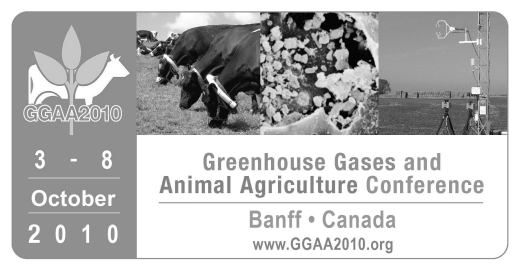

\title{
T25. Emissions of ammonia and greenhouse gases from dairy production facilities in Idaho
}

\author{
A. Leytem*, D. L. Bjorneberg and R. S. Dungan
}

Idaho is one of the top four milk producing states in the United States. While this commodity group is a very valuable part of the economy, there is concern over the impact of these production facilities on the generation of ammonia $\left(\mathrm{NH}_{3}\right)$ and greenhouse gases (methane, $\mathrm{CH}_{4}$; carbon dioxide, $\mathrm{CO}_{2}$; nitrous oxide, $\mathrm{N}_{2} \mathrm{O}$ ) which are linked to air quality degradation and global warming. To gain a better understanding of the on-farm emissions from these production facilities, we monitored both cattle housing and manure management systems on dairies in southern Idaho. Emissions estimates were determined utilizing inverse dispersion modeling. Emissions from animal housing on a per cow per day basis ranged from 0.03 to $0.25 \mathrm{~kg} \mathrm{NH}_{3}, 0.10$ to $0.93 \mathrm{~kg}$ $\mathrm{CH}_{4}, 8$ to $55 \mathrm{~kg} \mathrm{CO}_{2}$ and 0 to $46 \mathrm{~g} \mathrm{~N}_{2} \mathrm{O}$. Emissions from wastewater ponds on a square meter per day basis ranged from 0.25 to $9.4 \mathrm{~g} \mathrm{NH}_{3}, 19.4$ to $231 \mathrm{~g} \mathrm{CH}_{4}, 289$ to $855 \mathrm{~g} \mathrm{CO}_{2}$ and 0 to $1.28 \mathrm{~g} \mathrm{~N}_{2} \mathrm{O}$. Emissions from composting dairy manure on a square meter per day basis ranged from 0.34 to $3.45 \mathrm{~g} \mathrm{NH}_{3}$, 2.6 to $35.2 \mathrm{~g} \mathrm{CH}_{4}$, 204 to $1,263 \mathrm{~g} \mathrm{CO}_{2}$ and 0.12 to $2.67 \mathrm{~g} \mathrm{~N}_{2} \mathrm{O}$. Emissions of $\mathrm{NH}_{3}, \mathrm{CH}_{4}$ and $\mathrm{CO}_{2}$ had strong diurnal trends with emissions tending to be lower in the evening and early morning and then increasing throughout the day, while $\mathrm{N}_{2} \mathrm{O}$ emissions tended to be somewhat consistent. The opposite trend in $\mathrm{CH}_{4}$ emissions at the wastewater pond on the freestall dairy was observed during the fall where emissions tended to be lowest in the evening and early morning and then increase throughout the day. In the cattle housing area, $\mathrm{NH}_{3}$ emissions tended to be lower in the winter and greater in spring and fall, while $\mathrm{CH}_{4}$ emissions tended to be the greatest in the winter and spring. In the manure storage areas, $\mathrm{NH}_{3}$ emissions tended to be consistent over the measured periods, while $\mathrm{CH}_{4}$ emissions tended to increase from spring to fall as average temperatures increased. Emissions of $\mathrm{N}_{2} \mathrm{O}$ from all sectors seemed to be limited and did not demonstrate any clear seasonal trend. This dataset elucidates the importance of accounting for daily and seasonal variation in on-farm emissions as well as providing baseline emission factors for these dairy production facilities.

\section{T26. Use of spot samples from ruminant breath to quantify the methane production}

\section{J. Madsen*}

Quantification of the methane production from a ruminant requires measurement of the methane concentration as well as the volume of air originating from the ruminant. The concentration of methane and other gasses can be measured using different equipment such as photo acoustic analyzers, gas chromatographs or Fourier Transform IR (FTIR). It is more difficult to measure the volume of the air. Sulfuric hexafluoride ( $\mathrm{SF}_{6}$ ) has been used as tracer in many previous studies, but is a greenhouse gas itself and it has shown not to be very reliable (Pinares-Patino and Clark, 2008). Another approach is based on the cow's $\mathrm{CO}_{2}$ production (Madsen et al., 2010). The method uses $\mathrm{CO}_{2}$ as internal marker. The $\mathrm{CO}_{2}$ excretion can be calculated by using different data relating the animals $\mathrm{CO}_{2}$ excretion and heat production. When measuring in a livestock building with several cows, the $\mathrm{CO}_{2}$ production can be calculated as $185 \mathrm{ICO}_{2}$ per heat producing unit $(1 \mathrm{HPU}=1000 \mathrm{~W} / \mathrm{h})$ and the number of HPU can be calculated from the body weight (BW) and milk production of the cows (Pedersen et al. 2008). When measuring individual animals, the heat production can be estimated as above or from information on individual intake of metabolizable energy (ME) minus the energy in milk and BW gain. One litre of carbon dioxide is formed per $21.75 \mathrm{~kJ}$ heat produced (Madsen et al., 2010). In preliminary experiments with individual dairy cows in Automatic Milking System (AMS) and with kangaroos the concentration of $\mathrm{CO}_{2}$ and $\mathrm{CH}_{4}$ has been measured using portable equipment: GASMET 4030 (Gasmet Technologies Oy, Pulttitie 8A, FI-00880 Helsinki, Finland). When measuring in AMS it is considered that only insignificant amounts of $\mathrm{CO}_{2}$ and $\mathrm{CH}_{4}$ are excreted 


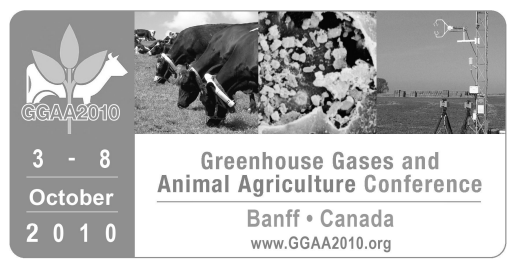

by other routes than the breath. Using $\mathrm{CO}_{2}$ in the individual spot sample of breath as marker for the amount of breath has shown that 1 ) the number of samples can be reduced dramatically when measuring the methane production in animal buildings (Bjerg et al. 2010), 2) the variation between dairy cows gives hope for selection for low methane production (Lassen et al., 2010), 3) Kangaroos produce only about $1 / 4$ of the methane compared to ruminants when fed comparable diets (Madsen et al., 2010) and 4) the method seems perfect to use in an AMS when different feeds or supplements are going to be tested for methane production.

\title{
T27. Nitrous oxide and methane emissions from a large beef feedlot
}

\author{
J.J. Michal*, E. Allwine, S. Spogen, S. Pressley*, P. O'Keeffe, B. K. Lamb and K.A. Johnson*
}

Measurements of nitrous oxide $\left(\mathrm{N}_{2} \mathrm{O}\right)$ emissions from ruminant CAFO's are limited so a study was conducted in spring 2009 to measure $\mathrm{N}_{2} \mathrm{O}$ and $\mathrm{CH}_{4}$ emissions from a large beef feedlot. The parts of the operation (animals, pens, manure piles and lagoons) that contribute to whole system emissions were measured. Emissions from the animal/pen subplot of the CAFO were measured from an area that contained $225 \mathrm{hd}$ of $400 \mathrm{~kg}$ growing and finishing steers. Nitrous oxide concentrations measured at seven points over $130 \mathrm{~m}$ along an access lane within the feedlot were variable and, at times, indistinguishable from ambient concentrations. During one observation period when the ambient temperature was $21^{\circ} \mathrm{C}$, relative humidity was $17.3 \%$, and pens were being cleaned, $\mathrm{N}_{2} \mathrm{O}$ concentrations averaged $396 \pm 16 \mathrm{ppb}$. During this same time period, $\mathrm{CH}_{4}$ concentrations averaged $4.7 \pm$ $0.1 \mathrm{ppm}$. After a rain event $(3.2 \mathrm{~cm}$ over $3 \mathrm{~d})$ when the pens had significant standing water and ambient temperature and relative humidity were $17^{\circ} \mathrm{C}$ and $31 \%$, respectively, concentrations of $\mathrm{N}_{2} \mathrm{O}$ increased to $443 \pm$ $13 \mathrm{ppb}$ and $\mathrm{CH}_{4}$ concentrations averaged $3.7 \pm 0.1 \mathrm{ppm}$. As pens dried and temperatures warmed above $23^{\circ} \mathrm{C}$, $\mathrm{N}_{2} \mathrm{O}$ concentrations decreased to ambient levels. In comparison, $\mathrm{CH}_{4}$ concentrations increased to $4.7 \mathrm{ppm}$ on $\mathrm{d}$ 2 following the rain event and decreased to $3.3 \mathrm{ppm}$ thereafter. Nitrous oxide concentration measurements downwind from a manure stack and runoff lagoon were approximately 380 and $\mathrm{CH}_{4}$ concentrations averaged $1.9 \mathrm{ppm}$ and $2.3 \mathrm{ppm}$ from the manure compost and lagoon, respectively. Nitrous oxide and $\mathrm{CH}_{4}$ fluxes will be calculated using the WindTrax inverse dispersion model. These data provide the information needed to derive accurate emission factors and design mitigation strategies.

T28. The $\mathrm{SF}_{6}$ tracer technique for estimation of methane emissions from cattle, effect of PVC and stainless steel sample collection devices

G. Molano*, K. Williams, J. I. Gere, R. Graton, M. P. Juliarena and C. S. Pinares-Patiño*

The estimation of methane $\left(\mathrm{CH}_{4}\right)$ emissions from ruminants using the sulphur hexafluoride $\left(\mathrm{SF}_{6}\right)$ tracer technique involves the use of sample collection devices made of stainless steel (SS cylinders) or polyvinyl chloride ( $\mathrm{PVC}$ yokes), but the relative efficiency of these containers in maintaining the $\mathrm{CH}_{4}$ and $\mathrm{SF}_{6}$ concentrations in the collected samples is unknown. Using the schedule of an ongoing experiment, which comprised 2-day $\mathrm{CH}_{4}$ emission measurements involving eight cows and two respiration chambers (16 cowdays), samples of inflow and outflow air streams of respiration chambers were collected over 5 cow-day $\mathrm{CH}_{4}$ measurements. The samples were simultaneously collected into both SS and PVC containers over approximately 24-h integrated periods, in conjunction with the respiration chamber measurements. At the time of respiration chamber measurements, the cows had $\mathrm{SF}_{6}$ permeation tubes deployed in their reticulo- 


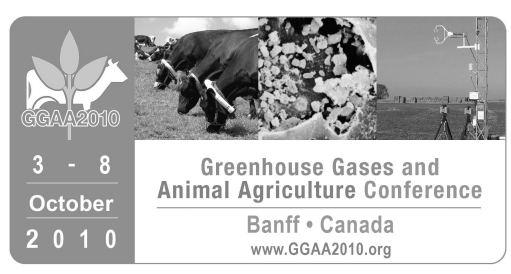

rumen. The inflow and outflow samples collected were analysed by gas chromatography following 80 days storage. It was found that $\mathrm{CH}_{4}$ and $\mathrm{SF}_{6}$ concentrations in the samples collected into the PVC containers were on average $18 \%$ lower $(\mathrm{P}<0.01)$ than those collected into the SS containers, but the collection devices did not differ $(\mathrm{P}>0.05)$ in the calculated $\mathrm{CH}_{4} / \mathrm{SF}_{6}$ ratio $(264,000 \mathrm{v} / \mathrm{v})$ or the estimated daily $\mathrm{CH}_{4}$ emission $\left(123 \mathrm{~g} \mathrm{cow}^{-1}\right)$. The reasons for the relative inefficiency of the PVC container compared to that of stainless steel containers in maintaining the concentration of the $\mathrm{CH}_{4}$ and $\mathrm{SF}_{6}$ gases are unknown. Nevertheless, this issue did not affect the estimated $\mathrm{CH}_{4}$ emissions in this experiment.

\section{T29. Enteric methane emissions from dairy cows fed different proportions of highly digestible grass silage \\ M. Patel*, R. Danielsson*, G. Börjesson, A. D. Iwaasa*, E. Spörndly, E. Wredle* and J. Bertilsson*}

Enteric methane $\left(\mathrm{CH}_{4}\right)$ emissions were measured in a duplicated $3 \times 3$ Latin square design from six lactating rumen-fistulated Swedish Red Breed (SRB) dairy cows using the sulfur hexafluoride $\left(\mathrm{SF}_{6}\right)$ tracer technique. Three diets with different proportions of highly digestible grass silage/concentrates were fed: 500/500, $700 / 300$ or $900 / 100 \mathrm{~g} \mathrm{~kg}^{-1}$ dry matter (DM) of total DM. Samples of rumen fluid were collected during the measurement period to investigate the relation between $\mathrm{CH}_{4}$ yield and production of ruminal volatile fatty acids (VFA). Feces samples were collected for determination of digestibility of the diets. The grass silage was based on timothy (Phleum pratense L.) and meadow fescue (Festuca pratensis L.). The composition of the silage (DM basis) was: metabolizable energy (ME) $11.5 \mathrm{MJ} \mathrm{kg}^{-1} \mathrm{DM}$, crude protein (CP) $195 \mathrm{~g} \mathrm{~kg}^{-1}$, neutral detergent fibre (aNDFom) $405 \mathrm{~g} \mathrm{~kg}^{-1}$ and DM 350 $\mathrm{g} \mathrm{kg}^{-1}$. Compositions of the total diets (on DM basis) were for respective diets (500/500, 700/300 and 900/100): aNDFom 299, 341 and $383 \mathrm{~g} \mathrm{~kg}^{-1}$, starch 173, 105 and $35 \mathrm{~g} \mathrm{~kg}^{-1}$ and organic matter digestibility (OMD) 758, 751 and $742 \mathrm{~g} \mathrm{~kg}^{-1}$. Daily dry matter intake (DMI) was restricted and averaged $15.2,15.5$ and $15.9 \mathrm{~kg}$ for the three diets, respectively. No significant differences in $\mathrm{CH}_{4}$ emissions were found between diets $(P>0.32)$. Average $\mathrm{CH}_{4}$ emissions in absolute values were 279,300 and $321 \mathrm{~g}$ day ${ }^{-1}$ animal $^{-1}$, respectively. These levels were within the range predicted by different theoretical models based on feed characteristics. Methane emissions per kg DMI did not differ $(P>0.36) ; 18.5,20.0$ and $20.7 \mathrm{~g} \mathrm{~kg}^{-1} \mathrm{DMI}^{\text {in }}$ the respective diet. Ruminal VFAs were $0.582,0.591$ and $0.589 \mathrm{~mol} \mathrm{ml}^{-1}$ VFA of acetic acid, $0.226,0.229$ and $0.236 \mathrm{~mol} \mathrm{ml}^{-1}$ VFA of propionic acid and for butyric acid $0.119,0.107$ and $0.100 \mathrm{~mol} \mathrm{~m}^{-1} \mathrm{VFA}$ in the respective diet. There was a small, but significant $(P<0.01)$ difference in butyric acid in the 500/500 diet. The results of enteric $\mathrm{CH}_{4}$ measurements and analyses of ruminal VFA indicate that enteric $\mathrm{CH}_{4}$ emissions from diets with a high forage proportion are comparable to diets with equal proportions of forage/concentrate (on a DM basis) provided that the forage is composed of highly digestible grass silage.

\section{T30. Design and construction of modular (and mobile) open-circuit chambers for monitoring gas emissions of large animals}

N. Peiren*, B. Sonck, J. M. Castro, D. DeBrabander, V. Fievez and S. De Campeneere

Methane emissions in ruminants are mainly effected by enteric fermentation. The latter process is influenced by feed and genetic predestination. To investigate mitigation strategies and to estimate ruminant methane emission, six open-circuit chambers for large ruminants are developed. Each chamber can house one large ruminant (dairy or beef cattle), but can also be adapted to house smaller ruminants and monogastric animals. 


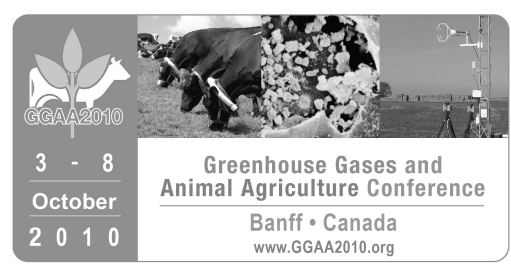

The chambers are constructed from polypropylene copolymer panels with an internal frame of stainless steel. The panels are welded together to make the construction airtight. Each chamber has three doors: one lateral door for milking dairy cows, one entrance door in the back and one front door for feed supply and cow exit. To reduce the feeling of captivity and improve visual contact between cows natural lighting in the chambers was maximized with windows in each door and in the side panels. The lying and standing stall is raised and equipped with a soft rubber mat. The feces and urine are collected in a removable basin installed behind the cow and under a slatted grid. A removable feeding trough is installed in front of the stall. The chambers can be moved with a forklift. The mechanical ventilation system is a central flow system to regulate the airstreams with one central exhaust fan for the six chambers. Each chamber air inlet is located in the lower panel of the front door. The air outlet is a $35 \mathrm{~cm}$ module with an integrated impeller and control valves and is installed in the roof panel at the rear end. The chambers will be grouped two by two and are each other's mirror image. This layout is the most space efficient and makes a modular construction of the ventilation system possible. Besides methane, other gases like carbon dioxide, nitrous oxide and ammonia can be continuously measured to calculate the gas emissions over certain time intervals and to monitor fluctuations over time.

\section{T31. A new procedure for soil-atmosphere trace gas flux estimation with static chambers}

S. O. Petersen*, A. R. Pedersen and K. Schelde

Quantifying trace gas emissions from contrasting manure materials or application methods require side-by-side comparisons where identical soil and climatic conditions can be assumed. For such investigations static chambers continue to be the method of choice, but trace gas accumulation is often not linear. A new procedure (HMR) for soil-atmosphere trace-gas flux estimation with static chambers is introduced, which classifies data series into three categories (i.e., nonlinear and linear concentration change over time, or concentration data within the range of experimental error from sites with no significant flux). A set of statistical data are provided for all three types of flux estimates. The particular nonlinear model has an exponential curvature which generally fits nonlinear static chamber concentration data well. HMR can be shown, mathematically, to be robust against horizontal gas transport through the soil or through leaks in the chamber. A total of 188 data series of nitrous oxide $\left(\mathrm{N}_{2} \mathrm{O}\right)$ fluxes from a two-year slurry application study were analyzed using HMR. In 2007 two injection methods were compared with trailhose application using untreated pig slurry, while in 2008 injection and trailhose application of untreated, digested and separated slurry were compared. On average $50 \%$ of all data series were non-linear, with an average flux increase over linear regression of 59\%. Non-linearity occurred across the entire range of fluxes observed $\left(0-1000 \mathrm{mg} \mathrm{N}_{2} \mathrm{O} \mathrm{m} \mathrm{m}^{-2}\right)$. Despite significant differences in the redistribution of slurry $\mathrm{C}$ and $\mathrm{N}$, there was no evidence for a relationship between nonlinearity and slurry type or application method. The HMR procedure has been implemented as a free add-on package for the free software R, available for download through CRAN (http://www.r-project.org).

\section{T32. Estimates of methane emissions from cattle and sheep and a range of management systems using open-path FTIR measurement technology \\ F. Phillips*, D. Griffith, M. Bai, T. Naylor* and F. Jones*}

Mitigation strategies for methane emissions are required to reduce the contribution of agriculture to a nation's greenhouse gas emissions. To confirm a mitigation strategy is effective requires measurement techniques with sufficient precision to detect the difference in emission strengths. The Open Path FTIR (OP-FTIR) system has 


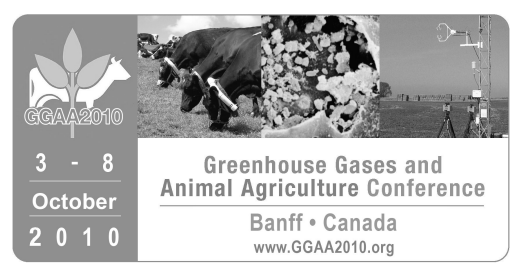

been designed to measure $\mathrm{CH}_{4}, \mathrm{CO}_{2}, \mathrm{NH}_{3}$ and $\mathrm{N}_{2} \mathrm{O}$ emissions from agricultural systems. The system consists of an FTIR spectrometer, a cryo-cooled detector and a modified Cassegrain telescope. An infrared beam reflected from a mirror array 100 to $150 \mathrm{~m}$ from the analyser allows for a line averaged analysis of the intervening atmosphere. The backward Lagrangian stochastic (BLS) model often used to retrieve emission strengths from the line concentrations is not ideal for grazing animals as it assumes an even source distribution. An alternate method utilizes a tracer gas released at a known rate close to the mouth of the animal. The two gases are carried by the same wind turbulence to the OP-FTIR system where they are measured simultaneously. The $\mathrm{CH}_{4}$ emission rate is inferred from the tracer gas flow rate and the two gas concentrations, with a herd averaged emission value provided, typically, every 3 min and reported as an hourly average. The feasibility of the OPFTIR measurement system to distinguish between mitigation strategies is influenced by the precision in estimating the tracer gas emission rate; instrument precision in measuring the gas concentrations; enhancement in $\mathrm{CH}_{4}$ and tracer gas concentrations; and uncertainty in the local background concentrations. Under supplementary feeding, animal intensity can be maximized, increasing the gas plume concentration at the line sensors. However under grazing conditions animal intensity is limited by pasture requirements. The emissions from 60 steers on increasing supplementary feed intake $\left(4.26,7.71\right.$ and $\left.9.29 \mathrm{~kg}_{\text {animal }}{ }^{-1} \mathrm{~d}^{-1}\right)$ were estimated using the OP-FT IR tracer system as $83 \pm 12,96 \pm 10$ and $112 \pm 19 \mathrm{~g}^{\text {animal }}{ }^{-1} \mathrm{~d}^{-1}$, respectively, compared to $71 \pm 13,90 \pm 11$ and $119 \pm 16 \mathrm{~g}_{\text {animal }}{ }^{-1} \mathrm{~d}^{-1}$ using the $\mathrm{SF}_{6}$ tracer technique. Under grazing conditions, the hourly averaged emissions from a small herd of cows ( 20 to 25 ) showed around $15 \%$ variation. Error analysis indicates measurement uncertainty contributed in the order of $10 \%$ of the uncertainty, indicating the variability in animal emissions is an important contribution to the uncertainty in the estimates. This paper will report on the measurement of $\mathrm{CH}_{4}$ emissions from cattle and sheep from a range of management systems, using the OP-FTIR tracer technology.

\section{T33. Validation of the $\mathrm{SF}_{6}$ tracer technique for estimation of methane emissions from sheep using respiration chambers}

C. S. Pinares-Patĩno*, K. R. Lassey*, R. J. Martin, G. Molano*, M. Fernandez, S. MacLean, E. Sandoval, D. Luo and H. Clark*

Attempts to validate the sulphur hexafluoride $\left(\mathrm{SF}_{6}\right)$ tracer technique for the estimation of methane $\left(\mathrm{CH}_{4}\right)$ emissions from ruminants have yielded mixed results. These studies either used permeation tubes with a long history of deployment in the animals, involved small numbers of animals or used partial enclosure of animals instead of respiration chambers. This study was conducted with a relatively large number of experimental units (sheep) and took some control of uncertainties regarding the release rate of $\mathrm{SF}_{6}$. Twenty-four wether sheep housed in covered yards and fed on commercial lucerne silage at fixed levels to achieve common feed intakes between individuals and across the study were administered with fresh $\mathrm{SF}_{6}$ permeation tubes. Following 10-day acclimatization in pens, the sheep were staggered in three groups of 8 sheep each in order to match the availability of 8 respiration chambers. Each group was transferred to individual metabolic crates and habituated to breath collection harnesses for 3 days before breath samples were collected daily over 6 consecutive days for $\mathrm{CH}_{4}$ emission estimation using the $\mathrm{SF}_{6}$ technique (TRACER). Sheep were then brought into respiration chambers for $\mathrm{CH}_{4}$ measurements over 4 consecutive days (CHAMBER). While sheep were in respiration chambers, the chamber's inlet and outlet gas streams were collected into evacuated yokes, as for the tracer technique procedures. All samples (breath and background air) collected in yokes were analysed for $\mathrm{CH}_{4}$ and $\mathrm{SF}_{6}$ mixing ratios by gas chromatography. These mixing ratios were then used to estimate $\mathrm{CH}_{4}$ emissions using tracer technique procedures (TRACER IN CHAMBER) as for the TRACER (in metabolic crates) 


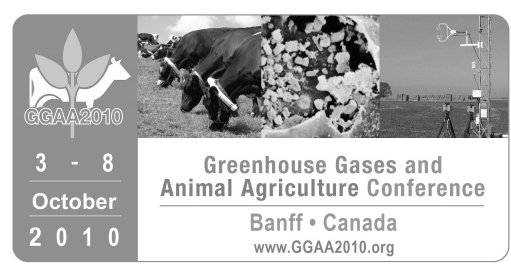

estimates. The mean \pm s.d daily $\mathrm{CH}_{4}$ emissions for the TRACER, CHAMBER and TRACER IN CHAMBER procedures were $14.8 \pm 2.4,13.9 \pm 1.0$ and $16.1 \pm 2.8 \mathrm{~g}$, respectively. Although the TRACER and CHAMBER emission estimates did not differ $(P>0.05)$, the TRACER estimates were associated with much larger between-animal and within-animal variability than the CHAMBER values, and the relationship between CHAMBER and TRACER estimates was poor. The theoretical rate of recovery of $\mathrm{SF}_{6}$ from the chamber gases calculated by dividing the calculated daily emission of $\mathrm{SF}_{6}$ (i.e., the net mixing ratio of $\mathrm{SF}_{6} \times$ chamber daily air flow) by the known calibrated release rate of $\mathrm{SF}_{6}$ was $10 \%$ lower than that of $\mathrm{CH}_{4}$. It is concluded, that on average, emissions using the $\mathrm{SF}_{6}$ tracer technique match those obtained from chambers, but the relationship between their estimates is poor and possibly due to a mismatch in behaviour of the tracer and trace gases.

\title{
T34. Measurement of ammonia fluxes at a cattle feedlot using micrometeorological and spectroscopic techniques
}

\author{
S. Pressley*, B. Lamb, P. O’Keeffe, G. Allwine, J. Michal*, G. Mount and K. Johnson*
}

The majority of the reactive nitrogen $(\mathrm{N})$ inputs to the atmosphere are estimated to come from agricultural sources. Confined animal feeding operations (CAFO) in particular are estimated to contribute a large portion of agricultural ammonia $\left(\mathrm{NH}_{3}\right)$ emissions. At elevated levels, $\mathrm{NH}_{3}$ becomes an odour concern and contributes to regional air quality problems by serving as a precursor to fine particulate matter. However, actual emission rates from CAFOs are highly uncertain. $\mathrm{NH}_{3}$ measurements were conducted at a CAFO in order to quantify $\mathrm{NH}_{3}$ emissions. Measurements were conducted using two approaches. Relaxed eddy accumulation (REA) techniques were employed to measure $\mathrm{NH}_{3}$ fluxes and coincidently $\mathrm{NH}_{3}$ concentrations were measured using an open path, differential optical absorption spectroscopy (DOAS) method. The DOAS line-averaged concentrations can be used with an inverse modeling method to estimate fluxes for comparison to the direct REA flux measurements. Measurements were conducted over a two-week period in April, with heavy rains during the middle of the campaign. $\mathrm{REA} \mathrm{NH}_{3}$ fluxes collected after the rain event (as the site was drying) averaged $142 \pm 87$ $\mu \mathrm{g} \mathrm{m}^{-2} \mathrm{~s}^{-1}$ and were from an upwind fetch of $100 \mathrm{~m}$ which typically encompassed 225 head of $400 \mathrm{~kg}$ growing and finishing steers. Typical line averaged $\mathrm{NH}_{3}$ concentrations across the $110 \mathrm{~m}$ DOAS path were between 0.5 1.5 ppmv for several days during this same period. Using an inverse modeling method (WINDTRAX), $\mathrm{NH}_{3}$ fluxes will be calculated using the measured DOAS concentrations for comparison to the REA flux results.

\section{T35. In vitro rumen methane output of perennial ryegrass samples prepared by freeze drying or thermal drying \\ P. Purcell*, M. O’Brien, T. Boland* and P. O'Kiely*}

In many ruminant nutrition studies, feeds are dried in heated ovens with forced air ventilation and milled through a screen with $1 \mathrm{~mm}$ apertures in order to obtain a physically representative but small sample. Drying methods involving heat have been shown to change the chemical composition of a feed. As a result, it is feasible that changes in the chemical composition during thermal drying could affect the in vitro rumen methane output measured on the dried samples. Consequently, the objectives of this study were to determine the effect of freeze drying $\left(-55^{\circ} \mathrm{C}\right.$ for $\left.72 \mathrm{~h}\right)$ vs. thermal drying $\left(40^{\circ} \mathrm{C}\right.$ for $\left.48 \mathrm{~h}\right)$ on the chemical composition and methane output of perennial ryegrass samples taken at five stages of the primary growth (12 May, 26 May, 9 


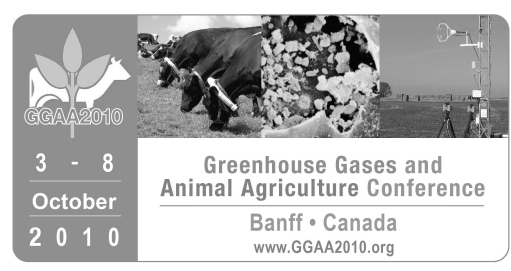

June, 23 June, and 7 July 2009 - defined as Cuts 1 to 5, respectively) using the in vitro rumen gas production technique (IVRGPT). It was found that drying method had no effect on methane output. Methane output per gram of dry matter (DM) incubated decreased linearly with advancing grass maturity while methane output per gram of DM digested increased linearly with advancing grass maturity. The magnitude of the changes in chemical composition due to drying method was small and not biologically significant. It was concluded that the thermal drying method used on a range of grass samples had a similar effect to freeze drying on in vitro rumen methane output, reflecting the small magnitude of changes in chemical composition.

\title{
T36. $\mathrm{CO}_{2}$ emission in Tanzania-grass submitted rotational stocking intensities by goats
}

\author{
A.C. Ruggieri*, N.L. Santos, N.C. Meisler, V. Costa e Silva and P. E. Silva Martins, N. La Scala Jr., D.B. Teixeira
}

It was aimed at to evaluate the $\mathrm{CO}_{2}$ emission in Tanzania-grass submitted rotational stoking intensities under Jaboticabal, Sao Paulo, Brazil weather conditions. The total area of Tanzania-grass was $6,000 \mathrm{~m}^{2}$ formed in December of 2000 e divided in paddocks. The experiment was evaluated in repeated measures, in a complete randomized design, with three stocking intensities $(0.8,1.6$ e 2.4 residual LAI) and ten repetitions. The intensities were definite by LAI (Leaf Area Index) residual in the end of the grazing cycle. The LAl was estimated with sward analyzer instrument - AccuPAR ${ }^{\circledast}$ (PAR/LAl ceptometer -Decagon). The grazing by goats (30 $\mathrm{Kg}$ of $\mathrm{BW}$ ) was established when sward reach $95 \% \mathrm{LI}$ (light interception) and the duration of the grazing was 8 hours. To the soil $\mathrm{CO}_{2}$ emission it was utilized a portable instrument of chamber flux $\mathrm{LI}-\mathrm{COR}^{\circledR}$ (LI-8100); the $\mathrm{CO}_{2}$ emissions measurements were realized nine times. The emissions of $\mathrm{CO}_{2}$ from soil were submitted to variance analysis and means were compared by Tukey test at $5 \%$ probability. The $\mathrm{CO}_{2}$ emissions decreased in all grazing intensities during the evaluations (average of 7.98 to $4.52 \mu \mathrm{mol} \mathrm{m} \mathrm{m}^{-1}$ ), however, at the beginning of the evaluations the lower grazing intensity $(2.4 \mathrm{LAl})$ resulted in lower emissions of $\mathrm{CO}_{2}\left(7.0 \mu \mathrm{mol} \mathrm{m} \mathrm{m}^{-2}\right)$ compared to the more grazing intensity (LAl 0.8) with $8 . \mu \mathrm{mol} \mathrm{m} \mathrm{m}^{-2} \mathrm{~s}^{-1}$. But in the third and fourth evaluations the $\mathrm{CO}_{2}$ emissions although smaller, the emissions were higher $\left(5.67\right.$ and $\left.5.57 \mu \mathrm{mol} \mathrm{m}^{-2} \mathrm{~s}^{-1}\right)$ in the lower grazing intensity, when compared to higher intensity $\left(4.26,4\right.$ th, $\left.74 \mu \mathrm{mol} \mathrm{m} \mathrm{m}^{-2} \mathrm{~s}^{-1}\right)$. In the ninth measure, the $\mathrm{CO}_{2}$ emissions were similar ( $\mathrm{P}>0.05)$ among grazing intensities. Thus, when the soil moisture is high, the $\mathrm{CO}_{2}$ emissions in the highest grazing intensity is higher, then, when the soil moisture decreases, it was observed higher emissions at lower intensities.

\section{T37. Emissions from $\mathrm{N}_{2} \mathrm{O}, \mathrm{CH}_{4}$ and $\mathrm{NH}_{3}$ from a grass sward grazed by beef heifers in a mobile outdoor system during winter}

E. Salomon* and L. Rodhe*

Extensive, economically viable overwintering systems for beef cattle that are environmentally friendly and have minimal impact on climate change are urgently needed. This project evaluated the environmental impact of a system for overwintering beef cattle on aftergrass after the last silage cut. A group of 34 heifers was kept outdoors during November-December with access to a grazing area that was expanded step-wise from 1500 to $4500 \mathrm{~m}^{2}$ and a canvas shelter. The feeding area, including feed racks for silage, was moved weekly to prevent point loads of nutrients. Nitrous oxide $\left(\mathrm{N}_{2} \mathrm{O}\right)$, methane $\left(\mathrm{CH}_{4}\right)$ and ammonia $\left(\mathrm{NH}_{3}\right)$ emissions were determined in two $15 \times 15 \mathrm{~m}^{2}$ feeding sub-areas, with one more trampled and one less trampled, and for a $3 \times 10 \mathrm{~m}^{2}$ control sub-area with ungrazed aftergrass. Net $\mathrm{N}$ input to the pad was calculated. Ammonia emissions were measured 


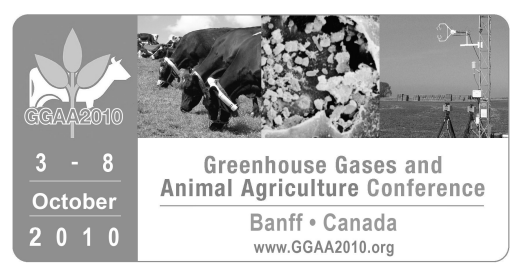

by micrometeorological mass balance in two periods during grazing, while $\mathrm{N}_{2} \mathrm{O}$ and $\mathrm{CH}_{4}$ were measured using a closed chamber method with nine chambers per sub-area on 10 occasions in the period December-April, after the cattle had left the pen. At the end of grazing, the mineral- $\mathrm{N}$ in the clay loam soil $(0-30 \mathrm{~cm}$ depth) was mainly in the form of $\mathrm{NH}_{4}-\mathrm{N}$, with 45.3, 27.7 and $11.4 \mathrm{~kg} \mathrm{NH}_{4}-\mathrm{N}$ ha ${ }^{-1}$ in more and less trampled and control subareas, respectively. Rain or snow fell during the four weeks the cattle were on the pad, so the soil was water-logged. The mean air temperature was below zero in December-February and above zero in November and in March-April. Ammonia losses were small. Mean accumulated $\mathrm{N}_{2} \mathrm{O}$ emissions were much higher for the control sub-area $\left(0.73 \mathrm{~kg} \mathrm{~N}_{2} \mathrm{O}-\mathrm{N} \mathrm{ha}{ }^{-1}\right)$ than for the more and less trampled sub-areas $\left(0.05\right.$ and $0.33 \mathrm{~kg} \mathrm{~N} \mathrm{~N}_{2} \mathrm{O}-\mathrm{N}$ $\mathrm{ha}^{-1}$, respectively). The higher $\mathrm{N}_{2} \mathrm{O}-\mathrm{N}$ emissions from the control may have been due to better conditions for nitrification/denitrification in the untrampled grass sward. Overall, the less trampled sub-area acted as a $\mathrm{CH}_{4}$ sink during the whole measuring period, with mean accumulated $\mathrm{CH}_{4}-\mathrm{C}$ of $-0.11 \mathrm{~kg} \mathrm{ha}^{-1}$. The more trampled sub-area acted as a sink during winter, but mean accumulated emissions were $0.16 \mathrm{~kg} \mathrm{CH}_{4}-\mathrm{C} \mathrm{ha}{ }^{-1}$ in spring. The control plot had the highest $\mathrm{CH}_{4}$ emissions (mean $0.28 \mathrm{~kg} \mathrm{CH}_{4}-\mathrm{C}$ ha ${ }^{-1}$ ). Emissions of $\mathrm{N}_{2} \mathrm{O}$ and $\mathrm{CH}_{4}$ were thus lower from grassland grazed by beef cattle during November-December than from ungrazed grassland.

\section{T38. Simultaneous emissions and dispersion of the ammonia plume inside and around a dairy farm in Segovia (Spain)}

F. Sanz, G. Montalvo, J. L. Goméz, C. Piñeiro*, M. Bigeriego and M. J. Sanz

A large proportion of the ammonia $\left(\mathrm{NH}_{3}\right)$ emitted locally is deposited in the immediate neighborhood of the source rather than transported over long distances. Quantitative information about the spatial location of emission sources, as well as estimations of the emissions, is crucial for target-oriented abatement. In addition, a suitable spatial resolution and the acquisition of data in different climatic conditions is crucial for a realistic distribution of $\mathrm{NH}_{3}$ sources and sinks. Few studies have been undertaken that show the distribution of $\mathrm{NH}_{3}$ emissions around point sources in the southern Europe. In general, ammonia gas deposits close to the source of emission; studies in the area surrounding a poultry farm in UK reported deposition fingerprints of less than 1 $\mathrm{km}$ (Skiba et al. 2006). In Spain, concentration fields decreased in the laying hens farm to levels of 3 to $5 \mu \mathrm{g} / \mathrm{m}^{3}$ (background levels for the area) within distances of less than $600 \mathrm{~km}$ whereas in the case of a broiler meat farm, concentrations at $600 \mathrm{~m}$ were twice that (Sanz et al. 2006). The aim of this paper was to determine $\mathrm{NH}_{3}$ concentrations in the surroundings of a dairy farm in Segovia, since no measurements around this type of farms are available, and to combine the measurement with estimates of the fluxes of ammonia from the farm. Ammonia concentrations in the area surrounding the farm were determined by Ferm type passive samplers (Sanz et al. 2006) located $2 \mathrm{~m}$ above ground in 60 sampling points. To estimate the fluxes from the farm building, continuous measurements with an Innova (mod. 1412-5) were performed in different points. The concentrations nearby the stable were of maximum $150 \mu \mathrm{g} / \mathrm{m}^{3}$ and decreased down $23 \mu \mathrm{g} / \mathrm{m}^{3}$ within $200 \mathrm{~m}$. The wind direction determined the shape of the plume. The background concentrations were estimated at 5 $\mu \mathrm{g} / \mathrm{m}^{3}$. The estimated $\mathrm{NH}_{3}$ emissions from the stable were $10.47 \mathrm{~kg} \mathrm{NH}_{3}$ animal ${ }^{-1} \mathrm{yr}^{-1}$. Those levels are lower that the ones used presently for the Spanish Corinair inventory. In addition, methane emissions were also estimated $\left(79.05 \mathrm{~kg}\right.$ of $\mathrm{NH}_{3}$ animal $\left.{ }^{-1} \mathrm{yr}^{-1}\right)$. 


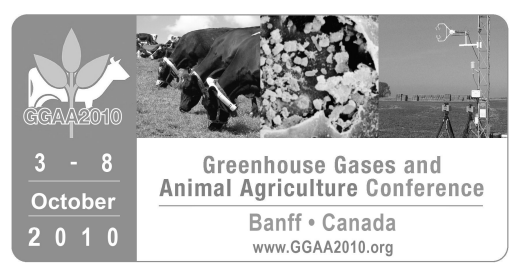

\title{
T39. Methane production and metabolizable energy requirements of Thai native cattle
}

\author{
K. Sommart*, N. Tangjitwattanachai, M. Otsuka, S. Udchachon and A. Takenaka*
}

This study was conducted to evaluate metabolizable energy requirements for maintenance in Thai native beef cattle by using the indirect calorimetry method. Fifteen Thai native beef cattle were randomly allocated to one of three dietary treatments in a completely randomized design with 3 metabolizable energy intake (MEI) level (1.1 of maintenance, 1.5 of maintenance and 1.9 of maintenance) for 78 days. The oxygen consumption, carbon dioxide, and methane production were calculated for heat production measurement. The results showed that $\mathrm{OM}$ and $\mathrm{CP}$ intake were influenced $(P<0.05)$ by level of MEl. Energy excretion in feces and heat production were similar among $1.5 \mathrm{M}$ and $1.9 \mathrm{M}$, but greater than $1.1 \mathrm{M}$. Energy loss in urine was not different $(P$ $>0.05$ ) of all groups. Methane production (range 150.8-206.64 $\mathrm{L} \mathrm{d}^{-1}$ ) was increased when increased MEI. Methane energy loss per GEI and heat energy loss per GEI were decreased by increased MEI. Estimates of maintenance requirements were measured by using simple linear regression analysis [regressing nutrients intake $\left(\mathrm{g} \mathrm{kg}^{-1} \mathrm{BW} 0.75 \mathrm{~d}^{-1}\right)$ against nutrients retention $\left.\left(\mathrm{g} \mathrm{kg}^{-1} \mathrm{BW} 0.75 \mathrm{~d}^{-1}\right)\right]$. A significant simple linear relationship between energy retention (ER) on metabolizable energy intake (MEI) were obtained, $E R=-283.1124$ (SE = $64.4211)+0.5324(\mathrm{SE}=0.0895) \mathrm{MEI}\left(\mathrm{n}=15, \mathrm{R}^{2}=0.7793, \mathrm{RSD}=9.5176, P<0.01\right)$. The analysis of intercepts results in a common requirement for NEm of $283.11 \mathrm{KJ} \mathrm{kg}^{-1} \mathrm{BWO} 0.75 \mathrm{~d}^{-1}$, and the partial efficiency of use of ME to NEm of 0.53 . Metabolizable energy requirements for maintenance requirement for maintenance were determined to be $531.76 \mathrm{KJ} \mathrm{kg}^{-1} \mathrm{BW} 0.75 \mathrm{~d}^{-1}$.

\section{T40. The sulphur hexafluoride $\left(\mathrm{SF}_{6}\right)$ tracer technique for methane emission estimation: Effect of rumen residence time of $\mathrm{SF}_{6}$ permeation tubes in red deer}

N. Swainson, S. O. Hoskin, I. M. Brookes and H. Clark*

The sulphur hexafluoride $\left(\mathrm{SF}_{6}\right)$ tracer technique is widely used for the estimation of methane $\left(\mathrm{CH}_{4}\right)$ emissions from individual ruminants, particularly whilst grazing. The success of the $\mathrm{SF}_{6}$ technique is reliant upon accurate determination of the release rate of $\mathrm{SF}_{6}$ gas from the permeation tube whilst in the rumen. However, the effects of the rumen environment and permeation tube rumen residence time on the release rate of the $\mathrm{SF}_{6}$ gas are not clearly understood. This study aimed to determine the effect of $\mathrm{SF}_{6}$ permeation tube rumen residence time on the release rate of $\mathrm{SF}_{6}$ gas and calculated methane $\left(\mathrm{CH}_{4}\right)$ production $\left(\mathrm{g} \mathrm{CH}_{4} \mathrm{~d}^{-1}\right)$ in grazing Red deer. The $\mathrm{CH}_{4}$ emissions of Red deer stags grazing permanent perennial ryegrass-based pasture were estimated daily for 4 days at 4.5, 6.5, 9 and 11.5 months of age, corresponding to 9, 65, 150 and 212 days since permeation tube deployment at the midpoint of each measurement period. Permeation tubes normally used for sheep were inserted orally 7 days prior to the first $\mathrm{CH}_{4}$ measurement. Permeation tubes were recovered from three deer after the second $\mathrm{CH}_{4}$ measurement and from the remaining ten deer at the end of the experiment. Release rates of $\mathrm{SF}_{6}$ gas from permeation tubes were determined pre-deployment-only (uncorrected $\mathrm{SF}_{6}$ release rates), or by pre-deployment with adjustment for $\mathrm{SF}_{6}$ release rates from permeation tubes recovered at the termination of the experiment (corrected $\mathrm{SF}_{6}$ release rates) after permeation tubes resided within the rumen of red deer for 212 days. The corrected $S_{6}$ release rates did not differ $(P=0.0725)$ from uncorrected $\mathrm{SF}_{6}$ release rates after 9 days of tube deployment. In contrast, after 65 and 212 days of permeation tube deployment, corrected release rates were 16 to $27 \%(P<0.05)$ lower than the uncorrected $\mathrm{SF}_{6}$ release rate, respectively. The mean calculated $\mathrm{CH}_{4}$ production of deer was also reduced by up to $15 \%(\mathrm{P}<$ 0.0001 ) when calculated using corrected, compared with uncorrected, $\mathrm{SF}_{6}$ release rates. This study implies that use of uncorrected $\mathrm{SF}_{6}$ release rates determined pre-deployment may not be representative of the actual $\mathrm{SF}_{6}$ 


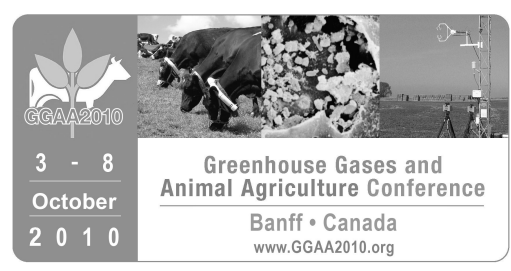

release rate from tubes during deployment and may give misleading estimates of $\mathrm{CH}_{4}$ production if measurements are undertaken when permeation tube residence times are 65 days or longer. Results from this study also suggest that permeation tubes should be recovered at the termination of experiments to improve the accuracy of calculated $\mathrm{CH}_{4}$ emissions.

\section{T41. Variability of collected $\mathrm{SF}_{6}$ gas concentrations in the breath samples of sheep and cattle: Defining criteria for the systematic exclusion of data when using the $\mathrm{SF}_{6}$ tracer technique N. Swainson, S. O. Hoskin, I. M. Brookes and H. Clark*}

The sulphur hexafluoride $\left(\mathrm{SF}_{6}\right)$ tracer gas technique assumes that $\mathrm{SF}_{6}$ gas behaves similarly to methane $\left(\mathrm{CH}_{4}\right)$ and the ratio of the two gases can be used to calculate the daily $\mathrm{CH}_{4}$ production $\left(\mathrm{CH}_{4} \mathrm{~g} \mathrm{~d}^{-1}\right)$ of ruminant livestock. Recent reports have highlighted highly variable concentrations of $\mathrm{SF}_{6}$ gas between-days and withinanimals and/or unusually low concentrations of $\mathrm{SF}_{6}$ gas in breath samples that are near ambient $\mathrm{SF}_{6}$ gas concentrations in collected breath samples from both sheep and cattle. This is despite $\mathrm{CH}_{4}$ gas concentrations being consistent, both between-days and within-animals and at greater than ambient concentrations, indicating that the collection of the breath samples was not problematic. As a result of highly variable concentrations of $\mathrm{SF}_{6}$ gas within the collected breath samples of three experiments with sheep and one with cattle, criteria were sought to define a systematic method decision tree of including or excluding estimates of $\mathrm{CH}_{4}$ production based on the concentrations of both $\mathrm{SF}_{6}$ and $\mathrm{CH}_{4}$ gases from the collected breath samples of sheep and cattle. The data used to define the ranges presented in the decision tree for sheep and cattle were sourced from The New Zealand Methane Database, from 2002 to 2007, encompassing; 15 independent sheep experiments totalling $3542 \mathrm{SF}_{6}$ and $\mathrm{CH}_{4}$ data points; and 17 independent cattle experiments totalling $5170 \mathrm{SF}_{6}$ and $\mathrm{CH}_{4}$ data points. The application of the decision tree to data that appeared to have low and variable concentrations of $\mathrm{SF}_{6}$ in the collected breath samples to three sheep experiments and one cattle experiment reduced the coefficient of variation (CV) of $\mathrm{CH}_{4}$ production from $1400 \%$ in sheep and $797 \%$ in cattle to $49 \%$ and $42 \%$, respectively. Nevertheless, these new CVs are greater than those reported elsewhere of 2.2 to $42 \%$ within sheep and $17 \%$ between sheep and a between and within-animal CV of 8 to $18 \%$ in cattle. The use of the decision tree to exclude data reduced the variability of estimated $\mathrm{CH}_{4}$ yield, for both sheep and cattle, between and within-animals, but still allowed for a wide range of $\mathrm{CH}_{4}$ yield estimates and did not appear to create a bias towards high or low $\mathrm{CH}_{4}$ emissions.

\section{T42. Comparison of two methods for measuring methane emissions from beef cattle grazing Rhodes grass dominated pastures}

N. W. Tomkins*, S. M. McGinn*, D. A. Turner* and E. Charmley*

Australia's northern rangelands are dominated by beef production. Paddocks are large; often in excess of 120 $\mathrm{km}^{2}$ and seasonal fluctuations in rainfall significantly affect available forage biomass and digestibility. Extensive beef cattle production generates $45 \%$ of northern Australia's estimated total value of agricultural production. Enteric methane $\left(\mathrm{CH}_{4}\right)$ from ruminants is a principal source of greenhouse gas (GHG). Major abatement of GHG emission intensities ( $\mathrm{t} \mathrm{CH}_{4} / \mathrm{t} \mathrm{LW}$ gain) are required if the northern beef industry is to contribute to national reductions in GHG emissions. Measurements from the northern herd are yet to be reliably quantified. Here we report the use of an indirect micrometeorological technique to quantify methane emissions from Brahman (Bos 


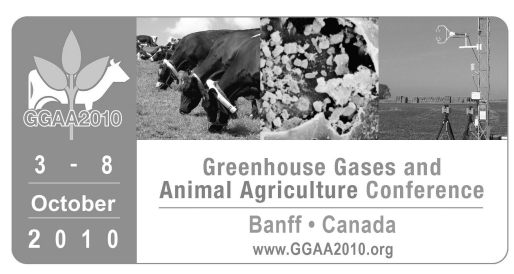

indicus) steers grazing tropical pastures. Eighteen steers, initial LW $222 \pm 3.8 \mathrm{~kg}$ (mean \pm sem), sequentially grazed five 1-ha paddocks containing Rhodes grass (Chloris gayana), and two paddocks containing Leucaena ( $L$. leucocephala)/Rhodes grass. Methane mixing ratios were measured over 7 to $10 \mathrm{~d}$ in each paddock using an open-path laser at 1-s sampling intervals for $55 \mathrm{~s}$, along five paths at a height of $1.8 \mathrm{~m}$. A three-dimensional sonic anemometer sampled wind components at $10 \mathrm{~Hz}$. Steers were fitted with GPS devices recording spatial data at 1 to $4 \mathrm{~Hz}$. Laser, sonic and GPS data were used to estimate emissions using a WindTrax dispersion model. Direct measures of individual emissions over $24 \mathrm{~h}$ were made using open-circuit calorimeters for the same steers fed freshly harvested Rhodes grass. Mean ( \pm sem) $\mathrm{CH}_{4}$ emissions measured using an open-path laser were $136 \pm 21.5 \mathrm{~g} / \mathrm{d}$ for steers grazing Rhodes, compared to $114 \pm 5.12 \mathrm{~g} / \mathrm{d}$ measured using open-circuit calorimeters. Mean daily emissions ranged from 117.9 to $174.2 \mathrm{~g} / \mathrm{d}$ when grazing Leucaena/Rhodes. The indirect micrometeorological technique has previously been used to estimate $\mathrm{CH}_{4}$ emissions from feedlots and is equally applicable to grazing situations allowing for group or herd measurements. Additional field trials across different tropical pastures and further data analysis are required.

\section{T43. Spatial and temporal variability of nitrous oxide emissions from an Australian irrigated dairy pasture \\ D. Turner*, D. Chen*, R. Edis, K. Kelly, F. Phillips* and Y. Li}

Understanding spatial and temporal variability of emissions of nitrous oxide $\left(\mathrm{N}_{2} \mathrm{O}\right)$ from soils to the atmosphere is essential in the design of statistically valid measurement programs to determine plot, farm and regional emission rates of $\mathrm{N}_{2} \mathrm{O}$ emissions. A study was conducted in February 2005 at the Kyabram Dairy Centre in northern Victoria, Australia, to determine the spatial and temporal variability of soil-atmosphere $\mathrm{N}_{2} \mathrm{O}$ emissions in a 2.4 ha border-check irrigation paddock. A herd of 300 lactating dairy cows (Holstein, average weight 550 $\mathrm{kg}$ ) grazed the paddock for approximately $24 \mathrm{~h}$ and $50 \mathrm{~mm}$ of flood irrigation was applied soon after. 108 minichambers were placed on a $10 \mathrm{~m} \times 20 \mathrm{~m}$ grid covering 1.7 ha of the paddock. Fluxes of $\mathrm{N}_{2} \mathrm{O}$ from the area under each mini-chamber were estimated from the change in headspace concentration after closure for 60 min. Chamber gas-samples were taken in the mid-afternoon immediately prior to irrigation and for 8 days postirrigation. Soil samples were taken from beside each mini-chamber at the beginning of the measurement period and from under the mini-chamber at the end of the experiment and analyzed for mineral $\mathrm{N}$ (ammonium and nitrate) and soil water content. Nitrous oxide emissions and soil variables were analyzed using descriptive and geo- statistics. Emissions between the chambers were highly variable ranging from 0 to $>90,000 \mathrm{ng} \mathrm{N} \mathrm{m}^{-2} \mathrm{~s}^{-}$ ${ }^{1}$ with coefficients of variation (CV) of $370-950 \%$. Of the 108 chambers one located close to the paddock gate had extremely high $\mathrm{N}_{2} \mathrm{O}$ emissions ( 90 to $>90,000 \mathrm{ng} \mathrm{N} \mathrm{m}^{-2} \mathrm{~s}^{-1}$ ) on every occasion sampled contributing to the very high $\mathrm{CV}$ values. Immediately prior to irrigation the average $\mathrm{N}_{2} \mathrm{O}$ emission from the chambers was $0.3 \mathrm{ng} \mathrm{N}$ $\mathrm{m}^{-2} \mathrm{~s}^{-1}$. The average $\mathrm{N}_{2} \mathrm{O}$ emission increased to $32.6 \mathrm{ng} \mathrm{N} \mathrm{m}^{-2} \mathrm{~s}^{-1}$ four days after irrigation then decreased to 5.5

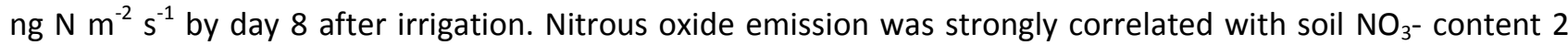
days after irrigation due to denitrification in the wet soil, whereas at 8 days after irrigation $\mathrm{N}_{2} \mathrm{O}$ emission was strongly correlated to both $\mathrm{NO}_{3}$ - and $\mathrm{NH}_{4}+$ due to both nitrification and denitrification in the more aerobic soil conditions. 


\section{NOTES}




\title{
SESSION 4: ORAL ABSTRACTS
}

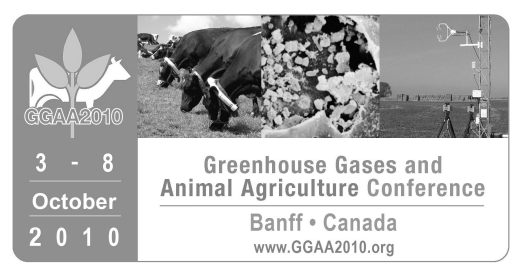

\section{PLEASE NOTE: Authors denoted with an asterisk are registered GGAA2010 delegates}

\author{
Lowering ruminant methane emissions through improving feed conversion efficiency \\ G. Waghorn* and R. Hegarty*
}

Improvements in feed conversion efficiency (FCE) can be applied to individual animals as well as to production from the land - as in a farm system. Our focus relates mainly to food production from individuals. Within any population there is divergence in the efficiency that individuals use feed for maintenance and production; primarily due to variance in digestion and metabolism. Intake variation from the predicted population mean has been termed residual feed intake (RFI), with low values indicating an efficient animal. Efficient animals require less feed than average and can be expected to produce less methane (and nitrous oxides) than the population average for similar level of production. Selection for this trait will lower methane emissions, unless more stock are carried to use the feed not required by efficient animals. There are few published evaluations of methane yields from animals with divergent RFI and there is no evidence that efficient animals have a different methane yield (MY) expressed as $\mathrm{CH}_{4} \mathrm{~kg}^{-1}$ feed DM intake. If efficient animals have a higher rumen digestion than average, then MY may increase. Of equal or greater importance than RFI is the need to select high producing animals because this will reduce emissions/unit of production, referred to as emissions intensity (Ei). Research should identify productive individuals that have a low RFI to minimise Ei and maintain food production. The extent to which $\mathrm{CH}_{4}$ can be reduced by selection for RFI will depend on the heritability of efficiency, dispersal of efficient animals through all populations and their resilience (robustness). The benefit of RFI for lowering greenhouse gas (GHG) emissions is its universal application, irrespective of farming system (confined, intensive and extensive grazing) and especially because efficient animals are likely to increase profitability for farmers. Efficient animals are already in all herds and flocks and research must identify and remove inefficient individuals, whilst retaining and ensuring efficient ones are fit for purpose. However, greatest benefits for reducing emissions and increasing production will be associated with good animal management practice (appropriate genetics, reproductive performance, longevity, etc.) with efficient animals superimposed. Good systems management will improve profitability, and apply to both intensive and extensive systems to increase food production, and lower Ei. One dilemma for agriculturists will be feeding grains to ruminants, because gains in efficiency, especially in the reduction of Ei are likely to be greatest with concentrate rations, but feeding grain to ruminants is a poor use of resources when food is in short supply.

\section{In-field quantification of methane emissions from grazing Angus beef cows divergently selected for Residual Feed Intake \\ F. M. Jones*, F. Phillips* and T. Naylor*}

Residual feed intake (RFI) is measure of feed efficiency and is calculated as the difference in actual feed intake above and below the predicted or expected intake by beef cattle based on their size. Selecting cattle for lower RFI will lead to a decrease in feed intake by young cattle and cows with no compromise in growth or the size of cattle (Herd et al. 2003). Level of feed intake is known to influence methane emissions by livestock (Johnson et al. 1995). Hegarty et al. (2007) determined a relationship between methane production rate and RFI in cattle fed a grain-based ration. This experiment aimed to determine group levels of methane production by low 


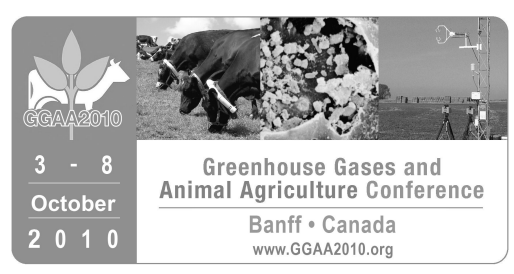

efficiency (LE; high RFI) or high efficiency (HE; low RFI) Angus cows grazing two different pasture qualities (low: 7.1\% CP, 7.3 MJ ME/kg DM, 57\% DMD; and high: 15\% CP, $11.5 \mathrm{MJ} \mathrm{ME/kg} \mathrm{DM,} \mathrm{81 \%} \mathrm{DMD)} \mathrm{while} \mathrm{in} \mathrm{two}$ physiological states (pregnant, non-lactating; and lactating with calf at foot, respectively). The cows were from lines selected for high or low RFI (Herd et al. 2003) and had been tested for RFI as heifers. The genetic merit for $\mathrm{RFI}$, as estimated breeding values, for the $25 \mathrm{LE}$ cows was $+0.68+/-\mathrm{kg} /$ day and for the $25 \mathrm{HE}$ cows was $-0.69+/-$ $\mathrm{kg} /$ day. Methane emissions were measured using Open Path Fourier Transform Infrared (OP-FTIR) spectrometry. Measurements were made over separate $6-d$ periods to obtain a group average. Pasture intakes were estimated by daily visual assessment of biomass. While pregnant, the LE cows' estimated daily DM intake was $10.7 \mathrm{~kg} / 500 \mathrm{~kg} \mathrm{LW}$ and their methane emission was $129.3 \pm 33 \mathrm{~g} / 500 \mathrm{~kg} \mathrm{LW}$. Values for HE cows were $10.2 \mathrm{~kg} / 500 \mathrm{~kg} \mathrm{LW}$ and $130 \pm 24 \mathrm{~g} \mathrm{CH}_{4} / 500 \mathrm{~kg} \mathrm{LW}$. While lactating, with calf at foot, daily DM intake by LE cows and calves was $13.1 \mathrm{~kg} / 500 \mathrm{~kg} \mathrm{LW}$ and methane emissions were $186 \pm 31 \mathrm{~g} / 500 \mathrm{~kg} \mathrm{LW}$, compared with values of $14.0 \mathrm{~kg} / 500 \mathrm{~kg} \mathrm{LW}$ and $170 \pm 35 \mathrm{~g} \mathrm{CH}_{4} / 500 \mathrm{~kg} \mathrm{LW}$ for the HE cows. Grazing lower quality pasture, the pregnant HE cows had slightly higher feed intake than did the LE cows, and differences in their methane emissions were not significant. While grazing higher quality pastures, the lactating HE cows had higher estimated intake and lower emissions than the LE cows, but their calves had lower LW. The observed variation in estimated methane emissions was dominated by day-to day variations, indicating that using RFI selection as a breeding strategy for reducing methane emissions may not produce measurable reductions under pasture field testing conditions.

\section{Can enteric methane emissions be lowered without lowering animal production? C. Grainger* and K.A. Beauchemin*}

Ruminant livestock are important contributors to global greenhouse gas emissions and this mainly results from their production of enteric methane. Our paper examines promising mitigation options that reduce enteric methane production without decreasing, and in some cases even increasing, animal performance. Mitigation options examined include animal selection, farming systems, and dietary strategies. Mitigation options not considered because they are the subject of other review papers are secondary plant products and direct manipulation of the rumen microbiota. A promising animal based option is the identification of high and low emitters; studies in New Zealand with sheep have identified differences of up to $25 \%$ (g methane/kg of dry matter intake) between the highest and lowest methane emitters. Also examined is the effect of selection for residual feed intake, for both beef and dairy cattle, on methane emissions and animal production. Farming system strategies (dairy and beef) are examined using examples from New Zealand, the Republic of Ireland and Canada. Profitable options that can reduce methane emissions by up to $30 \%$, while maintaining animal production, are those that reduce the number of unproductive animals, improve genetic merit of livestock, or improve pasture and forage quality. Dietary strategies that show the most promise are dietary supplementation with lipids, condensed tannins, biofuel co-products, enzymes/yeasts or concentrates and these are examined for both total mixed ration and pasture-based grazing systems. Other strategies that show less promise such as monensin supplementation are also examined. If a target of a 40-50\% reduction in enteric methane emissions from ruminant livestock is to be achieved then additivity of effects will be required, such as use of animals with high feed conversion efficiency ( $10 \%$ reduction in methane) in a farming system that involves lower replacement animals (10-15\% reduction in methane) and offered a diet that reduces methane (10-30\% reduction). These are strategies that can be implemented with existing knowledge, and as research in this area continues, new options for methane reduction are expected. 


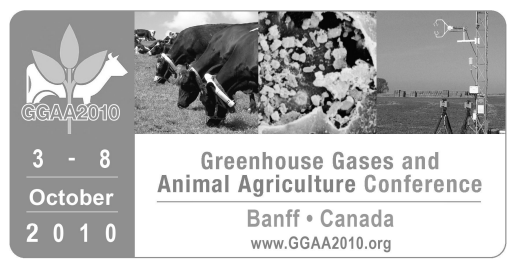

\section{Effects of neutral detergent fiber (aNDF) digestibility of grass silage on enteric methane emissions from dairy cows}

S.K. Nes*, T. Garmo, A.V. Chaves, O. M. Harstad*, A. D. Iwaasa*, S. J. Krizsan, K. Beauchemin*, T. A. McAllister*, L. Norell, E. Thuen, D. Vedres, H. Volden

The objective of this experiment was to study the effect of aNDF digestibility of grass silage on enteric methane $\left(\mathrm{CH}_{4}\right)$ emission from dairy cows fed two levels of concentrate. Six rumen fistulated Norwegian Red cows (594 $\pm 62 \mathrm{~kg}, 41 \mathrm{~d} \pm 20 \mathrm{~d}$ in milk; $34 \pm 5 \mathrm{~kg}$ yield) were used in a $3 \times 2$ factorial experiment, carried out in different sequences for handling possible carry-over effects between periods, with 4-24 d experimental periods with the last $11 \mathrm{~d}$ used for sampling. The treatments were grass mixtures of timothy - meadow fescue silage $(n=3)$ contrasting in aNDF digestibilities (aNDF/kg feed aNDF; assessed in sheep); high (HD, 864), medium (MD, 763) and low (LD, 734) combined with two concentrate levels; low $5 \mathrm{~kg} / \mathrm{d}$ and medium $9 \mathrm{~kg} / \mathrm{d}$. Concentrate contained no aNDF and was composed mainly of wheat starch (73\%). Intake of silage was restricted to $90 \%$ of ad libitum during sampling. Milk yield and composition, feed intake, ruminal $\mathrm{pH}$, ammonia, volatile fatty acid concentrations, microbial synthesis, passage rates and total-tract digestibility were determined. In each period, enteric methane emission was measured over $5 \mathrm{~d}$ using the sulfur hexafluoride $\left(\mathrm{SF}_{6}\right)$ tracer technique. Concentrate level had no effect on $\mathrm{CH}_{4}$ emissions either expressed as $\mathrm{CH}_{4} / \mathrm{d}(P=0.39)$, as proportion of gross energy intake (GEI) $(P=0.75)$ or as $\mathrm{g} \mathrm{CH}_{4} / \mathrm{kg}$ of milk $(P=0.75)$. Silage aNDF digestibility had no effect $(P=0.13)$ on $\mathrm{CH}_{4}$ emissions/d, but when expressed as proportion of GEl it was lower $(P<0.01)$ for HD $(4.82 \%)$ as compared to LD (6.04 \%) silage. Additionally, $\mathrm{HD}$ silage had lower $(P<0.05) \mathrm{CH}_{4}$ emissions/kg milk (11.01) as compared to LD silage (14.72). These results indicate that harvesting grass silage at high aNDF digestibility could serve as a strategy to reduce enteric $\mathrm{CH}_{4}$ emission in Norwegian dairy cows.

Dietary nitrate supplementation reduces methane emission in beef cattle fed sugarcane-based diets R.B.A. Hulshof*, A. Berndt*, J.J.A.A. Demarchi, W.J.J. Gerrits and H.B. Perdok*

The objective of this study was to determine the effect of dietary nitrate $\left(\mathrm{NO}_{3}\right)$ on methane emission and rumen fermentation parameters in Nelore $x$ Guzera (Bos Indicus) beef cattle fed a sugarcane-based diet. The experiment was conducted at Instituto de Zootecnia, Nova Odessa, São Paulo State, Brazil. The study included sixteen steers weighing $283 \pm 49 \mathrm{~kg}$ (mean $\pm \mathrm{SD}$ ), six rumen-fistulated and ten intact, in a cross-over design. The animals were blocked according to body weight and fistula, thereafter randomly allocated to either the control (1.2\% urea in diet $\mathrm{DM})$ or the nitrate $\left(2.2 \% \mathrm{NO}_{3}\right.$ in diet $\left.\mathrm{DM}\right)$ diet. The diets were iso-nitrogenous and consisted of sugarcane and concentrates (60:40 on DM basis), fed as a total mixed ration. Methane emission was measured using the sulphur hexafluoride $\left(\mathrm{SF}_{6}\right)$ tracer technique. DMI was not affected $(P=0.14)$ by addition of $\mathrm{NO}_{3}$ to the diet. The daily methane production per animal was reduced $(P<0.001)$ by $32 \%$ when steers were fed the nitrate diet. Methane emission per $\mathrm{kg}$ of DMI was $27 \%$ lower $(P<0.001)$ on the nitrate diet $(13.6$ vs. 18.6 $\mathrm{g} / \mathrm{kg}$ DMI. Methane losses as a fraction of gross energy intake $(\mathrm{GEI})$ were lower $(P<0.001)$ on the nitrate diet (4.4\% of GEI) than on the control (5.9\% of GEI). The rumen fluid ammonia-nitrogen concentration was significantly higher $(P=0.046)$ for the nitrate diet. The total concentration of VFAs was not affected by nitrate in the diet, the proportion of acetic acid tended to be higher $(P=0.091)$ and propionic acid lower $(P=0.064)$ on the nitrate diet. In conclusion, dietary inclusion of nitrate reduces methane emission and tends to increase acetate and decrease propionate molar proportions in rumen fluid. 


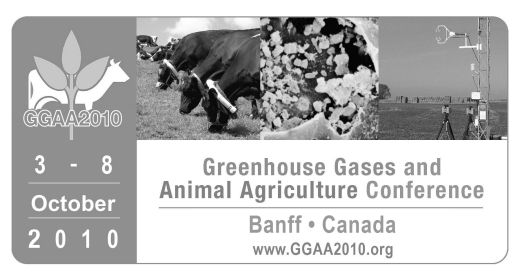

\section{Essential oils and opportunities to mitigate enteric methane emissions from ruminants C. Benchaar*}

In recent years, methane from ruminant production has received increased attention because of its contribution to the greenhouse effect and global warming. Enteric methane emissions result during microbial fermentation of feed within the rumen and represent a loss in productive energy for the animal. Typically, in ruminants, methane energy losses represent between 2 and $12 \%$ of gross energy intake. Accordingly, several nutritional strategies have been suggested to help mitigating enteric methane emissions from ruminants. The well documented antimicrobial activity of essential oils has recently prompted interest in whether these bioactive compounds can be used to selectively inhibit rumen methanogenesis. A number of studies have recently evaluated the effects of essential oils to reduce methane production. Most of the studies conducted to date have been laboratory based (i.e., in vitro) and short-term. Phenolic compounds (e.g., thymol, eugenol, carvacrol), essential oils with high concentrations of phenolic compounds (e.g., thyme and oregano oils), cinnamon oil and its main component cinnamaldehyde, garlic essential oil and its derivatives, and horse radish, rhubarb and frangula essential oils have been shown to be effective, in decreasing methane production in vitro in a dose-dependent manner. However, the inhibition of methane production occurred at high doses (>300 mg $\mathrm{I}^{-1}$ of culture fluid) and was in many cases associated with a decrease in total volatile fatty acid (VFA) concentration and feed digestion. Some essential oils such as garlic, cinnamon rhubarb and frangula may exert a direct effect on methanogenic archae. Evidence for in vivo antimicrobial activity of essential oils has been equivocal to date probably because of the capacity of rumen microbes to adapt and degrade these secondary metabolites. Furthermore, many of the concentrations of essential oils that have favourably affected rumen fermentation in vitro are too high to be achieved in vivo and are impractical in terms of feeding due to potentially deleterious effects on the efficiency of rumen fermentation and palatability and possible toxicity issues. Based on the results available to date, it appears that some essential oils (e.g., garlic and its derivatives; cinnamon) exhibited in vitro their ability to reduce enteric methane production in ruminants. However, there is a need for further in vivo investigation to determine whether these compounds can be used successfully to inhibit rumen methanogenesis. The challenge remains to identify the essential oils that selectively inhibit rumen methanogenesis at practical feeding rates, with lasting effects and without depressing feed digestion.

\section{Effect of various spices on in vitro degradability, methane and fermentation profiles of different ruminant feeds}

A. S. Chaudhry* and M. M. H. Khan

Methane is a major greenhouse gas as it is a recognised contributor to the global warming. As methane is an end product of microbial fermentation in the rumen, its reduction from ruminant feeds could be beneficial in terms of better energy-use and feed efficiency by the animal. Spices which have been safely consumed by the humans could be tested as alternative supplements to reduce methane emission from ruminant livestock. This study tested the effects of adding five spices (cinnamon, clove, coriander, cumin and turmeric) each at a fixed level of $30 \mathrm{mg}$ to each $\mathrm{g}$ of wheat flour (wheat) as the common substrate on the total gas, methane, degradability, ammonia and VFA profiles during their in vitro incubation for $24 \mathrm{~h}$. All the spices reduced total gas $(P<0.05)$ and methane production $(P<0.05)$ from wheat when these values were compared with those of the wheat alone (control = with no spices). Total gas volume and methane production were lowest for coriander, followed by turmeric, cumin and cinnamon when compared with those for the control. The IVD of the wheat was significantly $(P<0.05)$ reduced in the presence of cinnamon but not by other spices than the control. While, rumen ammonia concentration was highest in the presence of cumin $(P<0.01)$ followed by 


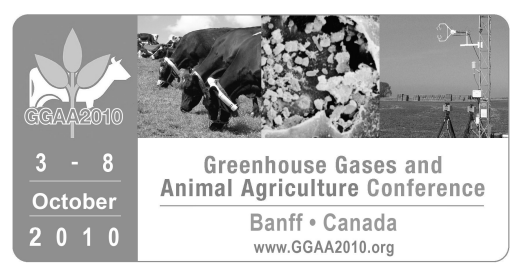

coriander and turmeric, it was lowest in the presence of clove $(P<0.01)$. The presence or absence of spices did not affect the $\mathrm{pH}$ and total VFA concentration of rumen fluid when incubated with wheat. However, the presence of clove did significantly reduce the proportion of acetic acid $(P<0.05)$. The study was then extended to test the effect of these spices on the in vitro fermentation and methane profiles of some selected forages. It appeared that most spices of this study were able to modify methane emission of different ruminant feeds without any detrimental effects on either degradability or fermentation profiles in vitro. However, it would be necessary to find the correct levels and types of these spices to suit specific feeds in order to obtain their most desirable impacts on methane from ruminants in various situations.

\section{Limited suitability of dietary coconut oil to reduce enteric methane emission from dairy cattle M. Hollmann* and D. K. Beede*}

Dietary medium-chain fatty acids contained in coconut oil (CO) reduce synthesis of enteric methane in ruminants. Feeding $0.0,13.3,26.7$ and $33.3 \mathrm{~g} \mathrm{CO} \mathrm{kg}^{-1}$ of dietary dry matter to lactating Holstein dairy cows (>35 $\mathrm{kg} \mathrm{d}^{-1} 4 \%$ fat-corrected milk yield [FCMY]) led to enteric methane emissions of 462, 446, 291 and $250 \mathrm{~g} \mathrm{~d}^{-1} \mathrm{cow}^{-}$ 1 , respectively. However, CO reduced intake of dietary energy. Apparent neutral detergent fiber (NDF) digestion and FCMY were reduced in a quadratic fashion. The results of the four dietary treatments (scenarios) were modeled to simulate enteric methane emissions: 1) for the national-level (U.S.) dairy herd to maintain national FCMY; and 2) for a representative dairy farm with a constant number of all dairy animals $(n=356)$ across scenarios. We assumed constant enteric methane emission per unit of gross energy intake from all pregnant, non-lactating cows and replacement heifers in all scenarios. Total cows plus replacements needed to maintain national FCMY in each of the four scenarios were 13.9, 13.4, 17.5 and 18.1 million, respectively. Enteric methane reduction per unit of FCMY was 8 and $12 \%$ for the 26.7 and $33.3 \mathrm{~g} \mathrm{~kg}^{-1}$ CO scenarios, respectively, compared with the $0.0 \mathrm{~g} \mathrm{~kg}^{-1} \mathrm{CO}$ scenario. This does not account for additional environmental costs for extra feed production associated with increased feed needs of 5.5 and $6.3 \%$, respectively. Enteric methane emissions and feed needs were reduced by 6.0 and $8.1 \%$, respectively, in the $13.3 \mathrm{~g} \mathrm{~kg}^{-1} \mathrm{CO}$ scenario compared with the $0.0 \mathrm{~g} \mathrm{~kg}^{-1} \mathrm{CO}$ scenario. Additionally, CO reduced utilization of ration NDF (humanindigestible fiber) for FCMY in both models. In the farm-level model, acreage needed to supply all forages and corn grain for rations was reduced from $129 \mathrm{ha} \mathrm{yr}^{-1}$ to 124,112 and $109 \mathrm{ha} \mathrm{yr}^{-1}$ for the respective scenarios. However, annual FCMY also declined: 16,$600 ; 17,900 ; 15,300$ and $15,100 \mathrm{~kg} \mathrm{ha}^{-1}$, respectively. Thus, revenue from reductions in enteric methane emission must compensate for the loss of income from reduced milk sales to remain financially sustainable in the latter two scenarios. Improvements with the $13.3 \mathrm{~g} \mathrm{~kg}^{-1} \mathrm{CO}$ scenario are due primarily to increased FCMY per cow and enhanced feed conversion efficiency. Consequently, there was only minor, if any improvement in sustainability of national- and farm-level dairy production predicted by these models, when $\mathrm{CO}$ is fed to partially inhibit enteric methane production. 


\title{
SESSION 4: POSTER ABSTRACTS
}

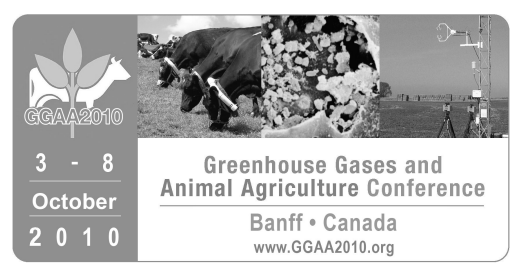

\section{PLEASE NOTE: Authors denoted with an asterisk are registered GGAA2010 delegates}

\author{
T44. Effect of dietary forage to concentrate ratio on lactation performance and methane emission \\ from dairy cows \\ M. Aguerre*, M. A. Wattiaux*, J. M. Powell* and G. A. Broderick
}

Our objective was to determine the effect of feeding diets with different forage to concentrate ratios $(\mathrm{F}: \mathrm{C})$ on performance and methane $\left(\mathrm{CH}_{4}\right)$ emission from lactating dairy cows. Eight multiparous Holstein cows (means \pm standard deviation: $620 \pm 38 \mathrm{~kg}$ of body weight (BW); $41 \pm 34 \mathrm{~d}$ in milk (DIM)) and 8 primiparous Holstein cows ( $546 \pm 38 \mathrm{~kg}$ of BW; $75 \pm 40$ DIM) were blocked by parity and randomly assigned to one of four life-sized emission chambers, each constructed to house four cows in a modified tie-stall barn. Also, chambers were randomly assigned to one of four dietary treatments sequences in a single $4 \times 4$ Latin squares design. Dietary treatments, fed as total mixed rations, included the following F:C ratio: 47:53, 54:46, 61:39 and 68:32 (diet dry matter (DM) basis). Forage consisted of alfalfa silage and corn silage in a 1:1 ratio. Methane emissions were measured during the last $4 \mathrm{~d}$ of each period. Air samples entering and exiting each chamber were analyzed for $\mathrm{CH}_{4}$ concentration with a photo-acoustic field gas monitor (Innova Model 1412). Increasing F:C ratio had no effect on DM intake $\left(20.2 \pm 2.1 \mathrm{~kg} \mathrm{cow}^{-1} \mathrm{~d}^{-1}\right)$, milk yield $\left(37.7 \pm 2.8 \mathrm{~kg} \mathrm{cow}^{-1} \mathrm{~d}^{-1}\right)$, feed efficiency (milk/DM intake, $1.91 \pm 0.24)$, milk fat content $(3.70 \pm 0.21 \%)$ and yield $\left(1.39 \pm 0.01 \mathrm{~kg} \mathrm{cow}^{-1} \mathrm{~d}^{-1}\right)$ and milk true protein yield $(1.00$ $\left.\pm 0.06 \mathrm{~kg} \mathrm{cow}^{-1} \mathrm{~d}^{-1}\right)$. Relative to $47: 53 \mathrm{~F}: \mathrm{C}$ ratio $(2.73 \%)$, milk true protein content did not change $(2.71 \%)$, but decreased to $2.66 \%(P<0.05)$ and $2.61 \%(P<0.05)$ when $\mathrm{F}: \mathrm{C}$ ratio was $54: 46,61: 39$, and $68: 32$, respectively. Higher forage diet tended to increase $\mathrm{CH}_{4}$ emission $(26.9 \mathrm{~g} / \mathrm{cow} /$ hour, $P=0.06$ and $32.5 \mathrm{~g} / \mathrm{kg} \mathrm{DM}$ intake, $P=0.07)$. Also, higher forage diet increased $(P<0.01)$ the $\mathrm{CH}_{4}$ emission per unit of milk yield. Relative to the 47:53 F: $\mathrm{C}$ ratio diet, $\mathrm{CH}_{4}$ emission was increased by $13 \%$ in the intermediate forage inclusion rates (15.2 vs. 17.2 $\mathrm{g} / \mathrm{kg}$ milk, respectively; $P<0.05)$, the latter value being further increased $(P<0.05)$ to 19.2 for the diet with 68:32 F:C ratio (a $26 \%$ increase compared with 47:53 F:C). There was a linear increase in $\mathrm{CH}_{4}$ emission rate, $\mathrm{CH}_{4}$ emission per unit of DM intake and $\mathrm{CH}_{4}$ emission per unit of milk yield with increasing levels of dietary $\mathrm{F}: \mathrm{C}$ ratio (all $P$-values were $<0.02$ ). Under the conditions of this study, feeding higher levels of forage in the diet had negligible effects on animal performance and milk composition, but increased the $\mathrm{CH}_{4}$ emission.

\section{T45. A comparative genomics analysis of rumen methanogens}

E. Altermann*, W. Kelly, S. Leahy, S. Lambie, P. H. Janssen, L. Zhang, A. Klieve*, D. Ouwerkerk, M. Morrison* and G. Attwood*

New Zealand scientists have recently published the first complete genome of a rumen methanogen, Methanobrevibacter ruminantium M1. While this has opened up new avenues in research to identify targets that antagonize the growth and/or metabolism of ruminal methanogens, we also recognized the limitations posed by having only one representative rumen methanogen genome sequence. Comparative efforts to identify truly rumen methanogen specific and conserved genetic islands will only be possible once complete genomes of members of the most relevant rumen methanogen clades become available. To further this aim, our group has set out to culture and purify six additional methanogens and sequence their genomes under the 


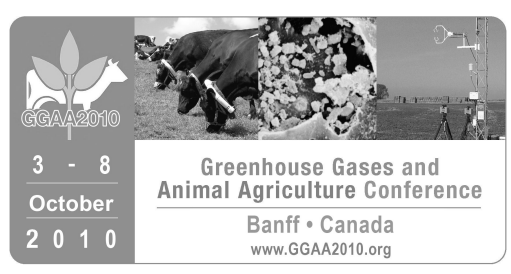

Pastoral Greenhouse Gas Research Consortium umbrella. A parallel effort has been undertaken by the Beef CRC for Genetic Technologies, where a similar number of methanogen strains have been isolated and two genomes are being sequenced. Here we report the current state of this research programme, introducing Methanobacterium formicicum BRM9, Methanobrevibacter sp. SM9, Methanobrevibacter sp. YLM1, Methanosarcina sp. CM1, and Methanosphaera sp. 3F5. In addition, Methanobacterium bryantii MOH (YE299, Beef CRC) and Methanobrevibacter sp NT7 (YE286, Beef CRC) are included in this analysis. Most genomes are presently in draft state, with gap closing underway reducing the number of contigs and scaffolds. A comparative analysis of the new genomes against $M$. ruminantium $\mathrm{M} 1$, and methanogens from other environments, using a new functional genome distribution algorithm will indicate levels of conservation, preserved gene synteny, and lifestyle adaptation. Initial analyses between genomes indicated that, while gene content is largely conserved - preserving core functionality between organisms - gene synteny may diverge significantly.

\section{T46. Methane production and kinetic fermentation from diets containing different products of soy}

J. C.ardoza de Araujo Neto, V. R. Vasconcelos, A. L. Abdalla*, I.C. de Silva Bueno, M. R. Santos R. Peshanha, L. A. Castilho and A. Alves Azevedo

The aim of this work was to determine how replacing diets of soybean meal with soybean byproducts high in lipid content would affect ruminal methane $\left(\mathrm{CH}_{4}\right)$ formation, fermentation parameters and post ruminal protein digestibility in vitro. Four diets with equal energetic and protein values containing soybean milk, soybean grains or extruded soybean as substitutes for soybean meal (control diet) were evaluated using in vitro technique of gas production (GP). The in vitro intestinal digestion of proteins was determined in the portion of diets which were not degraded after an in vitro incubation of $16 \mathrm{~h}$ with rumen fluid and treated with pepsin and pancreatin. The control diet had higher $(\mathrm{P}<0.05) \mathrm{GP}$ and proportion of $\mathrm{CH}_{4}$ compared to the extruded soybean diet and soybean milk diet, whereas extruded soybean diet showed the lowest $(P<0.05)$ values in methane formation per $\mathrm{g} D M$ and $\mathrm{OM}$ incubated $\left(40.4 \mathrm{ml} \mathrm{g}^{-1} \mathrm{DM}\right.$ and $\left.43.4 \mathrm{ml} \mathrm{g}^{-1} \mathrm{OM}\right)$, respectively. Lipids had little effect on the dry and organic matter degradation of the diets, but the methane production per degraded sample was influenced by the lipids. Extruded soybean diet presented lowest $(P<0.05)$ rumen protein degradability while there were no differences detected for all the experimental diets in the intestinal protein digestibility. Diets containing a high level of ether extract had decreased methane formation in vitro.

\section{T47. Nutritional evaluation of baby corn husk - A new feed resource for livestock}

M.P.S. Bakshi and M. Wadhwa*

In India about 7.5-8.75 metric tons of baby corn is produced/ha, out of which only $15 \%$ is the edible baby corn cob and $85 \%$ is constituted by outer peels called baby corn husk (BCH). This is a waste product and poses a threat to the environment. In this study an attempt was made to assess the nutritional worth of $\mathrm{BCH}$ as livestock feed. In the first experiment treatments were as follows: 1) fresh chaffed BCH, 2) BCH wilted for 2-3 days and 3 ) fresh $\mathrm{BCH}$ mixed with chaffed rice straw in a 70:30 ratio (BCH-RS). The $\mathrm{BCH}$ mixed with rice straw was ensiled, in triplicate, in lab silos for 42 days. The in-vitro gas production studies revealed that the net gas production (NGP), NDF and true OM digestibility, and ME availability was highest $(P<0.01)$ in $\mathrm{BCH}$ followed by that in ensiled $\mathrm{BCH}$ and lowest in ensiled $\mathrm{BCH}-\mathrm{RS}$. The methane production as percent of net gas production was also lowest $(P<0.01)$ in $\mathrm{BCH}$ and highest in ensiled $\mathrm{BCH}-\mathrm{RS}$. The total and individual volatile fatty acid 


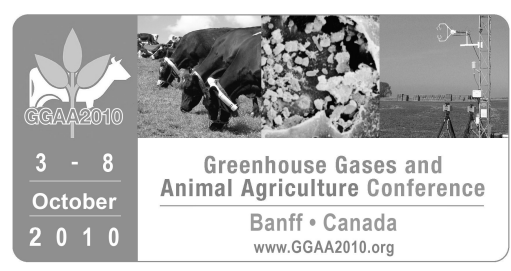

production was comparable in fresh $\mathrm{BCH}$ and ensiled $\mathrm{BCH}$ but higher $(P<0.05)$ than $\mathrm{BCH}-\mathrm{RS}$ silage. The relative proportion of individual volatile fatty acid was comparable in all the groups. In the second experiment, 10 male Murrah buffalo calves ( $147.6 \pm 15.9 \mathrm{~kg} \mathrm{BW}$ ) divided into 2 equal groups were offered ad libitum either chaffed conventional green maize fodder or fresh chaffed $\mathrm{BCH}$ with daily supplementation of $25 \mathrm{~g}$ mineral mixture and common salt for 30 days. The green maize and fresh $\mathrm{BCH}$ contained 91.75 and $94.25 \% \mathrm{OM}, 8.6$ and $11.70 \% \mathrm{CP}$, 68 and $62 \%$ NDF and 33.0 and $24 \%$ cellulose, respectively. The daily DM intake was significantly higher $(P<$ 0.05 ) in buffalo calves fed conventional green fodder as compared to chaffed $\mathrm{BCH}$. The digestibility of all the nutrients was higher $(P<0.05 ; P<0.01)$ in fresh $\mathrm{BCH}$ as compared to green maize fodder. The $\mathrm{N}$-intake, $\mathrm{N}$ exertion through feces and urine of animals fed green maize or fresh $\mathrm{BCH}$ was comparable. The $\mathrm{N}$-retained and apparent biological valve of protein was high in fresh $\mathrm{BCH}$ as compared to the green maize fed group, but the differences were statistically non significant. The rumen studies revealed that the calves offered $\mathrm{BCH}$ as compared to those offered green maize had high total-N (115.4 vs. $109.6 \mathrm{mg} \mathrm{dl}^{-1}$ SRL), TCA-N (56.23 vs. 43.96 $\mathrm{mg} \mathrm{dl}^{-1}$ ) but slightly low TVFAs $\left(103.5\right.$ vs. $115.0 \mathrm{mM} \mathrm{l}^{-1}$ ). In the third experiment 5 buffalo calves (347.8 \pm $14.4 \mathrm{~kg} \mathrm{BW}$ ) were offered concentrate mixture supplemented with ensiled $\mathrm{BCH}$ and wheat straw in 40:30:30 ratio on DM basis as TMR. The digestibility of nutrients and $\mathrm{N}$-retention were considerably higher than that of calves offered fresh $\mathrm{BCH}$. The higher digestibility of nutrient, $\mathrm{N}$-retention, apparent biological valve and favorable rumen environment conclusively revealed that fresh or ensiled $\mathrm{BCH}$ was highly acceptable and palatable as compared to conventional maize fodder.

\title{
T48. Methane mitigation by plant pigments and antioxidants in rumen fluid involves degradation of the active compounds
}

\author{
P.M. Becker*, P. G. van Wikselaar, J. Ilgenfritz, C. Franz and K. Zitterl-Eglseer
}

Secondary plant compounds such as catechin and resveratrol, and those pigments and antioxidants present in extracts of grape seed (Vitis vinifera L.) and bilberry (Vaccinium myrtillus L.) were shown to reduce methane production in rumen fluid. The plant substances were tested in a simplified model of ruminal methane production, using glycerol tripolylactate (Hydrogen Release Compound) as maintenance substrate for rumen bacteria. Fumarate, a known inhibitor of methane production, served as a reference compound in the in vitro tests. The methane-mitigating efficiencies of the plant extracts and compounds were calculated by subtraction of the methane quantity produced in flasks with the interfering additives from the one in blank flasks without additives. Then, the volume of the methane drop was translated into mmole by means of the Ideal Gas Law. Extracts of grape seed and bilberry and the pure compounds catechin and resveratrol had higher methanemitigating efficiencies than did fumarate at comparable concentrations. Although the mode of action of the plant compounds is largely unclear, chemical extraction of putative active compounds from the assays followed by HPLC analysis showed a drastic decrease of the plant compounds in question, such as anthocyanins and procyanidins. In the case of resveratrol, only $0.14 \%$ of the initial amount was recovered at the end of incubation. Hence, it can be concluded that the phenolic compounds were altered and degraded in the experimental model of ruminal methane production. Therefore, the methane-mitigating plant substances do not seem to imply the risk of bioaccumulation or persistence, but even offer the possibility of functioning as alternative electron sinks to methane precursors. 


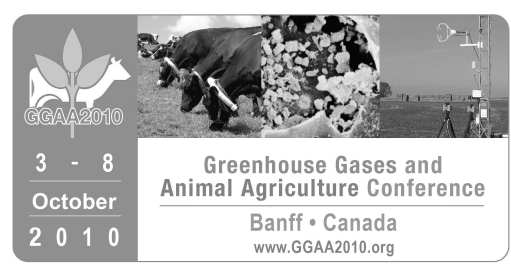

T49. Efficacy of plant phenolics from medicinal and aromatic plants on rumen fermentation, protozoal population and methanogenesis in vitro

R. Bhatta*, L. Baruah, S. Saravanan and K. T. Sampath

The present study was carried out to determine the effect of tannins from 21 medicinal and aromatic plant leaves on rumen fermentation, protozoa population and methanogenesis in vitro. Total phenol (TP) content in Terminalia chebula was $>270 \mathrm{~g} \mathrm{~kg}^{-1} \mathrm{DM} ;>70$ and $>50 \mathrm{~g} \mathrm{~kg}^{-1} \mathrm{DM}$, respectively in Hemigraphis colorata and Sapindus laurifolia. The TP content was $<45 \mathrm{~g} \mathrm{~kg}^{-1} \mathrm{DM}$ in rest of the samples. Activity of tannins, as represented by the increase in gas on addition of PEG-6000 ranged from nil (zero) to $133 \%$, with highest recorded in Terminalia chebula. The rumen fermentation and methane production were studied after $24 \mathrm{~h}$ incubation in the in vitro Hohenheim gas method. The methane production reduction potential (MRP) was calculated by assuming net methane concentration for the control straw (Elusine coracana) as $100 \%$. The methane production reduction potential (MRP) of Tinospora cordifolia and Lantana camera was $>50 \%$. The MRP of zero for Cinnamomum camphora meant that the methane concentration for this sample was the same as that of the control straw. Similarly, zero values of percent increase in methane on addition of PEG for Ammi majus, Cascabela thevetia, Ipomea nil, Aristolochia indica and Lantana camera illustrated that the tannins in these samples did not contribute to methane concentration. The increase in total protozoa was $>50 \%$ in Cascabela theretica and Aristolochia indica on addition of PEG. The percent increase in Entodinia was more in incubations with PEG compared to that of Holotricha, indicating higher susceptibility of these protozoa to tannin. Out of the 21 samples, there was increase in population of Entodinia in 12.

\section{T50. Effect of supplementing forage-based diets for late-gestation wintering beef cows with dried distillers grains plus solubles or rolled barley grain on methane emissions \\ H. C. Block*, A. D. Iwaasa*, C. D. Robins and S. L. Scott}

To complement a drylot trial evaluating the effects of supplementing forage-based diets for late-gestation wintering beef cows, replicated Latin square evaluations of digestibility and methane emissions were carried out over two winters. Each evaluation used nine late-gestation beef cows $(688 \pm 30 \mathrm{~kg}$ BW year 1; $712 \pm 30 \mathrm{~kg}$ BW year 2) in individual outdoor pens in three 21-d evaluation periods. Treatments were an un-supplemented control diet (CONT; $60 \%$ alfalfa brome hay: $40 \%$ barley silage year $1 ; 60 \%$ oat straw:40\% barley silage year 2 ), a dried distillers grains plus solubles supplemented diet (DDGS; $80 \%$ control diet:20\% dried distillers grains plus solubles), and a rolled barely grain supplemented diet (RBAR; $80 \%$ control diet:20\% rolled barley grain). Diet dry matter intakes were estimated over 4 (year 1 ) or 5 (year 2 ) d during the last week of each period. Methane and carbon dioxide emissions were estimated via the $\mathrm{SF}_{6}$ marker and PVC yoke sampling method over $3 \mathrm{~d}$ during the last week of each period. Temperatures during the collection periods were $-19,-19$, and $-22^{\circ} \mathrm{C}$ in year 1 and $-21,-21$, and $-13^{\circ} \mathrm{C}$ in year 2 . No effects of treatments on methane $(P=0.87)$ or carbon dioxide $(P=$ $0.40)$ emissions estimates were detected. The RBAR and DDGS treatments had greater $(P<0.05) D M$ intake than the CONT diet. Similar methane emissions with greater DMI, and improved feed efficiency (drylot trial) suggest supplementing late-gestation wintering beef cows diet with rolled barley grain or DDGS can reduce the methane emissions per unit of production. 


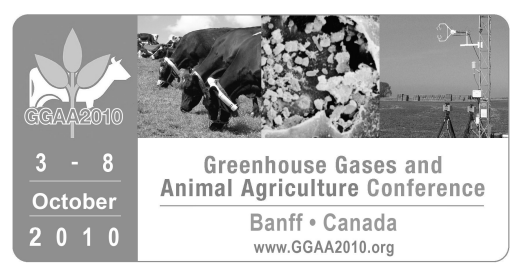

\title{
T51.Effect of oral nitroethane administration on enteric methane emissions and ruminal fermentation in cattle
}

E. G. Brown, R. C. Anderson*, G. E. Carstens, H. Gutierrez-Bañuelos, L. J. Slay, T. R. Callaway and D. J. Nisbet

Methane is known to be a potent greenhouse gas and its release to the atmosphere contributes to global warming. Ruminal methane production represents a loss of $2-15 \%$ of the animal's gross energy intake (GEI) and contributes nearly $20 \%$ of the United States total emission of this gas. Earlier studies have evaluated the methane-inhibiting potential of select short chain nitrocompounds such as nitroethane but results demonstrating potential effects of these inhibitors on expired methane emissions are lacking. In the present study, we examined the effects of oral nitroethane administration on animal methane emissions, ruminal methane-producing activity and fermentation balance in growing calves fed a roughage-based diet ( $\mathrm{ME}=2.1$ Mcal kg-1 DM). Twenty-four Holstein steers averaging ( \pm SD) $317 \pm 6.5 \mathrm{~kg}$ body weight were randomly allocated in two groups ( 3 steers per treatment per group) to treatments of $0(0 X), 30(1 X), 60(2 X)$ and $120(4 X) \mathrm{mg}$ nitroethane per kg BW per day. Treatments were administered via oral gavage twice daily (0800 and 1600) for 8 days. Not unexpectedly, initial and final body weight were unaffected $(P>0.14$; SEM $=3.3)$ by nitroethane treatment during this short duration experiment. Dry matter intake (DMI) was affected $(P<0.01 ; \mathrm{SEM}=0.24)$ by nitroethane treatment, with DMI of steers administered $2 X$ nitroethane $\left(7.21 \mathrm{~kg} \mathrm{~d}^{-1}\right)$ being $14 \%$ lower than by steers administered $0 \mathrm{X}$ or $1 \mathrm{X}$ nitroethane ( 8.40 and $8.44 \mathrm{~kg} \mathrm{~d}^{-1}$, respectively) but not different from steers administered $4 \mathrm{X}$ nitroethane $\left(7.80 \mathrm{~kg} \mathrm{~d}^{-1}\right.$, respectively). When compared to control steers (0X), exhaled methane emissions $(6.86 \% \mathrm{GEI})$ and ruminal methane-producing activity $\left(5.83 \mu \mathrm{mol} \mathrm{CH}_{4} \mathrm{ml}^{-1} \mathrm{~h}^{-1}\right)$ were reduced $(P<0.05)$ by 22 and $25 \%$, respectively, in steers administered nitroethane at the $4 \mathrm{X}$ treatment dose (SEM $=$ 0.59 and 1.91, respectively). Ruminal volatile fatty acid accumulations were unaffected $(P>0.08)$ by nitroethane treatment indicating minimal effect of treatment on fermentation balance. These results demonstrate that nitroethane appears to be an effective anti-methanogenic compound following short-term oral administration to growing steers fed high-roughage diets. Further research is warranted to determine if strategies using nitroethane or similar anti-methanogenic nitrocompounds may be sustainable in ruminant animal production systems over the long term. Ultimately, nitrocompounds that can be reduced by the rumen microbiota to yield compounds of nutritional value to the host animal would be preferable.

\section{T52. Natural additives to dairy cow rations as potential factors decreasing methane emission}

\author{
A. Cieslak*, P. Zmora, E. Pers-Kamczyc and M. Szumacher-Strabel*
}

Methane emission from ruminants significantly affects global warming as well as animal production by causing economic loss of feed energy. However, the effect of a diet supplemented with natural additives on the extent of methane production by rumen Archaea is still not well documented. Moreover, routine researches on rumen protozoa in relation to dietary supplementation are usually focused on the evaluation of total protozoa count and do not include qualitative analysis. The aim of the current study was to present in vitro and in vivo changes in methanogen and ciliate population and also to monitor changes in methane emission from dairy cows fed diets supplemented with blended rapeseed and fish oils, yeast and tannins. The in vitro experiment was carried out in the RUSITEC system. The basic diet was supplemented with (i) $2 \%$ of tannins in dietary DM, (ii) $5 \%$ of rapeseed and fish oil in dietary DM in the proportion of $1: 1$, and (iii) yeast $\left(5 \mathrm{~g} \mathrm{~d}^{-1}\right.$ animal $\left.{ }^{-1}\right)$. Incubated rumen fluid was analyzed for methane production and basic biochemical parameters. Additionally, quantitative and qualitative analysis of rumen ciliate population was made. The in vivo experiment was carried out using 4 


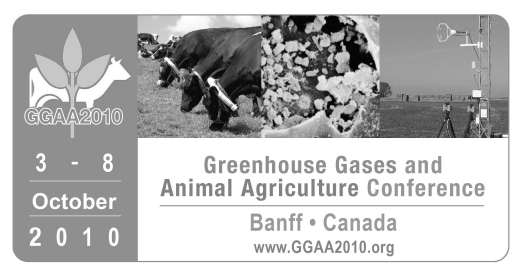

cannulated dairy cows in a $4 \times 4$ Latin square design. The animals were fed diets supplemented with blended rapeseed and fish oils in the proportion of 1:1 (up to 5\% of DM in a diet), yeast Saccharomyces cerevisiae strain CNCMI1077 or extract of Folium Vitisidaeae (2\% of DM in a diet). The following parameters were analyzed in rumen fluid samples: final fermentation products, protozoal and bacterial counts, methane production and daily milk production. Moreover, in order to monitor the total count of methanogens (Archaea) as well as to identify two strains: Methanobacteriales and Methanomicrobiales, the fluorescent in situ hybridization (FISH) technique was applied. In the in vitro studies, a reduction of methane emission was observed in the group with tannin supplementation. Simultaneously, the extract from $F$. Vitisidaeae reduced the methane emission calculated per $1 \mathrm{~kg}$ of milk by $12 \%$. Supplementation with yeast caused mitigation of methanogenesis by $16 \%$. The population of Methanobacteriales was significantly decreased $(P<0.05)$ after tannin supplementation. The extract of $F$. Vitisidaeae was the most effective natural additive decreasing ruminal methanogenesis.

\title{
T53. Methane suppressing effect of flaxseed in diets containing hay or silage
}

\author{
Y.-H. Chung*, M.-L. He, S. M. McGinn*, T. A. McAllister* and K. A. Beauchemin*
}

Including flaxseed (flax) in the diet of cattle can increase n-3 fatty acid content of milk and meat. Our study investigated the potential of flax to reduce enteric methane $\left(\mathrm{CH}_{4}\right)$ emissions from cows when added to diets containing hay or silage. Effects of forage type and flax inclusion on ruminal fermentation and apparent nutrient digestibility were also studied. Twelve ruminally cannulated, non-lactating Holstein cows were used in a replicated $4 \times 4$ Latin Square design with 21-d periods. Experimental diets (50:50 forage to concentrate ratio; DM basis) were formulated as a $2 \times 2$ factorial using either alfalfa-grass (mostly grass, chopped) mixed hay or barley silage as the forage source with or without 15\% (ration DM; provided $5.2 \%$ added fat) ground flax as a partial replacement of barley grain. Diets were fed once daily as a total mixed ration. Enteric $\mathrm{CH}_{4}$ production was measured for $3 \mathrm{~d}$ using the sulphur hexafluoride tracer gas technique. Without flax inclusion, cows produced 31,26 or $29 \%$ less $(\mathrm{P}<0.5) \mathrm{CH}_{4}$ when fed hay compared with silage (207 vs. $300 \mathrm{~g} \mathrm{CH}_{4}$ head $^{-1} \mathrm{~d}^{-1}, 19.6$ vs. $26.4 \mathrm{~g} \mathrm{CH}_{4} \mathrm{~kg}^{-1}$ of DMI, or 30.4 vs. $42.9 \mathrm{~g} \mathrm{CH}_{4} \mathrm{~kg}^{-1}$ of digestible DMI, respectively). The lower $\mathrm{CH}_{4}$ emissions per unit of intake from cows fed hay, as compared with those fed silage, may be partially attributable to lower ruminal $\mathrm{pH}$ due to sorting of the hay diet. Including flax in the hay diet did not further suppress $\mathrm{CH}_{4}$ emissions whereas, including flax in the silage diet reduced $(\mathrm{P}<0.5)$ daily $\mathrm{g} \mathrm{CH}_{4}$ per head by $36 \%$ and $\mathrm{CH}_{4}$ production per $\mathrm{kg} \mathrm{DMI}$ and per $\mathrm{kg}$ digestible DMI by 33 and $28 \%$, respectively. Flax inclusion lowered $\mathrm{CH}_{4}$ emissions of cows fed the silage diet in part by depressing $(P<0.5)$ fermentation of ruminal fibre and total tract fibre digestibility, a response not observed with the hay diet. Our study demonstrated that including $15 \%$ ground flax in a barley silage-based diet, with an aim of enhancing $n-3$ fatty acid content of meat, is an effective practice to mitigate enteric $\mathrm{CH}_{4}$.

\section{T54. Use of feed intake as an indirect selection trait for reduction of methane emissions in grazing beef cattle \\ D. J. Cottle*}

In Australia, cattle are the largest single source of greenhouse gas emissions from the agricultural sector. Genetic selection for lower emitting cattle can be attempted by direct or indirect selection. A short fed domestic index has been used to predict the genetic gain in beef cattle traits with feed intake or methane production used as selection criteria with various assumed carbon prices. Indirect selection for reduced 


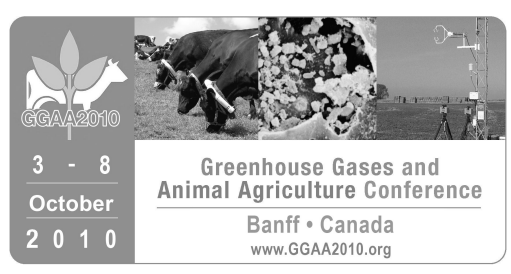

methane emissions via feed intake was predicted to be more cost effective than direct measurement via methane emissions. It is suggested that pasture feed intake of cattle is preferable to residual feed intake, measured in a feedlot, as a selection criterion for grazing cattle. A pasture intake measurement system to assist such genetic selection is being developed.

\section{T55. Australian native plant Eremophila glabra affects fermentability and reduces methane output from a sheep diet fermented in artificial rumen (Rusitec) \\ Z. Durmic, C. Raphalen and P. Vercoe*}

Recent studies showed that Australian native plant Eremophila glabra produces significantly less methane than oaten chaff or lucerne when incubated in vitro in batch culture with rumen fluid and addition of this plant may moderate methane output during fermentation of these substrates in the rumen. An experiment was conducted using Rumen Simulation Technique (Rusitec), to compare the fermentation patterns of a standard sheep ration (SR; $1 \mathrm{~kg}$ oaten chaff: $0.25 \mathrm{~g}$ part lupins: $0.025 \mathrm{~g}$ minerals) with or without supplementation with E. glabra. The system was allowed to stabilize for 7 days on SR before introducing freeze-dried leaf material from E. glabra in three vessels, at a level of $25 \%$ of total substrate (EG; $15 \mathrm{~g} \mathrm{E}$. glabra and $45 \mathrm{~g}$ SR). The remaining three control vessels continued receiving daily $60 \mathrm{~g}$ of SR. This regime was maintained for 8 days, during which $\mathrm{pH}, \mathrm{VFA}$ and $\mathrm{NH}_{3}$ concentrations as well as volume and the composition $\left(\mathrm{CH}_{4}\right.$ and $\left.\mathrm{CO}_{2}\right)$ of gas produced were measured daily. Overall, gas production and $\mathrm{CO}_{2}$ concentrations were not affected by the addition of $E$. glabra, but $\mathrm{CH}_{4}$ concentrations were significantly decreased on all sampling days. The $\mathrm{CH}_{4}$ was reduced from $13.1 \%$ (day 0 ) to $1.7 \%$ immediately after the $E$. glabra addition (day 1 ) and continued to decrease daily until it reached $0 \%$ (day 6 ). Zero readings for methane in the EG treatment maintained until the end of the experiment (day 8). Inclusion of E. glabra was also accompanied with a significant increase in $\mathrm{pH}$ (from day 5 onwards), and decrease in VFA and $\mathrm{NH}_{3}$ concentrations (from day 2 onwards). The results from this study are preliminary, but demonstrate that inclusion of E. glabra can reduce methane production when added to a sheep diet. The antimethanogenic effect persisted over eight days; however, it was also accompanied with inhibition of fermentative traits. Supplementation of E. glabra may be beneficial in reducing methane in ruminants consuming fibrous diets, but further studies are required to optimize the inclusion level that is less detrimental on rumen fermentation.

\section{T56. Dietary linseed and starch supplementation decreases methane production of fattening bulls M. Eugène*, C. Martin, M. M. Mialon, D. Krauss, G. Renand and M. Doreau}

Greenhouse gases (GHG) impacts on climate changes are a major concern worldwide and enteric methane $\left(\mathrm{CH}_{4}\right)$ is the most important GHG emitted at the farm scale $(50-60 \%)$ in ruminant production systems. Dietary concentrate and lipid supplementations reduce $\mathrm{CH}_{4}$ emission, but their association is not known. This study aimed to determine $\mathrm{CH}_{4}$ production from bulls fed a high-concentrate diet supplemented or not with extruded linseed. Fifty-six Charolais bulls were allocated to 2 treatments and fattened during 16 months (start at 8.5 months and $339 \mathrm{~kg} \mathrm{BW})$. Control diet (C) contained a concentrate rich in fiber (40\% NDF, 2.8\% EE) and linseed supplemented diet (LS) contained a concentrate rich in starch and with $6 \%$ DM of extruded linseed ( $33 \%$ starch, 4.7\% EE). Concentrate and straw were available ad libitum. Feed intake was measured $5 \mathrm{~d}$ per week and animals were weighed bimonthly. Methane production was determined using the $\mathrm{SF}_{6}$ gas tracer method for each bull at 3 periods (start, middle and end of fattening). Ruminal fluid sample was collected by 


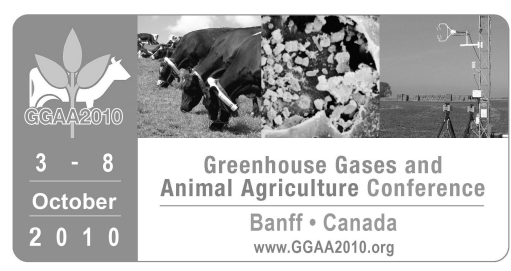

ruminocentesis to measure $\mathrm{pH}$ and VFA. Data were analyzed with Proc Mixed (SAS). Concentrate:straw ratio was 87:13 on DM basis for both diets and average daily gains (ADG) were 1.385 vs $1.465 \mathrm{~g} / \mathrm{d}$ for bulls fed $C$ and LS diet $(P=0.09)$, respectively. Bulls fed LS diet had lower DM intake $(P<0.05)$ and higher net energy (NE) intake $(P=0.05)$ than bulls fed $\mathrm{C}$ diet. Bulls fed $\mathrm{LS}$ diet had lower $\mathrm{CH}_{4}$ production (g/d and $\mathrm{g} / \mathrm{NE}$ intake) than bulls fed $\mathrm{C}$ diet (-19\% and $-24 \%$ for the first 2 periods, $P<0.01$, respectively), but no differences were observed at the end of fattening. Bulls fed LS diet had higher $\mathrm{CH}_{4}$ (g/kg DM intake) than bulls fed $\mathrm{C}$ diet $(+22 \%, P<0.05$,) at the end of fattening, whereas no difference was observed before. Bulls fed LS diet had lower ruminal VFA and acetate concentration than bulls fed $C$ diet $(-13 \%$ and $-23 \%, P<0.001$ respectively), but diet had no effect on $\mathrm{pH}$. A moderate supplementation with extruded linseed lipids, combined with high-starch diet, decreased methanogenesis. This was mainly due to a lower DM intake, and was stable at the start and middle of fattening for $\mathrm{CH}_{4}(\mathrm{~g} / \mathrm{d}$, and $\mathrm{g} / \mathrm{NE}$ intake), however it declined at the end. Overall, bulls fed LS diet produced the lowest $\mathrm{CH}_{4}$ output when expressed as $\mathrm{g} / \mathrm{kg}$ ADG $(-18 \%, P<0.001)$.

\section{T57. Effect of digestibility of grass-clover silage and concentrate to forage ratio on methane emission from dairy cows}

A. L. Frydendahl Hellwing* and M. R. Weisbjerg

That methane emission from dairy cows is affected by concentrate to forage ratio is well known, whereas the effect of the quality of grass-clover silage is not well described. Besides this, the purpose of the present study also was to test our new facilities for measuring methane emission from dairy cows and the working routines. Twenty-four Holstein cows were allocated to eight different treatments and blocked according to parity. Treatments were in a $2 \times 4$ design, two concentrate to forage ratios and four different grass-clover silages. The grass-clover silages (A, B, C, D) were produced during the 2009 growth season. A was primary growth made in the beginning of May, B was second 1st regrowth made in middle of June, $C$ was 3rd regrowth made in the beginning of August and $D$ was 3rd regrowth made at the end of August. The energy concentrations were 6.6, 6.0, 6.5 and 6.1 MJ NEL kg ${ }^{-1}$ DM for silage A, B, C and D, respectively. Total mixed ration forage DM consisted of $2 / 3$ of one of the respective grass-clover silages and $1 / 3$ maize silage, and concentrate (soya meal and wheat) proportion of DM was $20 \%$ (low) or $50 \%$ (high). Methane emissions from the cows were measured $20-22 \mathrm{~h}$ in one of four chambers working after the principles for indirect calorimetry The air flow was measured continuously, and the concentrations of methane, oxygen and carbon dioxide were measured in ingoing and outgoing air from the chambers every $12.5 \mathrm{~min}$. The cows were milked and feed twice daily, and yield and intake were registered. The experiment was analyzed as a $2 \times 4$ factorial design with parity as block effect. The methane emissions as total emission and per kg milk yield were significantly affected by concentrate proportion, but not by silage type. Cows on the high concentrate diets produced on average $617 \mathrm{~L}$ of methane and cows on the low concentrate diet $770 \mathrm{~L}$ of methane per $24 \mathrm{~h}$. The experiment showed that the system worked and measured reliable values for methane emission in relation to diets and feed intake, although accuracy of relating methane emission to feed intake was hampered by the short $20-22 \mathrm{~h}$ chamber measuring periods.

\section{T58. Poultry litter as a source of minerals for growing calves fed corn silage}

H.M. Gaafar*, K.F.A. El-Riedy and R.M. Abou-Aiana

Twenty four male Friesian calves averaging $175 \mathrm{~kg}$ body weight were used to study the effect of feeding rations containing different levels of poultry litter and corn silage on mineral balance and concentration of in hair, 


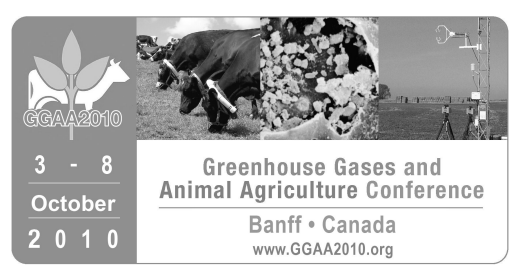

blood and seminal plasma and body tissues. Calves were divided into four similar groups assigned randomly to feed on three experimental rations as follows: R1 (control): $65 \%$ concentrate feed mixture $+20 \%$ berseem hay $+15 \%$ rice straw. R2: $12.5 \%$ poultry litter $+12.5 \%$ ground corn grain $+75.0 \%$ corn silage. $R 3: 25.0 \%$ poultry litter $+25.0 \%$ ground corn grain $+50.0 \%$ corn silage. $R 4: 37.5 \%$ poultry litter $+37.5 \%$ ground corn grain $+25.0 \%$ corn silage. The results showed that the contents of calcium (Ca), phosphorus (P), magnesium ( $\mathrm{Mg}$ ), sodium $(\mathrm{Na})$, potassium $(\mathrm{K})$, copper $(\mathrm{Cu})$, zinc $(\mathrm{Zn})$, manganese $(\mathrm{Mn})$, iron $(\mathrm{Fe})$ and cobalt $(\mathrm{Co})$ in poultry litter were higher compared with corn grain and corn silage. The contents of $\mathrm{Ca}, \mathrm{P}, \mathrm{Mg}, \mathrm{Na}, \mathrm{K}, \mathrm{Cu}, \mathrm{Zn}, \mathrm{Mn}, \mathrm{Fe}$ and $\mathrm{Co}$ in the experimental rations increased with increasing the level of poultry litter and decreasing the level of corn silage. The intake, excretion in feces and urine, apparent absorption and retention of $\mathrm{Ca}, \mathrm{P}, \mathrm{Mg}, \mathrm{Na}, \mathrm{K}, \mathrm{Cu}, \mathrm{Zn}, \mathrm{Mn}, \mathrm{Fe}$ and Co (g or $\mathrm{mg} /$ day) increased significantly $(P<0.05)$ with increasing the level of poultry litter and decreasing the level of corn silage. The concentrations of $\mathrm{Ca}, \mathrm{P}, \mathrm{Mg}, \mathrm{Na}, \mathrm{K}, \mathrm{Cu}, \mathrm{Zn}, \mathrm{Mn}$, Fe and $\mathrm{Co}$ in hair, blood and seminal plasma of Friesian calves increased significantly $(P<0.05)$ with increasing the level of poultry litter and decreasing the level of corn silage in the rations. Also, the contents of $\mathrm{Ca}, \mathrm{P}, \mathrm{Mg}, \mathrm{Na}, \mathrm{K}, \mathrm{Cu}, \mathrm{Zn}, \mathrm{Mn}, \mathrm{Fe}$ and $\mathrm{Co}$ in liver, kidneys, testis and muscle of Friesian calves increased significantly $(P<0.05)$ with increasing the level of poultry litter and decreasing the level of corn silage in the rations.

\section{T59. Productive and reproductive performance of lactating cows and buffaloes fed total mixed rations (TMR)}

H.M.A. Gaafar*, A.M.A. Mohi El-Din and M.I. Bassiouni

Two experiments were conducted to study the effect of feeding total mixed ration (TMR) on productive and reproductive performance of lactating cows and buffaloes. In experiment 1 (winter feeding): 21 Friesian cows and 21 buffaloes fed rations consisted of DM basis of $40 \%$ concentrate feed mixture, $40 \%$ fresh berseem and $20 \%$ rice straw (control ration), 30\% concentrate feed mixture, 35\% fresh berseem, $20 \%$ corn silage and $15 \%$ rice straw (TMR1) and 35\% fresh berseem, 30\% corn silage, 14\% rice straw, $10 \%$ corn grain, $5 \%$ soybean meal, $5 \%$ wheat bran and 1\% premix (TMR2). In experiment 2 (summer feeding): 21 Friesian cows and 21 buffaloes fed rations consisted of DM basis of $60 \%$ concentrate feed mixture, $20 \%$ berseem hay and $20 \%$ rice straw (control ration), $50 \%$ concentrate feed mixture, $15 \%$ berseem hay, $20 \%$ corn silage and $15 \%$ rice straw (TMR1) and $15 \%$ berseem hay, $30 \%$ corn silage, $14 \%$ rice straw, $20 \%$ corn grain, $10 \%$ soybean meal, $10 \%$ wheat bran and $1 \%$ premix (TMR2). Results showed that the contents of DM, CP, CF, EE and ash tended to decrease, but the contents of OM and NFE tended to increase with TMR. TMR2 showed significantly $(P<0.05)$ the highest digestibility coefficients and nutritive values and were significantly higher $(P<0.05)$ with winter than summer feeding. The digestibility coefficients of DM, OM, CF and EE were significantly higher $(P<0.05)$ for buffaloes than cows. Cows and buffaloes fed TMR2 showed the highest DM and TDN intakes and the lowest DCP intake and were significantly higher $(P<0.05)$ for winter feeding compared with summer feeding. The intake of DM, TDN and DCP were nearly similar for cows and buffaloes. The yield of actual milk and 4\% FCM were higher significantly $(P<0.05)$ for cows and buffaloes fed TMR1\&2 compared with those fed control ration and for winter than summer feeding. The yield of actual milk was significantly higher $(P<0.05)$ for cows than buffaloes, while the yield of $4 \%$ FCM was nearly similar. Cows and buffaloes fed TMR2 recorded significantly $(P<0.05)$ the highest contents of fat, lactose, SNF and TS in milk and those fed control ration had the highest protein and ash contents. The contents of all milk constituents were nearly similar for winter and summer feeding and the contents of all milk constituents except ash were significantly higher $(P<0.05)$ for buffaloes than cows. The amounts of DM and DCP per kg FCM were significantly lower $(P<0.05)$ for cows and buffaloes fed TMR1\&2 than those fed control ration, but TDN was nearly similar. The amounts of DM, TDN and DCP per kg FCM were significantly lower $(\mathrm{P}<0.05)$ for winter than summer feeding and cows than buffaloes. Cows and buffaloes fed 


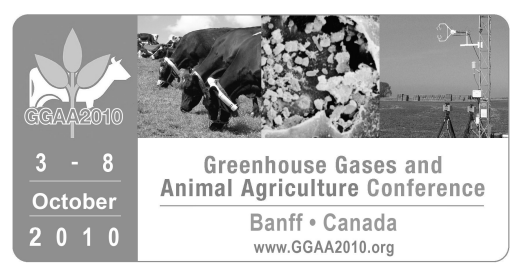

TMR1\&2 showed significantly $(P<0.05)$ the lowest average daily feed cost and feed cost per kg FCM and the highest output of FCM yield and economic efficiency. Average daily feed cost, feed cost per kg FCM were significantly lower $(P<0.05)$ and the output of FCM yield and economic efficiency were significantly higher $(P<$ $0.05)$ for winter than summer feeding. The output of FCM yield and economic efficiency were significantly higher $(P<0.05)$ for cows than buffaloes. Cows and buffaloes fed TMR2 showed significantly $(P<0.05)$ the short periods of first estrus and service, service period, days open and calving interval, the lowest service per conception and the highest conception rate. The periods of first estrus and service, days open and calving interval were short, the service per conception was lower and the conception rate was higher for summer than winter feeding $(P<0.05)$. The periods of first estrus and service, service period, days open and calving interval were short, the service per conception was lower and the conception rate was higher for cows than buffaloes $(P<0.05)$.

\section{T60. Isolation and characteristics of new reductive acetogens from the rumen} M.-J. Gu*, J.-N. Bae*, S.-H. Kim, M. J. Alam, C.-O. Jeon, Y.-K. Oh and S.-S. Lee*

Reductive acetogenesis is an alternative hydrogen-utilizing pathway to methanogenesis in the rumen and has potential as a strategy for reducing ruminant greenhouse gas emissions. Homoacetogens use the WoodLjungdahl pathway for growth on hydrogen and carbon dioxide as the sole energy source. The objective of this study was to isolate and identify new homo-reductive acetogenic bacterium from rumen contents of Holstein cows, Korean black goats and Korean native cattle (Hanwoo) and evaluate the characteristics of these strains on the effect of methane reduction. Fifty-two acetogenic ruminal bacteria in various ruminant animals were isolated from AC-B1 medium (TD Le Van et al., 1998) and analyzed the 16S rRNA gene sequence using the NCBIBLAST search and EzTaxon server. Most of the identified sequences had the high homology to Proteiniphilum acetatigenes TB107T (AY742226), Eubacterium limosum ATCC 8486T (M59120) known as acetogens, Alkaliphilus crotonoxidans B11-2T (AF467248) degrading butyrate, Bacillus thermoamylovorans CNCM I-1378T, moderately thermophilic and amylolytic bacterium, and else the diverse sequences showed. To measure the presence of rumen homoacetogens, we examined sequences of formyltetrahydrofolate synthetase (FTHFS), a key enzyme of the Wood-Ljungdahl pathway. A phylogenetic tree was constructed based on 4 identified strains encoding FTHFS sequences, together with other sequences from public databases and from novel nonhomoacetogenic bacteria isolated from the rumen. Acetate production and other fermentation end products by FTHFS-containing 4 isolates supplied $\mathrm{H}_{2}$ and $\mathrm{CO}_{2}$ or glucose as substrates were determined using the high performance liquid chromatography (HPLC) method. All isolates produced acetate from $\mathrm{H}_{2}$ and $\mathrm{CO}_{2}$ and glucose compared with reference acetogenic strains. The highest amount of acetic acid was detected with the strain of $\mathrm{G} 2 \mathrm{HO} 4$ derived from Korean native goat's rumen and butyrate produced only when added to the glucose.

\section{T61. Effect of feeding fresh white clover (Trifolium repens) or perennial ryegrass (Lolium perenne) on methane emissions from sheep}

K. Hammond*, S. O. Hoskin, C. S. Pinares-Patĩno*, J. L. Burke, G. C. Waghorn* and S. Muetzel

Enteric methane $\left(\mathrm{CH}_{4}\right)$ fermentation in ruminants is an important contributor to global anthropogenic emissions of greenhouse gases. Methane emissions are most often measured using respiration chambers or by the sulfur hexafluoride $\left(\mathrm{SF}_{6}\right)$ tracer gas technique. Using the $\mathrm{SF}_{6}$ technique, it has been shown that sheep fed 


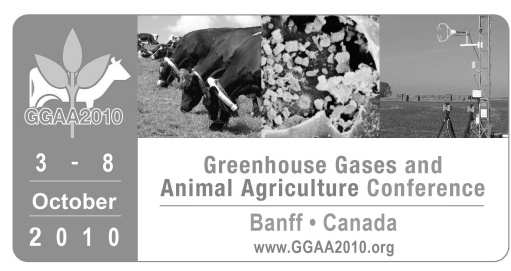

white clover (Trifolium repens) can yield up to $50 \%$ less $\mathrm{CH}_{4}(\mathrm{~g} \mathrm{CH} / \mathrm{kg} \mathrm{DMI})$ than sheep fed ryegrass (Lolium perenne). If this could be confirmed, it offers an opportunity to reduce $\mathrm{CH}_{4}$ emissions from pastoral-based ruminant livestock systems. Respiration chambers are accepted as most accurate for measuring $\mathrm{CH}_{4}$ emissions and were therefore used in two experiments to compare $\mathrm{CH}_{4}$ emissions from wether sheep fed either freshly harvested white clover (clover) or perennial ryegrass (ryegrass). For experiments 1 and 2, sheep had a 10-d period for adaptation to respective diets and then were placed in respiration chambers where $\mathrm{CH}_{4}$ emissions were determined for two consecutive days. In experiment 1 , sheep were fed at $1.5 \mathrm{X}$ and $1.8 \mathrm{X}$ maintenance energy requirements for clover and ryegrass, respectively. Methane yield $\left(\mathrm{g} \mathrm{CH}_{4} / \mathrm{kg} \mathrm{DMI}\right.$ ) was $12 \%$ lower $(P=0.04)$ for clover-fed (19.8) compared with grass-fed sheep (22.5). In experiment 2 , clover and ryegrass were compared when fed at both $0.8 \mathrm{X}$ and $2.0 \mathrm{X}$ maintenance energy requirements. Methane yield was similar $(P=0.24)$ for sheep fed clover and ryegrass at $0.8 \mathrm{X}$ maintenance ( 27.1 and 25.5 , respectively). However, for sheep fed at 2.0X maintenance, methane yield was $7 \%$ higher $(P=0.05)$ for clover-fed (23.4) compared with ryegrass-fed sheep (21.7). Other researchers using respiration chambers to measure $\mathrm{CH}_{4}$ emissions by beef cattle and calves fed white clover versus ryegrass, or by sheep fed persian clover (Trifolium resupinatum $\mathrm{L}$ ) versus ryegrass, reported findings similar to those reported here. Thus, the earlier finding using the $\mathrm{SF}_{6}$ technique; that white clover could yield up to $50 \%$ less methane than ryegrass, is not supported by the more accurate respiration chamber technique. We conclude that the use of white clover as an alternative fresh forage to ryegrass does not present an opportunity to reduce enteric $\mathrm{CH}_{4}$ emissions from ruminants.

\section{T62. Effect of neutral detergent fibre content of grass silage on in vitro methane production}

S. Hanche-Olsen Liest $\left.\varnothing\right|^{*}$, L. Holtshausen*, K.A. Beauchemin*, O.M. Harstad*, T.A. McAllister*, S.K. Nes* and H. Volden

The objective of this experiment was to investigate the effect of neutral detergent fibre (aNDF) content of grass silage on in vitro methane $\left(\mathrm{CH}_{4}\right)$ production. A mixed Timothy (Phleum pretense)/Meadow fescue (Festuca pratensis) stand was harvested at aNDF contents (DM basis) of 42\% (LaNDF), 54\% (MaNDF) and 65\% (HaNDF). Forages were cured to $27 \% \mathrm{DM}$ and treated with a formic acid-based additive ( $4.5 \mathrm{~L} /$ tonne of grass) and ensiled in round bales sealed with plastic. Total tract digestibilities of aNDF, assessed by total collection of feces from nine sheep ( $n=3$ per silage quality), were estimated at 86,76 and $73 \%$ for LaNDF, MaNDF and HaNDF, respectively. Silage samples were freeze-dried and ground through a 1-mm screen, and incubated in buffered ruminal fluid (700 mg DM/75 mL; $n=5)$. Methane production and in vitro aNDF digestibility (DaNDF) were determined after 24 and $48 \mathrm{~h}$ of incubation. The LaNDF silage had highest $(P<0.05)$ DaNDF at $24 \mathrm{~h}(48 \%)$ and 48 $\mathrm{h}(70 \%)$. In contrast, there were only minor and non-significant differences $(P>0.05)$ in DaNDF between silages MaNDF and HaNDF, both at $24 \mathrm{~h}$ (37 vs 39\%) and at $48 \mathrm{~h}$ (57 vs 58\%). Production of $\mathrm{CH}_{4}$ from LaNDF, MaNDF and HaNDF at $24 \mathrm{~h}$ was $97.7,82.4$ and $48.0 \mathrm{~mL} / \mathrm{g}$ aNDF digested, respectively, and $115.4,96.9$ and $64.7 \mathrm{~mL} / \mathrm{g}$ aNDF digested at $48 \mathrm{~h}$. Silage quality affected $(P<0.05)$ methane production adjusted per $\mathrm{g}$ aNDF digested at both incubation times. Our study shows that $\mathrm{CH}_{4}$ production per $\mathrm{g}$ aNDF digested decreases with increasing aNDF content of grass silages, and that it is more closely related to aNDF content than to in vitro aNDF digestibility. 


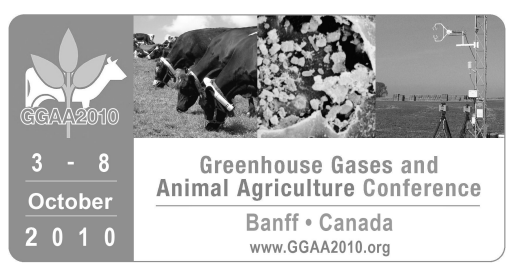

\title{
T63. Effect of easily fermentable carbohydrates on methane emission at different pH
}

\author{
M. Cattani, H.H. Hansen*, F. Tagliapietra and I.K. Hindrichsen*
}

Easily fermentable carbohydrates in concentrates can have different effects on methane emission at different $\mathrm{pH}$ levels. Feeding high concentrate levels in a diet twice a day will decrease $\mathrm{pH}$ more compared to a total mixed ration and thereby influence methane production and emission. The influence of easily fermentable carbohydrates and different $\mathrm{pH}$ levels has not been fully explored for exploitation in mitigation strategies. The aim of the current study was to measure the effect of sucrose versus starch over time at three different $\mathrm{pH}$ levels on total gas and methane production, volatile fatty acids, ammonia and fibre degradation. A new, wireless in vitro gas production system with attached gas-tight bags was used. The gas-tight bags could be removed easily and stored for later analyses by gas chromatography. The experimental diets contained $100 \%$ hay, or $50 \%$ hay with either $50 \%$ corn starch, $50 \%$ sugar or $25 \%$ corn starch and $25 \%$ sugar. The diets were incubated in three buffers with three $\mathrm{pH}(6.8,6.6,6.4)$. The fermentation was stopped after 10,24 and 48 hours to measure $\mathrm{pH}$, total gas and methane production. Gas production was measured every minute and released to gas-tight bags, when gas pressure exceeded $0.5 \mathrm{psi}$. As expected, the amount of total gas produced per gram organic matter fermented was significantly lower for the basal hay diet when compared to a diet with added carbohydrates. Addition of sugar resulted in significantly more gas at 10 hours compared to starch for all three $\mathrm{pH}$ levels. However, no significant difference in gas production was detected for sugar versus starch at 24 or 48 hours of incubation. Total gas production significantly increased with increasing pH levels from 10 to 48 hours for all diets. Total methane production per $\mathrm{g} \mathrm{OM}$ from the basal GH diet was significantly less compared to the three rations with easily fermentable carbohydrates. However, the NDF digestibility of the three concentrate diets was significantly less compared to the GH diet. Total methane per g OM production increased significantly different between 6.8 and 6.6, but not significantly different between 6.6 and 6.4. The proportion of methane of total gas was significantly less for the $\mathrm{GH}$ diet at 10 hours, while there was no significant difference at 24 or 48 hours. The results suggest that differences of methane emission between sucrose and starch may be of lesser importance than the significant difference between the higher and lower $\mathrm{pH}$ levels.

\section{T64. Genetic basis for methane emission in the dairy cow}

\author{
D. Heimeier*, S. Berry, S. Davis*, R. Spelman, L. McNaughton and K. Lehnert
}

Methane emissions from livestock contribute to the worldwide methane production. As methane is a potent greenhouse gas, it is important to find ways to reduce methane production from livestock without compromising productivity. Methanogenic bacteria that live in symbiosis in the rumen generate methane from free hydrogen, representing energy loss for the animal. Methane production can be influenced by environmental conditions, such as feed composition. However, a genetic basis for methane production in ruminants has not yet been established. To determine the genetic component of methane production, as well as phenotypic correlations, we utilized the F2 generation of a Friesian Jersey Crossbred (FJXB) trial. Methane emission was measured in 650 dairy cows in their $2^{\text {nd }}$ lactation using the $\mathrm{SF}_{6}$ tracer technique. Additional phenotype measurements were taken throughout the animals' lives, including milk production, composition and processing traits of milk, as well as fertility, live-weight, health, and welfare. DNA from the F2 animals, their F1 dams and sires, and select grandsires were genotyped across the genome, initially with 285 microsatellite markers, and subsequently with 6,634 single nucleotide polymorphisms (SNP). The methane 


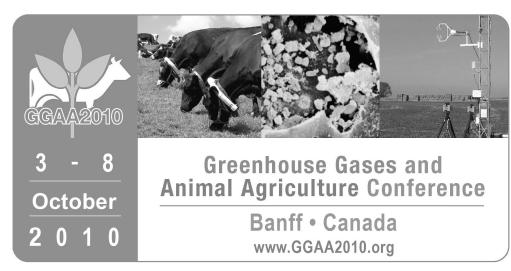

measurements were made in mid lactation on 300 and 350 pasture grazed dairy cows in two consecutive years in the summer months of January/February in 2004 and 2005. Dry mater intake (DMI) was estimated from individual live-weight and milk yield. Average methane production varied significantly between years with 330g/d (Std Dev=42.0) and 290g/d (Std Dev=34.6) ( $<<0.001)$. Statistical analyses revealed significant positive correlation of methane phenotypes with live-weight $\left(r^{2}=0.27\right)$ and $\mathrm{DMI}\left(r^{2}=0.19\right)$. The strongest correlations were observed between total methane emission and milk fatty acid composition, in particular branched chain fatty acids $\left(r^{2}=-0.25\right.$ to -0.47$)$ and short chain fatty acids $\left(r^{2}=0.21\right)$. Quantitative trait loci (QTL) analysis was undertaken as a genome wide scan based on all methane phenotypes (total methane g/d; methane g/kg DMl; methane g/l milk). Significant QTLs were identified for all methane phenotypes, suggesting that genetic variation may influence methane production. Future studies will focus on identification of candidate genes and their genetic, variation and the understanding of biological pathways, which link genes and phenotypic correlations.

\title{
T65. Effect of hydrogen peroxide administration on rumen fermentation of sheep
}

\author{
K. Hirakawa*, T. Matsumoto*, H. Nishigaki, R. Asa-Morikawa, Y. Mihara, T. Nishida* and J. Takahashi*
}

Methane $\left(\mathrm{CH}_{4}\right)$ is a major greenhouse gas attributed to animal agriculture and has high energy, thus $\mathrm{CH}_{4}$ emissions by ruminants contribute not only to significant loss of digestible energy ingested by ruminants but also to global warming. Mitigation of the $\mathrm{CH}_{4}$ emissions by ruminants is therefore an important issue both in aspects of economy and environment. In an earlier study, we found that hydrogen peroxide $\left(\mathrm{H}_{2} \mathrm{O}_{2}\right)$ inhibited methane production from ruminal fermentation in vitro. It showed the potential of $\mathrm{H}_{2} \mathrm{O}_{2}$ as a non-persisting methane reducer. In this study, we investigated the in vivo effect of $\mathrm{H}_{2} \mathrm{O}_{2}$ administration. A preliminary experiment was conducted using one sheep and $\mathrm{H}_{2} \mathrm{O}_{2}$ administered at different dosing levels. The sheep was fed twice daily with a maintenance level of timothy grass hay, with free access to water and a trace mineralized salt block. At the morning feeding time, $0,0.5,0.75$ or $1.0 \mathrm{mmol} / \mathrm{kg}^{0.75}$ body weight of $\mathrm{H}_{2} \mathrm{O}_{2}$ (in $50 \mathrm{~mL}$ distilled water) were administrated through the ruminal fistula. After a 6-d administration, the volume of $\mathrm{CH}_{4}$ emission was analyzed with a respiratory hood system for 3 days and ruminal fluid was collected $0,1,2,3,4,5,6,7$ and $8 \mathrm{~h}$ after administration at the last day of each dosing level. Through this experiment, negative effects on physical condition of the sheep were not observed, and methane emission was reduced in a dose-dependent manner. Ruminal A/P ratio was decreased and lactate production was increased, which enhanced consumption of hydrogen. These results suggested that $\mathrm{H}_{2} \mathrm{O}_{2}$ changed a metabolic flux of the ruminal fermentation and led to the mitigation of $\mathrm{CH}_{4}$ emission. To quantify the effect of $\mathrm{H}_{2} \mathrm{O}_{2}$ on mitigation of methane emission, an experiment designed as a $4 \times 4$ Latin square was conducted using four sheep. Animal feeding and dosing were the same as in the previous experiment. Although methane production ( $\mathrm{mL} / \mathrm{kg}^{0.75}$ body weight) tended to decrease after administration of $\mathrm{H}_{2} \mathrm{O}_{2}$, suppression was not dose-dependent. Little differences were found in VFA production, lactate production and diet digestibility. Larger scale investigations are needed to elucidate the effect of $\mathrm{H}_{2} \mathrm{O}_{2}$ on ruminal methanogenesis.

\section{T66. Effect of hydrogen peroxide on ruminal fermentations in vitro}

K. Hirakawa*, T. Matsumoto*, R. Asa-Morikawa, H. Nishigaki, Y. Mihara and J. Takahashi*

Methane emitted by ruminants not only leads to a significant loss of digestible energy ingested by ruminants but also contributes to global warming, and mitigation of methane emissions by ruminants is an important 


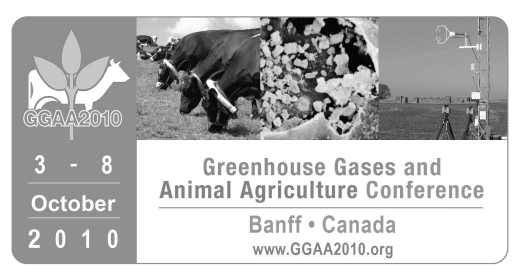

issue both in aspects of economy and environment. In response, various ruminal methane production inhibitors have been developed. We have embarked on research attempting to apply a bacteriocin produced by a lactic acid-producing bacterium to reduce the methane production. Previously we reported that Lactobacillus plantarum TUA1490L culture broth inhibited methane production from ruminal fermentation in vitro. In that study, we found that TUA1490L culture broth lost the inhibitory effect by the addition of catalase $(265 \mathrm{U} / \mathrm{mL}$, $25^{\circ} \mathrm{C}, 1 \mathrm{~h}$ ). We concluded that the methane production inhibitor produced by TUA1490L was hydrogen peroxide $\left(\mathrm{H}_{2} \mathrm{O}_{2}\right)$, which suggested the usefulness of $\mathrm{H}_{2} \mathrm{O}_{2}$ as an inexpensive and persistence-free inhibitor of methane production. Thus, we investigated the effect of $\mathrm{H}_{2} \mathrm{O}_{2}$ on ruminal fermentation in vitro. Incubation mixtures included $400 \mathrm{~mL}$ of ruminal fluid taken from two non-lactating Holstein cows that had free access to a basal diet of timothy grass hay, $400 \mathrm{~mL}$ of autoclaved artificial saliva, $5 \mathrm{~g}$ of timothy grass hay and $5 \mathrm{~g}$ of concentrate. Hydrogen peroxide was added to yield $0,0.3,1.0$ or $2.0 \mathrm{mM}$ final concentrations, and cultures were incubated at $42^{\circ} \mathrm{C}$ for $16 \mathrm{~h}$. Methane production was inhibited by the addition of $\mathrm{H}_{2} \mathrm{O}_{2}$ in a dosedependent manner, with $1.0 \mathrm{mM} \mathrm{H}_{2} \mathrm{O}_{2}$ yielding a $30 \%$ reduction. Adding $\mathrm{H}_{2} \mathrm{O}_{2}$ caused a rapid increase of oxidation-reduction potential (ORP) and the inhibition of methane production was in accordance with the ORP increase. Methane production resumed as, during incubation, the ORP recovered to the initial value. The composition of bacterial and archaeal flora were analyzed by DGGE, which revealed them unchanged following addition of $\mathrm{H}_{2} \mathrm{O}_{2}$ at concentrations less than $1.0 \mathrm{mM}$. These results suggest that adding $\mathrm{H}_{2} \mathrm{O}_{2}$ to in vitro ruminal incubations suppresses methane production activity of ruminal methanogens, but does not kill them.

\section{T67. Rumen fermentation and production effects of Origanum vulgare $L$. in lactating dairy cows}

A. N. Hristov*, J. A. Tekippe, K. S. Heyler, T. W. Cassidy, V. D. Zheljazkov, S. K. Karnati and G. A. Varga

A lactating co trial was conducted to study the effects of dietary addition of oregano leaf material (Origanum vulgare L.; 0, control vs. $500 \mathrm{~g} \mathrm{~d}^{-1}, \mathrm{OV}$ ) on ruminal fermentation and methane production, total tract digestibility, manure gas emissions, $\mathrm{N}$ metabolism, organoleptic characteristics of milk, and dairy cow performance. Eight primiparious and multiparious Holstein cows ( 6 of which were ruminally cannulated) were used in a switch-over design trial with 2, 21-d periods. Cows were fed once daily. The OV material was topdressed and mixed with a portion of the total mixed ration (TMR). Cows averaged $41 \pm 3.3 \mathrm{~kg} \mathrm{~d}^{-1} \mathrm{milk}^{\mathrm{and}} 80 \pm$ $12.5 \mathrm{~d}$ in milk (DIM) at the beginning of the trial. Rumen $\mathrm{pH}$, concentration of total and individual VFA, and microbial protein outflow were not affected by treatment. Ruminal ammonia $\mathrm{N}$ concentration was increased by OV compared with the control (5.3 vs. $4.3 \mathrm{mmol} \mathrm{L}^{-1}$ ). Rumen methane production was reduced by $40 \%$ in the OV treatment $\left(P=0.004\right.$ ). Intake of DM (average of $26.6 \pm 0.83 \mathrm{~kg} \mathrm{~d}^{-1}$ ) and apparent total tract digestibly of nutrients did not differ between treatments. Average milk yield, milk fat, protein, and lactose concentrations, milk urea nitrogen, and somatic cell count were unaffected by diet. Milk sensory parameters were also not affected by treatment. Fat-corrected $\left(35 \mathrm{~g} \mathrm{~kg}^{-1}\right)$ milk yield and fat corrected milk feed efficiency were increased $\left(P=0.03\right.$ and $<0.001$, respectively) by OV compared with the control (42.2 vs. $40.7 \mathrm{~kg} \mathrm{~d}^{-1}$ and $1.63 \mathrm{vs} .1 .53 \mathrm{~kg}$ $\mathrm{kg}^{-1}$, respectively). Urinary and fecal $\mathrm{N}$ losses, and manure ammonia and methane emissions were unaffected by treatment. Under the current experimental conditions, supplementation of dairy cow diets with $500 \mathrm{~g} \mathrm{~d}^{-1}$ of Origanum vulgare L. had no effect on nutrient intake and digestibility, but drastically reduced methane production in the rumen. Cows fed Origanum vulgare L. produced more FCM and had increased feed efficiency. 


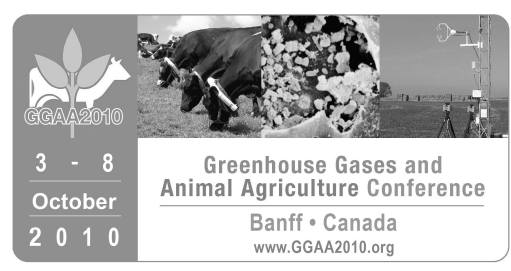

\section{T68. Effect of different molecular-weight condensed tannin fractions from Leucaena forage on methane production}

X. D. Huang*, J. B. Liang*, H. Y. Tan, R. Yahya and Y. W. Ho

Condensed tannins (CTs) from plants have been shown to exhibit nutritional, environmental and veterinary benefits in ruminant production. It is now known that the effect of CTs on animal nutrition is multi-factors, but their molecular weights and/or chemical structures seem to play the more vital roles. The average molecular weight of the purified CTs and that of the five different fractions (fractionated by size exclusion chromatography procedure), extracted from 62-2-8 Leucaena hybrid-Bahru (LLB) forage was determined using $\mathrm{Q}-\mathrm{TOF}$ LC/MS in this study. Results of the study indicated that various degrees of polymerization, up to hexamer were found in the five different CTs fractions from LLB with the highest molecular weights of 1348.80 $\mathrm{Da}$ for the first fraction and decreased to $494.56 \mathrm{Da}$ for the fifth fraction. The five different CT fractions were used to test the hypothesis that CTs of higher molecular weights have stronger effect on dry matter (DM) and nitrogen digestibility, and methane gas production. Our results showed that inclusion of CTs from different molecular-weight fractions decreased in vitro total and methane gas productions, with the highest molecularweight fraction recorded the most significant effect of $61.59 \%$ methane reduction as compared to the control (without CTs). In addition, the ratio of methane to total gas of the treatment groups decreased with increasing molecular weight of CTs as compared to the control. The above results suggested that inclusion of CTs from Leucaena LLB has direct effect on methane production, with those of higher molecular weight exhibited higher reductions.

\section{T69. Use of dried distillers' grains with solubles to reduce enteric methane emissions from growing beef cattle \\ M. Hünerberg*, T. A. McAllister*, S. M. McGinn*, K. A. Beauchemin*, E. Okine*}

Elevated dietary fat levels have been shown to depress ruminal methane $\left(\mathrm{CH}_{4}\right)$ production. Since oil enriched by-products such as dried distiller grains from corn (CDDGS) [ $100 \mathrm{~g}$ crude fat/kg dry matter (DM)] or wheat (WDDGS) ( $50 \mathrm{~g}$ crude fat/kg DM) are widely used in the North American feedlot industry, there is a growing interest in evaluating the impact of CDDGS and WDDGS on enteric $\mathrm{CH}_{4}$ emissions from beef cattle. The objectives of this study were to determine if inclusion of CDDGS or WDDGS in backgrounding (high forage) diets reduces enteric $\mathrm{CH}_{4}$ emissions from beef cattle, and if the oil in corn was responsible for any response observed. The experiment was designed as a replicated $4 \times 4$ Latin square with 21 -d periods using 16 ruminally fistulated crossbreed heifers (389.9 kg \pm ?34.9). The control diet contained $550 \mathrm{~g} / \mathrm{kg} \mathrm{DM}$ of whole crop barley silage, $350 \mathrm{~g} / \mathrm{kg}$ DM of barley grain, $50 \mathrm{~g} / \mathrm{kg}$ DM of canola meal, and $50 \mathrm{~g} / \mathrm{kg} \mathrm{DM}$ of supplement. Treatment diets were formulated by completely replacing barley grain and canola meal in the control diet with CDDGS, WDDGS, or WDDGS plus pure corn oil (WDDGS+oil). Oil was added to WDDGS to achieve the same level as CDDGS (99.5 g crude fat/kg DM). All diets were fed as total mixed rations once daily ad libitum. Four large environmental chambers with 2 animals in each chamber were used to measure enteric emissions over $4 d$ in each period. Heifers offered the control diet produced $24.5 \mathrm{~g} \mathrm{CH}_{4} / \mathrm{kg} \mathrm{DM}$ intake (DMI) or lost $8 \%$ of their gross energy (GE) intake as $\mathrm{CH}_{4}$. Compared to the control diet, enteric $\mathrm{CH}_{4}$, as $\mathrm{g} / \mathrm{kg} \mathrm{DMI}$ or percentage of GE intake, was reduced $(p<0.05$ ) by $18 \%$ or $22 \%, 10 \%$ or $17 \%$, and $18 \%$ or $21 \%$, for the CDDGS, WDDGS, and WDDGS+oil diets, respectively. This study demonstrates that including CDDGS and to a lesser extent WDDGS reduces enteric $\mathrm{CH}_{4}$ emissions from backgrounding beef cattle, and that this response arises mainly from the presence of oil in CDDGS. 


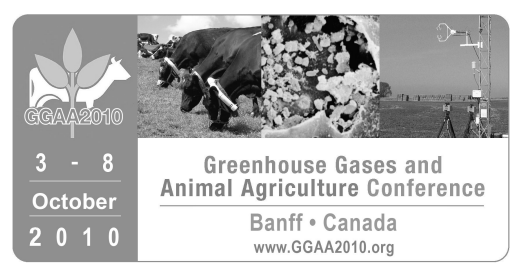

T70. Evaluating the grazing and methane emissions of sainfoin (Onobrychis viciaefolia Scop.) compared to alfalfa and grass mixed pastures grown in Western Canada

\author{
A. D. Iwaasa*, A. Chaves and S. M. McGinn*
}

Study objective was to compare the beef and forage production and methane $\left(\mathrm{CH}_{4}\right)$ emissions of yearling beef cattle grazing alfalfa and hybrid brome mixture $(A+G)$ and sainfoin $(S)$ pastures. Sainfoin and $A+G$ were established in 2003 and the pastures were grazed at the $S$ bloom stage and when the alfalfa was about $10 \%$ bloom, respectively. Experimental design was a $2 \times 2$ factorial (forages: $S$ and $A+G$ and pasture utilization: 50 and 70\%) with three replications. From 2004 to 2006, average daily gains (ADG), available forage yield (AYD), grazing days (GD), total live production (TLP) and $\mathrm{CH}_{4}$ emissions were collected yearly. No interactions ( $\mathrm{P}>$ 0.05 ) were observed for AYD and TLP; however, significant three way interaction was observed for GD and ADG. Three way interactions were re-examined by analyzing the data by pasture utilization. Forage yield and TLP were higher $(P<0.05)$ for $A+G$ versus $S$, and values were 4,640 and 3,929 $\pm 194 \mathrm{~kg}$ of $D M$ ha $^{-1}$ and 128.4 and $72.4 \pm 11.2 \mathrm{~kg} \mathrm{ha}^{-1}$, respectively. Average daily gains did differ $(P>0.05)$ between the $A+G$ and $S$ pastures over years for each pasture utilization rate. No interactions $(P>0.05)$ were found for total $\mathrm{CH}_{4}$ emissions and expressed per unit dry matter intake; only year main effects were significant $(\mathrm{P}<0.05)$. Methane emissions and per unit dry matter intake for 2004, 2005 and 2006 were 192.8, 175.4 and $197.2 \pm 7.7 \mathrm{~g} \mathrm{of} \mathrm{CH}_{4} \mathrm{hd}^{-1} \mathrm{~d}^{-1}$, and 19.0, 29.2 and $30.9 \pm 1.4 \mathrm{~g}$ of $\mathrm{CH}_{4}$ per $\mathrm{kg}$ of DMI, respectively. For $\mathrm{S}$ and $\mathrm{A}+\mathrm{G}$ pastures there was a negative relationship ( $r=-0.50, \mathrm{P}=0.05)$ between $\mathrm{AYD}$ and $\mathrm{CH} 4$ emissions. The study did not observe a major reduction in $\mathrm{CH}_{4}$ emissions as a result of $\mathrm{S}$ condensed tannin content levels, although a negative trend was observed $(\mathrm{r}=-$ $0.46, P=0.09$ ). Further research is needed to better determine the effects of $S$ stage of maturity and grazing preference on $\mathrm{CH}_{4}$ emissions and forage productivity.

\title{
T71. Different physical forms of rapeseed as fat source to reduce enteric methane emission from dairy cows \\ M. Johannes*, A. L. Frydendahl Hellwing*, P. Lund*, M. R. Weisbjerg and T. Hvelplund
}

Fat is a promising feed content to reduce enteric methane $\left(\mathrm{CH}_{4}\right)$ production. In Denmark, rapeseed meal and rapeseed cake (RSC) are common feedstuffs and rapeseed is a domestic oil plant. The purpose of this trial was to study if the physical form of rapeseed fat has an impact on its $\mathrm{CH}_{4}$-reducing properties and on feed digestion. The experiment was conducted as a $4 \times 4$ Latin square design with four rumen, duodenum and ileum fistulated cows ( 1 primiparous and 3 multiparous) and four diets. The cows were 193 days in milk (sd 67) and had a milk yield of $28.7 \mathrm{~kg}$ (sd $7.2 \mathrm{~kg}$ ). The diets were a control diet with rapeseed meal with $4 \%$ fat and three diets supplemented with RSC with $24 \%$ fat, whole crushed rapeseed (RS) with $49 \%$ fat and rapeseed oil (RSO), respectively. In the control diet, the fat content was $3.2 \%$ and in the three fat diets $6.4 \%$. The fat-free rapeseed content was constant for all diets. Forage percentage of the diet was 50 with maize and grass silage (maize:grass 46:54). All compositions refer to DM. The experiment consisted of four periods; during the third week of every period, samples were taken from the different fistulae in order to determine digestibility. Methane production was measured in four open-circuit respiration chambers during the fourth week of the period. According to data from the first three periods, all three fat treatments decreased $\mathrm{CH}_{4}$ production by on average $16 \%$ (expressed as litre per kg DM intake). Rapeseed cake depressed $\mathrm{CH}_{4} \mathrm{~kg}^{-1} \mathrm{DM}$ intake by $10.9 \%(P=$ $0.06)$, RS by $19.2 \%(P=0.02)$ and RSO by $18.4 \%(P=0.03)$. The energy loss as $\mathrm{CH}_{4}$ as percentage of gross energy (GE) intake was decreased from $8.1 \%$ for the control diet to $6.9(P=0.04), 6.2(P=0.02)$ and $6.3 \%(P=0.02)$ for RSC, RS and RSO, respectively. Intake was numerically depressed for the RSO diet but this was not statistically 


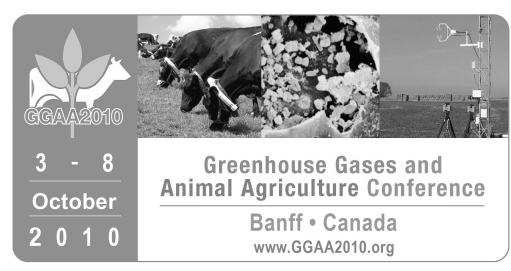

significant. Rapeseed fat depressed $\mathrm{CH}_{4}$ emissions regardless of the source; however, there was a tendency for a lower effect of RSC compared to RS $(P=0.12)$ and RSO $(P=0.18)$. Since there is evidence that RSO can depress feed intake, RS can be regarded as the most favourable fat source according to the present experiment to reduce $\mathrm{CH}_{4}$ production.

\section{T72. Effects of NDF and NFC digestibility on methane emission by lactating Holstein cows fed grass silage-based total mixed ration \\ H. Kasuya* and J. Takahashi*}

The experiment was conducted to investigate the effects of NDF digestibility on methane $\left(\mathrm{CH}_{4}\right)$ emission by lactating Holstein dairy cows fed grass silage (GS)-based total mixed rations (TMR). Methane emission was determined using an open-circuit respiratory head cage system. In the first experiment, to evaluate the effect of NDF digestibility of grass silage on $\mathrm{CH}_{4}$ emission, six lactating cows were randomly assigned to a duplicated 3 $\times 3$ Latin square design in the first-cut (1st) GS, and second-cut (2nd) GS with or without formic acid as a supplement. The GS with or without formic acid as forage in the total mixed ration did not affect the $\mathrm{CH}_{4}$ emission from dairy cows. Each value indicated $470.3 \mathrm{~L} / \mathrm{d}$ at the $1 \mathrm{st} \mathrm{GS}, 459.7 \mathrm{~L} / \mathrm{d}$ at the $2 \mathrm{nd} \mathrm{GS}$ with formic acid and $475.3 \mathrm{~L} / \mathrm{d}$ at the 2 nd GS without formic acid. In the second experiment, to evaluate the effect of digestible structural carbohydrate on $\mathrm{CH}_{4}$ emission, six lactating cows were fed TMR consisting of first-cut GS and concentrate with high NDF concentrate containing low level of potato starch (S), high level of potato pulp silage $(\mathrm{P})$ or pre-gelatinized maize $(\mathrm{M})$. Methane emission by lactating dairy cows was not affected by the treatment $(538.5 \mathrm{~L} / \mathrm{d}, 556.6 \mathrm{~L} / \mathrm{d}$ and $536.7 \mathrm{~L} / \mathrm{d})$. However, $\mathrm{CH}_{4}$ emission per DM intake of $\mathrm{P}$ was significantly lower than that of $\mathrm{S}(P<0.05)$. Additionally, $\mathrm{CH}_{4}$ emission per intake of digestible NDF was significantly lower $(P<0.05)$ with $\mathrm{P}$ than with $\mathrm{S}$. In the third experiment, to clarify the effect of non-structural carbohydrate on methane emission, six lactating dairy cows were fed TMR containing medium pre-gelatinized corn and/or high pre-gelatinized corn according to a duplicated $3 \times 3$ Latin square design. High pre-gelatinized corn increased NFC digestibility $(90.4,92.5$ and $95.1 \%)$. However; $\mathrm{CH}_{4}$ emission by lactating dairy cows was not affected by the treatment $(538.5 \mathrm{~L} / \mathrm{d}, 556.6 \mathrm{~L} / \mathrm{d}$ and $536.7 \mathrm{~L} / \mathrm{d})$. From the results of trials for lactating dairy cows $(n=54)$, the correlation analyses have been done between $\mathrm{CH}_{4}$ emission and NDF. The correlation coefficients between $\mathrm{CH}_{4}$ emission and NDF intake was $0.56(P<0.01)$, however, the correlation coefficients between $\mathrm{CH}_{4}$ emission per DM intake and NDF digestibility was $-0.30(P<0.05)$. This result indicated low content and high digestibility NDF may contribute to reducing $\mathrm{CH}_{4}$ of lactating dairy cows fed grass silage as a basal feed.

\section{T73. Determination of the methane mitigating potential of garlic oil and one of its most abundant compounds - diallyl disulfide - in sheep}

F. Klevenhusen*, J. O. Zeitz*, S. Duval*, M. Kreuzer* and C. R. Soliva

Ruminant livestock is one of the largest sources of anthropogenic methane emissions. Currently research on non-invasive methane mitigation strategies via feed supplementation is intensively pursued. Identifying supplements which do not negatively affect diet palatability and digestibility is a key challenge in that respect. Based on indications from the literature of a potential anti-methanogenic activity of garlic (Allium sativum), garlic oil (GO) and diallyl disulfide (DADS), GO's most abundant compound, were tested in sheep. Six animals were subjected to a duplicate $3 \times 3$ Latin square design. In three 23 -day experimental runs, the sheep were individually offered hay and concentrate (1:1) twice daily. The two test substances GO and DADS were fed in amounts of 5 and $2 \mathrm{~g} \mathrm{~kg}^{-1}$ total dietary dry matter (DM), respectively, to the sheep with the morning feeding by 


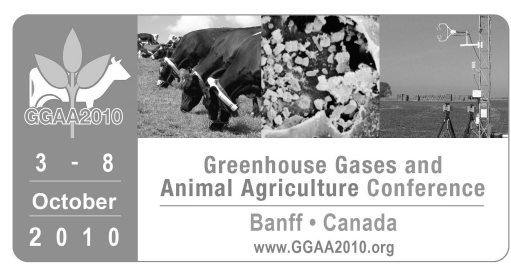

stirring them with the concentrate after being mixed with molasses. The control diet was supplemented with molasses only. Respiratory measurements were conducted on experimental days 7 and 8 (period 1 ) as well as on days 17 and 18 (period 2). Ruminal fluid samples were obtained on days 19 and 23. From days 15 to 22 urine and feces were quantitatively collected. When including data from periods 1 and 2, dietary GO supplementation decreased $(P<0.05)$ daily methane formation and daily methane related to body weight compared to the control, with DADS being intermediate. Relating methane to organic matter and neutral detergent fiber digested revealed that DADS, but not GO, lowered methane production by proportionately $0.11(P<0.05)$ and $-0.19(P=0.05)$ compared to the control, respectively. There was no period effect on methane formation indicating the absence of adaptation processes between periods 1 and 2. Total DM intake was not affected by GO and DADS, although concentrate intake was decreased $(P=0.08)$ in the $G O$ treatment by proportionately -0.13 of the control. Digestibility of organic matter and neutral detergent fiber, as well as energy utilization, were increased $(P<0.05)$ with DADS by proportionately $0.06,0.19$ and 0.10 relative to the control, respectively. Nitrogen balance was not affected by any treatment, which was also true for microbial counts in the ruminal fluid. In conclusion, DADS but not $\mathrm{GO}$ decreased $\mathrm{CH}_{4}$ formation related to the nutrients digested, thus being a promising $\mathrm{CH}_{4}$ mitigator. Further, DADS exhibited improved feed use efficiency. The limited palatability of the GO-supplemented concentrate makes this supplement less useful in feeding practice.

\section{T74. Cashew nut shell liquid, a novel candidate feed additive for ruminants: Potency as a methane- reducing agent}

Y. Kobayashi*, Y. Suzuki, Y. Watanabe, S. Koike, M. Mochizuki and K. Magashima

Cashew nut shell liquid (CNSL), which contains microbicidal phenolic compounds, was evaluated for its potency as a candidate feed additive for ruminants and compared to ionophore monensin. Rumen fluid from sheep was employed as an inoculum in an in vitro batch culture experiment. The rumen fluid was diluted 1:1 with artificial saliva and anaerobically incubated for $18 \mathrm{~h}$ with five mixtures of concentrate and hay $(90: 10,70: 30,50: 50$, 30:70 and 10:90) with a supplementation at final concentration with $500 \mathrm{mg} \mathrm{L}^{-1} \mathrm{CNSL}$ or $5 \mathrm{mg} \mathrm{L}^{-1}$ monensin. Gas and volatile fatty acid (VFA) production for each mixture were determined. Although methane reduction by monensin was not observed with mixture with the highest proportion of hay, reduction by CNSL was observed for all mixtures. The degree of methane reduction was higher for CNSL (22-57\%) than that for monensin (15$35 \%$ ), and methane reduction by either additive was larger for higher proportions of concentrate. Propionate enhancement was higher for CNSL (25-59\%) than monensin (12-24\%), but enhancement by monensin was not significant with the mixture with the highest proportion of hay, and enhancement by CNSL was observed regardless of the substrate mixture. In addition, the enhancement by both additives became larger for greater proportions of concentrate. Although total gas was reduced by the addition of CNSL and monensin, total VFA production was not affected. Based on these results, CNSL, rich in microbicidal phenolic compounds, is considered to be a strong potential candidate for a feed additive with selective activity against rumen microbes such as Gram-positive rumen bacteria. The resulting shift in fermentation that occurs with the use of CNSL produces less methane and more propionate. 


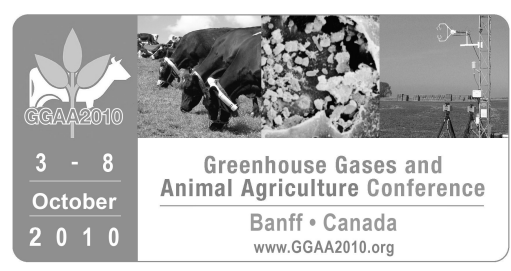

\section{T75. Enteric methane production from conventional and non-conventional feed ingredients based complete feeds}

J.S. Lamba, M. Wadhwa* and M.P.S. Bakshi

The present study was undertaken to estimate the enteric methane production from complete feeds by in-vitro gas production technique, while the methane was estimated by GLC. Amongst 6 energy supplements, 9 protein supplements, 3 types of brans, the methane production was lowest in waste bread, cotton seed cake (CSC), tomato pomace, spent brewer's grains (SBG) and de-oiled rice bran. Amongst the 15 isonitrogenous and isocaloric concentrate mixtures formulated, those containing CSC, SBG gave the best results with respect to low methane production. Amongst 5 non leguminous single cut forages, 5 straws and stovers, methane production was lowest in green pearl millet forage and rice straw. The above screened feedstuffs were used to formulate 5 complete feeds under each of the concentrate to roughage ratios of 30:70, 40:60 and 50:50. The roughages used were either green pearl millet alone or green pearl millet and rice straw in 50:50 ratios in a $5 \mathrm{x}$ $3 \times 2$ factorial set up. Regardless of concentrate to roughage ratio and type of concentrate, complete feed containing pearl millet produced low $(P<0.01)$ methane, higher digestibility of nutrients and ME than that produced when pearl millet-RS was used as roughage. Methane production was lowest $(P<0.01)$ when high level of concentrate $(50 \%)$ was used. The contribution of methane to net gas production, increased with the increase in the level of roughages in the diet. The methane production, was lowest $(P<0.01)$ in the complete feed containing $30 \%$ CSC followed by one containing 30\% SBG and highest $(P<0.01)$ in complete feed containing mustard cake. The production of total VFA's and that of individual VFAs was higher $(P<0.01)$ when only green pearl millet was used as a roughage. The propionate and butyrate production increased $(P<0.01)$ with the increase in concentrate level. The TVFA and individual VFA production was highest $(P<0.01)$ in the diets containing SBG. The A:P ratio was observed to be lowest $(P<0.01)$ in the complete feeds containing SBG. It was concluded that enteric methane production could be reduced considerably by formulating the complete feed containing waste bread, cotton seed cake, tomato pomace, and spent brewers grains supplemented with green pearl millet with concentrate to roughage ratio of 40:60.

\section{T76. Improving milk nutritional and environmental value with flaxseed supplemented diets}

J. Laurain*, G. Chesneau, G. Mairesse, M. Guillevic, N. Hirshberg and P. Weill

This experiment studied the effect of two different forms of flaxseed on dairy cow's milk composition and methane output over a one year period. Fifteen organic farms based on stored grass diets were divided into two groups: one with flax meal supplementation (FM, 11 farms) and one with extruded whole flax supplementation (EF, 4 farms). This poster presents results from January 2009 (Control month: C) to May 2009 (after 3 months of supplementation, February was a transition month). The average supplementation was 2.1 $\mathrm{kg}^{-1} \mathrm{~d}^{-1}$ cow for FM and $0.9 \mathrm{~kg}^{-1} \mathrm{~d}^{-1}$ cow for EF. Quantities of FM supplementation depended on forage quality of the farms while EF supplementation was fixed. Compared with the control month, both groups (FM and EF) showed a significant improvement of the milk fatty acids (FA) profile, the main effects were: a decrease in C16:0 ( 32.5 vs. $28.8 \%$ and 33.6 vs. $27.3 \%$, respectively) and an increase in $C 18: 3$ (0.74 vs. $0.91 \%$ and 0.64 vs. $1.02 \%$, respectively). Methane output was calculated from milk fatty acids composition using equations based on SFA milk content and an equation based on FA and milk Production. All equations of methane calculations showed a reduction of $\mathrm{CH}_{4}$ output compared to the control (C) for both groups (FM and EF): when calculated with the equation based on C16:0 (468 vs. 406 and 488 vs. $382 \mathrm{~g} \mathrm{CH}_{4}^{-1} \mathrm{~d}^{-1}$ cow, respectively), the equation based on C8:0 to C16:0 FA (416 vs. 367 and 436 vs. $345 \mathrm{~g} \mathrm{CH}_{4}^{-1} \mathrm{~d}^{-1}$ cow, respectively) and the equation based on FA and milk Production (13.5 vs. 12.2 and 13.9 vs. $11.6 \mathrm{~g} \mathrm{CH}_{4}^{-1} \mathrm{~L}^{-1}$ of milk, respectively). This survey suggests that it 


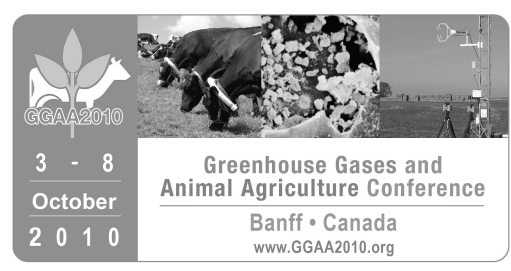

is possible to improve milk environmental and nutritional quality at the farm level without altering performances (not published).

\section{T77. Glycerol as a feed supplement for ruminants: Ruminal degradation rate and in vitro fermentation characteristics and methane production}

S.-Y. Lee*, S.-M. Lee, Y.-B. Cho, D.-K. Kam, S.-C. Lee, C.-H. Kim* and S. Seo*

Glycerol has been considered to be rapidly fermented to propionate in the rumen even though experimental measurements for degradation rate and VFA production in the literature are variable. Considering the negative relationship between methane production and propionate, glycerol may have an effect on reducing methane production in the rumen; however, little data have been reported about reduction in enteric methane production by adding glycerol. The objectives of this study, therefore, were to determine ruminal degradation rate of glycerol and the effect of adding glycerol on in vitro fermentation characteristics and methane production. Glycerol $(0.5 \mathrm{~g})$, alfalfa $(0.5 \mathrm{~g})$, corn $(0.5 \mathrm{~g})$, alfalfa $(0.5 \mathrm{~g})+$ glycerol $(0.1 \mathrm{~g})$, and corn $(0.5 \mathrm{~g})+$ glycerol $(0.1 \mathrm{~g})$ were anaerobically incubated in vitro using strained rumen fluid for $0,3,6,12,24$ and $48 \mathrm{~h}$. At each time point, total gas and methane production, $\mathrm{pH}$, ammonia and VFA were measured. By fitting a simple exponential model with a single lag, we obtained a fractional gas production rate of $0.049 \mathrm{~h}^{-1}$ with a lag time of $8.13 \mathrm{~h}$ for glycerol, which has a significantly slower rate and longer lag than other substrates $(\mathrm{P}<0.01)$. After 12 $\mathrm{h}$ of incubation, however, total gas and methane production from fermentation of glycerol were rapidly increased, and at $24 \mathrm{~h}$ no difference in total gas production between alfalfa and glycerol treatments was observed. The maximum gas production estimate from curve fitting of the gas production was $222.4 \mathrm{ml} \mathrm{g}^{-1}$, which was not different from the value for corn. Fermentation of glycerol produced VFA in favour of propionate over acetate and showed the lowest $A: P$ ratio among the treatments at $24 h$ incubation $(P<0.05)$. Adding glycerol decreased total gas and methane production $(P<0.05)$ but not total VFA production at $24 \mathrm{~h}$ incubation. This implies that adding glycerol may increase the efficiency of using energy of substrates. Based on the amount of digestible energy (DE, $\mathrm{kJ}$ ) provided in each treatment, glycerol supplementation even more significantly decreased methane production per $D E$ content $(P<0.01)$. In conclusion, fermentation kinetics of glycerol may be altered by the adaptation of rumen microbial population to glycerol supplementation and substrates co-incubated. Without adaptation, degradation of glycerol is relatively slower than other conventional feedstuffs. On the basis of DE provided by the substrates used in this study, supplementation of glycerol may have a potential to decrease methane production and to increase the efficiency of using dietary energy in a ruminant ration.

\section{T78. Effects of dietary forage to concentrate ratio on nutrient digestibility and methane emission from Sika deer and Korean Native Black goats}

D.-H. Li, S.-H. Kim and S.-R. Lee*

This study was conducted to determine the effects of dietary forage to concentrate ratio $(F: C)$ on nutrient digestibility and methane emission from Sika deer and Korean native black goats. Three male growing Sika deer (mean BW, $19.2 \mathrm{~kg}$ ) and three male growing Korean native black goats (mean BW, $18.7 \mathrm{~kg}$ ) were fed three diets, each species, in a $3 \times 3$ Latin square design. Experimental diets, consisting of chopped tall fescue hay and a mixture of cracked corn, soybean meal, minerals, and vitamins, were prepared for iso-nitrogenous diets (17\% $\mathrm{CP}$ ) having relative proportions of $\mathrm{F}: \mathrm{C}$ ratio (dry matter basis) of $25: 75,50: 50$ and $73: 27$. Animals were fed $2 \%$ of live weight once a day. Each experimental period consisted of a 7-day adaptation period and 3 days for the 


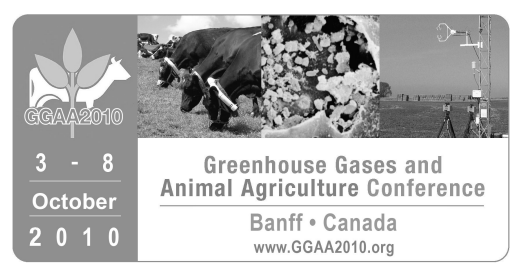

measurement of apparent digestibility of dry matter and of $\mathrm{CH}_{4}$ and $\mathrm{CO}_{2}$ emissions using an open-circuit chamber system. Apparent dry matter digestibility increased $(\mathrm{P}<0.05)$ with decreasing $\mathrm{F}: \mathrm{C}$ ratio of diets in both deer and goats. The dry matter digestibility in goats was greater $(P<0.05)$ than that in deer regardless of $\mathrm{F}: \mathrm{C}$ ratio. The emission of $\mathrm{CH}_{4}$ from deer increased $(\mathrm{P}<0.05)$ as the $\mathrm{F}: \mathrm{C}$ ratio decreased, whereas no effect was observed in goats. At the $\mathrm{F}: \mathrm{C}$ ratio of $73: 27, \mathrm{CH}_{4}$ emissions in deer $\left(0.46 \mathrm{I} \mathrm{kg}^{-1} \mathrm{BW}\right.$ day $\left.{ }^{-1}\right)$ was less $(\mathrm{P}<0.05)$ than that in goats $\left(0.65 \mathrm{I} \mathrm{kg}^{-1} \mathrm{BW}\right.$ day $\left.{ }^{-1}\right)$. However, the $\mathrm{CH}_{4}$ emission in deer $\left(0.91 \mathrm{I} \mathrm{kg}^{-1} \mathrm{BW}\right.$ day $\left.{ }^{-1}\right)$ at $\mathrm{F}: \mathrm{C}$ ratio of $25: 75$ was $(\mathrm{P}<0.05)$ greater than that in goats $\left(0.52 \mathrm{I} \mathrm{kg}^{-1} \mathrm{BW} \mathrm{day}{ }^{-1}\right)$ at the same ratio. The amounts of $\mathrm{CO}_{2}$ emission were not affected by $\mathrm{F}: \mathrm{C}$ ratio in both deer and goats, and were unaffected by the species. Overall, dry matter digestibility increased as dietary F:C ratios decreased. As dietary F:C ratios decreased, $\mathrm{CH}_{4}$ emission increased in deer, but not in goats. This might be due to the difference in ruminal fermentation patterns between deer and goats.

\title{
T79. Effects of yucca and quillaja saponins on methane emissions from Holstein steers
}

\author{
W. Li* and W. Powers*
}

Two saponin sources, yucca (from Yucca Schidigera) and quillaja (from Quillaja saaponaria) were selected to determine their effects on enteric methane $\left(\mathrm{CH}_{4}\right)$ generation from Holstein steers. Steers $(\mathrm{n}=12$; initial BW $=$ $284 \mathrm{~kg} \pm 16.4$ ) were randomly assigned to 1 of the 3 diets (Control, Yucca and Quillaja) using a Latin Square design (14 d per period). Steers were housed in individual environmentally controlled rooms. Room $\mathrm{CH}_{4}$ concentration was monitored using an INNOVA 1412 photoacoustic analyzer (LumaSense Technologies, Ballerup, DK). Treatment diets were formulated based on saponin content, resulting in $1.5 \%$ inclusion of quillaja powder and $0.64 \%$ inclusion of yucca powder. The overall ADG (100.3g) was not affected by saponin inclusion. While both Yucca and Quillaja increased ADFI $(p<0.05)$ compared to the Control diet, $(6.58 \mathrm{~kg}, 6.51$ $\mathrm{kg}$, and $6.29 \mathrm{~kg}$, respectively). Daily $\mathrm{CH}_{4}$ emission mass $(78,301 \mathrm{mg} / \mathrm{d})$ and emission rate $(50.19 \mathrm{mg} / \mathrm{min})$ were not affected by saponin addition ( $P>0.05$ ). On a BW basis, the overall daily emission mass was $251.75 \mathrm{mg}$ $\mathrm{CH}_{4} / \mathrm{kg} \mathrm{BW}$ and no differences were observed among treatments. The same trend was observed when the daily mass was expressed on a $\mathrm{kg}$ DMI basis $(12,196 \mathrm{mg} / \mathrm{kg} \mathrm{DMI} ; \mathrm{P}>0.05)$. Data showed that, at the inclusion rate used in our study, neither yucca nor quillaja saponin altered $\mathrm{CH}_{4}$ emission from Holstein steers.

T80. The effect of ground ear maize based diets on the performance, nutrient digestibility, enteric methane emissions and rumen fermentation characteristics of beef cattle

B. M. Lynch, D. A. Kenny and T. M. Boland*

Ground ear maize (GEM) is a novel feedstuff produced by ensiling the chopped maize ear and offers a higher quality feedstuff compared to conventional forage maize. The current study aimed to evaluate the effect of GEM on performance, nutrient digestibility and enteric $\mathrm{CH}_{4}$ emissions of finishing beef heifers. A commercial crop of maize (var. Benecia) was harvested for GEM (consisting of the cobs, husks and very limited stalk) on 29 October 2008 using an Olimac stripper maize header. The GEM was then ensiled in round wrapped plastic bales by an Orkel baler. Thirty beef heifers (Limousin $\times$ Friesian) were randomly allocated to one of two treatments (1) GEM-based diet and, (2) barley grain-based diet, both of which were isonitrogenous (130 $\left.\mathrm{g} \mathrm{k}^{-1} \mathrm{CP}\right)$, isofibrous (268 $\mathrm{g} \mathrm{kg}^{-1} \mathrm{NDF}$ ) and isoenergetic (18 MJ GE kg-1 DM). The heifers were offered ad libitum access to feed. Both diets were offered as a TMR which included soybean meal to balance for CP and grass silage in the 


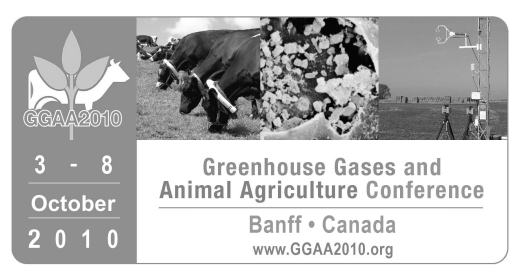

GEM TMR and chopped straw in the barley TMR to balance as a source of fibre. Daily feed intake was recorded for each animal for a period of 52 days. Daily $\mathrm{CH}_{4}$ emissions were determined using a calibrated tracer $\left(\mathrm{SF}_{6}\right)$ technique. Methane emissions were recorded over a $24 \mathrm{~h}$ period for 5 consecutive days starting on day 23 . Fecal grab samples were taken from the animals on days 23 and 24 in order to determine nutrient digestibility using the AIA method. Heifers offered the GEM based diet had higher DMI $(P<0.01)$ and ADG $(P<0.05)$ and a higher digestibility of DM $(P<0.001)$, OM $(P<0.001)$, nitrogen $(P<0.001)$, starch $(P<0.001)$ and $G E(P<0.001)$ compared to those offered the barley based diet. In addition heifers offered the GEM had lower overall daily ( $P$ $<0.05)$ and DMl corrected $\mathrm{CH}_{4}$ emissions $(\mathrm{P}<0.01)$ compared to those offered the barley based diet. Results from this study demonstrate that heifers offered a GEM based diet during the finishing period had higher DMI, gained $200 \mathrm{~g}$ more live weight per day and emitted $21 \%$ less DMI corrected $\mathrm{CH}_{4}$ compared to those offered the barley diet.

\section{T81. Methane output in dairy cows in response to long-term feeding of grass-based diets supplemented with linseed or rapeseed}

C. Martin, D. Pomiès, A. Ferlay, M. Eugène*, B. Martin, M. Doreau and Y. Chilliard

Adding lipids $(<5 \%)$ to ruminant diets is an effective means of mitigating methane $\left(\mathrm{CH}_{4}\right)$ output without impairing animal performances (Martin et al., 2008; Beauchemin et al., 2009). However, results concerning the long-term effect of lipids on methanogenesis are scarce and are inconsistent in the case of whole cottonseed (Grainger et al., 2010) or a mixture of linseed and fish oil (Woodward et al., 2006) added during 3 months. The aim of this study was to evaluate $\mathrm{CH}_{4}$ output in dairy cows after a lipid supplement was added to diets during the entire previous and current lactations. The trial was conducted with 21 Holstein dairy cows allocated in 3 dietary treatments for 2 lactations. During the indoor periods, cows were fed grass-silage (45\% DM), hay (15\% $\mathrm{DM})$ and concentrate (40\% DM) and during the outdoor periods, cows were grazing pasture and received daily $5 \mathrm{~kg}$ concentrate. The diets were not supplemented $(C T L, n=8)$ or supplemented with extruded linseed ( $r$ ich in C18:3n-3; LS, $n=8$ ) or extruded rapeseed (rich in C18:1n-9; RS, $n=5$ ) with a similar level of oil added (3\% DM). During the 2nd lactation, individual $\mathrm{CH}_{4}$ and milk production were measured daily on two successive periods (5 days each) at two-month intervals during which animals were fed indoors or outdoors. Methane production was measured using the $\mathrm{SF}_{6}$ gas tracer method (Martin et al., 2008). Data were analyzed using repeated measurement ( 2 periods) with PROC MIXED (SAS). The statistical model included diet, period and diet $\times$ period as fixed effects. No diet effect $(P=0.96)$ was observed on milk yield averaging 27.9 and $23.2 \mathrm{~kg} \mathrm{~d}^{-1}$ for indoor and outdoor periods, respectively $(P<0.01)$. The amount of $\mathrm{CH}_{4}$ emitted daily by dairy cows differed between diets $\left(685,552\right.$ and $804 \mathrm{I} \mathrm{d}^{-1}$ on average for CTL, LS and RS, respectively; $\left.P<0.0001\right)$ for both periods $(P=0.69)$. They were lower for LS $(-19 \%$ on average; $P<0.01)$ and higher for RS $(+17 \%$ on average; $P<0.05)$ compared to CTL. Expressed in litres per kg of milk, $\mathrm{CH}_{4}$ output between diets tended to be lower for $\mathrm{LS}(-22 \%$ on average; $P$ $=0.07)$ and similar for RS (+11\% on average; $P=0.60)$ compared to CTL, irrespective of the period $(P=0.70)$. After more than one year of a continuous lipid supplementation of grass-based diets, we observed that extruded linseed decreased, while extruded rapeseed increased $\mathrm{CH}_{4}$ output in dairy cows. 


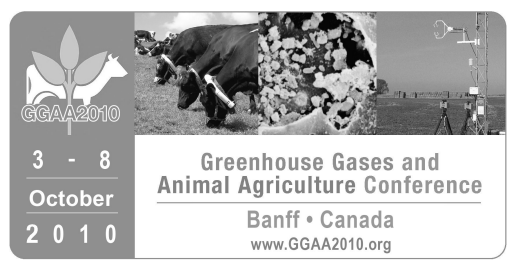

\title{
T82. Methane output of various ensiled feeds determined using the in vitro total gas production technique \\ E. J. Mc Geough*, D. A. Kenny, M. O’Brien and P. O'Kiely*
}

The measurement of methane output in vivo is complex, expensive and requires considerable labor and feed inputs. Thus, in vitro techniques that reliably estimate the methane output associated with feed ingredients are necessary. The objective of this experiment was to determine the methane output of a number of ensiled feeds varying in chemical composition using the in vitro total gas production technique. A range of ensiled grains and forages were assessed in a series of six replicated experiments. High moisture wheat, barley and triticale grains, which were relatively high in starch and low in NDF concentration were encompassed in Exp. 1 and 2. In contrast, Exp. 3 to 6 involved maize and WCW silages, alone or in combination with grass silage that ranged from medium to low concentrations of starch and from medium to high concentrations of NDF. Feed samples $(0.5 \mathrm{~g})$ were inoculated with a rumen fluid/buffer mixture and incubated at $39{ }^{\circ} \mathrm{C}$ for $24 \mathrm{~h}$ after which time the methane concentration of the head space gas and DM disappearance were determined. The methane responses were regressed on chemical analyses as explanatory variables using the MIXED procedure of SAS. When the data from the six experiments were combined it was observed that $96 \%$ of the total variation in methane output per gram of feed DM incubated was accounted for by NDF, in vitro OMD and ash. Of these variables, the greatest single response was with NDF. When expressed per unit of feed DM disappeared, 78\% of the variation in methane output was explained by NDF, in vitro OMD, starch and starch ${ }^{2}$. In both instances, methane output was negatively related to NDF and positively related to starch, which is in contrast with numerous in vivo studies where diets varying in carbohydrate composition were offered ad libitum. Thus, it is concluded that within the conditions of the present experiment, the in vitro total gas production technique did not reliably reflect expected in vivo responses where diets are consumed ad libitum. Thus, modification of this technique is required when investigating the methane output of feeds varying widely in chemical composition.

\section{T83. Ranking forage species for methane production using batch culture in vitro fermentation}

\author{
S. J. Meale*, A. V. Chaves, J. Baah and T. A. McAllister*
}

An in vitro batch culture study was conducted to determine methane outputs and fermentation characteristics of contrasting forage species. Common grasses, legumes and shrubs (i.e. forage types) used for livestock grazing in parts of Australia and Ghana were tested. Grass (Fabaceae) species included Andropodon gayanus, Brachiaria ruziziensis and Pennisetum purpureum. Legume (Poaceae) species included Cajanus cajan, Cratylia argentea, Gliricidia sepium, Leucaena leucocephala and Stylosanthes guianensis and shrub species included Annona senegalensis, Moringa oleifera, Securinega virosa and Vitellaria paradoxa. Mature leaves of these plants were harvested in the field, dried at $55^{\circ} \mathrm{C}$ and ground through a $1 \mathrm{~mm}$ screen prior to incubation. Serum bottles $(50 \mathrm{~mL})$ contained $500 \mathrm{mg}$ of forage, modified McDougall buffer $(15 \mathrm{~mL})$ and rumen fluid $(5 \mathrm{~mL})$ were incubated under anaerobic conditions at $39^{\circ} \mathrm{C}$ for $24 \mathrm{~h}$. Triplicate samples of each forage type were removed after $0,2,6,12$, and 24 hours of incubation for determination of gas, ammonia and VFA concentrations, with methane being measured after $24 \mathrm{~h}$. Data were analysed using the mixed model procedure of SAS. Concentration of NDF as a \% of dry matter (DM) ranged from 37.7 - 59.0 (grasses), 67.1 - 71.3 (legumes) and 28.8 - 51.7 (shrubs). Crude protein concentrations (\% DM) of the respective grasses, legumes and shrubs were 11.2 - 30.1, 9.9 - 24.9 and 7.2 - 8.7. After $24 \mathrm{~h}$ of in vitro incubation cumulative gas production, ammonia concentrations, proportions of acetate and propionate of total VFA and in vitro DM disappearance did not 


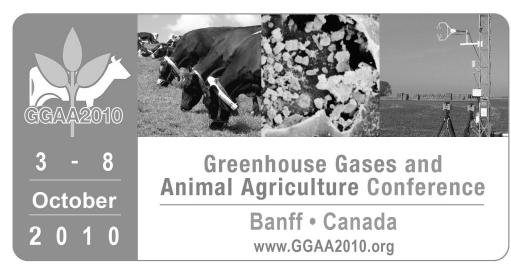

differ ( $P>0.12$ ) by forage types (i.e. between legumes, grasses and shrubs). However, total volatile fatty acid (VFA) accumulation and butyrate proportion appeared to be similar for legumes and grasses, and lower for $(P=0.0017)$ shrubs. Overall methane concentrations (expressed as $\mathrm{mg} \mathrm{CH} / \mathrm{g} D M$ incubated) tended to be lower $(P=0.10)$ for shrubs compared to grasses or legumes. All fermentation characteristics differed $(P<0.01)$ between species within forage type. In regard to methane $\left(\mathrm{mg} \mathrm{CH}_{4} / \mathrm{g} \mathrm{DM}\right)$, the rankings within forage types in ascending order were Brachiaria $=$ Pennisetum $>$ Andropogon, Gliricidia $>$ Cratylia $>$ Stylosantes $>$ Cajanus $=$ Leucaena, and Moringa $>$ Annona $=$ Securinega $>$ Vitellaria, respectively. These results suggest that batch culture incubation is a useful tool which facilitates ranking forage species in regards to methane outputs and fermentation characteristics.

\title{
T84. Including essential oils in ruminal batch cultures, or in diets fed to lactating dairy cows: effects on methane emissions
}

\author{
S. J. Meale*, A. V. Chaves, I. Schei, T. A. McAllister*, A. D. Iwaasa*, W. Z. Yang and C. Benchaar*
}

In experiment 1, eleven essential oils (EO) or essential oil compounds (EOC) were included at $0,20,100,250$ and $400 \mathrm{mg} \mathrm{L}^{-1}$ in 24-h batch culture ruminal incubations to assess their effects on fermentation of a 40:60 forage:concentrate diet. Treatments were: control (no additive), allicin, anethol, cassia, citronel, cresol, garlic, gerianol, juniperberry, linalool, star-anise and p-cymene. Methane production, total VFA accumulation and proportions of individual VFA were assessed. Compared with other treatments, garlic oil at 100, 250 and 400 $\mathrm{mg} \mathrm{L}^{-1}$ decreased methane production, proportion of acetate (A) in total VFA, and the acetate:propionate (A:P) ratio, and increased the proportions of propionate and butyrate. Included at 250 or $400 \mathrm{mg} \mathrm{L}^{-1}$, juniperberry oil increased $(P<0.05)$ total VFA accumulation compared to other treatments. These results suggest that the garlic and juniperberry oils may have potential for favorably modifying rumen fermentation, but the effects are dose-dependent. In experiment 2 , these oils were studied further using four ruminally cannulated, lactating Holstein cows (705 $\pm 50 \mathrm{~kg} \mathrm{BW} ; 113 \pm 13 \mathrm{DIM}$ ) in a $4 \times 4$ Latin Square with 21-d periods, comprising $11 \mathrm{~d}$ adaptation to diet and $10 \mathrm{~d}$ of measurements. Treatments (per cow) were: control (no additive), monensin (300 $\mathrm{mg} \mathrm{d}^{-1}$; positive control), garlic oil $\left(5 \mathrm{~g} \mathrm{~d}^{-1}\right)$ and juniperberry oil $\left(2 \mathrm{~g} \mathrm{~d}^{-1}\right)$. Cows were fed a TMR ration of 40:60 forage:concentrate to meet ad libitum intake with energy and protein sufficient to support milk production of $30 \mathrm{~kg} \mathrm{~d}^{-1}$. Methane and $\mathrm{CO}_{2}$ emissions were measured using the sulphur hexafluoride $\left(\mathrm{SF}_{6}\right)$ tracer technique. Treatment did not affect $(P>0.05) \mathrm{CH}_{4}$ or $\mathrm{CO}_{2}$ production, whether expressed as $\mathrm{g} \mathrm{d}^{-1}, \mathrm{~g} \mathrm{~kg}^{-1} \mathrm{DMI}, \mathrm{g}$ $\mathrm{kg}^{-1}$ milk or as $\mathrm{g} \mathrm{kg}^{-1} \mathrm{DMI} / \mathrm{BW} 0.75$. Average $\mathrm{CH}_{4}$ and $\mathrm{CO}_{2}$ production across treatments were $353 \mathrm{~g} \mathrm{~d}^{-1}$ and 21.3 $\mathrm{kg} \mathrm{d}^{-1}$, respectively. Results from this in vivo study suggest that feeding garlic oil $\left(5 \mathrm{~g} \mathrm{~d}^{-1}\right)$, juniperberry $\left(2 \mathrm{~g} \mathrm{~d}^{-1}\right)$ and monensin ( $330 \mathrm{mg} \mathrm{d}^{-1}$ ) to lactating dairy cows in the current experimental conditions had no effects on $\mathrm{CH}_{4}$ production. At the doses administered, the effects of garlic and juniperberry oil observed in vitro were not realized in vivo probably due to different concentrations used and intrinsic characteristics of each individual system.

\section{T85. Evaluation of effects of grass water-soluble carbohydrate on methane emissions from grazing lambs}

T. Misselbrook*, E. J. Kim, N. Bulmer, R. Murray, N. Scollan and D. Chadwick*

Grass varieties with elevated water-soluble carbohydrate (WSC) content increase the efficiency of nitrogen utilization in the rumen and have been shown to increase productive output. There are suggestions that they may also reduce methane emissions from grazing ruminants through lower fibre content and improved 


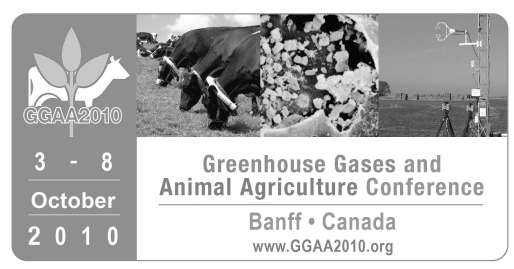

digestibility. This study aimed to assess the effect of high WSC grasses on enteric methane emissions from grazing lambs. Twenty lambs (Texel-mule cross) were allocated to each of two ryegrass (Lolium perenne) pastures, a control (cv Premium) and a tri-mix of high WSC varieties with different heading dates (AberStar, AberMagic and AberAvon). Lambs were grazed continuously through the growing season (April to June 2009) and methane emission measurements were made periodically using mobile polytunnels as large dynamic chambers, in-situ on the grazed plots. On each measurement occasion, five lambs were randomly selected from those grazing each plot and were placed inside the polytunnel. Air was drawn through the tunnel at a controlled rate and methane concentrations at the inlet and outlet of each polytunnel were monitored continuously using a photoacoustic analyzer. An equilibrium period of approximately $12 \mathrm{~h}$ was allowed after lambs entered the polytunnel, after which emission measurements were made for $24 \mathrm{~h}$. A total of ten measurements were made from each treatment over the grazing season, with measurements being made concurrently from treatments on each occasion. Ammonia emissions were also measured, using acid absorption flasks to measure inlet and outlet concentrations from each polytunnel. Measurements were also made of lamb live weight gain, sward height, estimates of intake (using exclosure cages) and grass composition. Lamb daily live weight gains were lower than expected, due to a dry spring season, but were significantly greater from the high WSC treatment than the control (approximately 160 and $110 \mathrm{~g}$ per animal per day, respectively). Methane emissions from lambs grazing both treatments showed consistent diurnal patterns, with peak emission rate during the evening. Mean emission rates were lower from the high WSC treatment at 8.0 litres per lamb per day, compared with 10.5 litres per lamb per day for the control. These emission rates are lower than reported elsewhere, probably due to the low intake rates and live weight gain. There was no significant difference in ammonia emission between treatments.

\section{T86. Comparison of cold pressed canola, brewers grains and hominy meal as dietary supplements suitable for reducing enteric methane emissions from lactating dairy cows}

P. J. Moate*, S. R. O. Williams, C. Grainger*, M. C. Hannah and R. J. Eckard*

There are little data in the scientific literature concerning the in vivo effects of dietary lipid supplementation on enteric methane emissions from lactating dairy cows. The purpose of this experiment was to evaluate four dietary treatments designated Control (CON), brewers grains (BG), cold pressed canola (CPC) and hominy meal (HM) for their effects on milk production and methane emissions. Sixteen mid-lactation Holstein cows were used in a $4 \times 4$ Latin-square experiment with the four dietary treatments fed as totally mixed rations over 21 day treatment periods. All diets contained approximately $60 \%$ forage $(5 \mathrm{~kg}$ DM of lucerne hay and $7 \mathrm{~kg} \mathrm{DM}$ of pasture silage). The concentrate portion of the CON diet contained $6 \mathrm{~kg} \mathrm{DM}$ of cracked wheat and $1.4 \mathrm{~kg} \mathrm{DM}$ of solvent extracted canola meal and was formulated to contain approximately $2.6 \%$ total fat. For the BG, CPC and HM diets, part of the cracked wheat and solvent extracted canola meal was substituted with the designated fat supplement so that the resulting experimental diets contained approximately $5.6 \%$ total lipid. Fat supplementation did not influence total dry matter intake, and there were only small although significant $(P<0.05)$ negative effects on milk yield and concentrations of milk fat and milk protein. The HM diet resulted in a significant $(\mathrm{P}<0.05)$ reduction in methane emissions when expressed either in $\mathrm{g}$ methane/cow/day, $\mathrm{g}$ methane/kg DMI, or g methane/L milk. The BG diet also significantly $(P<0.05)$ reduced methane emissions when expressed as g methane/cow/day or g methane/L milk, while the CPC diet decreased methane emissions when expressed in terms of $g$ methane/L milk. Combining data from the fat supplemented diets enabled comparison of methane emissions from the CON diet with methane emissions from the fat supplemented diets. Fat supplementation caused a significant $(\mathrm{P}<0.05)$ reduction in methane emissions: 500, $462 \mathrm{~g}$ methane/cow/day; 25.0, 23.2 g methane/kg DMI and 23.3, $20.5 \mathrm{~g}$ methane/L milk for the CON and fat 


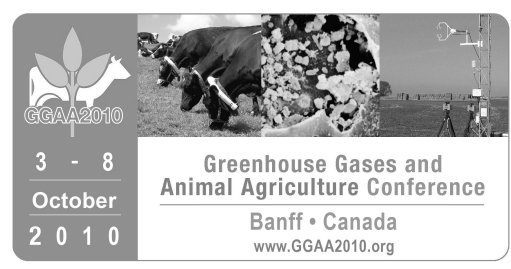

supplemented groups respectively. Similarly, by combing data from all of the fat supplemented groups, regression analysis revealed that fat supplementation reduced methane emissions for up to 10 weeks. Combining the results of this investigation with data from the scientific literature we conclude that for each $1 \%$ increase in dietary lipid concentration, enteric emissions are reduced by $0.79 \mathrm{~g}$ methane $/ \mathrm{kg} \mathrm{DMI}$ or by approximately $3.5 \%$. These findings allow estimation of the magnitude of enteric methane abatement strategies based on dietary lipid supplementation.

\section{T87. Greenhouse gas production (GHG) in finisher pigs is affected by dietary protein content and diet ingredients}

J. K. A. Atakora, S. Moehn* and R. O. Ball*

Lowering protein content in pig diets reduces $\mathrm{N}$-excretion, but also changes diet carbon and fiber content and fiber composition, and may therefore affect $\mathrm{CH}_{4}$ and $\mathrm{CO}_{2}$ produced by pigs. Our objective was to study the effect of decreasing dietary protein contents on performance and GHG production by finisher pigs. In exp. 1, 12 female pigs each were fed corn- (C) or wheat-barley-based (WB) conventional (HP) and protein-reduced, amino acid supplemented diets (LP) in a cross over design. In exp. 2, 12 castrated male pigs were fed the WH-HP diet or a very low protein diet (VLP) based on barley plus free amino acids in a cross-over design. These diets, formulated to achieve equal intake of metabolizable energy and true available amino acids, contained crude protein at 19.3\% (WB-HP), 16.0\% (WB-LP), 15.7\% (C-HP), 13.1\% (C-LP) and $11.5 \%$ (VLP). After N-balance over 7 $\mathrm{d}, \mathrm{CO}_{2^{-}}, \mathrm{CH}_{4^{-}}$and heat production and $\mathrm{O}_{2}$ consumption were measured over a $4 \mathrm{~h}$ or $24 \mathrm{~h}$ period using an opencircuit respiration system. Daily gain $(780 \mathrm{~g} / \mathrm{d}, \mathrm{SE} 14)$ and gain:feed $(0.36, \mathrm{SE} 0.01)$ did not differ among diets $(P$ $>0.10)$. Protein deposition was lower in WB-HP and C-LP than the other groups $(P<0.05)$. Protein and carbon digestibility were lower for $C$ than WB diets $(P<0.005)$ but not affected by protein level $(P>0.20)$. N excretion was decreased by dietary protein reduction $(P=0.001)$ and similar for $C$ and WB diets $(P=0.99)$. C-excretion was not affected by dietary protein $(P=0.63)$ but was lower $(P=0.001)$ for $C$ than WB diets. Lowering dietary protein reduced $\mathrm{CH}_{4}(P=0.022)$ and heat production $(P=0.009)$ but did not affect expired $\mathrm{CO}_{2}$. Corn diets reduced expired $\mathrm{CO}_{2}(P=0.017)$ but had similar $\mathrm{CH}_{4}$ and heat production $(P>0.10)$ as WB diets. The effect of feed intake on $\mathrm{CO}_{2}$ and $\mathrm{CH}_{4}$ production was not significant $(P>0.1) . \mathrm{CH}_{4}$ production was more closely related to dietary protein than fiber contents and decreased by $7.7 \mathrm{~g} / \mathrm{d}$ (SE 2.9, $P=0.010)$ per \%-point dietary protein reduction. Carbon and $\mathrm{N}$-excretion decreased by $0.15 \mathrm{~g} / \mathrm{d}(\mathrm{SE} 0.02, P=0.001)$ and $0.10 \mathrm{~g} / \mathrm{d}(\mathrm{SE} 0.02, P=0.001)$ $\mathrm{g}$ carbon and $\mathrm{N}$-intake, respectively. A reduction of dietary protein contents leads to a reduction of $\mathrm{CH}_{4}$ production and $\mathrm{N}$ and carbon excretion, which may lead to lower GHG emissions from manure.

\section{T88. Effect of phytase-xylanase supplementation to wheat-based diets on energy metabolism and greenhouse gas (GHG) production in growing-finishing pigs}

J. K. A. Atakora, S. Moehn* and R. O. Ball*

Protein reduction and enzyme, e.g., phytase and xylanase, addition in pig diets can decrease nutrient excretion, and possibly GHG emissions. Our objective was to study the effects of protein (CP) reduction and phytase and/or xylanase inclusion in pig diets on performance, energy content and nutrient utilization. In a randomized complete block design, 72 gilts ( $58 \pm 6 \mathrm{~kg}$, initial BW) were fed ad libitum six wheat-based diets: high CP control (C), low CP with added amino acids and phosphate (LP+), low CP without phosphate (LP-), and LP- diets with added phytase $(P)$, xylanase $(X)$ or phytase plus xylanase $(P X)$. The pigs underwent a $7 \mathrm{~d}$ balance period followed by $24 \mathrm{~h}$ indirect calorimetry to calculate $\mathrm{C}-\mathrm{N}$ balance. The same diets were fed restrictively to 6 ileally 


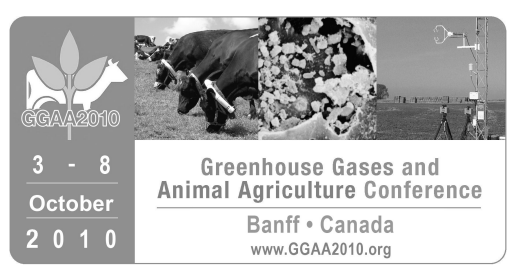

canulated pigs in a Latin square to determine ileal digestibility. Energy metabolism was assessed using the carbon- $N$ balance method. Daily gain $(664 \mathrm{~g} / \mathrm{d}, \mathrm{SE} 16)$ and gain:feed $(0.318 \mathrm{SE} 0.07)$ were not affected by dietary treatment $(P>0.1)$. Protein retention $(132 \mathrm{~g} / \mathrm{d} \mathrm{SE} 6)$ was greater $(P=0.04)$ in protein-reduced diets. Dietary net energy increased with BW $(P=0.001)$ and phytase inclusion $(P=0.050)$. Urinary and fecal $\mathrm{N}$ and carbon excretion were decreased in low CP diets $(P<0.01)$ and increased $(P=0.001)$. Phytase inclusion decreased phosphorus $(P=0.001)$ and calcium excretion $(P=0.047)$. Protein reduction reduced $(P=0.015) \mathrm{CH}_{4}$ production by $0.96 \mathrm{~g} / \mathrm{d}$ (SE 0.41) per \%-point protein reduction. The production of $\mathrm{CO}_{2}$ was not affected by dietary treatment. These results indicate that feeding low CP and phosphorus diets with added synthetic amino acids and phytase to finisher pigs optimizes the utilization of dietary energy, minimizes nutrient excretion and lowers $\mathrm{CH}_{4}$ production by pigs while maintaining or improving pig performance.

\section{T89. Reducing dietary protein in sow diets can reduce greenhouse gas (GHG) production} J. K. A. Atakora, S. Moehn*, J. McMillan and R. O. Ball*

Reducing dietary protein (CP) in sow diets is associated with changes in dietary fiber and starch contents, which can affect the efficiency of nutrient utilization and hind gut fermentation. This may affect $\mathrm{C}$ - and $\mathrm{N}$-excretion and $\mathrm{CO}_{2}, \mathrm{CH}_{4}$ and heat production. This question was studied in 4 non-pregnant and 22 gestating and lactating sows, fed conventional (HP) or protein-reduced, amino acid supplemented (LP) diets meeting requirements (NRC 1998). Non-pregnant sows received barley-based (B-HP, 14.6\% CP; B-LP, $11.8 \%$ CP) or corn-based diets (CHP, 13.2\% CP; C-LP, 9.7\% CP). The diets for pregnant sows were based on barley (HP, 16.3\% CP; LP, $13.5 \%$ CP). Lactating sow diets based on wheat and barley contained $21.1 \%$ CP (HP) and 18.2\% CP (LP). The $\mathrm{CO}_{2}, \mathrm{CH}_{4}$ and heat production and $\mathrm{O}_{2}$ consumption were measured 4-h periods using an open-circuit respiration system, twice per diet in non-pregnant sows, and on day 40 and 95 in pregnancy and day 6 and 16 in lactation. Nexcretion was assessed using an indigestible marker (feces) and the urinary $\mathrm{N}$ :creatinine ratio. Methane production was lower by $60 \%$ for B-LP vs. B-HP $(P=0.001)$ in non-pregnant sows, but similar for both corn diets $(P>0.1)$, and lower for the corn-based than the barley-based diets $(P=0.006) . \mathrm{CO}_{2}$ production tended $(P=$ $0.06)$ to be greater for the LP diets, and greater $(P=0.07)$ for barley- vs. corn- based diets in non-pregnant sows. Heat production was not affected by protein content or diet type $(P=0.98)$. The $\mathrm{CO}_{2}$ and heat production and $\mathrm{O}_{2}$ consumption were reduced in pregnant sows fed LP diets $(P<0.02)$ by $4.8,5.9$ and $5.7 \%$, respectively, were lower at day $40(P<0.07)$ than at day 95 and lower $(P<0.05)$ during the 2 nd than 3 rd parity. During lactation, $\mathrm{CO}_{2}$ and heat production and $\mathrm{O}_{2}$ consumption were lower for LP by $6.6 \%(P=0.005), 9.4 \%(P=0.061)$ and $8.8 \%(P=0.054)$, respectively. Reducing dietary protein reduced urinary $(P<0.05)$ but not fecal $(P=0.38)$ $\mathrm{N}$-excretion, and tended to reduce fecal $\mathrm{C}$-excretion $(P=0.08)$, thus may lead to a proportional emission of GHG from manure. The reduced heat production indicates an improved nutrient utilization in low protein diets. Feeding low protein diets to sows will reduce $\mathrm{CH}_{4}$, depending on the type of diet, thus contributing to a reduction of GHG production.

\section{T90. Decreasing gas production rate and digestibility of barley grain using fat coating method}

H. R. Mohammadian-Tabrizi, H. Sadeghipanah, M. Chamani, Y. Ebrahim- Nejad, H. Fazaeli, A.Mirhadi and M.H.Palizdar*

A rapid method for measuring gas production (GP) during incubation of feeding stuffs with rumen liquor in vitro is described. The aim of this study was to investigate the GP rate and digestibility of barley grain coated with hydrogenated tallow (HT) and hydrogenated palm oil (HP) in different types and levels $(0,20,40,60$ and $80 \%$ ) to decrease gas produced in vitro. Approximately $200 \mathrm{mg}$ (DM basis) of sample is weighed and inserted in 


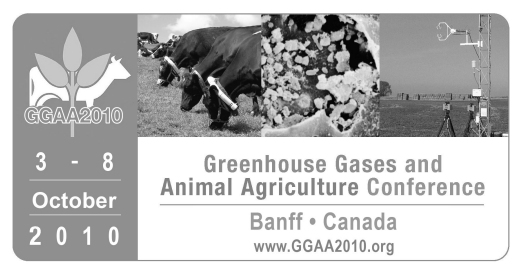

glass syringes, then mixed with the inoculum and artificial saliva, which the initial volume of the syringes reached to $30 \mathrm{ml}$ and incubated at $39^{\circ} \mathrm{C}$ in a ventilated oven. Gas production was recorded after $0,2,4,6,8$, $12,24,48,72$ and $96 \mathrm{~h}$. Data were analyzed using SAS programs. The equation of $p=a+b\left(1-e^{-c t}\right)$, and the values of $a, b$ and $c$ computed. The outcome of the present study showed that experimental fat which was added to barley grain to protect it from fermentation, reduced in vitro degradability determined using the gas test technique. Addition of experimental fat (HT and HP) to barley grain could significantly decrease GP during incubation times $(P<0.01)$. In comparison to HP fat, coating barley grain with HT fat resulted in significantly reduced GP $(P<0.01)$. Consequently it seems that if we could use experimental fats as a coating factor to slow down the fermentation of cereal grains (like barley and wheat grains) in the rumen, it could lead to prevention of metabolic diseases like acidosis. Moreover this processing could alter the values of starch reaching the small intestine to produce more glucose for high producing animals like dairy cows.

\section{T91. Tropical tanniniferous legumes used as an alternative to mitigate sheep enteric methane emission \\ G. D. Moreira, H. Louvandini, C. McManus, P.M.T. Lima, O. Primavesi, C. Longo and A. L. Abdalla*}

Condensed tannins (CT) are polyphenolic compounds which have been considered antinutritional composites; nowadays their ability to modulate food nutrients as protein and energy, optimizing their assimilation through the ruminants digestion, and mitigation of enteric methane $\left(\mathrm{CH}_{4}\right)$ are being intensely studied. The present study presents the first preliminary results from Brazil using the $\mathrm{SF}_{6}$ tracer technique adapted from cattle studies to evaluate the capacity of CT present in three tropical leguminous forage (Leucaena leucocephala (LEU), Stizolobium aterrimum (MUC) and Mimosa caesalpiniaefolia Benth (SAN)) to reduce enteric $\mathrm{CH}_{4}$ production in Santa Inês hair sheep. The adaptation of the technique from cattle studies was shown to be efficient but several adjustments needed to be carried out. The standardized chromatograph curves used for cattle were below the values found for sheep. This calibration is still being resolved. Twelve male lambs ( 27.88 $\pm 2.85 \mathrm{~kg} \mathrm{LW}$ ) were randomly allocated in individual metabolic cages for 20 days adaptation followed by 6 days for measuring food intake and enteric $\mathrm{CH}_{4}$ emission. All lambs received water, mineral supplement and Cynodon dactylon v. Coast-Cross hay ad libitum. The experimental treatments consisted of supplementation along with the hay, including soybean meal $(71 \%)$ and corn grain $(29 \%)$ (Control-CON); soybean meal (15\%), corn grain (3\%) and leucaena hay (82\%) (LEU); soybean meal (16\%), corn grain (15\%) and mucuna hay $(69 \%)$ (MUC) and soybean meal (28\%), corn grain (19\%) and mimosa hay (53\%) (SAN), calculated to provide $4 \%$ CT (except for CON) in an isoproteic and isoenergetic diet. Dry matter intake ( $\mathrm{g} \mathrm{DMI} \mathrm{kg}{ }^{-1} \mathrm{LW} \mathrm{day}^{-1}$ ) was lower for sheep receiving LEU (22.0) than CON (29.3), MUC (31.2) and SAN (31.6). The sheep that received LEU also showed an emission of $7.9 \mathrm{CH}_{4} \mathrm{~g} \mathrm{~d}^{-1}$, significantly lower than $\mathrm{CON}\left(10.5 \mathrm{CH}_{4} \mathrm{~g} \mathrm{~d}^{-1}\right), \mathrm{MUC}\left(10.4 \mathrm{CH} 4 \mathrm{~g} \mathrm{~d}^{-1}\right)$ and SAN $\left(11.3 \mathrm{CH}_{4} \mathrm{~g} \mathrm{~d}^{-1}\right)$. However, when the $\mathrm{CH}_{4}$ emission per dry matte $\mathrm{r}$ intake was considered, there were no significant differences among treatments $\left(0.366,0.365,0.335\right.$ and $0.355 \mathrm{~g} \mathrm{CH}_{4} \mathrm{~g}^{-1} \mathrm{DMI} \mathrm{kg}{ }^{-1} \mathrm{LW} \mathrm{d}^{-1}$, respectively, for CON, LEU, MUC and SAN). A tendency for sheep receiving MUC $(P=0.15)$ to produce less methane than sheep fed CON diet (without TC) was observed. It is suggested that for a sustainable sheep production system the use of tropical tanniniferous legumes may reduce $\mathrm{CH}_{4}$ emission. 


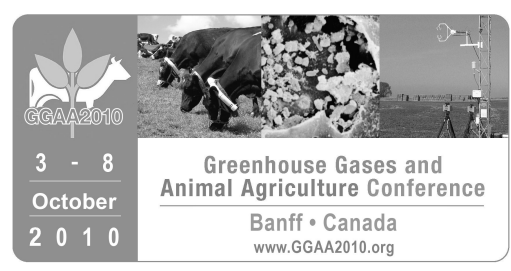

\title{
T92. Physiological status can affect methane yield in sheep fed lucerne pellets
}

\author{
S. Muetzel, S. O. Hoskin, C. Grainger* and H. Clark*
}

A previous experiment with ewes offered fresh-cut pasture indicated that the methane yield $\left(\mathrm{g} \mathrm{CH}_{4} / \mathrm{kg} \mathrm{DMI}\right)$ was increased by $20 \%$ when ewes were lactating compared with when they were pregnant or immediately post-weaning. The design of the experiment meant that there two possible confounding factors that may have influenced methane yield, over and above the effect of lactation. The quality of the pasture changed over the course of the experiment and the lactating sheep had a higher level of intake than the dry ewes. To eliminate these potentially confounding factors, an experiment was conducted to measure the effect of physiological status of ewes on $\mathrm{CH}_{4}$ yield when offered a diet at the same level of intake and of the same quality. The experiment was conducted with two groups of eight ewes each, a control group (dry ewes) and a lactating group with single lambs. Both groups were fed lucerne (Medicago sativa) pellets at the same intake level (1.8 to $2.2 \mathrm{x}$ maintenance energy requirement). The experiment had four measurement periods that coincided, for the lactating group, with late pregnancy, twice during lactation and one post-weaning. Between periods, the animals grazed pasture and were adapted for $10 \mathrm{~d}$ to the lucerne pellets before calorimetry measurements were made. The design of the experiment enabled the effect of physiological status on $\mathrm{CH}_{4}$ yield to be examined within- and between-animals. Compared to the previous experiment with fresh pasture, the $\mathrm{CH}_{4}$ yield of lucerne pellets was $29 \%$ lower $(P<0.001)$. In agreement with the earlier work, a $15 \%$ increase in $\mathrm{CH}_{4}$ yield $(P=0.026)$ was observed, within-animal, between late pregnancy and lactation. However, $\mathrm{CH}_{4}$ yield of the lactating group was similar during and after lactation. Consistent with the between-animal comparison there was no difference in $\mathrm{CH}_{4}$ yield between the control and the lactating group during and after lactation. There was also no difference in $\mathrm{CH}_{4}$ yield when pregnant and dry ewes were compared. It is concluded that physiological status can affect $\mathrm{CH}_{4}$ yield. However, the results do not allow a conclusion as to whether the effect on $\mathrm{CH}_{4}$ yield is attributed late pregnancy or lactation. Therefore this should be re-examined with sheep and also investigated in cattle.

\section{T93. Potential of California chaparral plants to mitigate in vitro methane emissions and ammonia levels in rumen fluid}

N. Narvaez*, Y. Wang, Z. Xu and T. McAllister*

Effects of eleven chaparral species (California, USA) on reducing $\mathrm{CH}_{4}$ emissions and ammonia ( $\mathrm{NH}_{3}-\mathrm{N}$ ) production during ruminal fermentation of mixed barley silage:barley grain-based growing (GD) and finishing (FD) diets were assessed in vitro. Serum bottles containing $500 \mathrm{mg}$ of GD or FD as substrate, $50 \mathrm{mg}$ of dried and ground chaparral and $40 \mathrm{~mL}$ of inoculum were incubated at $39^{\circ} \mathrm{C}$ for $48 \mathrm{~h}$ (GD; Exps. 1 and 2) or $24 \mathrm{~h}$ (FD; Exp. 3). Control vials contained $550 \mathrm{mg}$ of substrate. Total gas and $\mathrm{CH}_{4}$ production were measured at 4, 8, 12, 24, and (in Exps. 1 and 2 only) at $48 \mathrm{~h}$. Total volatile fatty acids (VFA) and $\mathrm{NH}_{3}-\mathrm{N}$ concentrations, and apparent DM disappearance (DMD) were determined after $48 \mathrm{~h}(\operatorname{Exp} 1$ and 2) and $24 \mathrm{~h}(\operatorname{Exp}$. 3). With FD, gas production was reduced $(P<0.001)$ by all chaparral plants, whereas with $\mathrm{GD}$, it was unaffected by Baccharis pilularis and Eriodyction californicum. All chaparral species incubated with either diet reduced $(P<0.001)$ apparent $D M D$, except $E$. californicum with GD. Methane production (\% of total gas and per g DM) from GD was reduced $(P<0.003)$ by 4 of the 11 chaparral species: B. pilularis, E. californicum, Adenostoma fasciculatum, Quercus douglasii, and the other 3 Arctostaphylos spp. (A. canescens, A. glandulosa and A. stanfordiana), Ceanothus cuneatus, Heteromeles arbutifolia, Quercus durata and Quercus wislizenii did not affect the $\mathrm{CH}_{4}$ produced as \% in total gas but reduce $(P<0.001)$ it as per $\mathrm{g}$ DM. In contrast, $B$. pilularis, $E$. californicum, $A$. fasciculatum, $Q$ 


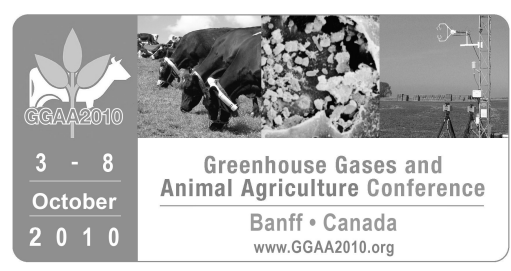

douglasii and $A$. stanfordiana did not affect $\mathrm{CH}_{4}$ production from $\mathrm{FD}$ (as $\%$ of total gas), and $A$. canescens, $A$. glandulosa and the other three chaparral species increased $(P<0.03)$ it. However, $B$. pilularis and $E$. californicum reduced $(P<0.05) \mathrm{CH}_{4}$ per $\mathrm{g}$ DM. All species reduced $(P<0.001) \mathrm{NH}_{3}-\mathrm{N}$ accumulation except $E$. californicum and $H$. arbutifolia with FD and C. cuneatus, E. californicum, and the three Arctostaphylos spp. with GD. Total VFA was unaffected by chapparal, except $A$. canescens and $C$. cuneatus with GD (reduced; $P<0.01$ ), but acetate:propionate ratios were increased $(P<0.001)$ in all cases except by $B$. pilularis with $G D$. Effects of chaparral plants on ruminal fermentation are diet-dependent. Greatest effects were observed with reducing $\mathrm{CH}_{4}$ production from $\mathrm{GD}$ and $\mathrm{NH}_{3}-\mathrm{N}$ accumulation from $\mathrm{FD}$. Of the chaparral species investigated, B. pilularis, $E$. californicum, and $A$. fasciculatum showed potential to improve fermentation efficiency by decreasing $\mathrm{CH}_{4}$ production and $\mathrm{NH}_{3}-\mathrm{N}$ concentration without adversely influencing fermentability of feed.

\title{
T94. The use of sandalwood extracts and analogues thereof to modify rumen fermentation
}

\author{
C. J. Newbold*, A.Y. Ali and K.J. Hart
}

Sandalwood extracts prepared from trees of the genus Santalum are widely used in perfume industry and harvested commercially. As part of an ongoing screening of plant extracts capable of manipulating rumen fermentation we have noted that sandalwood extract (selected from a screening of almost 2500 such compounds) prevents the growth of E.coli 0157 and Listeria monocytogenes in rumen like conditions; reduces the rate of bacterial breakdown by rumen protozoa (allowing more protein to be absorbed by the gut of the animal and thus boosting production); and decreases the emission of the important greenhouse gas methane in in vitro batch incubations. Futhermore, based on the chemical structure of the essential oils in the extract, determined by GC-MS, (1-Methyl-2-(1,2,2-trimethylbicyclo[3.1.0]hex-3-ylmethyl)cyclopropyl) methanol (Javanol, Givaudan SA, Switzerland) was identified as typical of a family of sandalwood analogues that could decrease methane production in vitro. Further trials in the Rumen simulating fermentor, Rusitec have confirmed that Javanol decreased ammonia concentrations by $30 \%$, methane production by up to $25 \%$ and significantly reduced $E$. coli 0157 survival after 9 hours. When added at the rate of $2 \mathrm{ml} / \mathrm{d}$ to the diet of sheep receiving a mixed diet of chopped hay, barley, Soya and molasses Javanol decreased methane emissions by $20 \%$ when expressed per unit of live weight gain and increased nitrogen retention by $15 \%$. Sandalwood extract and chemical analogues thereof have the potential to be used as additives to animal foodstuff in order to bring about important and beneficial changes in ruminant digestion.

\section{T95. Effects of diet rich in "fibre" or in "starch and lipid" on environmental impacts of bull-fattening system}

T.T.H. Nguyen, M. Eugene*, H.M.G. van der Werf, G. Chesneau, M. M. Malon and M. Doreau

Mitigation strategies for enteric $\mathrm{CH}_{4}$ emissions should be evaluated through a multicriteria assessment of environmental impacts. Enteric $\mathrm{CH}_{4}$ from bulls fed a high-concentrate diet based on cereals supplemented with extruded linseed was reduced by $23 \%$ ( $\mathrm{g} \mathrm{kg}^{-1}$ body weight gain) in comparison with a high-concentrate diet based on fibre-rich co-products (Eugène et al., 2010, this symposium). This study aimed at comparing environmental impacts, in particular GHG emissions, of a bull fattening system from the age of 8.5 to 16 months with these two diets using the life cycle assessment method. The fibre-rich diet (F) comprised $13 \%$ straw and $87 \%$ concentrate including $22 \%$ bran, $22 \%$ dehydrated alfalfa and $21 \%$ dehydrated beet pulp. The 


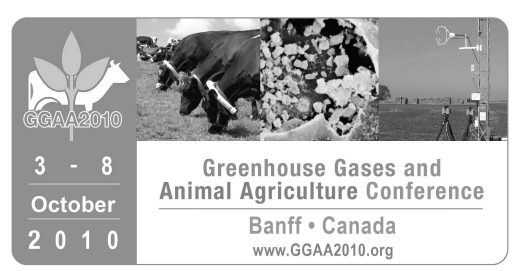

starch and lipid-rich diet (SL) comprised $13 \%$ straw and $87 \%$ concentrate including $46 \%$ cereals and $6 \%$ extruded linseed. The system included production and transport of feed ingredients and associated upstream processes, emissions from the animals and manure storage. The hypotheses on the farm location were north of France for diet $\mathrm{F}$ and southwest of France for diet SL. The functional unit was $1 \mathrm{~kg}$ of body weight gain (BWG) then during the fattening period. Enteric $\mathrm{CH}_{4}$ was either measured by Eugène et al. (2010), or estimated using the IPCC (2006) Tier 2 method, or the equation P of Ellis et al. (2009). Emissions from manure management were calculated according to IPCC. Emissions associated with feeds were calculated based on practices in France, especially for fertilizer application and feed technology. Enteric $\mathrm{CH}_{4}$ contributed 47 and $44 \%$ to climate change $\left(\mathrm{CO}_{2}, \mathrm{CH}_{4}\right.$ and $\mathrm{N}_{2} \mathrm{O}$ emissions) impact for diets $\mathrm{SL}$ and $\mathrm{F}$, respectively, based on the measured data. Climate change impact for diet SL was $27 \%$ lower than for diet F. The reduction of $23 \%$ of enteric $\mathrm{CH}_{4}\left(\mathrm{~g} \mathrm{~kg}^{-1}\right.$ of BWG) observed with the bulls receiving diet SL (Eugène et al., 2010) resulted in a $10 \%$ decrease in climate change impact of diet SL compared to diet F. Predicted enteric $\mathrm{CH}_{4}$ by IPCC and Ellis et al. (2009) was lower (-60 and $-33 \%$, respectively) than the measured value for both diets. Therefore, climate change impact based on predicted enteric $\mathrm{CH}_{4}$ by IPCC and Ellis et al. (2009) was 28 and $15 \%$ lower, respectively, than climate change based on measured data. Diet SL was better than diet $\mathrm{F}$ in terms of acidification and cumulative energy demand but had higher eutrophication and land occupation impacts than diet F. Terrestrial ecotoxicity potential was the same for both diets.

\section{T96. Effect of lactose ureide on methane emission and ruminal fermentation in vitro} T. Nishida*, S. Hayasaki, K. Kida, T. Matsumoto*, R. Asa-Morikawa and J.Takahashi*

An in vitro continuous incubation system was used to evaluate effects of increasing addition of lactose ureide (LU, Japan Dairy Technical Association, Tokyo, Japan) prepared by reaction of whey with urea on ruminal fermentation and methane emission. Four $1000 \mathrm{ml}$ fermentation vessels were used for $24 \mathrm{~h}$ incubation and replicated 3 times. The culture media consisted of $400 \mathrm{ml}$ of strained rumen fluid collected from ruminally cannulated non-lactating Holstein cows and $400 \mathrm{ml}$ of McDougall's buffer. The culture media were anaerobically incubated with $10 \mathrm{~g}$ of a mixture of ground concentrate and Timothy hay $(1: 1, \mathrm{w} / \mathrm{w})$ at $39^{\circ} \mathrm{C}$ for $24 \mathrm{~h}$ without $\mathrm{LU}(0 \mathrm{~g})$, with $5 \mathrm{~g}, 10 \mathrm{~g}$ and $15 \mathrm{~g}$ of LU administration. Gas emission from each fermentation vessel was measured continuously by infrared methane and carbon dioxide gas analyzers. Samples of incubated media were withdrawn from the fermentation vessels at $0,2,4,6,8$ and $24 \mathrm{~h}$ of incubation and were stored at $-18^{\circ} \mathrm{C}$ for further analysis of volatile fatty acids (VFA) and ammonia nitrogen. Methane and carbon dioxide were both produced more in 5, 10 and $15 \mathrm{~g}$ of LU addition than without LU and most in $15 \mathrm{~g}$, but there were no differences between 5 and $10 \mathrm{~g}$ of LU addition. Medium pH was significantly lower in 10 and $15 \mathrm{~g}$ than in 0 and $5 \mathrm{~g}$ of LU addition at $24 \mathrm{~h}$. Lactose ureide administration increased numerically acetate concentrations at $24 \mathrm{~h}$ after dosing LU in 5, 10 and $15 \mathrm{~g}$ of $\mathrm{LU}$ addition compared to without LU. Propionate concentration increased (P $<0.05$ ) at $24 \mathrm{~h}$ in $15 \mathrm{~g}$ of LU addition compared to without LU, and numerically increased in 5 and $10 \mathrm{~g}$ of LU addition compared to without LU. Total VFA concentration increased $(\mathrm{P}<0.05)$ at $24 \mathrm{~h}$ in 10 and $15 \mathrm{~g}$ of LU addition compared to without LU. Ammonia nitrogen concentrations were markedly increased $(P<0.05)$ at $2 \mathrm{~h}$ in 5,10 and $15 \mathrm{~g}$ of LU addition compared to without LU, but were still below toxic levels. There were no differences in ammonia nitrogen concentrations among 5, 10 and $15 \mathrm{~g}$ of LU addition and without $\mathrm{LU}$ at 8 and $24 \mathrm{~h}$. Results suggest that LU has an enhancing effect on rumen methanogenesis and fermentation and may have potential as both energy and protein sources for growing ruminal protozoa and microbes. 


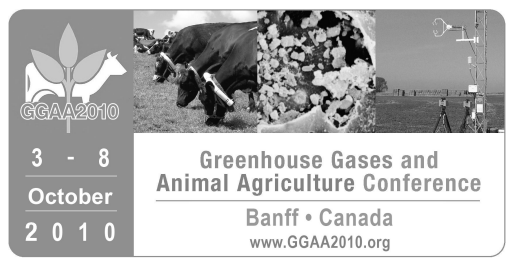

T97. Effects of an iodo-propane and cyclodextrin complex supplement on methane production, ruminal fermentation and digestibility in Korean native cattle

\author{
Y. K. Oh, C. W. Kim, K. H. Kim, S. C. Lee, S. K. Hong, Y. J. Seol and K. H. Park*
}

Effects of iodo-propane and cyclodextrin complex (IP-CD) on methane production, ruminal fermentation and digestibility were investigated using both in vitro and in vivo methods. Ruminal fluid collected from Korean native cattle was mixed with buffer solution (1:4) and incubated $(30 \mathrm{ml})$ anaerobically at $39^{\circ} \mathrm{C}$ for 6,12 and $24 \mathrm{~h}$ with or without IP-CD plus corn starch as a substrate. The IP-CD was added at different concentrations $(0,2.8$, 5.6 and $\left.11.2 \mathrm{~g} \mathrm{~L}^{-1}\right)$. The $\mathrm{pH}$ of the medium was affected $(P<0.05)$ by the addition of IP-CD. Total volatile fatty acids were increased and ammonia- $N$ was decreased. IP-CD addition decreased molar proportion of acetate and increased propionate. IP-CD decreased $(P<0.05) 92-98 \%$ of methane in vitro. Four Hanwoo steers were used within a cross-over design for the in vivo study. The steers were fed timothy and concentrate mixture (1:1) supplemented with or without IP-CD ( $2 \%$ of feed dry matter). The addition of IP-CD inhibited $(P<0.05)$ methane from 37.2 to $29.6 \mathrm{~kg} \mathrm{head}^{-1}$ year ${ }^{-1}$. IP-CD did not affected apparent digestibilities of dry matter and neutral detergent fibre while increased $(P<0.05)$ crude protein. Therefore, the present IP-CD as a methane inhibitor may be utilized.

\title{
T98. Effects of in vitro rumen protection of soybean meal coated with fat on digestibility and gas production rate using gas test technique
}

M. H. Palizdar*, H. Sadeghipanah, H. Amanlou, K. Nazer Adl and A. Mirhadi

We utilized an in vitro rumen gas production technique to evaluate soybean meal coated with different types and levels of hydrogenated fats for total gas production, metabolizable energy (ME) and organic matter digestibility (OMD) contents. The aim of this study was also to investigate the kinetics of fermentation for soybean meal (SBM) protected with different types [hydrogenated tallow (HT) and hydrogenated palm oil (HP)] and levels $\left(0,200,400,600\right.$ and $\left.800 \mathrm{~g} \mathrm{~kg}^{-1}\right)$ of fat to decrease rumen digestibility of organic matter and gas production (GP). Approximately $200 \mathrm{mg}$ (DM basis) of sample was weighed and inserted in glass syringes. Inoculum and artificial saliva, totalling $30 \mathrm{ml}$, was then added to the syringes which were then incubated at $39{ }^{\circ} \mathrm{C}$ in a ventilated oven. GP was recorded after $0,2,4,6,8,12,24,48,72$ and $96 \mathrm{~h}$. There were differences among fat coated treatments and SBM in total GP at $6,8,12,24$, and $48 \mathrm{~h}$ of in vitro incubation, and the treatments differed $(\mathrm{P}<0.01)$ in rate of and potential gas production. The result of the present study showed that experimental fats when mixed by soybean meal to protect it from microbial fermentation, reduced in vitro digestibility of organic matter and GP during the time of incubation. In compare to HT, coating soybean meal with HP resulted in significantly reduced GP $(P<0.01)$. Furthermore the values of $b$ and $a+b$ reduced significantly since soybean meal was coated with these two types of fat $(P<0.01)$. It seems that one of the possible strategies to reduce total GP from dairy cows or feedlot cattle is coating some portions of dietary concentrate with supplemental fats in the form of hydrogenated free fatty acids like HT or HP. Accordingly a reduction in the fermentation rate of organic matter and proteins could reduce the total GP as $\mathrm{NH}_{3}, \mathrm{CO}_{2}$ and $\mathrm{CH}_{4}$ in the rumen and may provide more protein for absorption in the small intestine. 


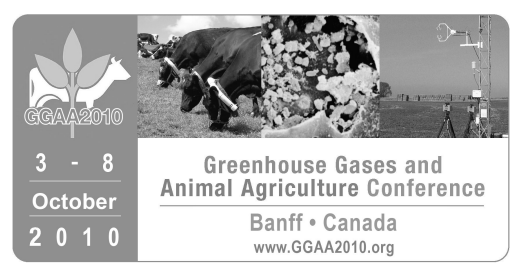

T99. Fibrolytic potential of anaerobic fungi (Piromyces sp.) isolated from wild cattle and wild blue bull in pure culture and effect of their addition on in vitro fermentation of wheat straw and methane emission by rumen fluid of buffaloes

\author{
S. S. Paul*, S. M. Deb, B. S. Punia, D. Singh and R. Kumar
}

Ten isolates of anerobic fungi of Piromyces genus from wild cattle and blue bull (five isolates from each host species) were evaluated for fibrolytic ability in pure culture and for their suitability for use as microbial additive in buffaloes and their effect on methane emission. In pure culture, only two out of five isolates from wild cattle degraded wheat straw efficiently, whereas all the five isolates from blue bull degraded wheat straw efficiently. The isolate CF1 (isolated from wild cattle) showed the highest apparent digestibility (53.4\%), true digestibility $(70.8 \%)$ and neutral detergent fibre digestibility (75\%) of wheat straw after $5 \mathrm{~d}$ of incubation. When added to rumen fluid of buffalo, all the 5 isolates from wild cattle increased $(P<0.05)$ in vitro apparent digestibility of wheat straw as compared to control (received autoclaved culture) but all the 5 isolates from blue bull failed to influence in vitro digestibility of wheat straw. The isolate CF1 showed the highest stimulating effect on straw digestion by buffalo rumen fluid microbes and increased apparent digestibility $(29.4 \%$ vs. $51.9 \%$; $P<0.05)$, true digestibility $(57.9 \%$ vs. $36.5 \%$; $P<0.05)$, neutral detergent fiber degradability $(51.5 \%$ vs. $26.9 \% ; P<0.05)$ of wheat straw as compared to control after $24 \mathrm{~h}$ of fermentation. There was also significant increase in fungal count, enzyme activities of carboxymethyl cellulase and xylanase in CF1 added group as compared to control group. Gas and methane production per $g$ truly digested dry matter of straw were comparable among all the groups including control. Wild cattle and blue bull harbor some anaerobic fungal strains having strong capability to hydrolyse fibre. The fungal isolate CF1 has a high potential to be used as microbial feed additive in buffaloes for improving digestibility of fibrous feeds without increase in methane emission per unit of digested feed.

T100. Evaluating the effects of tannins on the extent and rate of in vitro measured gas and methane production using the Automated Pressure Evaluation System (APES)

W. F. Pellikaan*, E. Stringano, J. Leenaars, D.J.G.M. Bongers, S. van Laar-van Schuppen, J. Plant and I. MuellerHarvey

An in vitro study was conducted to investigate the effect of tannins on the extent and rate of gas and methane production, using an automated pressure evaluation system (APES) that was modified to allow methane measurement. In this study three condensed (CT; Quebracho, Grapeseed extract, Tea tannins) and four hydrolizable tannins (HT; Tara tannins, Valonea, Myrabolan, Chestnut) were evaluated, with lucerne as the control substrate. Tannins were added to the substrate at an effective concentration of $10 \%$ either with or without polyethylene glycol (PEG6000), and incubated for $72 \mathrm{~h}$ in a pre-warmed buffered medium mixed with rumen liquid pooled from four lactating dairy cows. After inoculation fermentation bottles were immediately connected to the APES to measure total cumulative gas production (organic matter corrected volume, OMCV). The lids of the fermentation bottles contain an opening which is normally gas-tight sealed with a brass cap. The brass caps were modified to allow sampling from the bottle headspace using a gas-tight syringe $(25 \mu \mathrm{L}$, Hamilton). To ensure fully gas-tight and closed fermentation system rubber septa were placed in the brass caps. During the incubation period 10 gas samples were taken from the bottle headspace at time $t=1,4,7,11$, $15,23,46,52$ and $68 \mathrm{~h}$, and analysed on methane by gas chromatography. A Gompertz model was fitted to the methane concentration patterns and model estimates were used to determine the total cumulative methane production $\left(\mathrm{OMCV}_{-} \mathrm{CH}_{4}\right)$. Addition of Quebracho reduced the OMCV significantly $(P=0.003)$ whilst the other tannins did not seem to affect OMCV distinctly. The addition of PEG resulted in an increase in OMCV for 


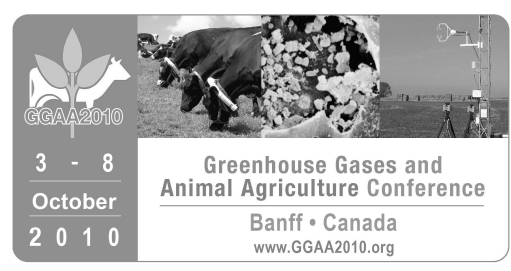

Quebracho $(P=0.003)$, Valonea ( $P=0.064)$ and Grapeseed extract $(P=0.078)$, suggesting a potentially undesirable effect of these tannins on the extent of fermentation. Addition of Quebracho and Grapeseed extract significantly reduced the maximum rate of gas production $(P=0.003)$, which suggests that microbial activity is seriously affected by these tannins. With respect to methane production Quebracho, Valonea, Myrabola and Grapeseed gave a significant decrease in the $\mathrm{OMCV}^{-} \mathrm{CH}_{4}$ and the maximum rate of gas production $(P=0.009)$. Addition of Chestnut extract, Tara tannins and Tea tannins did not seem to affect total gas production or methane production. The current study showed that Valonea and Myrabola gave the most promising results in reducing methane production without having negative effects on the total gas production.

\section{T101. Repeatability of methane emissions from sheep}

C.S. Pinares-Patĩno*, J. C. McEwan, K. G. Dodds, S. Muetzel, E. A. Cárdenas*, R. S. Hegarty*, J. P. Koolard and H. Clark*

Breeding of ruminant livestock for low methane $\left(\mathrm{CH}_{4}\right)$ emission seems an attractive avenue for mitigation of enteric $\mathrm{CH}_{4}$ emissions. This approach to work requires that the mechanism responsible for animal-to-animal variation in emissions is both repeatable and heritable and has no unwanted relationships with production and functional traits. In 2008, a flock of 105 ewe lambs (9 month old) of the Central Progeny Testing (CPT) programme of Meat \& Wool New Zealand were screened for their $\mathrm{CH}_{4}$ yields (i.e., emissions per unit feed dry matter intake, DMI) when a standard forage diet (molassed-grass silage) was fed at restricted levels (1.3 maintenance) and $\mathrm{CH}_{4}$ emissions measured for a single day in respiration chambers over four separate measurement periods. The mean $\mathrm{CH}_{4}$ yield of lambs was $18.4 \pm 2.0 \mathrm{~g} \mathrm{~kg}^{-1} \mathrm{DMI}$, and the estimate of repeatability for $\mathrm{CH}_{4}$ yield was 0.16 . Based on the initial screening process, the 10 lowest and the 10 highest $\mathrm{CH}_{4}$ yielding sheep were selected and retained for further study. A 7.9\% difference in $\mathrm{CH}_{4}$ yield between the low and high emission ranking sheep (17.8 vs. $19.2 \mathrm{~g} \mathrm{~kg}^{-1} \mathrm{DMI}$ ) was observed at the screening stage. Following the sheep screening, two subsequent measurements of $\mathrm{CH}_{4}$ yield were conducted between May and July 2009. The first repeated measurement was conducted while sheep were fed on fresh-cut perennial ryegrass pasture, whereas the second repeated measurement was conducted on a concentrate:forage (wheat grain:lucerne hay; 40:60, fresh basis) pelleted diet. The mean $\mathrm{CH}_{4}$ yields of the selected low and high $\mathrm{CH}_{4}$ emitting sheep fed pasture were $22.5 \pm 2.0$ and $24.4 \pm 1.1 \mathrm{~g} \mathrm{~kg}^{-1} \mathrm{DMl}$, respectively, whereas the corresponding values for sheep fed pellets were $18.6 \pm 6.3$ and $23.6 \pm 5.0 \mathrm{~g} \mathrm{~kg}^{-1} \mathrm{DMI}$. Most of the animals maintained their emission rankings over the three measurement stages, but a few individuals behaved atypically.

\section{T102. Methane emissions from cattle stocked at high density and fed pasture at three feeding levels}

C. S. Pinares-Patiño*, J. Laubach, F. M. Kelliher, G. Molano*, E. A. Cárdenas*, S. MacLean, E. Sandoval and G. Taylor.

The sulphur hexafluoride $\left(\mathrm{SF}_{6}\right)$ tracer technique is widely used for the estimation of methane $\left(\mathrm{CH}_{4}\right)$ emissions from grazing animals. It is an animal-scale method and its application is typically limited to up to 30 animals at one time. This is not representative of herd sizes usually found in intensive grazing systems such as dairying, where in order to maximise pasture utilisation, high stocking densities are applied. Alternatively, paddock-scale methods such as micro-meteorological techniques, operate unobtrusively by measuring the $\mathrm{CH}_{4}$ emitted into 


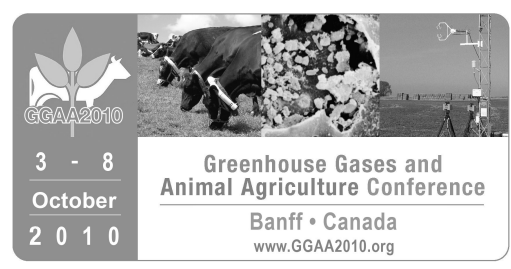

the atmosphere as it is transported away by the wind and dispersed by turbulence. A study was conducted in order to compare animal- and paddock-scale-based methods of $\mathrm{CH}_{4}$ emissions estimation to account for changing feeding levels under simulated high stocking density. This study is concerned with the animal-scale method only. Sixty-one one year old Friesian $\times$ Hereford crossbred steers were managed to simulate a high stocking density grazing situation ( $62 \mathrm{~m}^{2}$ per animal) using a pasture-free paddock enclosure. The cattle were fed pasture silage twice daily at three increasing feeding levels (low, medium and high) over three consecutive periods (Periods 1-3) of 1 week duration. Feeding levels were set according to maintenance energy requirements of the steers (1.0, 1.5 and $2.0 \times$ maintenance). At each feeding level, $\mathrm{CH}_{4}$ emissions of individual animals were estimated using the $\mathrm{SF}_{6}$ tracer technique over 3 consecutive days. The estimated dry matter intakes (DMI) at the low, medium and high feeding levels were 260, 409 and $567 \mathrm{~kg} \mathrm{day}^{-1}$ herd $^{-1}$, respectively. Daily $\mathrm{CH}_{4}$ emissions increased with the increase in feeding level $(70.8 \pm 13.5,89.7 \pm 11.1$ and $119.1 \pm 16.4 \mathrm{~g}$ animal ${ }^{-1}$ for low, medium and high, respectively) and the calculated $\mathrm{CH}_{4}$ yields were $16.6,13.4$ and $12.8 \mathrm{~g} \mathrm{~kg}^{-1}$ DMI. The lack of accurate measurement of feed intake precluded the assessment of any feeding level effect on $\mathrm{CH}_{4}$ yield (emissions per unit of intake). Nevertheless, the results suggest that $\mathrm{CH}_{4}$ yields from pasture silage feeding may be lower than from fresh pasture. Differences in $\mathrm{CH}_{4}$ emissions due to forage conservation methods may have important implications for emission inventory and mitigation strategies.

\section{T103. The impact of grazing management on in vitro methane emissions of perennial ryegrass sampled throughout the growing season \\ P. Purcell*, M. O'Brien, T. Boland*, M. O'Donovan and P. O'Kiely*}

This study determined the methane production of perennial ryegrass grown under a well managed Irish dairy production system and managed under four strategies consisting of two levels of herbage mass (HM; high 2400 and low $\sim 1600 \mathrm{~kg} \mathrm{DM} / \mathrm{ha}$ ), and two levels of sward allowance (SA; high 20 and low $15 \mathrm{~kg} \mathrm{DM} /$ cow per day) throughout the grazing season in a $2 \times 2$ factorial arrangement of treatments using the in vitro gas production technique (IVGPT). Samples were taken during five 22-d sampling periods (SP) throughout the growing season and analysed for in vitro methane and total gas production using rumen liquid and artificial saliva as inoculants. The data were analysed using a model that accounted for the effects of HM, SA, HM $\times$ SA, and stage of season (repeated measures), and correlations over time. A spatial covariance structure was also used. Methane production per gram of DM incubated and digested were higher for the high HM treatment. Sward allowance had no effect on methane production, and methane production per gram of DM incubated was highest during SP 1 and lowest during SP 3 and 4. Methane production per gram of DM digested was also lowest during SP 3 and 4 . The acetic acid to propionic acid (A:P) ratio and the non-glucogenic ratio (NGR) were lowest during SP 1 and highest during SP 5. Whereas HM and SP had statistically significant effects on in vitro methane production, the biological scale of these effects was quite small. This likely reflects the narrow range in sward quality produced by the rotational grazing systems used. These differences in methane production were not evidently reflective of variation in grass chemical composition or in vitro rumen VFA.

\section{T104. The effect of tea waste on methane production in Ongole crossbred cattle}

A. Purnomoadi*, M. F. Harlistyo, R. Adiwinarti, E. Rianto, O. Enishi and M. Kurihara*

Twelve Ongole crossbred cattle (aged 1.5 years, weighed $206 \mathrm{~kg}$ ) were used to study the effect of tea waste inclusion on methane production. The cattle were divided into three groups (four heads in each group) for the concentrate feeding treatments [i.e., concentrate feeding composed of tea waste $10 \%$ and rice bran $90 \%$ 


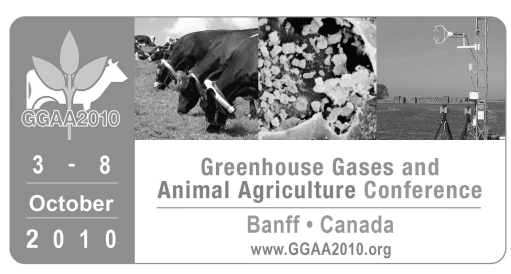

(T1Rb9), tea waste $20 \%$ and rice bran $80 \%$ (T2Rb8) and tea waste $30 \%$ and rice bran $70 \%$ (T3Rb7)]. The concentrate feeding was given to cattle at $2 \%$ of body weight while rice straw was ad libitum. Daily intake of dry matter (DMI), methane production and body-weight gain (BWG) were measured. Methane emission was measured by Facemask method which was performed for 10 minutes in $3 \mathrm{~h}$ intervals over two days. Body weight gain was determined after cattle were raised under the experimental feeding for 5 weeks. The results indicated that among the treatments the DMI was similar $\left(6.98,6.64\right.$ and $\left.6.92 \mathrm{~kg} \mathrm{~d}^{-1}\right)$, as well as BWG $(746,614$ and $\left.739 \mathrm{~g} \mathrm{~d}^{-1}\right)$. Methane production of the cattle among the treatments was similar, being 178.7, 169.5 and $170.5 \mathrm{~L} \mathrm{~d}^{-1}$, respectively, as well as in methane production per kg DMI $\left(25.7,25.6\right.$ and $\left.24.9 \mathrm{~L} \mathrm{~kg}^{-1} \mathrm{DMI}\right)$, and methane production per daily BWG $\left(241.4,277.6\right.$ and $238.4 \mathrm{~L} \mathrm{~kg}^{-1}$ BWG). However, this study showed that inclusion of tea waste in feeding treatments resulted in a low methane conversion ratio, ranging from 5.1-5.9\% of energy intake.

\section{T105. Relationship between fatty acid content of perennial ryegrass and in vitro methane production}

C. Quinlan, A. K. Kelly, M. Cristilli, M. B. Lynch and T. M. Boland*

The supplementation of ruminant diets with plant oils containing polyunsaturated fatty acids (PUFA) has proved effective in reducing enteric methane emissions. Grazed grass is a rich source of PUFA, predominantly linoleic and linolenic acid. Increasing the content of PUFA in grazed grass may offer an opportunity to reduce enteric methane emission from grazing ruminants. The objective of this study was to assess the relationship between linoleic acid and linolenic acid contents in perennial ryegrass and in vitro methane production. Perennial ryegrass samples were collected across a range of harvest dates and varieties during the 2007 growing season. Samples were oven dried at $40^{\circ} \mathrm{C}$ for $48 \mathrm{~h}$, then ground to pass through a 1-mm screen. A one step methylation method (Sukhija and Palmquist 1988) was used for FA methylation. The FA profile was determined by gas chromatography using a Varian GC (Chromopak) CP-3800 equipped with a FID detector and a CP-7420 column (Varian-Chromopack). Individual methane emissions were measured using the in vitro rumen gas production technique of Mauricio et al. (1999). Rumen fluid was collected from three fistulated Friesian steers at 0930 prior to feeding (60:40 grass silage to concentrate ration). Concentrate composition was: (g/kg) 830 barley, 100 soya, 50 molasses, 20 mineral and vitamins mix. Increasing linoleic acid content reduced methane output per $g$ DM incubated $(P<0.01)$ and per $g$ DM digested $(P<0.001)$. Linolenic acid content was also negatively related to methane output per $g$ DM incubated $(P<0.001)$ and per $g$ DM digested $(P<0.001)$. Methane output per $g$ DM digested increased $(P<0.001)$ with increasing NDF content and decreased with increasing crude protein content $(P<0.001)$. The results of this study suggest that increasing PUFA content in perennial ryegrass may offer a potential methane mitigation strategy for grazing ruminants, although further work is required to quantify the response in vivo.

\section{T106. Methane production by lactating dairy cows fed diets containing allicin, glycerol or naked oats \\ C. K. Reynolds*, D. J. Humphries, P. Kirton, L. A. Crompton, J. A. N. Mills and D. I. Givens}

Our objective was to measure effects of dietary supplements on methane production by lactating dairy cows. Four Holstein-Friesian dairy cows in mid-lactation were fed total mixed rations (TMR) containing on a dry matter (DM) basis $37.5 \%$ grass silage, $12.5 \%$ maize silage, $50 \%$ concentrates and $13.9 \%$ crude protein. Cows received one of 4 treatments in a $4 \times 4$ Latin Square design experiment within 5 week periods. Treatments 


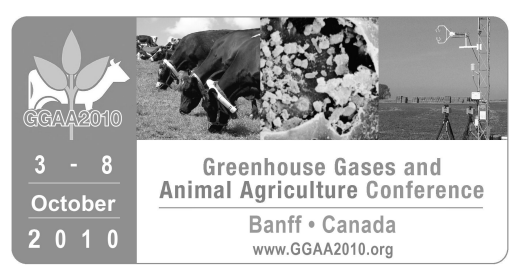

were the control ration or the control ration supplemented with: $1 \mathrm{~L}$ of an aqueous garlic extract solution (5000 $\mathrm{mg} \mathrm{L}^{-1}$ allicin; Neem Biotech, Cardiff, UK), glycerol at $10 \%$ of ration DM, or naked oats to provide supplemental lipid at $2 \%$ of ration DM. Glycerol and naked oats replaced cereals in the concentrates, which were formulated to be isonitrogenous to control concentrates. Measurements of methane production and energy and nitrogen balance were obtained during the last week of each period using respiration calorimetry and digestion trials. Data were analyzed using mixed models testing fixed effects of diet and random effects of period and cow. Feed DM intake (DMI; $19.3 \mathrm{~kg} \mathrm{~d}^{-1}$ for control) was not affected by treatments, but was numerically lower for naked oats $\left(18.3 \mathrm{~kg} \mathrm{~d}^{-1}\right)$ such that NDF intake was reduced by $791 \mathrm{~g} \mathrm{~d}^{-1}(P<0.10)$ as oil intake increased by 273 $\mathrm{g} \mathrm{d}^{-1}(P<0.01)$. Feeding naked oats increased milk yield by $2.7 \mathrm{~kg} \mathrm{~d}^{-1}(P<0.10)$ and reduced milk protein concentration $(P<0.05)$. There was no effect of allicin or glycerol on DMI, milk yield, or methane production, but feeding glycerol increased milk urea concentration $(P<0.01)$. Feeding naked oats reduced methane production $(P<0.10)$ from $566 \mathrm{~L} \mathrm{~d}^{-1}$ to $494 \mathrm{~L} \mathrm{~d}^{-1}$ such that methane $\mathrm{kg}^{-1} \mathrm{DMI}$ was reduced $(P<0.10)$ from 30.7 to $27.5 \mathrm{~L}$ and methane $(\mathrm{MJ})$ per $\mathrm{MJ}$ of milk energy was also reduced $(0.255 \mathrm{vs.} 0.201 ; P<0.01)$. In addition, milk nitrogen excretion as a percentage of nitrogen intake was increased (35.1 vs. 39.3; $P<0.05$ ) by feeding naked oats. Although glycerol can be absorbed directly or fermented to propionate, in the present study methane production was not affected by replacing starch with glycerol in a TMR. Allicin has been reported to reduce methane production in vitro and in sheep, but had no effect on methane production by lactating dairy cows in total $\left(573 \mathrm{~L} \mathrm{~d}^{-1}\right)$ or per kg DMI $(28.5 \mathrm{~L})$. As reported previously for other fat sources, feeding naked oats reduced methane production and increased milk yield by lactating dairy cows.

\section{T107. Effect of babassu palm (Orbignya phalerata) co-products in sheep diet upon nutrient digestibility and enteric methane production}

V. Rodrigues Vasconcelos, L. Alves Dantas Filho and M. M. Ramos Azevedo and A. L. Abdalla*

The aim of this work was to evaluate the use of babassu (Orbignya phalerata) co-products (cake and meal) in diets for sheep on nutrients digestibility and enteric methane production. Eleven Santa Inẽs male sheep, live weight (LW) $29 \pm 3.3 \mathrm{~kg}$, were randomly dived in three groups and offered three experimental diets for two periods of $21 \mathrm{~d}$ each. The diets consisted of Cynodon spp hay (50\%), corn grain (32\%) and soybean meal (16\%) for the control group (CNTRL); Cynodon spp hay (31\%), corn grain (32\%), soybean meal (15\%) and babassu meal (20\%) for BMEAL group and Cynodon spp hay (33\%), corn grain (32\%), soybean meal $(13 \%)$ and babassu cake (20\%) for BCAKE group. After $14 \mathrm{~d}$ adaptation period in grouped pens, the animals were kept in individual chambers for controlling feed intake, refusals and excretions daily. On the last two days of metabolism trial, the chambers were covered for the gas exchange assay and the outgoing air was sampled using a peristaltic pump. Methane on air sampled was measured using a GC. The protein, fiber and fat content of the diets were not different $(P>0.05)$ among tested diets (162, 168 and $162 \mathrm{~g} \mathrm{CP} / \mathrm{Kg}$ DM (SED 22.7); 636, 635 and $650 \mathrm{~g}$ NDF/Kg DM (SED 50.9) and 29, 19, and $28 \mathrm{~g} \mathrm{EE/Kg} \mathrm{DM} \mathrm{(SED} \mathrm{8.1),} \mathrm{respectively,} \mathrm{for} \mathrm{CNTRL,} \mathrm{BMEAL} \mathrm{and} \mathrm{BCAKE).}$ Dry matter intake (DMI) was not affected by treatment $(P>0.05,856 \mathrm{~g} / \mathrm{d}$ (SE 74.8)) but the inclusion of babassu significantly $(P<0.02)$ reduced DM digestibility $(0.72,0.67$ and $0.66 \mathrm{~g} / \mathrm{kg}$ (SED 0.022) for CNTRL, BMEAL and BCAKE, respectively). CNTRL group produced significantly $(P<0.05)$ more $\mathrm{CH}_{4}$ than the babassu groups $(29,19$ and $21 \mathrm{~L} / \mathrm{d}$ (SED 2.7)), but when considering the digestible DMI, BMEAL showed lower $(P=0.072) \mathrm{CH}_{4}$ production (36, 24 and $29 \mathrm{~g} \mathrm{CH}_{4} / \mathrm{kg} \mathrm{DDMI} / \mathrm{d}$ ). It is suggested that babassu meal, which is a co-product easily available in the NE of Brazil may be introduced for sheep feeding in small holder farms. 


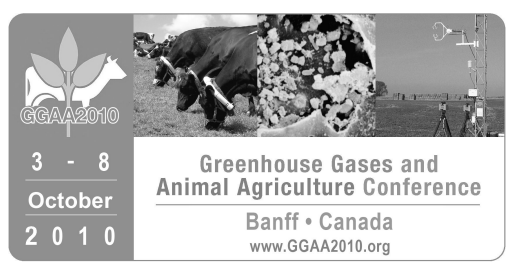

\section{T108. Effect of C18 fatty acid supplementation of grazing dairy cows on enteric methane, ammonia and volatile fatty acid production}

J. Rowntree, K. M. Pierce, F. Buckley, D. A. Kenny and T. M. Boland*

Globally, agriculture accounts for $50 \%$ of the anthropogenic emissions of $\mathrm{CH}_{4}$, a potent greenhouse gas (GHG) with enteric fermentation in ruminant animals making up 32\% of these $\mathrm{CH}_{4}$ emissions. Dairy cows produce a significantly larger amount of $\mathrm{CH}_{4}$ than do other cattle and ruminants and this represents a loss of up to $8.5 \%$ of the cow's gross energy intake (GEI). The objective of this study was to assess the impact of C18 fatty acid supplementation on ruminal $\mathrm{CH}_{4}$ emissions, volatile fatty acid (VFA) and ammonia $\left(\mathrm{NH}_{3}\right)$ production of grazing dairy cows. Forty-five Holstein Friesian cows were blocked on parity and allocated to one of three dietary treatments, balanced for days in milk and pre-experimental milk yield in a randomised block design. All treatments were allocated $17 \mathrm{~kg}$ grazed grass DM per cow per day and concentrates $(4 \mathrm{~kg} \mathrm{DM} / \mathrm{d})$ containing (FW basis) $160 \mathrm{~g} / \mathrm{kg}$ of stearic acid (Control), soya oil (SO) or linseed oil (LO). Individual $\mathrm{CH}_{4}$ emissions were measured over five days using the $\mathrm{SF}_{6}$ technique at 17 (Period I) and 44 (Period II) days post diet introduction. On the final day of Period I and Period II, rumen samples were taken from each cow using a Flora rumen scoop. Statistical analysis was performed using the mixed procedure of SAS with terms included for treatment, period and their interaction. Both treatment and period affected daily $\mathrm{CH}_{4}$ output and $\mathrm{CH}_{4}$ output per kilogram of milk solids and there was a significant treatment $\times$ period interaction for SO $(P<0.001)$. During $\mathrm{PI}$, SO and LO reduced daily $\mathrm{CH}_{4}$ output compared to the Control but during PII, only LO reduced daily $\mathrm{CH}_{4}$ output. LO diet, when compared to SO and the Control, showed a reduction $(P<0.05)$ in total VFA concentrations, however acetate to propionate ratios did not differ among treatments $(P>0.05)$. Both SO and LO reduced rumen ammonia concentrations $(P<0.001)$ with a concurrent increase in milk protein concentration $(P<0.001)$ compared to the Control. Both SO and $\mathrm{LO}$ show potential to reduce ruminal $\mathrm{CH}_{4}$ emissions by grazing dairy cows. The effects of LO appear to have a greater persistency over time. Reduced rumen ammonia concentrations and increased milk protein concentration suggest an alteration in nitrogen metabolism which may have an impact on nitrogen excretion. This merits further investigation.

\section{T109. Effects of medium chain fatty acids and a formulated product of their mixture on rumen fermentation in vitro}

D. Sawada*, S. Koike, T. Yasui and Y. Kobayashi*

Medium chain fatty acids (MCFA) could be potential natural materials for the reduction of ruminal methanogenesis because they have various antibacterial properties. We investigated effects of MCFA (caprylic acid, capric acid and lauric acid) and of a formulated product of MCFA (Aromabiotic cattle) (Vitamex N.V., Drongen, Belgium) on ruminal fermentation in a series of batch culture experiments. The tested material (each MCFA or Aromabiotic cattle) was added at different levels ( 0 as control, $0.2,0.4,0.6$ and $0.8 \mathrm{~g} \mathrm{~L}^{-1}$ in final concentration) to a test tube in which ground hay and concentrate had been placed in different ratios (25:75 and 75:25) with diluted rumen fluid. Tubes were anaerobically incubated at $39^{\circ} \mathrm{C}$ for $18 \mathrm{~h}$ to determine gas, $\mathrm{pH}$, VFA and lactate. The incubation was carried out in triplicate. Supplementation of capric acid reduced methane production by up to $78 \%$ irrespective of dietary condition. However, the great inhibition of rumen fermentation by capric acid was evident from a drastic decrease of total VFA production (16-62\%). Caprylic acid (0.8 $\mathrm{g} \mathrm{L}^{-1}$ ) reduced methane production by ca. $20 \%$ without a decrease of total VFA production. Then, an increase of propionate proportion and a decrease of butyrate proportion were accompanied. Lactate was accumulated under the presence of caprylic acid with a high concentrate diet. Lauric acid reduced methane production in a dose dependent manner (11-74\%). Then, an increase of propionate proportion was accompanied. However, 


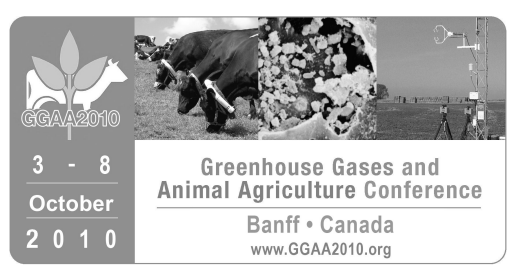

total VFA production was significantly decreased with a higher dose of lauric acid $\left(>0.6 \mathrm{~g} \mathrm{~L}^{-1}\right)$. Aromabiotic cattle, a commercial product including various MCFA, reduced methane production by ca. $20 \%$ without a decrease in total VFA production. The effective supplementation level was found to be more than $0.8 \mathrm{~g} \mathrm{~L}^{-1}$. The alteration of fermentation pattern with Aromabiotic cattle was affected by dietary conditions (i.e., propionate production was increased with a high concentrate diet, while lactate concentration was increased with a low concentrate diet). These results suggest that caprylic acid, lauric acid and Aromabiotic cattle are effective for reducing methane production without great inhibition of rumen fermentation. These three materials are roughly divided into two groups according to the difference in fermentation products. One is the material to steadily increase propionate production, while the other is that to cause accumulation of lactate, a propionate precursor. Such difference is speculated to be due to the variation between the materials in selective antibacterial activity against rumen bacteria.

\section{T110. Effect of tannin rich sorghum on performance and in vivo enteric methane production in sheep}

P.B.G. Schiavinatto, A. L. Abdalla*, B. Berenchtein, P. Pimental Santos, H. Louvandini and C. Costa

Tannin rich sorghum grain may replace corn grain in ruminant diets also aiming to reduce enteric methane $\left(\mathrm{CH}_{4}\right)$ production due to condensed tannin (CT) content. Twenty male Santa Ines lambs (18 $\left.\pm 0.6 \mathrm{~kg} \mathrm{BW}\right)$ were randomly divided into five groups. All the animals were fed with Tifton hay (Cynodon spp) (40\%), minerals (3\%), soybean meal (16.5\%) and corn grain (40.5\%) for a week prior to the trial. The control group (C100) were maintained on this diet and for the treated groups, the corn was replaced by $25,50,75$ and $100 \%$ of tannin rich sorghum grain, [respectively group S25 (30.3\% corn plus $10.1 \%$ sorghum), S50 ( $20.2 \%$ corn plus $20.2 \%$ sorghum), S75 (10.1\% corn plus $30.3 \%$ sorghum) and S100 ( $40.5 \%$ sorghum]. The animals were kept in individual pens for $75 \mathrm{~d}$, receiving the experimental diet (3\% BW). Dry matter intake was recorded daily and BW changes calculated at weekly weightings ( $10 \mathrm{~h}$ fasting). For the metabolism trial (days 76 to 83 ), the animals were maintained on individual cages for controlling feed intake, refusals and excretions daily. From day 84 , the animals were moved to open-circuit chambers for the gas exchange assay and the outgoing air was sampled using a peristaltic pump. Methane on air sampled was measured using a GC. The protein and fiber content of the diets were similar (206 $\pm 4.5 \mathrm{~g} \mathrm{CP} \mathrm{kg}^{-1} \mathrm{DM} ; 364 \pm 24 \mathrm{~g} \mathrm{NDF} \mathrm{kg}^{-1} \mathrm{DM}$ ) and CT content was 0, 2.02, $4.04,6.06$ and 8.1 eq $g$ of leucocynidin $\mathrm{kg}^{-1} \mathrm{DM}$, respectively for C100, S25, S50, S75 and S100. The biological effect of CT was $18 \%$ (equivalent to $49 \mathrm{mg}$ of acacia tannin extract). There were significant quadratic effects ( $\mathrm{P}$ $<0.05)$ of level of sorghum inclusion on feed intake $\left(y=0.00002 x^{2}+0.0021 x+0.5511, r^{2}=0.7714\right)$ and body weight change $\left(y=-0.007 x^{2}+0.653 x+62.419, r^{2}=0.9715\right)$. For $\mathrm{CH}_{4}$, level of sorghum inclusion did not show significance ( $P>0.05$ ): 20, 17, 20, 16 and $20 \mathrm{~L} \mathrm{CH}_{4} \mathrm{~d}^{-1}$ (C100, S25, S50, S75 and S100, respectively) and the contrast corn vs. sorghum were 23 and $19 \mathrm{~g} \mathrm{CH}_{4} \mathrm{~kg}^{-1}$ DMI (SED 1.69) $(P=0.239)$. It is suggested that tannin rich sorghum grain can be used in replacement of corn in diets for growing lambs, but longer period studies are still necessary regarding its effect on $\mathrm{CH}_{4}$ production.

\section{T111. Monitoring of methane and hydrogen production from the rumen of cows fed cashew (Anacardium occidentale) nut shell liquid}

T. Shinkai*, M. Mitsumori*, O. Enishi, A. Takenaka* and Y. Kobayashi*

Methane and hydrogen emission from Holstein cows fed cashew nut shell liquid (CNSL) was monitored to know the advantage to use CNSL-including pellet as a feed additive for reducing the greenhouse gas emission from 


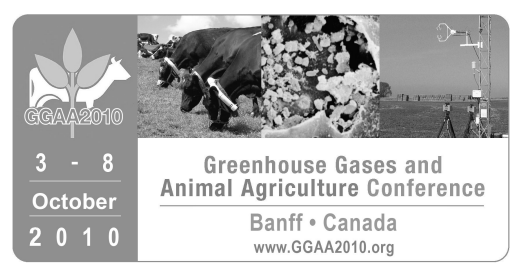

ruminants. To monitor the gas emission, three ruminally fistulated Holstein cows (average $572 \mathrm{~kg}$ in body weight) were kept individually in the respiration chamber under the aeration control (600 L per min). The cows were given a concentrate and chopped timothy hay in the ratio of $6: 4(\mathrm{w} / \mathrm{w})$ twice a day (0930 and 1630). The cows were fed without CNSL for the first four weeks (control period), and then with CNSL at $4 \mathrm{~g} 100 \mathrm{~kg}^{-1}$ body weight for the next two weeks (CNSL-treated period). Methane production was determined by the calculation with methane concentration in the flowing-out air, which was monitored every 6 min by infrared radiation sensor. The monitor for hydrogen gas was set inside each respiration chamber to minutely measure hydrogen. The monitoring was conducted for the last three consecutive days of each period. In the control period, active methane production was monitored for several hours after the feeding, and then the methane production decreased to reach a stable level. All the CNSL-treated cows showed a high methane reduction rate after the feeding, and the reduction continued for about $7 \mathrm{~h}$ at least. Overall, the reduction of methane emission in the CNSL-treated period was $19.3 \%$ on average $(15.7,17.0$ and $25.2 \%$, respectively). Hydrogen detected by feeding any diet disappeared in $2 \mathrm{~h}$ after the feeding. However, it took a longer time to start emitting hydrogen in CNSL-treated cows compared with the control. The maximum concentration of hydrogen was higher (165$178 \%$ ) for two cows, while it was lower (75\%) for a cow in the CNSL-treated period in comparison with the control period. These results suggest that there are two possible mechanisms for the methane reduction with CNSL feeding. One is the methane reduction following the less generation of hydrogen gas by CNSL, the other is that given by the direct suppression of hydrogen-consuming methanogens by CNSL.

\section{T112. Abatement of ruminal methanogenesis by supplementing different bioactive compounds or garlic oil as determined in Rusitec}

C. R. Soliva, S. Amelchanka, S. M. Duval* and M. Kreuzer*

Currently, the abatement of ruminal methanogenesis via feed additives is of high priority in ruminant research. However, the application of most strategies tested is limited by the concomitantly impaired microbial nutrient fermentation. Therefore, the search for such compounds is still ongoing. The aim of the present experiment was to compare the $\mathrm{CH}_{4}$ mitigating potential of several pure compounds with the oil of garlic. Garlic had been recently demonstrated in vitro to possess methane-mitigating properties. Four 10-day experimental runs were carried out using an 8-fermenter Rusitec system simultaneously incubating one control diet and seven treatment diets with ruminal fluid from a donor cow. The basal (control) diet [15 g feed dry matter (DM)] consisted of ryegrass hay, barley, soybean meal (1:0.7:0.3) and a vitamin-mineral mixture. Compared to the control diet, the treatment diets were supplemented ( $\mathrm{g} \mathrm{kg}^{-1}$ diet $\left.\mathrm{DM}\right)$ with allyl isothiocyanate (5), lovastatin (10), chenodeoxycholic acid (10), 3-azido-propionic acid ethyl ester (APEE, 10), levulinic acid (20), and 4[(pyridin-2-ylmethyl)-amino]-benzoic acid (PABA, 20) and garlic oil (20). Compared with the control, garlic oil, APEE, allyl isothiocyanate, and lovastatin significantly inhibited ruminal $\mathrm{CH}_{4}$ formation in absolute terms by 91 , 98,59 and $42 \%$, respectively. The same was true for $\mathrm{CH}_{4}$ related to units of degraded neutral detergent fibre (NDF; decline by $91,98,40$ and $39 \%$, respectively). Chenodeoxycholic acid and levulinic acid had no effect on $\mathrm{CH}_{4}$ formation in Rusitec, while PABA even increased $\mathrm{CH}_{4}$ emissions. The short-chain fatty acid concentration in the incubation liquid was not affected by any of the pure compounds or garlic oil compared to the control. The acetate-to-propionate ratio, however, was increased by lovastatin and PABA, with PABA doubling this ratio. Garlic oil decreased protozoal counts at concomitantly increased bacterial numbers while APEE significantly increased protozoal counts. Chenodeoxycholic acid completely defaunated incubation liquid and decreased NDF degradation by $26 \%$ compared to the control. The only other substance adversely affecting NDF degradation $(-18 \%)$ was PABA, which in addition also decreased the apparent crude protein degradation $(-11 \%$ 


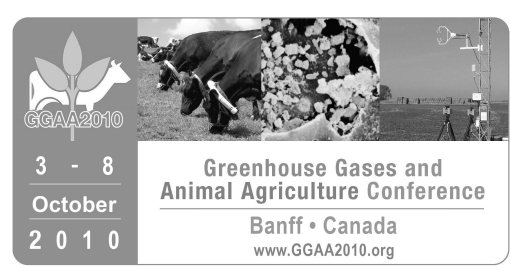

compared to the control). From the present results obtained in vitro it can be concluded that garlic oil and APEE were superior in $\mathrm{CH}_{4}$ mitigation to all other compounds tested, followed by allyl isothiocyanate and lovastatin. Chenodeoxycholic acid, levulinic acid and PABA showed little potential as $\mathrm{CH}_{4}$ mitigating compounds or as otherwise promising rumen modifiers. Further studies have to show that the corresponding supplements are effective, palatable and safe in live animals as well.

\title{
T113. In vitro ruminal methane production, enzyme activity and post ruminal protein digestibility of tanniniferous tropical plants
}

\author{
Y. A. Soltan, A. L. Abdalla*, A. Salah Morsy, S.M.Ahmed Sallam, B. Berenchtein and R. Canonenco De Araujo
}

Egyptian tanniniferous plants [i.e., prosopis leaves (Prosopis juliflora) or pods, acacia (Acacia saligna), atriplex (Atriplex halimus), and leucaena (Leucaena leucocephala)], were evaluated to determine their effects on gas and methane $\left(\mathrm{CH}_{4}\right)$ formation, ruminal fermentation parameters, degradability and post ruminal protein digestion in vitro. Tifton-85 (Cynodon $s p$ ) was used as a control and the semi-automatic system for GP was used. Three step in situ/in vitro procedures were used to measure the post-ruminal protein digestion. The results indicated that both acacia and leucaena leaves showed higher condensed tannins content (63 and 46 eq-g leucocynidin $\mathrm{kg}^{-1} \mathrm{DM}$, respectively) and showed the highest tannin activity compared with the other experimental plants. Acacia, leucaena and prosopis leaves had the lowest $(P<0.01) \mathrm{GP}(127,149$ and $156 \mathrm{~mL} g$ ${ }^{1} \mathrm{DM}$, respectively) and methane production (14.6, 17.1 and $17.6 \mathrm{~mL} \mathrm{~g}^{-1} \mathrm{DM}$, respectively), while prosopis pods had the highest $(P<0.01)$ values for GP and methane production. Prosopis pods had the highest $(P<0.05)$ total volatile fatty acids $(\mathrm{VFA})$, propionic acid $(\mathrm{P}<0.01)$ and lowest $(\mathrm{P}<0.05) \mathrm{pH}$ value. Acacia had the lowest $(\mathrm{P}<$ $0.05)$ rumen $\mathrm{NH}_{3}-\mathrm{N}\left(26.6 \mathrm{mg} 100 \mathrm{~mL}^{-1}\right)$. Prosopis leaves showed the lowest $(\mathrm{P}<0.01)$ protozoa account 1.93 $\left(10^{5} \mathrm{~mL}^{-1}\right)$. There were no significant differences detected in the carboxymethyl cellulase and $\alpha$ amylase activity among investigated tanniniferous plants. Atriplex leaves and prosopis pods showed the highest $(P<0.01)$ apparently or truly degradation of dry and organic matter degradation (DMD and OMD), while acacia leaves presented the lowest $(P<0.01)$ mean values of the degradation. As it was expected acacia and leucaena leaves reduced $(P<0.01)$ both rumen degradable protein (RDP, 7.1 and $15.4 \%$, respectively) and intestinal protein digestibility (IPD), while prosopis pods and leaves and atriplex leaves had the highest RDP and IPD values. It is concluded that acacia leaves suppressed $\mathrm{CH}_{4}$ emission but with detrimental effect on DMD, OMD and IPD, while prosopis and leucaena leaves could be used as alternative feed recourses in ruminant production in the tropical and sub tropical areas of Egypt because of favourable modification of rumen fermentation.

\section{T114. Methane production in Thai native beef cattle fed low quality roughage based diets}

K. Sommart*, K. Kongphitee, M. Otsuka, S. Udchachon and A. Takenaka*

The objective of this study was to estimate methane production in Thai native beef cattle fed Ruzi straw or rice straw based diets. Twelve Thai native bulls (body weight $318.42 \pm 28.87 \mathrm{~kg}$.) were used in this experiment. Dietary treatments were applied in a randomized complete block design (RCBD) and consisted of ad libitum mixed concentrate with Ruzi straw based diet (T1), ad libitum concentrate with rice straw based diet (T2) and leveling step feeding of concentrate with rice straw based diet (T3). The results indicated that dry matter intake, organic matter intake and neutral detergent fiber intake of cattle fed ad libitum (T3; 5.78, 5.81 and 1.44 $\mathrm{kg} \mathrm{d}^{-1}$, respectively) were higher $(P<0.05)$ than $\mathrm{T} 1\left(4.59,4.72\right.$ and $1.31 \mathrm{~kg} \mathrm{~d}^{-1}$, respectively) and T2 $(4.63,4.66$ and $1.26 \mathrm{~kg} \mathrm{~d}^{-1}$, respectively). Methane production and methane energy of cattle fed ad libitum (T3) were higher $(P<0.001)\left(190.3 \mathrm{Ld}^{-1}\right.$ and $\left.1.72 \mathrm{MJ} \mathrm{kg}^{-1} \mathrm{BW} 0.75 \mathrm{~d}^{-1}\right)$ than T1 $\left(151.4 \mathrm{Ld}^{-1}\right.$ and $1.38 \mathrm{MJ} \mathrm{kg}^{-1} \mathrm{BW} 0.75 \mathrm{~d}^{-1}$, 


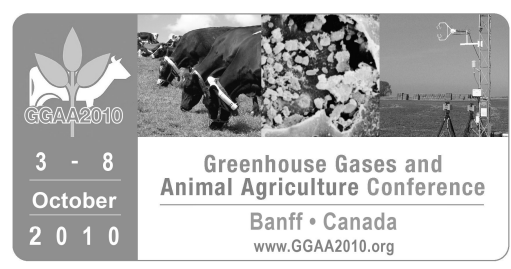

respectively) and T2 (146.3 $\mathrm{L} \mathrm{d}^{-1}$ and $1.28 \mathrm{MJ} \mathrm{kg}^{-1} \mathrm{BW} 0.75 \mathrm{~d}^{-1}$, respectively). Methane emission pattern at various times of day and cumulative methane emission of cattle fed ad libitum (T3) was higher than cattle fed ad libitum Ruzi straw based diet (T1) and cattle fed ad libitum rice straw based diet (T2). The results indicated methane production was not different among low quality roughage based diets ranging from 144.2-190.3 $\mathrm{L} \mathrm{d}^{-1}$.

\section{T115. Evolution of methane formation of bulls supplemented with Acacia tannins, maca or lupines during fattening}

S. M. Staerfl*, M. Kreuzer* and C. R. Soliva

Promising means for mitigating methane from ruminants are often based on the strategic use of plants characterized by secondary metabolites. Although this research provided several promising options, proof of a long-term efficacy is mostly lacking. Therefore, the aim of the present study was to investigate the $\mathrm{CH}_{4}$ mitigating potential of three plant-derived supplements when being fed to bulls over the entire fattening period. Twenty-four growing-fattening bulls (Brown Swiss $\times$ Limousin) were divided into four groups $(n=6)$. Bulls were fed individually on diets consisting of maize silage ad libitum and concentrate which contained either no supplement (control) or an extract rich in condensed tannins [Acacia mearnsii, targeted: $3 \%$ of daily dry matter intake (DMI)], dried hypocotyls of maca (Lepidium meyenii, a high Andean plant producing a belowground storage organ rich in various metabolites; targeted: $1.5 \%$ of DMI d ${ }^{-1}$ ), or lupine seeds (Lupinus albus; targeted: $6 \%$ of $\mathrm{DMI} \mathrm{d}^{-1}$ ). Three 8-day measurement periods were conducted at body weights of $142 \pm 7 \mathrm{~kg}$ (period 1), $345 \pm 30 \mathrm{~kg}$ (period 2), and $429 \pm 37 \mathrm{~kg}$ (period 3), respectively. In these periods, DMI as well as excreta (non-separated) were daily registered and sampled. During 2 days $(2 \times 22.5 \mathrm{~h})$ each, methane emission was measured in open circuit respiratory chambers. Average daily gains were calculated from monthly weight determinations across the entire fattening period. Bulls consumed 3.7, 7.0, and 7.3 $\mathrm{kg} \mathrm{DM} \mathrm{d}^{-1}$ in periods 1,2 , and 3 , respectively, and there were no significant treatment differences in daily nutrient intake. In period 1 , the supplementation of tannin, maca, and lupines resulted in numerically decreased methane emissions $(-31,-13$ and $-6 \%$, respectively), compared to control (only $n=4$ in period 1 ). In period 2, methane emission was clearly decreased $(P<0.05)$ only with the tannin diet $(-24 \%)$, whereas the maca and lupines treatments did not differ from the control. In period 3, the magnitude of the tannin effect even increased ( $-36 \%$ methane compared to the control). Maca and lupine supplementation again resulted only in numerically lower methane emissions $(-8$ and $-10 \%$, respectively) than the control. Average daily gains and feed conversion efficiency did not differ $(P<$ 0.05 ) with the feeding treatments. However, digestibility of neutral detergent fiber was significantly reduced with tannin supplementation. The present results confirm the methane mitigating effect of Acacia mearnsii tannins and, more importantly, demonstrate its long-term efficacy. Despite their nature as plants rich in secondary metabolites, maca and lupines appeared much less efficient, if not inefficient, in suppressing in vivo methane formation.

\section{T116. Effect of different oils and plant extracts on methane production from in vitro ruminal fermentation}

T. M. Storlien*, O. M. Harstad*, T. A. McAllister*, N. Narvaez* and Y. Wang

Two in vitro experiments were conducted to investigate the effects of different oils and plant extracts on methane $\left(\mathrm{CH}_{4}\right)$ production from a ground barley grain (47\%) and barley silage (53\% on DM basis) mixed diet. In Exp 1, the diet was incubated in buffered ruminal fluid alone (control) or with canola oil (CO), sunflower oil (SO), cod liver oil (CLO) or a 70:30 (v/v) mixture of CO and CLO (MIX), with oils included at either 2.5 or $5 \%$ of 


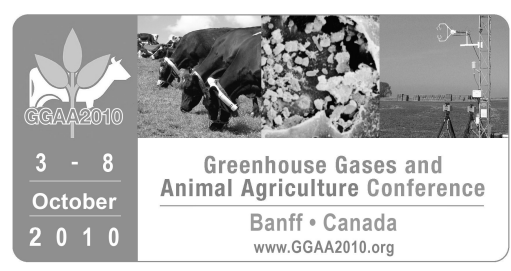

diet DM. Both $\mathrm{CH}_{4}$ production and dry matter digestibility (DMD) were measured at $24 \mathrm{~h}$ of incubation. None of the treatments affected the production of $\mathrm{CH}_{4}$ per g substrate DM $(P>0.05)$, but all decreased $(P<0.05) \mathrm{DMD}$. Accordingly, $\mathrm{CH}_{4}$ production per g DMD increased $(P<0.05)$ for $\mathrm{SO}$ at $2.5 \%$ of $\mathrm{DM}$, and for CO, CLO and MIX at $5 \%$ of DM. In Exp 2, MIX (5\% of DM); hops extract (H) at 2.5 or $5.0 \%$ of DM (i.e., H2.5 and H5.0) and Yucca schidigera extract (S) at 75 or $150 \mu \mathrm{g} /$ vial (i.e., S75 and S150) were examined. Additionally, $\mathrm{H}$ and S were examined at each level with and without $\mathrm{MIX} . \mathrm{CH}_{4}$ production and DMD were determined at 12 and $48 \mathrm{~h}$ of incubation. With the exception of MIX and $\mathrm{H} 2.5$, all treatments reduced $\mathrm{CH}_{4}$ production per $\mathrm{g}$ substrate DM after 24 and $48 \mathrm{~h}$ of incubation. With the exception of $\mathrm{H} 2.5$ without $\mathrm{MIX}(P>0.05)$, all other treatments reduced $(P<0.05)$ DMD. Adding MIX increased the inhibitory effect of $H$ and $S$ on DMD. Thus, oil alone and in combination with $\mathrm{H}$ and $\mathrm{S}$ increased the amount of $\mathrm{CH}_{4}$ produced per $\mathrm{g}$ DMD. Although these additives reduced $\mathrm{CH}_{4}$ emissions they accomplished this through a suppression in DMD as opposed to a reduction in $\mathrm{CH}_{4}$ production per unit of DM fermented.

\section{T117. Effect of fresh reproductive forage chicory (Cichorium intybus) and perennial ryegrass (Lolium perenne) on methane emissions from sheep}

X. Z. Sun*, S. O. Hoskin, S. Muetzel, G. Molano* and H. Clark*

Published reports of methane $\left(\mathrm{CH}_{4}\right)$ yields $\left[\mathrm{g} \mathrm{CH}_{4} \mathrm{~kg}^{-1}\right.$ dry matter intake (DMI)] from sheep and deer fed fresh chicory (Cichorium intybus) suggest values to be about $30 \%$ less than yields from fresh ryegrass. Those measurements were made using the sulphur hexafluoride $\left(\mathrm{SF}_{6}\right)$ marker dilution technique to measure methane emissions and a trial was undertaken to confirm these findings with sheep by using calorimetry, currently the most accurate method of measuring methane emissions. Sixteen two-year-old wether sheep (live weight $53.6 \pm$ $3.8 \mathrm{~kg}$, mean \pm S.D.) were fed either fresh chicory or perennial ryegrass at 1.3 times maintenance energy requirements in late spring/early summer 2009 when both forages were in the reproductive state. Methane emissions were determined using individual animal calorimeters. Feeds differed significantly in their chemical composition with chicory, containing $856 \mathrm{~g}$ organic matter (OM), $117 \mathrm{~g}$ crude protein (CP) and $281 \mathrm{~g}$ neutral detergent fibre (aNDF), whereas ryegrass contained $916 \mathrm{~g} \mathrm{OM}, 85 \mathrm{~g} \mathrm{CP}$ and $499 \mathrm{~g}$ aNDF. DM intake was similar for both forages $\left(0.76 \mathrm{~kg} \mathrm{~d}^{-1}\right)$ and methane yields were 22.8 and $23.8 \mathrm{~g} \mathrm{CH}_{4} \mathrm{~kg}^{-1} \mathrm{DMI}$ for chicory and ryegrass, respectively $(P=0.18)$. Similar findings were evident from an in vitro trial, where chicory and perennial ryegrass in both vegetative and reproductive states were incubated in rumen fluid, without effects on methane yield. Despite large differences in composition, especially the proportion of aNDF, there were similar yields of methane from digestion of chicory and ryegrass. Chicory may not be a viable option for methane mitigation for pastoral-based sheep production systems.

\section{T118. A meta-analysis of malate effects on ruminal batch cultures}

E. M. Ungerfeld* and R. J. Forster

The objective of this analysis was to understand the effects of malate on methanogenesis in ruminal batch cultures, to help explain in vivo responses to malate supplementation. Published studies in which malate was supplemented to compete with methanogenesis for reducing equivalents were combined and responses of methane and volatile fatty acids production to malate addition regressed. Malate decreased methane production by $0.11 \mathrm{~mol} / \mathrm{mol}$, but there was no effect if no substrate was incubated. Despite being a propionate precursor, recovery of malate as propionate was only $0.49 \mathrm{~mol} / \mathrm{mol}$. Recovery of malate as acetate was 0.19 


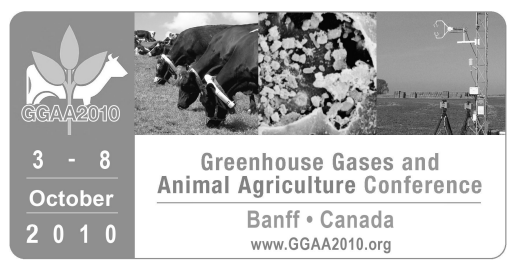

$\mathrm{mol} / \mathrm{mol}$, and butyrate production was unaffected by malate addition. In addition to low propionate recovery, release of reducing equivalents in the conversion of added malate to acetate is thought to have offset much of their incorporation into propionate, resulting in an inhibition of methanogenesis lower than the theoretical stoichiometrical decrease of $0.25 \mathrm{~mol}$ of methane/mol of added malate. Thermodynamic calculations show that the conversion of added malate to acetate would have been feasible. Malate recovery as acetate and propionate was numerically similar to what has been reported for fumarate, but the decrease in methane per mol of extra propionate produced was numerically greater for malate than for fumarate. If the stoichiometry of methane decrease per mol of malate supplemented to animals was similar to what was found in this analysis of in vitro batch cultures, it would be unlikely that malate supplementation could significantly improve animal performance through decreasing energy losses as methane.

\section{T119. Dietary nitrate persistently reduces enteric methane production in lactating dairy cows} S.M. van Zijderveld*, J. Dijkstra*, W.J.J. Gerrits, J.R. Newbold* and H.B. Perdok*

The anaerobic reduction of 1 mole of nitrate to ammonia consumes 8 moles of hydrogen and is thermodynamically more favourable than methanogenesis, which also consumes 8 moles of $\mathrm{H}_{2}$. Nitrate may therefore function as an alternative hydrogen sink to enteric methanogenesis when fed to ruminants. The ammonia generated can be utilized for microbial growth in diets low in crude protein. The aim of this experiment was to evaluate the methane mitigating effect of a dietary nitrate source and the persistency of this effect when this nitrate source is fed to dairy cows. Besides effects on methane production, the effects on animal performance and health were also monitored. Twenty lactating Holstein-Friesian dairy cows (milk production $33.2+6.0 \mathrm{~kg} /$ day; $104+58 \mathrm{DIM}$ ) were paired according to parity, milk production and lactation stage. Within a pair, cows were randomly allotted to one of two maize silage based diets containing either urea or nitrate (1.2 and $2.2 \%$ of diet DM, respectively) as non-protein nitrogen sources. Diets were formulated to be iso-nitrogenous. Cows were adapted to the diets for a period of 4 wks. During this adaptation period the concentrates containing the non-protein nitrogen sources gradually replaced a soybean meal based concentrate ( $25 \%$ per wk). After the adaptation period, cows were housed in indirect calorimetry respiration chambers for a period of $5 \mathrm{~d}$ to monitor methane production and animal performance. During the period in the chambers, animals were fed restrictedly ( $95 \%$ of ad libitum DMI) to avoid treatment effects on DMI and hence indirect effects on methane production. The measurement periods were repeated 3 times with 23-d intervals. Cows were kept on the same diets during the entire experiment. Nitrate intake averaged $398 \mathrm{~g} / \mathrm{day}$ for the cows on the nitrate treatment. Methane production was reduced by $16 \%(P=0.009)$ in the nitrate-fed cows and this reduction was not affected by time (treatment*time interaction $P=0.961$ ), indicating that the methane reducing effect was persistent over a 4-month period. Milk production was unaffected by treatment $(P=0.452)$, but milk protein content was lower $(P=0.041)$ for the nitrate-fed animals. Methemoglobin concentrations in blood were elevated $(4.0 \%$ of $\mathrm{Hb})$ in the nitrate-fed animals relative to the control $(0.4 \% \mathrm{of} \mathrm{Hb})$, but animals displayed no clinical signs of methemoglobinemia. Dietary inclusion of nitrate may be a useful tool to persistently lower enteric methane emissions from dairy cows. 


\section{T120. Effect of essential oils dissolved in different solvents on the in vitro enteric methane production}

M. Wadhwa*, J. S. Hundal, K. Kaur and M.P.S. Bakshi

This study was conducted to assess the effect of essential oils (EO) [i.e., Carvone (CAR), Cinamaldehyde (CIN) or Limonene (LIM)] at $3 \%$ of the substrate, dissolved in different solvents like water, methanol, ethanol, petroleum ether (PE) or propylene glycol (PG) on in vitro methane, volatile fatty acids (VFAs), digestibility of nutrients and ME availability from wheat straw in a $4 \times 5$ factorial. The in vitro gas production studies revealed that the net gas production (NGP) was depressed $(P<0.01)$ in all EO supplemented groups, as compared to the control irrespective of the solvent used. The supplementation of CAR reduced $(P<0.01)$ enteric methane production as compared to other EOs, which were close to control unsupplemented wheat straw. Irrespective of EO, ethanol followed by methanol proved to be better solvents as indicated by high $(P<0.01)$ NGP as compared to PE. The methane production was lowest $(P<0.01)$ in PE and PG. Irrespective of solvent used, the digestibility of NDF and true OM was depressed $(P<0.01)$ in all the EO supplemented groups as compared to the control. Amongst the EO the highest digestibility was observed in wheat straw supplemented with CIN. However, the ME availability was comparable with that of the control. Irrespective of EO, the digestibility of NDF and true OM was highest when water was used as solvent, which was comparable with that of methanol. The PE had the lowest fermentative $\mathrm{CO}_{2}$, while fermentative methane was lowest in PG. Irrespective of the solvent used, the total VFA production was improved $(P<0.01)$ in all the EO supplemented groups as compared to control. Cinamaldehyde and LIM improved the acetate production, CIN and CAR produced higher isovalerate, while propionate production was depressed in all the EO supplemented groups. The EO supplementation did not have any effect on butyric acid. Irrespective of EO, amongst the solvents, total VFAs were highest $(P<0.01)$ in PG followed by ethanol and methanol. The propionate and isovalerate were highest in PG supplemented groups. The relative proportion of VFAs revealed that acetate production was improved ( $P$ $<0.01)$ in CIN and LIM as compared to control, while the propionate production was depressed $(P<0.01)$ in all cases as compared to control, while isovalerate production was improved $(P<0.01)$ in all the groups as compared to control. Irrespective of EO, the relative proportion of acetate was highest in methanol followed by that in ethanol, while the propionate was highest when water was used as solvent followed by methanol. It was concluded that carvone dissolved in methanol can mitigate the enteric methane production, without affecting the VFA production or ME availability.

\section{T121. Immunological tools to reduce greenhouse gas emissions}

N. Wedlock*, G. Pedersen, T. Wilson, J. Baker, D. Dey, P. Janssen and B. Buddle

More than $30 \%$ of the greenhouse gases emissions in New Zealand are attributed to methane produced by livestock. We are exploring ways to harness the ruminant's immune system to reduce methanogen numbers and/or activity in the rumen. A vaccine that induces a strong and sustained salivary antibody response and delivers a high yield of anti-methanogen antibodies to the rumen could prevent the growth of methanogens or limit their ability to produce methane. We aim to identify key immunogenic antigens that are common to a range of methanogens, initially using three methanogen strains: Methanobrevibacter ruminantium M1, Methanobrevibacter sp. SM9 and Methanosarcinia barkeri CM1. Concurrently, we are investigating novel approaches to deliver methanogen antigens in adjuvants that enhance salivary antibody responses. Results to date have shown that methanogens are immunogenic in ruminants, and that both whole cell and sub-cellular preparations of methanogens induce strong systemic antibody and moderate salivary antibody responses in sheep. The proteins in the sub-cellular fractions were analysed by 2-D gel electrophoresis, Western blotting and liquid chromatography-tandem mass spectrometry (LC-MS/MS) to identify immunogenic proteins and 


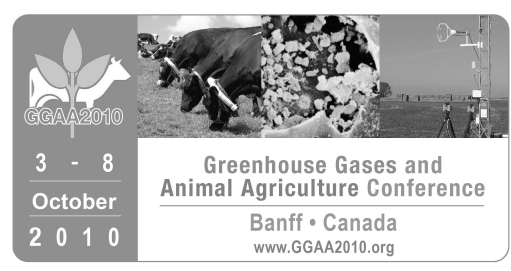

proteins that cross react with antisera raised against the different methanogens. Using these techniques, a number of potential vaccine antigens have been identified. Sheep antisera produced against certain subcellular fractions, notably a cytoplasmic fraction and proteins derived from a cell wall extract prepared from $M$. ruminantium $\mathrm{M} 1$, inhibited the production of methane by pure cultures of $M$. ruminantium $\mathrm{M} 1$. These fractions contained a wide repertoire of proteins and these preparations were refined further, by isoelectric focusing and molecular size fractionation, into a range of sub-fractions. Antisera against selected sub-fractions contained antibodies that are inhibitory to methanogens in in vitro cultures. This systematic process of refining and testing sub-cellular fractions from methanogens should help in identifying potential vaccine antigens. In parallel to this empirical approach to identify antigens, a number of surface exposed proteins with essential cellular functions have been identified by bioinformatics, and their potential as vaccine candidates is being investigated.

\section{T122. Tannin-free and tanniniferous legumes in lactating dairy diets affect in vitro ruminal fermentation characteristics and methane production by mixed ruminal microbiota in continuous cultures}

C. M. Williams, J.-S. Eun*, J. W. MacAdam, A. J. Young, V. Fellner, and B. R. Min

A beneficial effect associated with tanniniferous legumes is the reduction in ruminal methane $\left(\mathrm{CH}_{4}\right)$ emission due possibly to a deleterious effect of condensed tannins on methanogenic bacteria. Dual-flow continuous culture fermentors (working volume of $700 \mathrm{~mL}$ ) were used to determine the effects of feeding tannin-free (alfalfa and cicer milkvetch) and tanniniferous (birdsfoot trefoils and sainfoin) legumes in lactating dairy diets on in vitro $\mathrm{CH}_{4}$ production and ruminal fermentation characteristics by mixed ruminal microbiota. We hypothesized that $\mathrm{CH}_{4}$ and ammonia-nitrogen production would be reduced when alfalfa hay was replaced by cicer milkvetch and tanniniferous legumes as main forages in lactating dairy total mixed ration (TMR) diets. Fermentors were inoculated with filtered ruminal contents and allowed to adapt to experimental diets for $6 \mathrm{~d}$, followed by $3 \mathrm{~d}$ of sampling and data collection. All dietary treatments were formulated for lactating dairy cows in early lactation. Five TMR diets were evaluated, each containing a different forage source as hay: 1) alfalfa (AHT) as a control, 2) cicer milkvetch (CMVHT), 3) Norcen birdsfoot trefoil (NBFTHT), 4) Oberhaunstadter birdsfoot trefoil (OBFTHT) and 5) sainfoin (SFHT). The experiment was conducted as a $5 \times 5$ Latin square design. Culture $\mathrm{pH}$ was not influenced with the CMVHT, the NBFTHT and the OBFTHT when compared with the AHT, but increased when feeding the SFHT $(P<0.01)$. Total volatile fatty acid production and acetate molar proportion were not influenced by treatments. However, when compared to the AHT, molar proportion of propionate increased by feeding the CMVHT, but decreased by the SFHT $(P<0.01)$. Feeding the CMVHT decreased $(P<0.01)$ molar proportion of butyrate. Acetate to propionate ratio decreased with the CMVHT and the OBFTHT, but increased with the SFHT when compared to the AHT $(P<0.01)$. Digestibilities of dry matter and neutral detergent fiber (aNDF) were not influenced by dietary treatments. When compared to the AHT, $\mathrm{CH}_{4}$ production, as measured in headspace gas, decreased with the other treatments $(\mathrm{P}<0.01)$, whereas $\mathrm{CH}_{4}$ production expressed as $\mathrm{mM}$ per $\mathrm{g}$ of aNDF digested was only reduced by the CMVHT and the OBFTHT $(\mathrm{P}<$ 0.05). Ammonia-nitrogen concentration was reduced when feeding the CMVHT and the SFHT $(P<0.01)$, but was not affected $(P>0.10)$ when feeding the NBFTHT and the OBFTHT. While concentration of ruminal C18:0 was decreased by the CMVHT compared to other treatments, ruminal C18:1 cis and trans isomers were greatest with the $\mathrm{CMVHT}$. The decrease of in vitro $\mathrm{CH}_{4}$ production when feeding cicer milkvetch and birdsfoot trefoil may make these forages suitable for mitigating enteric $\mathrm{CH}_{4}$ emissions by lactating dairy cows. In addition, because these effective tannin-free and tanniniferous legume did not have negative impacts on 


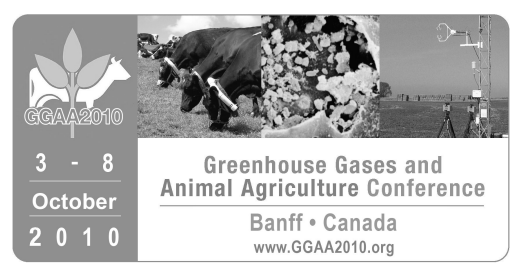

ruminal fermentation, these forages can maintain potential productive performance of lactating dairy cows when fed as main forage sources of TMR diets.

\section{T123. Tea saponins inhibit ruminal methane emission through the inhibitory effect on protozoa in Hu sheep \\ Y.-Y. Zhou, H.-L. Mao, F. Jiang, J.-K. Wang, J.-X. Liu* and C. S. McSweeney}

Twelve fistulated Hu sheep were used to investigate the effects of tea saponins (TS) on rumen fermentation, methanogenesis and microbial populations. All the sheep were defaunated by administration of sodium lauryl sulfate at first two weeks, and half of the defaunated sheep were then refaunated by inoculating normal rumen contents. Both defaunated and refaunated sheep were divided into two groups, and assigned to a $2 \times 2$ factorial arrangement without (RfN, DfN) or with TS (3 g/d) (RfTs, DfTs). After a feeding trial for 3 weeks, methane production was measured using simple open-circuit respiratory chambers. Samples of rumen fluids were then taken for analysis of rumen fermentation parameters and microbial ecology by real-time PCR. Populations of rumen methanogens, protozoa, fungi, Ruminococcus albus, $R$. flavefaciens, Fibrobacter succinogenes and $B$. fibrisolvens were expressed as a proportion of total rumen bacterial 16S rDNA. The inhibition of TS on daily methanogenesis $(10.6 \%)(P<0.05)$ was equivalent to defaunation $(12.7 \%)(P<0.05)$. Compared to that of RfN, ammonia-N concentrations were lower in RfTs, DfN and DfTs $(P<0.05)$, reduced by 12.9, 31.2, 33.9\%, while MCP concentration was enhanced $(P<0.05)$ by $16.4,29.2,36.0 \%$, respectively. Concentrations of total volatile fatty acids had no significant differences among all treatments, but proportion of individual acid varied, with an increased proportion of propionate in defaunted sheep $(P<0.05)$. The population of fungi and $R$. flavefaciens relative to total bacterial $16 \mathrm{~S}$ rDNA decreased $(P<0.05)$, while population of $B$. fibrisolvens increased $(P<0.05)$ by defaunation, but not by addition of TS. Population of $F$. succinogenes was inhibited by both defaunation and TS. The population of methanogens relative to total bacterial $16 \mathrm{~S}$ rDNA was inhibited obviously in defaunation groups compared to refaunation $(P<0.05)$. Protozoa population in RfTs was decreased markedly compared to that of $\operatorname{RfN}(P<0.05)$. The TS had an inhibitory effect on protozoa diversity $(P<0.05)$; and a restraining trend on methanogens diversity. In summary, TS can inhibit rumen protozoa, reduce rumen methane emission effectively and improve rumen fermentation. The reduction of methane production by TS may be mediated through the inhibitory effect on protozoa.

\section{NOTES}




\title{
SESSION 5: ORAL ABSTRACTS
}

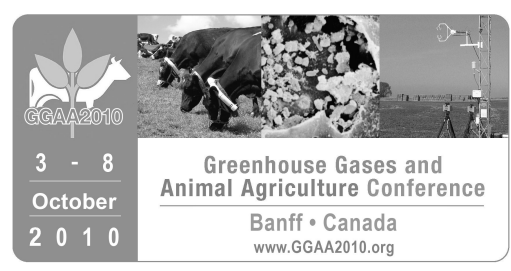

\section{PLEASE NOTE: Authors denoted with an asterisk are registered GGAA2010 delegates}

\author{
Does the complexity of the rumen microbial ecology preclude methane mitigation? \\ André-Denis G. Wright* and Athol V. Klieve*
}

Ruminant livestock are responsible for the production of a significant proportion of greenhouse gases, particularly methane (61 Tg per annum), that contribute to global warming and climate change. This methane is an end-product of the fermentation of plant material by the complex microbial ecosystem that resides in the rumen. Methanogenesis is undertaken by methanogenic archaea and represents a mechanism by which hydrogen is removed from the fermentation process in order to regenerate biochemical co-factors such as NAD+. The microbial ecosystem is very complex and involves thousands of species of bacteria, archaea, protozoa, fungi and viruses, in very dense populations (for example bacterial cells are above $10^{11}$ per $\mathrm{mL}$ of contents), interacting with feed, the host ruminant and each other. Not only is the ecosystem complex but also relatively poorly understood particularly inter-species interactions and interactions with the host. Less than $15 \%$ of the inhabitants have been cultured and characterised. However, knowledge of this ecosystem is rapidly accumulating, particularly with the advent of molecular biology and culture independent technologies. New high-throughput sequencing methodologies such as 454-pyrosequencing will greatly improve the rate of knowledge acquisition and techniques like Stable Isotope Probing will enhance the ability to unravel species inter-relationships. While we can expect an increase in knowledge of this complex ecosystem to improve our ability to predictably manipulate the ecosystem this has not prevented manipulation of the ecosystem or reductions in methane emissions in the past. Examples where this has happened are through the use of foreign and recombinant bacteria to reduce leucaena and fluoroacetate toxicity respectively, and reduction in methane emissions by changing feed and the use of feed additives (e.g. cereal grains, monensin, plant oils, $\mathrm{BES})$. The challenge is to mitigate methane emissions further and this will develop as our knowledge of the intricacies of this complex ecosystem is unravelled.

\section{Effect of fibre- and starch-rich finishing diets on methanogenic Archaea diversity and activity in the rumen of feedlot bulls}

M. Popova*, C. Martin, M. Eugène*, M. M. Mialon, M. Doreau and D. P. Morgavi*

Methanogenesis plays an important role in hydrogen pressure maintenance in the rumen and consequently in feed digestion. Recent studies in our laboratory found that moderate supplementation with extruded linseed lipids, combined with high-starch diet, decreased methanogenesis in bulls (Eugène et al., 2010; this symposium). However, the linkage between the dietary lipid supplementation and methanogens has not been well established. The aim of this work was to compare the methanogenic community in terms of number and diversity in the rumen of bulls fed high concentrate diets supplemented or not with linseed. Twenty Charolais bulls, divided in two groups, were fed for 16 months two fattening diets containing both $87 \%$ concentrate and $13 \%$ barley straw. The concentrate of the control diet (C), richer in fibre, contained $40 \%$ NDF, $7.4 \%$ starch and $2.8 \% \mathrm{EE}$. The concentrate supplemented with $6 \% \mathrm{DM}$ of extruded linseed (LS), higher in starch, contained $20 \%$ 


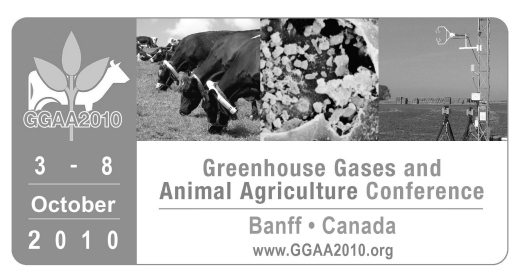

NDF, 33\% starch and 4.7\% EE. Bulls were slaughtered at an average age of $531 \pm 45$ days and $680 \pm 41 \mathrm{~kg} \mathrm{BW}$. Rumen content samples were taken for microbial community analysis after slaughter. Archaeal and eubacterial numbers were quantified by $\mathrm{qPCR}$, targeting the functional mcrA gene and the rrs gene, respectively. The diversity of the rumen methanogenic community was studied using PCR-DGGE. The biodiversity was assessed by the indices of Shannon, evenness and dominance calculated from the DGGE profiles. There was no difference between diets in the number of archaea and eubacteria expressed as log copies of mcrA or rrs / g $D M$ of rumen content $(P>0.05)$. The DGGE profile of the archaeal mcrA gene differed among individuals. $A$ lower number of bands $(P<0.05)$ was detected in bulls fed LS compared to bulls fed C. Shannon and evenness values were also lower $(P<0.05)$ for the methanogenic community of bulls fed $L S$. The predominant bands were different between $C$ and LS resulting in PCR-D GGE profiles that clustered by diet, suggesting a correlation between methanogenic diversity and linseed supplementation in diets. This study shows that dietary linseed supplementation had no effect on eubacterial and archaeal abundance in the rumen, but it significantly affected methanogenic community diversity. Further studies linking methanogens' activity (via mcrA mRNA) and other rumen microbes abundance and diversity are in progress and will allow better understanding of the microbial mechanisms of methanogenesis in cattle fed a diet supplemented or not with linseed.

\section{Effect of C-18 long-chain fatty acids on in vitro rumen microbial populations \\ A. Cièslak*, M. Szumacher-Strabel*, P. Zmora, E. Pers-Kamczyc, K. Wereszka, P. Skorka and T. Michalowski}

The study was carried out to investigate the effects of type and level of different C18-fatty acids (FA) on fermentation, methanogenesis and microbial population in long-term (28 days) cultures of Entodinium caudatum (EC), Eudiplodinium maggii (EM) and Epidinium ecaudatum (EE). The ciliates were cultured in vitro and the basal culture medium was composed of "caudatum" salt solution and food mixture. The control cultures were maintained on the basal medium, whereas the experimental ones were supplemented with stearic acid (SA), oleic acid (OA), linoleic acid (LN) and linolenic acid (LNA) in the proportion of $0.1,0.5,2.5$ and $5 \%$ each. Protozoa counts and methane concentration were measured in the post-cultured medium every fourth day. After long-term cultivation, on the final 28th day, the following parameters were monitored in post-cultured medium: $\mathrm{pH}$, ammonia, VFA concentration and methanogens population. Ciliates were counted under a light microscope. Methane concentration was quantified by gas chromatography. The fluorescence in situ hybridization (FISH) was used to quantify methanogens in the population. The effect of fatty acid was species dependent; however, long-term monitoring revealed that the EC and EE populations gradually adapted to the changed conditions. Fatty acids addition showed the potential to decrease methane production but it was not always related to changes in the number of methanogens. Decreased methane production was significant only for $5 \% \mathrm{LN}$ supplement to the EC culture and for $5 \%$ OA and LNA supplements to the EE culture. Results suggest that FA have the potential to reduce rumen methane production.

\section{Exploring rumen methanogen genomes to identify targets for methane mitigation strategies}

G. T. Attwood*, E. Altermann*, B. Kelly, S. M. Leahy, L. Zhang and M. Morrison*

Methane from ruminant livestock is generated by the action of methanogenic archaea, mainly in the rumen. A variety of methanogen genera are responsible for methane production, including a large group that still lacks cultivated representatives. To be generally effective, technologies for reducing ruminant methane emissions must target all rumen methanogens to prevent any unaffected methanogen from expanding to occupy the 


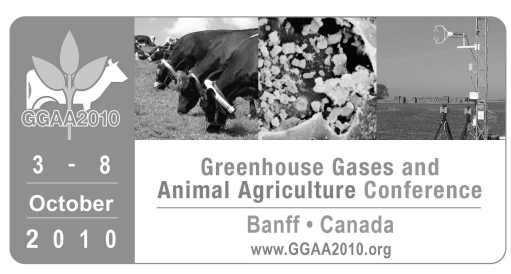

vacant niche. Interventions must also be specific for methanogens only so that other rumen microbes can continue their normal digestive functions. Therefore, a detailed knowledge of both the diversity and physiology of rumen methanogens is required to define conserved features that can be targeted for methanogen inhibition. Genome sequencing projects are underway in New Zealand and Australia on representatives of the three main methanogen groups found in the rumen; Methanobrevibacter, Methanomicrobium and the uncultured group, Rumen Cluster C. The completed Methanobrevibacter ruminantium genome and draft sequences from other rumen methanogen species are beginning to identify the underlying cellular processes that define these organisms and is leading to a better understanding of their lifestyles within the rumen environment. Although the work is mainly at the exploration stage, two types of opportunities for inhibiting methanogens are emerging: the inactivation of conserved methanogen enzymes by screening for, or designing, small inhibitors via a chemogenomics approach and identifying surface proteins shared among rumen methanogens that can be used as antigens in an anti-methanogen vaccine. Many of the conserved enzyme targets are involved in energy generation via the methanogenesis pathway, while the majority of the conserved surface protein targets are of unknown function. An understanding of the expression and accessibility of these targets within methanogen cells and/or microbial biofilms under ruminal conditions will be required for their development as methane mitigation technologies.

\section{Impact of an exogenous fibrolytic enzyme feed additive on the ruminal methanogenic community and methane production of dairy cows}

M. Zhou*, R. Chung*, K. A. Beauchemin*, L. Holtshausen*, M. Oba, L. L. Guan*

It is known that diets affect methanogenic population in the rumen and methane $\left(\mathrm{CH}_{4}\right)$ yield from ruminants, but the association between the structure of the ruminal methanogenic community and methane yield is not well understood. The objective of this study was to evaluate the effects of an exogenous fibrolytic enzyme supplement on the ruminal methanogenic community, $\mathrm{CH}_{4}$ production, and their relationship. In this study, 9 lactating Holstein cows (milk yield=38.3 $\pm 6.1 \mathrm{~kg} / \mathrm{d}$ ) were fed TMR diets supplemented with 0 (control), 361 (low) and 722 (high) nmol/kg TMR DM of an exogenous fibrolytic enzyme additive (Econase RDE; AB Vista, UK) in a $3 \times 3$ Latin square design with 21-d periods. Methane yield was measured using the $\mathrm{SF}_{6}$ method. Rumen digesta samples were collected and subjected to quantitative real-time PCR and PCR-denaturing gradient gel electrophoresis (PCR-DGGE) analyses. The $\mathrm{CH}_{4}$ yield normalized for dry matter intake (DMI) increased ( $P=0.01$ ) as the enzyme level increased: $19.1,20.8$, and $21.8 \mathrm{~g}$ of $\mathrm{CH}_{4} / \mathrm{kg} \mathrm{DMI}$, respectively for control, low, and high. The total number of methanogens did not differ among treatments and no relationship was found between total number of methanogens and $\mathrm{CH}_{4}$ yield. Rumen $\mathrm{pH}$ tended to be positively related to total number of methanogens $(P=0.10)$. PCR-DGGE analysis of methanogenic profiles identified 26 distinctive bands from all samples, including major bands representing Methanosphaera stadtmanae, Methanobrevibacter ruminantium, Methanobrevibacter smithii, Methanobrevibacter sp. AbM4, and Methanobrevibacter gottschalkii, which are the common methanogen species in the rumen. Categorical analysis of the PCR-DGGE bands showed that the PCR-DGGE band representing Msp. stadtmanae appeared in animals fed both low and high levels of enzyme but not in those fed the control diet, and the PCR-DGGE band representing Mbb. smithii DSM 2375 was only detected when animals were fed the high level of enzyme. Our findings suggest that the particular methanogenic structure at species/strain level, rather than the total number of methanogens, may affect $\mathrm{CH}_{4}$ yield. Adding fibrolytic enzyme supplements to diets may influence the structure of the methanogenic community by stimulating different species of methanogens in the rumen. 


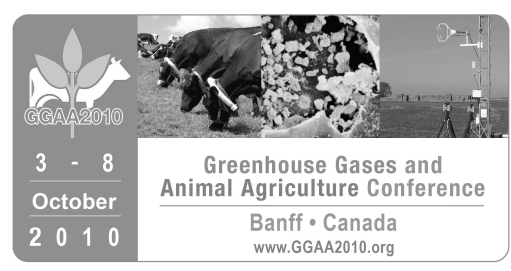

\title{
Animal variation in methane production, expression of mcrA gene and microbial numbers in the rumen of goats fed alfalfa hay with or without oats
}

\author{
L. Abecia*, E. Molina-Alcaide, A. I. Martín-García, G. Martínez and D. R. Yáñez-Ruiz*
}

This study was designed to evaluate the intra and inter animal variability of methane production and potential link with the expression of the mcrA gene and the numbers of the main microbial groups in the rumen of goats fed alfalfa hay with $(\mathrm{AHO})$ or without oats $(\mathrm{AH})$. For each diet methane production was measured in chambers during 3 consecutive days from 4 ruminally cannulated goats in two experimental periods with 15 days of difference to evaluate the persistency of the effects, resulting in 4 periods in total for the whole trial. Every measuring day rumen samples were taken $2 \mathrm{~h}$ after the morning feeding to quantify the expression of mcrA using RTqPCR and the copy numbers of 16S rRNA (for bacteria), 18S rRNA (for protozoa) and mcrA gene (for methanogenic archaea) by qPCR. Results show that daily methane production averaged 28.0 and $21.5 \mathrm{~L} \mathrm{~kg}^{-1}$ $\mathrm{DMI}$ for diets $\mathrm{AHO}$ and $\mathrm{AH}$, respectively with a variation within animals of 20.84 and $26.6 \%$. However, the methane emissions estimated over the first two hours after the morning feeding were much higher than for the whole day measuring period (averaged 60.8\%). The relative expression of the mcrA gene presented higher intra-animal variation for diet $\mathrm{AHO}(67.7 \%)$ than for $\mathrm{AH}(28.5 \%)$. The inter-animal variation averaged 19.6 and $26 \%$ for methane production and 71.8 and $84.8 \%$ for mcrA expression. The variation for the qPCR number of gene copies, respectively, for diets $\mathrm{AHO}$ and $\mathrm{AH}$ was 21.4 and $30.4 \%$ for total bacteria, 48.1 and $25.2 \%$ for protozoa and 33.8 and $28.2 \%$ for methanogenic archaea. Methanogenic archaeal numbers followed the same pattern as methane emissions; however, there was not agreement with the expressions leveles of the $m c r A$ gene. The high inter-animal variation in the expression levels of the mcrA gene together with the lack of agreement with the in vivo methane emissions may preclude the use of the gene expression as methane production indicator. Furthermore, the differences among animals in feeding pattern and the diurnal variation in rumen fermentation make a single spot rumen sample doubtfully reliable. Further research to investigate the consistency of the variation over extended periods of time in order to assess the suitability of the mcrA gene expression as an indicator of methanogenic activity in the rumen needs to be undertaken.

\section{Fungal secondary metabolites reduce rumen methane production in vitro and in vivo}

\section{P. Morgavi*, C. Martin and H. Boudra}

Decreasing methanogenesis without affecting fermentation and degradation of feeds in the rumen can reduce the environmental impact of ruminant production and have a beneficial effect on feed conversion efficiency. In this work metabolites produced by the fungus Monascus sp. were assayed for their antimethanogenic activity in vitro and in vivo. The capacity of seven strains of Monascus sp. to produce secondary metabolites was assessed in solid media. Monitored metabolites were: the Statins monacolin K, pravastatin, and mevastatin, and the mycotoxin citrinin. Extracts from five different selected solid media from the two strains producing the highest (HM) and lowest (LM) monacolin to citrinin ratio were tested in vitro. A commercial preparation of monacolin $\mathrm{K}$ was also used. Extracts in fermentation flasks were adjusted to a concentration of $20 \mathrm{mg} \mathrm{ml}^{-1}$ of monacolin K. Fermentation was not negatively affected by any treatment but one HM culture decreased methane production. This extract was further assayed in three sequential batch incubations where a marked decrease in methane was observed in the second and third batches. In contrast, methane produced in flasks with pure monacolin $\mathrm{K}$ was not different from controls. Rice on which the selected Monascus sp. was grown also decreased methane production when used as substrate for in vitro incubations. The effect of Monascustreated rice on methane production was then assayed in vivo. Six wethers were adapted for several weeks to a 


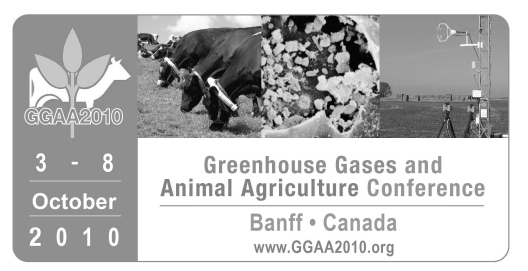

diet containing rice and hay (1:1 ratio). Rice was then replaced by treated rice and given to animals for nearly two weeks. Animals were monitored for a further two weeks after the treatment. Daily methane emissions decreased by $30 \%$ after 2-3 days into the treatment and remained low throughout the administration period. This change was associated with lower acetate to propionate ratio and lower numbers of methanogens in the treatment period as detected by qPCR (copy number of $\mathrm{mcrA} \mathrm{g}^{-1}$ rumen content). In contrast, no changes in the methanogenic community were observed by DGGE. Total bacteria and protozoa were marginally or not affected by the treatment. Methane emissions and the acetate to propionate ratio remained numerically lower in the two weeks post-treatment as compared to measures before treatment. Metabolites produced by Monascus appear to have an inhibitory effect upon methanogens and decreased methanogenesis in vitro and in vivo without any apparent negative effect on rumen fermentation. This strategy needs to be further explored and could be an abatement option under certain feeding situations. 


\title{
PLEASE NOTE: Authors denoted with an asterisk are registered delegates
}

\section{R01. Effect of coconut oil on rumen fermentation parameters and methane emissions using the poly-tunnel technique in Colombia}

\author{
E.A. Angarita Amaya*, C. Gonzalez, E. Martín, C. Laverde, O. Mayorga and R. Barahona
}

\begin{abstract}
This study was developed to evaluate in vivo the effect of inclusion of coconut oil on methane production and rumen function parameters. Was established and used the poly-tunnel technique a methodology to quantify methane emissions under in vivo conditions. Changes in ruminal populations were determined by qRT PCR. We used four Holstein heifers $200 \pm 4.7 \mathrm{~kg} \mathrm{BW}$, in a cross-over design with two experimental periods of 12 days each, evaluating two treatments: control (without oil) vs. treatment with $5 \%$ coconut oil ( $250 \mathrm{~g} / \mathrm{animal} / \mathrm{day})$. Rumen function parameters such as $\mathrm{pH}$ and VFA production did not differ between treatments. Ruminal populations showed changes with increases in the total bacteria $(P<0.0001)$, while fungi, protozoa and cellulolytic bacteria as Ruminococcos flavefaciens and Fibrobacter succinogenes decreased $(P<0.05)$ because of defaunation and the restrictive effect on adhesion mechanisms by the oil. The concentration of methanogenic bacteria did not change significantly $(P=0.07)$. However, methane production was reduced on average by $60 \%$ when including coconut oil, with 196.8 and $118.6 \mathrm{~L}$ /animal/day were reported for the control and treatment with oil respectively. According to the results, showed the effect of coconut oil on the reduction in rumen methane emissions in heifers and determined that changes in rumen methanogenic microorganisms are not directly associated with the response in the production of methane in vivo.
\end{abstract}

R02. Effect of Sambucus nigra on rumen fermentation parameters and methane emissions under in vivo conditions in Colombian high tropic

E.A. Angarita Amaya*, C. Ospina, O. Mayorga, E. Martín, C. Gonzalez, C. Ariza and F. Ossa

The methane $\left(\mathrm{CH}_{4}\right)$ production, ruminal population and patterns of fermentation $\mathrm{pH}, \mathrm{NH}_{3}-\mathrm{N}$ (ammonium) and VFA (volatile fatty acids) concentrations, was evaluate in four Holstein heifers with a body weight of $273 \pm$ $11.02 \mathrm{~kg}$, feeding with an experimental diet was composed of $100 \%$ Pennisetum clandestinum (8.5 Kg DM of kikuyu) hay for control and $70 \%$ Pennisetum clandestinum hay (7.3 Kg DM) with $30 \%$ of Sambucus nigra (1.2 $\mathrm{Kg}$ DM), both with mineral salt and ad libitum water availability, offered at 8:00 and 15:00. The methane production was measured using the poly-tunnel technique, in a cross-over design with two experimental periods, each period lasted 12 days, with the first 7 days allotted for diet adaptation and the next 2 days for adaptation to the poly- tunnel conditions and the remaining 3 days were the data collection period of methane each hour for three days (72 hours) and rumen samples was collected first and last day in each period for analysis of VFA, ammonium and changes in ruminal populations with qRT-PCR. The assays show a $52.5 \%$ decrease in methane emission when Sambucus $n$. was added to diet compared with control diet of Pennisetum c. Methane production rate was of $12 \mathrm{~L}$ of $\mathrm{CH}_{4} / \mathrm{kg}$ of DM intake for control vs. $6.3 \mathrm{~L} \mathrm{of} \mathrm{CH}_{4} / \mathrm{kg}$ of DM intake for Sambucus $(\mathrm{P}<0.001)$. Consumption of Sambucus resulted in a 44 and $47 \%$ reduction in levels of $\mathrm{CH}_{4} /$ animal/day (152.4 vs. 263.5 [control]) and per hour (13 vs. 7.3 [control]). The results indicate that Sambucus changes rumen fermentation, reducing the rumen microbial population, expressed in terms relative of 2- $\Delta \Delta C T$ from 0.025 to 0.00055 for total methanogens, 0.012 to 0,000066 in total fungi and 0.038 to 0.00018 in cellulolytic 


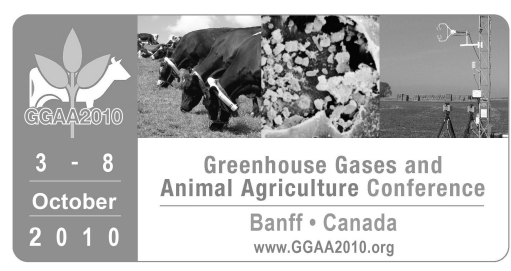

bacteria for treatments control and Sambucus. The reduction in populations was around 97, 98, and 99\% of each group respectively. The $\mathrm{pH}, \mathrm{NH}_{3}-\mathrm{N}$ and VFA concentrations was not significantly different $(\mathrm{P}<0.05)$, however acetic, propionic and butyric acid were $20 \%$ and $24 \%$ below control. The $30 \%$ of Sambucus nigra can be used as a potential nutritional strategy for reducing the methane production under grazing conditions in Colombian high tropic.

\title{
R03. The use of blanks for a reliable methane in vitro measurement when using rumen fermentation modifiers
}

R. C. de Araujo, A. V. Pires, G. B. Mourão, A. L. Abdalla* and S. M. A. Sallam

Blanks are used in vitro to correct for gas, methane $\left(\mathrm{CH}_{4}\right)$ and residual organic matter (OM) generated by inoculum $\mathrm{OM}$ degradation. Using rumen fermentation modifiers, the additive affects substrate as well as inoculum OM degradation. Thus, data correction using blank without additive may result in errors. The objective of this study was to evaluate the impact of using blanks containing additive (i.e., specific blanks) or blanks without additive to determine in vitro net gas and $\mathrm{CH}_{4}$ production. We used the semi automatic in vitro gas production technique including monensin sodium at $3 \mu \mathrm{M}$ (Experiment 1) or carvacrol, eugenol, and 1,8cineol at $667 \mathrm{mg} \mathrm{l}^{-1}$ of buffered rumen fluid (Experiment 2) in flasks with substrate and in blanks. Monensin reduced $(P \leq 0.02)$ total gas production in flasks containing substrate $\left(162.0 \mathrm{vs} .146 .3 \mathrm{ml} \mathrm{flask}^{-1}\right)$ and in blanks ( 84.4 vs. $\left.79.2 \mathrm{ml} \mathrm{flask}^{-1}\right)$. Methane production also decreased $(P \leq 0.05)$ by adding monensin to flasks containing substrate (15.7 vs. $\left.11.9 \mathrm{ml} \mathrm{flask}^{-1}\right)$ as well as in blanks (6.4 vs. $\left.5.0 \mathrm{ml}^{\text {flask }}{ }^{-1}\right)$. Inclusion of carvacrol or eugenol reduced $(\mathrm{P} \leq 0.05)$ gas and $\mathrm{CH}_{4}$ production in flasks with substrate and in blanks, although with more pronounced effects than monensin. For these three additives, correction for blank without additive resulted in lower gas and $\mathrm{CH}_{4}$ production than correction for specific blank. For instance, correcting carvacrol data using blank without this substance resulted in negative net gas and $\mathrm{CH}_{4}$ production $\left(-6.5\right.$ and $-1.5 \mathrm{ml}$ flask ${ }^{-1}$, respectively). These unbiological results occurred because gas and $\mathrm{CH}_{4}$ production in blank without carvacrol (46.1 and $2.1 \mathrm{ml}^{\text {flask }}{ }^{-1}$, respectively) were greater than in flasks containing substrate plus carvacrol (39.7 and $0.6 \mathrm{ml}$ flask ${ }^{-1}$, respectively). Correction of gas and $\mathrm{CH}_{4}$ production using blank without additive results in an overestimation of effects when compared with correction for specific blank. It is suggested to utilize blanks containing additive when rumen fermentation modifiers are evaluated in vitro.

\section{R04. Effects of berry extract on pathogenic microbial growth and rumen fermentation}

\author{
J. Chang*, Y.S. Kim, J. Song*, M.A. Park and I. Kwon
}

Methane is regarded as a main green house gas during rumen fermentation and a lot of efforts have been tried to reduce methane production through modifying rumen microbial population with feed supplements. Plant metabolites can prohibit microbial growth, stimulate immune function and others. For this reason, various plant extracts have been tried as feed supplement and some are in market. In this study, the effects berry extract on pathogenic bacterial growth and rumen fermentation were examined to test the possible use of berry extract as a feed supplement. According to paper disc diffusion method, antimicrobial activities against Salmonella, E. coli 0157:H7, Clostridium, Staphylococcus, Campylobacter and Bacillus cereus were detected with $1.6 \mathrm{mg}$ concentration. Minimum inhibition concentrations were ranged from $125 \mu \mathrm{g} / \mathrm{ml}$ to $500 \mu \mathrm{g} / \mathrm{ml}$ against pathogenic bacteria. To examine the effects on rumen microbial fermentation, different concentrations 


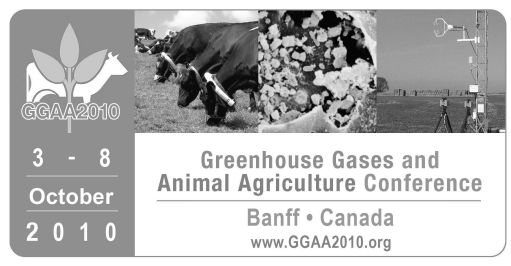

$(0,3.125,6.25,12.5,25$ and $50 \mathrm{mg} / \mathrm{L})$ of Rubus extracts were treated to in vitro rumen digestion system and incubated for $24 \mathrm{hrs}$. After incubation, gas production, methane production, $\mathrm{pH}$, dry matter (DM) digestibility and volatile fatty acid (VFA) concentrations were measured. The culture supernatant $\mathrm{pH}$ was not affected by concentration of Rubus extract $(\mathrm{P}<0.05)$. Whereas, DM digestibility and culture head gas production were decreased with increased extract concentration. The extract concentrations over $12.5 \mathrm{mg} / \mathrm{L}$ caused decrease in gas production per digested DM $(\mathrm{P}<0.05)$. The comparative concentration of methane among total produced gas in treatment group was lower than that of control with significance $(P<0.05)$. Methane productions in $12.5 \mathrm{mg} / \mathrm{L}$ and $25 \mathrm{mg} / \mathrm{L}$ of extract treatment groups were lower than that of control group by $22 \%$ and $23 \%$ respectively. There were no significant differences among treatment in ammonia concentration, total VFA production, and the molar ratio of acetate and propionate $(P>0.05)$. The change in rumen microbial population in in vitro system using quantitative PCR is under analysis.

\section{R05. Impacts of protozoal population on methanogenesis: A quantitative review} M. Eugene*, D. P. Morgavi*, M. Doreau and C. Martin

Starch-rich concentrates, lipids and plant extracts added to the ration are among the most common nutritional strategies explored to reduce enteric methane $\left(\mathrm{CH}_{4}\right)$ emission from ruminants. In addition to reducing methane emissions, a frequently observed effect of the addition of these feeds and supplements is a decrease in the number of ruminal protozoa. In order to evaluate the role of protozoa in these mitigation strategies, we propose to explore the relationship between $\mathrm{CH}_{4}$ production and ruminal protozoa concentration using a metaanalysis statistical approach. A quantitative review of all available data that reported measurements of dry matter intake (DMI), $\mathrm{CH}_{4}$ emissions and ruminal protozoa on the same animal was performed. The compiled database had a total of 18 studies obtained from both the literature and unpublished trials from our laboratory and contained 65 diets: 22 considered as controls and 5, 23 and 16 diets that were supplemented with concentrates, lipids and plant extracts, respectively. Cattle and small ruminants represented 47 and $53 \%$ of data, respectively. The DMI ranged from 0.7 to $22 \mathrm{~kg} \mathrm{~d}^{-1}$ (mean $\pm \mathrm{SD}, 7 \pm 7.4$ ), $\mathrm{CH}_{4}$ production ranged from 0.4 to $27 \mathrm{MJ} \mathrm{d}^{-1}(7 \pm 7.5)$ and protozoa concentration ranged from 0.3 to $32105 \mathrm{ml}^{-1}(7 \pm 6.1)$. Methane production was measured in open or respiratory calorimeter chambers or with the $\mathrm{SF}_{6}$ tracer method. Data were analysed using GLM procedure (Minitab Version 14), accounting for study effect as a fixed effect. The dietary contents (g $\left.\mathrm{kg}^{-1} \mathrm{DM}\right)$ of crude protein varied from 9 to $22(15 \pm 2.4)$, neutral detergent fibre from 26 to 61 (39 \pm 7.7$)$, nonfibrous carbohydrate from 28 to 43 (37 \pm 4.4$)$, ether extract from 2.5 to $10.4(4.4 \pm 2.55)$, and gross energy from 10.7 to $20.6 \mathrm{MJ} \mathrm{kg}^{-1} \mathrm{DM}(18.1 \pm 2.68)$. Preliminary relationships from this database show that protozoa numbers influenced positively and substantially methanogenesis: $\mathrm{CH}_{4} / \mathrm{DMI}\left(\mathrm{MJ} \mathrm{kg}^{-1}\right)=-1.6( \pm 0.5)+0.47( \pm$ 0.09) protozoa $\left(\log 10 \mathrm{ml}^{-1}\right) ;\left(n=65 ; r^{2}=0.64\right)$. The effect of the mitigation strategy, chemical composition of the diet and fermentative parameters (VFA, pH) will be tested in order to better explain some of the variations in the relationship observed. 


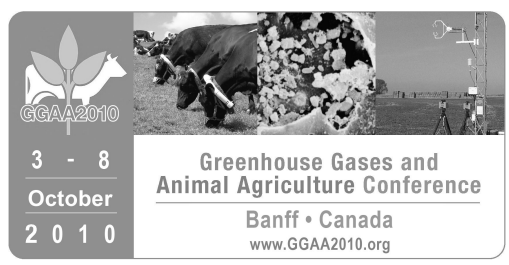

R06. Productive performance of lactating buffaloes fed rations containing sugar beet tops and corn silages

H. M. Gaafar*, E. M. Abdel-Raouf, M. M. Bendary, G. H. Ghanem and K. F. El-Reidy

Sixteen multiparous lactating buffaloes after 8 weeks of calving and weighing 500 to $600 \mathrm{~kg}$ were used in complete switch-back design with four groups. Buffaloes in the first group were fed the control ration (R1) consisting of DM basis of $60 \%$ concentrate feed mixture (CFM) $+20 \%$ rice straw (RS) $+20 \%$ berseem hay $(B H)$, while in the other groups were fed rations consisting of DM basis of $40 \%$ CFM $+20 \%$ RS $+40 \%$ sugar beet tops silage (SBTS) and corn silage (CS) in different ratios: 2:1 (R2), 1:1 (R3) and 1:2 (R4), respectively. Results showed that the contents of $\mathrm{CP}$ and ash increased with increasing the proportion of sugar beet tops silage, but $\mathrm{OM}, \mathrm{CF}$ and NFE contents increased with increasing the proportion of corn silage in the rations. The digestibility coefficients of DM, OM, CF, EE and NFE, TDN value and the intake of DM and TDN increased significantly $(P<$ 0.05 ) with increasing the level of corn silage. However, CP digestibility, DCP value and CP and DCP intake increased significantly $(P<0.05)$ with increasing levels of SBTS in the rations. The $\mathrm{pH}$ value and $\mathrm{NH}_{3}-\mathrm{N}$ concentration increased significantly $(P<0.05)$ with increasing levels of SBTS; however, TVFA's concentration increased significantly $(P<0.05)$ with increasing the level of corn silage in the rations. Buffaloes fed R3 recorded significantly $(P<0.05)$ the highest milk and 7\% FCM yield. However, those fed R1 had the lowest yield. The percentages of fat, lactose and TS increased significantly $(P<0.05)$ with increasing the level of corn silage; however the percentages of protein, SNF and ash increased significantly $(P<0.05)$ with increasing levels of SBTS in the rations. Animals fed R3 showed significantly $(P<0.05)$ the lowest amounts of DM and TDN required per $\mathrm{kg} 7 \% \mathrm{FCM}$ and $\mathrm{R} 4$ the lowest amounts of $\mathrm{CP}$ and DCP required per $\mathrm{kg} 7 \% \mathrm{FCM}$. However, those fed R1 revealed the highest amounts. Buffaloes fed R3 showed significantly $(P<0.05)$ the lowest feed cost $/ \mathrm{kg}$ $7 \%$ FCM and the highest price of 7\% FCM and economic efficiency, but those fed R1 had the opposite trend.

\section{R07. Evaluation of rations supplemented with fibrolytic enzyme on dairy cows performance 3. Productive performance of lactating Friesian cows}

H. M. Gaafar*, M. I. Bassiouni, A.M.A. Mohi El-Din, A. M. Metwally and M.A.H. Elshora

Thirty multiparous lactating Friesian cows with body weight of $500 \pm 25 \mathrm{~kg}$ were used the first 20 weeks of lactation. Cows were randomly assigned to six similar groups (5 in each) and fed the experimental rations consisted on DM basis of $60 \%$ CFM $+40 \%$ BH without (G1), or with fibrozyme (G2), CS without (G3), or with fibrozyme (G4) or RS without (G5), or with fibrozyme (G6). Fibrozyme was added at the level of $1 \mathrm{~g} \mathrm{~kg}^{-1} \mathrm{DM}$. Results showed that digestibility coefficients and nutritive values were significantly higher $(P<0.05)$ for rations containing $\mathrm{BH}$ or $\mathrm{CS}$ compared with those containing rice straw. Moreover, nutrient digestibility and nutritive values increased significantly $(P<0.05)$ with fibrolytic enzyme supplementation. Cows fed rations containing CS showed the highest DM and TDN intake and those fed rations containing BH had the highest CP and DCP intake, but those fed rations containing RS recorded the lowest intake. Moreover, the intake of TDN and DCP increased significantly $(P<0.05)$ with fibrolytic enzyme supplementation. Cows fed rations containing CS recorded the highest ruminal TVFA's concentration and lowest $\mathrm{pH}$ value, but those fed rations containing $\mathrm{BH}$ had the highest $\mathrm{NH}_{3}-\mathrm{N}$ concentration. Moreover, ruminal $\mathrm{pH}$ value and $\mathrm{NH}_{3}-\mathrm{N}$ concentration decreased, but TVFA's concentration increased significantly $(P<0.05)$ with fibrolytic enzyme supplementation. The $\mathrm{pH}$ value decreased, but TVFA's and $\mathrm{NH}_{3}-\mathrm{N}$ concentrations increased gradually until $4 \mathrm{~h}$ after feeding then showed the opposite trend at $6 \mathrm{~h}$. Cows fed rations containing CS recorded the highest actual milk and 4\% FCM yield followed by those fed rations containing $\mathrm{BH}$, but those fed rations containing RS had the lowest yield. The yield 


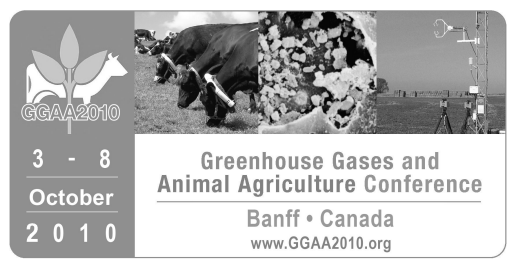

of actual milk and 4\% FCM increased significantly $(P<0.05)$ with fibrolytic enzyme supplementation. Cows fed rations containing CS recorded the highest percentages of fat, lactose and TS in milk and those fed rations containing $\mathrm{BH}$ showed the highest percentages of protein and SNF. However, cows fed rations containing RS had the lowest percentages of all milk constituents. Fibrozyme supplementation resulted in significant increases $(P<0.05)$ in the percentages of all milk constituents. Cows fed rations containing RS recorded the higher amounts of DM and TDN and those fed rations containing BH recorded the highest amounts of CP and DCP per $1 \mathrm{~kg}$ FCM. Fibrolytic enzyme supplementation led to significant $(P<0.05)$ decreases in the amount of DM and CP per kg FCM. Rations containing BH showed the highest average daily feed cost and feed cost $\mathrm{kg}^{-1}$ FCM and the lowest economic efficiency. Cows fed rations containing CS recorded the lowest feed cost $\mathrm{kg}^{-1}$ FCM and the highest output of FCM yield and economic efficiency. The feed cost $\mathrm{kg}^{-1} \mathrm{FCM}$ decreased, but the output of FCM yield and economic efficiency increased significantly $(P<0.05)$ with enzyme supplementation.

\section{R08. Analysis of archaeal ether lipids in bovine faeces}

F. L. Gill, R. J. Dewhurst*, E. J. Mc Geough*, P. O'Kiely*, R. D. Pancost and I. D. Bull

This study evaluated concentrations of archaeol, a lipid marker for Archaea, in cattle faeces. Twelve continental cross-bred steers were allocated at random to receive either a concentrate-based diet or a grass silage-based diet. Lipids were extracted from dried faeces, derivatized to trimethylsilyl ethers and analyzed by gas chromatography-mass spectrometry; methane production was estimated using the sulphur hexafluoride technique. Animals fed the grass silage-based diet consumed less feed ( 9.15 vs. $11.43 \mathrm{~kg} \mathrm{DM} \mathrm{d}^{-1} ; \mathrm{SED}=0.824 ; \mathrm{P}$ $<0.05$ ), emitted significantly more methane (341 vs. $\left.174 \mathrm{~g} \mathrm{~d}^{-1} ; \mathrm{SED}=60.5 ; \mathrm{P}<0.05\right)$ and produced faeces with higher concentrations of archaeol ( 30.6 vs. $5.1 \mathrm{mg} \mathrm{kg}^{-1} \mathrm{DM}$; SED $=5.42 ; \mathrm{P}<0.001$ ) than the animals fed the concentrate-based diet. Other dialkly glycerol lipids, such as hydroxyarchaeol, macrocyclic archaeol and unsaturated archaeol analogues, were not detected in the faeces. Since the feeds contained no archaeol, it was confirmed that archaeol is produced in the ruminant digestive tract, most likely by Archaea within the rumen. The relationship between methane emission and faecal archaeol concentration for individual animals was weak. Possible explanations include the inherent limitations of the sulphur hexafluoride technique, selective retention of Archaea in the rumen and variation in the profile of archaeal lipids related to the taxonomic composition of the population. Despite these limitations that require further study, faecal lipid biomarker analysis shows potential as a new method for studying ruminant methanogens.

\section{R09. Effect of prolonged feeding of a sainfoin (Onobrychis viciifolia Scop.)-based diet on methanogenic community in the rumen of dairy cows}

A. Guglielmelli, O. Perez, F. Tiemessen, M. Domenis, S. Calabrò, H. S. Smidt and W. F. Pellikaan*

An in vivo trial was conducted to investigate the effect of sainfoin tannins on methanogen numbers and rumen fermentation, and to assess adaptive behaviour of rumen microbiota while cows were maintained on sainfoin for an 8-wk period. Three ruminally fistulated dairy cows were placed on a lucerne-based 'uniformity' diet for a 2-wk period to allow animals to adapt to a tannin-free legume-based diet. After two weeks, the lucerne was exchanged for sainfoin. During the first $5 \mathrm{~d}$ of sainfoin feeding, animals received polyethylene glycol (PEG4000) intraruminally. Thereafter, the animals remained on their sainfoin-based diet for seven more weeks. Samples of rumen fluid were analysed for volatile fatty acids (VFA), ammonia $\left(\mathrm{NH}_{3}\right)$, the number of protozoa and 


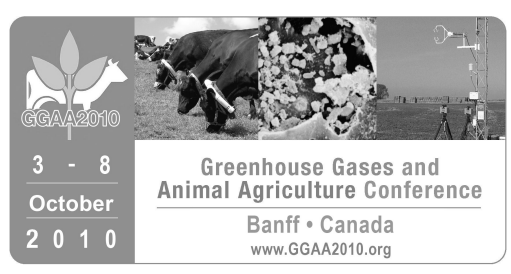

methanogenic Archaea. There was a significant $(P \leq 0.05)$ decrease in the number of protozoa in the first week after changing to the sainfoin diet. During the subsequent weeks of sainfoin feeding, the number of protozoa showed an increase at days 12, 15 and 37 after PEG treatment, however, their numbers remained numerically lower than during the sainfoin+PEG treatment $\left(6.00 \log _{10} / \mathrm{mL}\right)$. The Archaea followed a similar tendency but animal variation was considerably higher and the decreases were non-significant. Interestingly, this decrease began during PEG administration. Total VFA and $\mathrm{NH}_{3}$ follow a pattern similar to the protozoa numbers during the first week. Total VFA did not differ between the uniformity $(124.5 \mathrm{mmol} / \mathrm{L})$ and sainfoin+PEG diet (122.5 $\mathrm{mmol} / \mathrm{L})$, but a distinct decrease was observed after PEG treatment was stopped, with greatest effects on day 1 and day $4(P=0.082)$. Ammonia showed a numerical decrease when animals changed from uniformity diet (138 $\mathrm{mg} / \mathrm{L})$ to the sainfoin+PEG diet $(85.4 \mathrm{mg} / \mathrm{L} ; P \geq 0.267)$, followed by a further decrease during the first five days after stopping PEG treatment $(54.4 \mathrm{mg} / \mathrm{L} ; P \geq 0.088)$. Results suggest that PEG may not have been fully successful in completely blocking the effect of tannins, which is reflected in the numerical decline in protozoa and Archaea during PEG administration. Sainfoin tannins resulted in a partial inhibition of protozoa and methanogens. The initial decrease and successive increase in total VFA suggests that fermentation activity is not negatively affected by sainfoin. The consistent lower ruminal $\mathrm{NH}_{3}$ with sainfoin compared to lucerne suggests a protective effect of tannins on dietary protein. The tendencies of the different parameters suggest that the microbial population (protozoa, Archaea, other bacteria) respond in different ways to the sainfoin diet over time, suggesting adaptation to the dietary conditions.

\section{R10. Appearance of methanogens in rumen fluid of one to three week old hand-reared calves C.E.Guzman Rodriguez*, B. Fahey, C. E. Kentler and T. L. Frankel}

Feed additives of cultures of the yeast Saccharomyces cerevisiae have variable effects on methane production in ruminants. Yeast cultures and nucleotide products derived from them are increasingly being used in the calf rearing industry. We wished to determine whether nucleotides fed to young calves could influence the appearance or development of methanogens in the rumen. Friesian/Holstein bull calves were allowed to obtain colostrum from their dams for $24 \mathrm{~h}$ and were then hand-reared on milk replacer. The Control group (four calves) was given milk replacer (MR) twice daily and the Nucleotide group (four calves) was given MR twice daily to which was added $1 \mathrm{~g}$ nucleotide/feed (Ascogen, Chemaforma Ltd., Switzerland). From 7 days of age, hay and calf meal was available. Rumen fluid samples, aspirated with a stomach tube, were obtained at 7 , 14 and 20 days of age. Samples were frozen at $-80^{\circ} \mathrm{C}$ until analyzed: DNA was extracted with a ZR Fungal/Bacterial DNA Kit (Zymo Research) and analysis was carried out using Brilliant II SYBR Green QPCR Master Mix (Stratagene, Integrated Sciences) in a Stratagene M× 3000P qPCR (Agilent Technologies). Primers based on those of Skillman et al. (2004) for lambs were used to identify the presence of Methanobacterium spp. and Methanobrevibacter spp. Preliminary results showed no significant difference between control and nucleotide treatments and that both methanogens were present in most of the calves before a fully functioning rumen had developed. The results showed that similar to lambs reared by their dams on pasture (Skillman et al. 2004), Methanobrevibacter spp. were present from 7 days in most of the hand-reared calves. Unlike the lambs in which Methanobacterium spp were present in only a few lambs up to 48 days of age, the species was present in most of the calves at 7 days. The early colonization of the rumen of the calf by these methanogens needs to be assessed for their physiological importance to the calf as well as for the conditions in the rumen that facilitate such early colonization which could be of importance in long term control of methanogenic species in ruminants. 


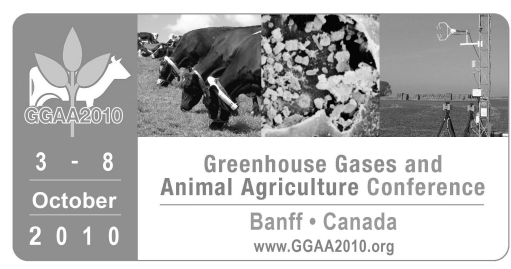

\title{
R11. Effect of easily fermentable carbohydrates on methane emission at different pH
}

\author{
H. H. Hansen*, M. Cattani, F. Tagliapietra and I. K. Auf der Maur Hindrichsen*
}

Easily fermentable carbohydrates in concentrates can have different effects on methane emission at different $\mathrm{pH}$ levels. Feeding high concentrate levels in a diet twice a day will decrease $\mathrm{pH}$ more compared to a total mixed ration and thereby influence methane production and emission. The influence of easily fermentable carbohydrates and different $\mathrm{pH}$ levels has not been fully explored for exploitation in mitigation strategies. The aim of the current study was to measure the effect of sucrose versus starch over time at three different $\mathrm{pH}$ levels on total gas and methane production, volatile fatty acids, ammonia and fibre degradation. A new, wireless in vitro gas production system with attached gas-tight bags was used. The gas-tight bags could be removed easily and stored for later analyses by gas chromatography. The experimental diets contained $100 \%$ hay, or $50 \%$ hay with either $50 \%$ corn starch, $50 \%$ sugar or $25 \%$ corn starch and $25 \%$ sugar. The diets were incubated in three buffers with three $\mathrm{pH}(6.8,6.6,6.4)$. The fermentation was stopped after 10,24 and 48 hours to measure $\mathrm{pH}$, total gas and methane production. Gas production was measured every minute and released to gas-tight bags, when gas pressure exceeded $0.5 \mathrm{psi}$. As expected, the amount of total gas produced per gram organic matter fermented was significantly lower for the basal hay diet when compared to a diet with added carbohydrates. Addition of sugar resulted in significantly more gas at 10 hours compared to starch for all three $\mathrm{pH}$ levels. However, no significant difference in gas production was detected for sugar versus starch at 24 or 48 hours of incubation. Total gas production significantly increased with increasing pH levels from 10 to 48 hours for all diets. Total methane production per $\mathrm{g}$ OM from the basal GH diet was significantly less compared to the three rations with easily fermentable carbohydrates. However, the NDF digestibility of the three concentrate diets was significantly less compared to the GH diet. Total methane per g OM production increased significantly different between 6.8 and 6.6 , but not significantly different between 6.6 and 6.4. The proportion of methane of total gas was significantly less for the $\mathrm{GH}$ diet at 10 hours, while there was no significant difference at 24 or 48 hours. The results suggest that differences of methane emission between sucrose and starch may be of lesser importance than the significant difference between the higher and lower $\mathrm{pH}$ levels.

\section{R12. Bacterial and archaeal community shifts by feeding of the novel methane-reducing agent cashew nut shell liquid}

S. Hayashi*, Y. Watanabe, R. Suzuki, S. Koike, K. Nagashima, M. Mochizuki and Y. Kobayashi*

Cashew nut shell liquid (CNSL) is expected as a candidate feed additive, because it reduces methane production and enhances propionate production in the rumen (Watanabe et al., Journal of Dairy Science, in press). Rumen bacterial and archaeal community of sheep fed the diet with or without CNSL was investigated to assess actions of CNSL against rumen microorganisms to cause methane reduction and propionate enhancement.

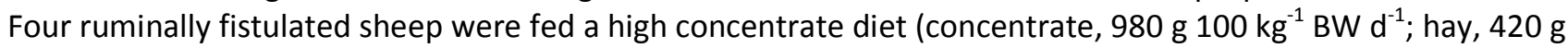
$100 \mathrm{~kg}^{-1} \mathrm{BW} \mathrm{d}$ ) for $2 \mathrm{wk}$ (control period), followed by the same diet but supplemented with CNSL for 4 wk (CNSL period) and again non-supplemented diet for 2 wk (post CNSL period). In the CNSL period, supplementation level of CNSL was initially (for the first $2 \mathrm{wk}$ ) set at the level of $2{\mathrm{~g} 100 \mathrm{~kg}^{-1} \mathrm{BW} \mathrm{d}}^{-1}$ and then doubled. Rumen content was sampled on the last day of each period before feeding and fermentation products were determined. In addition, bacterial and archaeal clone libraries targeting 165 rDNA and methyl coenzyme$M$ reductase $A$ gene, respectively, were generated from the mixture of DNA extracted from the rumen content of four sheep that was taken in control and CNSL periods. Propionate proportion in the rumen was significantly 


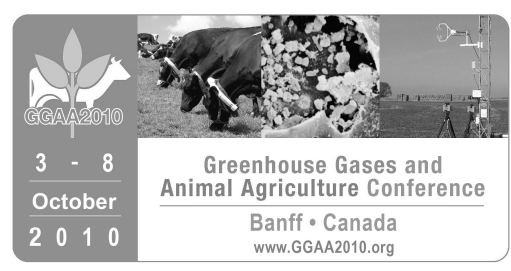

enhanced, while methane synthesis from the rumen content was significantly lowered with CNSL feeding. These were returned to the original levels after the cessation of CNSL feeding. Bacterial composition assessed by clone library analysis was drastically changed with CNSL feeding (i.e., the detection frequency of Treponema and Ruminococcus (formate and hydrogen producer) and Lactobacillus (lactate producer) was decreased by CNSL feeding). In contrast, the detection frequency of bacteria responsible for production of propionate and succinate (propionate precursor) including Megasphaera and Selenomonas was increased. Archaeal members were remarkably changed by CNSL feeding (i.e., Methanobrevibacter wolinii and Methanobrevibacter woesei, methanogenic species), never detected from the rumen, were abundantly detected when CNSL was fed. Meanwhile, Methanobrevibacter ruminantium, Methanobrevibacter smithii and other known ruminal methanogens decreased in terms of detection frequency when CNSL was fed. From these results, it is apparent that methane reduction and propionate enhancement with CNSL is mainly caused by the occurrence of bacterial and archaeal community shifts in the rumen.

\section{R13. Molecular characterization of ciliate communities in domestic ruminants - An opportunity for methane mitigation?}

S. Kittelmann* and P. H. Janssen

Ciliates make up almost $50 \%$ of the microbial biomass in the rumen ecosystem. They play a pivotal role in degrading fibrous plant material and in shaping prokaryotic communities in a predator-prey relationship. Furthermore, rumen ciliates harbor ecto- and endosymbiotic methanogens, and so are indirectly involved in formation of ruminant-derived methane. Despite their importance for rumen functioning, not much is known about the structure of ciliate communities in domestic ruminants. Here, we quantitatively and qualitatively assessed ciliate communities in New Zealand ruminants (sheep, cattle and deer) feeding on different diets. Quantitative PCR suggested that the relative abundance of ciliates compared to bacteria was similar in all samples. However, molecular fingerprinting of communities showed ruminant-specific differences in species composition. Moreover, community compositions of cattle were significantly influenced by the administered diets, in contrast to deer. The high animal-to-animal variation in sheep samples hampered the detection of a possible diet effect. Phylogenetic analysis of clone libraries from representative samples revealed that New Zealand ruminants were colonized by at least 9 genera of ciliates and allowed the assignment of samples to 2 distinct community types. Whereas cattle showed A-type communities, with most sequences closely related to the genera Polyplastron and Ostracodinium, deer and sheep (with one exception) harbored B-type communities, with the majority of sequences belonging to the genera Epidinium and Eudiplodinium. It has been suggested that species composition of ciliate communities may impact methane formation in ruminants, with the B-type producing more methane. Therefore, manipulation of the ciliate community may be a means of mitigating methane emissions from grazing sheep and deer in New Zealand. 


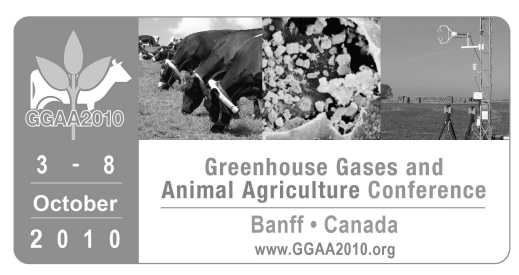

\section{R14. Medium-term effects of chloroform on methanogens and rumen function in cattle}

T. Knight, R.S. Ronimus, D. Dey, C. Toothill, G. Naylor, P. Evans, G. Molano*, A. Smith, M. Tavendale, C. PinaresPatino* and H. Clark*

Anthropogenic methane emissions are widely recognised as a world-wide problem primarily due to their strong greenhouse gas effects. Ruminant methane emissions also potentially represent a loss in dietary energy. Few recent studies are available examining the medium- or long-term effects of methanogen inhibitors. The aim of this study was to investigate the medium-term effects of a potent methanogen inhibitor on methanogen populations and important markers of rumen function. Six fistulated cows were divided into control $(n=3)$ and chloroform treatment groups $(n=3)$ and each fed at a fixed rate of $8.4 \mathrm{~kg}$ per day of dry matter. After an initial adjustment period the treatment cows were also dosed daily with $1.5 \mathrm{ml}$ of chloroform in $30 \mathrm{ml}$ of sunflower oil for 42 days; control cows only received sunflower oil. Key indicators of rumen function were monitored including rumen $\mathrm{pH}$, total protozoa, VFAs, ammonia!, rumen fill, apparent feed digestibility and apparent rumen digesta retention time. Methane emissions were monitored using the SF6 technique and methanogens using DGGE and a clone library. Methanogens and acetogens were monitored in a single cow by most probable number culturing methods. Chloroform, a well known inhibitor of methanogenesis, had an immediate and dramatic effect on both methane emissions and methanogen populations with the maximum effect occurring at about 1 week after the start of the treatment. Thereafter, methane emissions increased slowly reaching $62 \%$ of pre-treatment levels. The effect on methane emissions was reflected in dramatic effects on methanogen populations by the disappearance of dominant major bands normally associated with Methanobrevibacter, Methanosphaera species and/or members of the Methanomicrobiales in the treated cows but not the control cows. There were no significant effects of chloroform treatment on apparent rumen digesta retention time, apparent feed digestibility, $\mathrm{pH}$, ammonia or rumen fill. Total protozoa tended to increase during the trial in both control and treatment groups. The total VFA concentration was higher for the treated cows both during and immediately after cessation of the chloroform treatment. The acetate:propionate ratio was significantly lower $(\mathrm{P}<0.01)$ for the treated cows $(1.86)$ in the middle of the trial (days 18-22) than the control cows (2.74); it was not different shortly after the treatment stopped (days 46-50). This study has provided an opportunity to examine the composition of rumen methanogens and their ability to adapt to a potent methanogen inhibitor in vivo over an extended period of time, and its impact on general rumen function.

\section{R15. Isolation and identification of fumarate reducing bacteria from Korean black goats and Holstein cows \\ L. Mamuad, M.-J. Gu*, S.-H. Kim, M. J. Alam, J.-H. Lee*, Y.-K. Oh and S.-S. Lee*}

Reduction of methane from ruminants is one of the important issues for global ecology and animal nutrition. Fumarate reducing bacteria competes with the methanogens by utilizing $\mathrm{H}_{2}$. The experiment was conducted to identify and isolate the fumarate reducing bacteria which would reduce methane to improve cellulose digestion. Four different media were used in isolating bacteria from Korean native goats and Holstein cows. Different species of bacteria were isolated using different media. The basal media were added with different treatments such as Fumarate + Formate, Fumarate + Hydrogen, Formate and Hydrogen. Rumen fluid samples of Korean black goats were taken from slaughtered rumen while Holstein cow samples were taken from a cannulated animal. Samples were strained and transported immediately to the laboratory. All the media preparation, enrichment procedure, dilution, roll tube and pour plating to isolation of bacteria in the experiment were completed anaerobically. Isolates were identified using 16s rDNA, ARDRA, DNA purification 


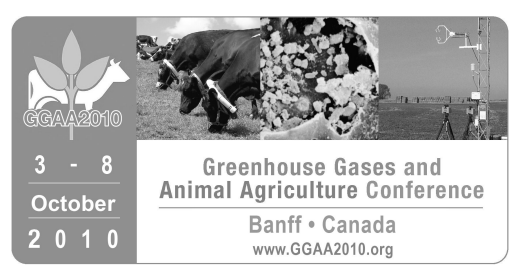

and the samples were submitted to the Macrogen. Sequence results were aligned using DNA Star and compared using BLAST program (NCBI) and EzTaxon. Results showed that numbers of bacterial isolates were comparatively higher in Korean native goats ( $8 \mathrm{spp}$.) than Holstein cows (3 spp.). Nine bacterial species belonging to Firmicutes are potential fumarate reducing bacteria which were identified in this study. These bacteria showed high homology with Bacillus licheniformis ATCC 14580T (CP000002), Bacillus smithii NBRC 15311T (AB271749), Bacillus subtilis subsp. Inaquosorum BGSC 3A28T (EU138467), Bacillus thermoamylovorans CNCM I-1378T (L27478), Clostridium bifermentans ATCC 638T (AB075769), Clostridium cochlearium ATCC 17787T (AB538429), Clostridium glycolicum DSM 1288T (X76750), Lactobacillus johnsonii ATCC 33200T (ACGR01000047) and Mitsuokella jalaludinii M9 DSM 13811T (AF479674). Presence of fumarate reductase gene was identified using frdA primers. According to the author, the using of primers has some limitations thus the results showed different sizes of bonds from different species of isolated bacteria. Only M. jalaludinii had the approximate size of $350 \mathrm{bp}$ than the others. This microorganism seems to be suitable bacteria in reducing methane which was confirmed by the primers. It is recommended that $M$. jalaludinii can be used efficiently as fumarate reducing bacteria for methane reduction. Furthermore, the isolated bacteria will be used to confirm the enzyme activity, reduction of methane, hydrogen, carbon dioxide and fumarate to improve the cellulose digestion in the rumen.

\section{R16. Evaluation of rumen methanogen diversity with diets containing corn dry distillers grains with solubles and condensed tannins using PCR-DGGE and qRT-PCR analysis}

R. Mohammed*, M. Zhou*, K. A. Beauchemin* and L. L. Guan*

Condensed tannins (CT) and distillers' grains from ethanol production have the potential to reduce greenhouse gases from ruminants. However, effects on methanogen diversity in cattle have not been investigated. The objective of this experiment was to evaluate the effect of corn dry distillers' grains with solubles (CDDGS) and CT from Acacia mearnsii on rumen methanogenic diversity using PCR-denaturing gradient gel electrophoresis (PCR-DGGE) and quantitative real time (qRT) PCR analysis of the 16S rRNA gene. Eight rumen-cannulated beef heifers were used in a replicated $4 \times 4$ Latin square design with four $35-\mathrm{d}$ periods. Diets were control (Ctrl; $0 \%$ CDDGS), 20\% CDDGS, 40\% CDDGS and 40\% CDDGS with 2.5\% (DM basis) CT (40\% CDDGST). All diets contained $8 \%$ barley silage with CDDGS and CT included by replacing an equivalent amount of barley grain from the Ctrl diet. Rumen digesta samples were collected before feeding on d 25 and d 28 from dorsal, ventral, cranial and caudal aspects of the rumen. Total DNA was extracted from the rumen digesta samples pooled by cows for each period. The PCR-products obtained by amplification with universal methanogen primers were subjected to PCR-DGGE analysis. Similarity of the DGGE profiles was determined using Dice's coefficient at $0.5 \%$ optimization and $0.625 \%$ tolerance. Bands corresponding to Methanosphaera stadmanae and Methanbrevibacter species were identified. Although no significant diet effect on total methanogen profiles was observed, some bands were found to be associated with Ctrl (bands 26, 36 and 43) and CDDGS diets (bands 9, 17, 19, 31 and 41). Quantitative RT-PCR analysis revealed that total methanogens were not different among the diets. Methane gas emissions also showed a similar trend. Findings from PCR-DGGE and qRT-PCR analysis indicated that inclusion of CDDGS or CT altered rumen methanogen diversity without affecting the total methanogen population. 


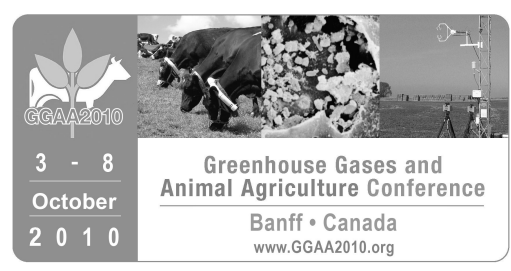

R17. Modifications to the total gas production technique for assessing the in vitro rumen methane output of feedstuffs of contrasting composition

\author{
A. Navarro-Villa, M. O'Brien, S. Lopez, T. Boland* and P. O'Kiely*
}

The objective of this study was to modify the in vitro rumen gas production technique (GPT) so that the methane output associated with contrasting feeds would better reflect in vivo findings. A phosphatebicarbonate saline solution was mixed with citric acid and used as a buffer. Varying quantities $(0.3,0.5$ and 0.7 $\mathrm{g}$ ) of each of three contrasting feeds (barley grain, grass silage and barley straw) were incubated in varying ratios of rumen fluid to buffer $(1: 2,1: 4$ and 1:6) in fermentation bottles containing $50 \mathrm{ml}$ of the rumen fluid + buffer medium. The effects on methane output per $\mathrm{g}$ of feed dry matter (DM) incubated and disappeared, apparent DM disappearance, decline in $\mathrm{pH}$ and other fermentation variables were evaluated after a $24 \mathrm{~h}$ incubation period. Increasing the quantity of feed incubated led to a decline in methane output per g DM incubated and disappeared and a decline in $\mathrm{pH}(\mathrm{P}<0.001)$. Increasing the proportion of rumen fluid in the mixture increased methane output per g DM incubated and disappeared and reduced $\mathrm{pH}(P<0.01)$. These results were consistent across the feeds tested. However, for grass silage, the apparent DM disappearance declined $(P<0.001)$ as the quantity of feed incubated increased, an outcome associated with a simultaneous decline in $\mathrm{pH}$. It is concluded that the preferred unit for expressing in vitro methane output is relative to DM disappeared, and that the incubation of $0.3 \mathrm{~g}$ dried milled feed with $50 \mathrm{ml}$ of rumen fluid and buffer mixture at a 1:2 ratio was the optimal combination for the buffer used.

\title{
R18. Effect of administration of novel sulphate reducing bacteria on in vitro methane emission and digestion of wheat straw by rumen fluid microbes of buffaloes
}

S. S. Paul*, S. M. Deb and D. Singh

Seven novel isolates of sulphate reducing bacteria of Fusobacterium genus from rumen of buffalo were evaluated for their suitability for use as microbial additive in buffaloes to reduce methane emission and stimulate fibre digestion under in vitro system. When added to rumen fluid of buffalo, all the 7 isolates reduced $(P<0.05)$ percent of methane in gas produced in fermentation vials, increased production of propionate with no change in hydrogen sulphide production. The isolate SRBBR 5 showed the highest reduction in methane emission in the process of straw digestion by buffalo rumen fluid ( $40 \%$ reduction; 2.94 vs. $1.77 \mathrm{mM}$ methane per $\mathrm{g}$ truly digested dry matter) as compared to control (received autoclaved culture) at $72 \mathrm{~h}$ of fermentation. There was also significant increase in fibre digestion (15\% increase in apparent digestibility; $40 \%$ increase in true digestibility), increase in enzyme activities of carboxymethyl cellulase, xylanase and acetyl esterase, increase in count of cellulolytic bacteria and sulphate reducing bacteria in incubation fluid with no change in count of methanogen or fungi in SRBBR5 added group as compared to control. On PCR assay, all the sulphate reducing bacterial isolates were positive for dissimilatory sulphite reductase gene. Sequencing of $16 \mathrm{~S}$ ribosomal DNA indicated that the SRB isolates have high homology with Fusobacterium genus. The study revealed that the sulphate reducing bacterial isolate SRBBR 5 has a high potential to be used as microbial feed additive in buffaloes for reducing methane emission and improving digestibility of fibrous feeds. 


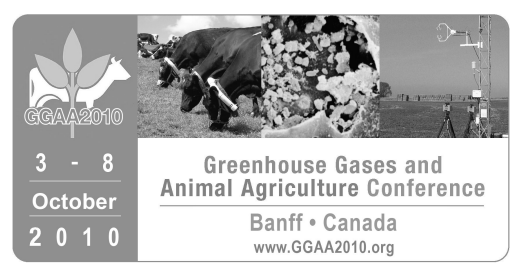

R19. The effect of inulin, pectin, corn and wheat starch on methane and short chain fatty acid production in ruminal fluid in an in vitro fermentation system

M. Poulsen*, R. G. Engberg* and B. B. Jensen

Methane emission from ruminants contributes to the greenhouse effect and reportedly is related to the composition of their feed. Through a series of in vitro fermentations we investigated the effect of $\mathrm{pH}$ on the fermentation of four carbohydrates with respect to methane and short chain fatty acid (SCFA) production. Fermentations were performed in undiluted rumen fluid after addition of one of four carbohydrate sources (pectin from sugar beets, inulin from chicory root, wheat or corn starch) at a final concentration of $1 \%$ (wt/vol) at $\mathrm{pH}$ values of 5.5, 6.0, 6.5 and 7.0. Undiluted rumen fluid without additives was used as control. Methane and SCFA production were measured at the beginning of the incubations and after 3, 6, 10, 24 and $48 \mathrm{~h}$, respectively. SCFA production was calculated as the production ratios (acetic acid:propionic acid:butyric acid) where SCFA from control treatment was subtracted to remove background SCFA production from organic material already in the rumen fluid at sampling. After $48 \mathrm{~h}$ the total methane production was significantly higher from carbohydrate-enriched rumen fluid as compared to the control. There was, however, no difference in the total methane production between the four carbohydrate sources. Furthermore, methane production from carbohydrate enriched treatments or the control was not significantly affected in the pH interval from 5.5 to 7.0, which indicated that pH 5.5 did not effectively inhibit activity of methanogenic Archaea. Acetic acid was the dominating SCFA produced in all in vitro fermentations. The fermentation of pectin resulted in the ratios of acetic acid to propionic and butyric acid of 72:26:2 at pH 5.5 and 78:24:-2.5 at 7.0, where the total production of butyric acid after $48 \mathrm{~h}$ at pH 7.0 was lower in the treatment than in the control. The low production of butyric acid compared to acetic and propionic acid is typical for the fermentation of cell wall associated carbohydrates. Corn and wheat starch fermentations resulted in close to identical SCFA production ratios of 61:20:20 and 64:31:5 for corn starch at pH 5.5 and 7.0, respectively, and ratios of 59:21:20 and 63:32:5 for wheat starch at pH 5.5 and 7.0, respectively. Fermentation of inulin stimulated butyrate production and resulted in SCFA ratios of 48:21:31 and 59:32:9 at $\mathrm{pH} \mathrm{5.5}$ and 7.0, respectively. In conclusion, methane production was not significantly affected by $\mathrm{pH}$ or carbohydrate source, whereas low pH stimulated butyric acid production for the four carbohydrate sources on the expense of propionic acid production.

\section{R20. A novel method to determine methane production simultaneously during in vitro gas production measurements \\ W. F. Pellikaan*, W. H. Hendriks, G. Uwimana., L.J.G.M. Bongers, P. M. Becker* and J. W. Cone*}

Many in vitro studies are performed to determine the influence of additives, such as oils and plant extracts, on methane production from rumen fluid. However, a reduction in methane production should not be accompanied by a reduction in overall fermentation of the organic matter. The gas production technique is an excellent tool to determine both rate and extent of rumen fermentation of organic matter in vitro. Advanced fully automated systems have been described and have shown their potential. However, simultaneous measurements of gas composition and methane were not possible, as the bottles should be kept closed during the incubations. We adapted our automated system to measure gas composition and methane during the incubations, without disturbing the system. A separate small opening with a screw cap and septum was made in each bottle. With a syringe, aliquots $(10 \mu \mathrm{L})$ of the gas in the headspace can be taken and immediately analyzed, using gas chromatography. The head space $(240 \mathrm{~mL})$ of the bottles is at the start of the incubations filled with $\mathrm{CO}_{2}$. During the incubation the gas produced from the fermentation is mixed with the gas in the 


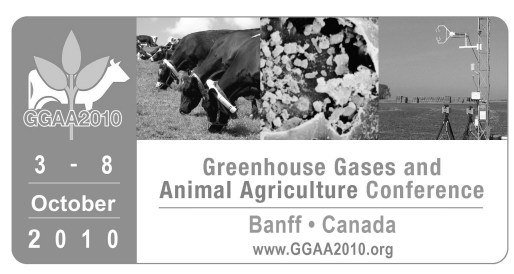

head space, but meanwhile also gas escapes from the system, as the used gas production technique is a venting one. So, the composition of the gas in the headspace is the result of the original $\mathrm{CO}_{2}$ and the gas produced by the fermentation, but without the escaped gas. Consequently, the methane synthesis from the fermentation has to be calculated from the determined methane concentration in the gas in the head space, taking account for the escaped gas. To test the suitability and accuracy of this system known amounts of methane were injected in bottles in the venting system and methane concentration in the headspace was determined. It proved that the calculated amount of methane coincided with the expected concentration of methane. An experiment was conducted with different feedstuffs, recording fermentation gas production and methane production and their relationships were calculated. There was variation in methane production between the different feedstuffs and also during the incubations. Maize and soybean hulls were supplemented with the additives monensin, sodium-2-bromoethanesulphonate (BES), cinnemaldehyde and tea tannins, to reduce methane fermentation and the relationship between methane production and organic matter fermentation was calculated. The adapted gas production equipment showed to be a powerful tool to determine rate and extent of fermentation and simultaneously methane production.

\section{R21. Effect of sodium nitrate and nitrate reducing bacteria on in vitro methane production and feed fermentation with buffalo rumen liquor}

P.C. Sakthivel*, D. N. Kamra*, N. Agarwal and L.C. Chaudhary

Effects of three levels of sodium nitrate $(0,5$ and $10 \mathrm{mM})$ on three diets varying in wheat straw and concentrate ratios (70:30, low concentrate, LC; 50:50, medium concentrate, $M C$ and 30:70, high concentrate, $\mathrm{HC}$ ) were studied using an in vitro gas production test for gas and methane production, and in vitro true digestibility (IVTD) of feeds and residual nitrate and nitrite contents at $24 \mathrm{~h}$ of incubation at $39^{\circ} \mathrm{C}$ with buffalo rumen liquor. The inclusion of sodium nitrate at 5 and $10 \mathrm{mM}$ significantly $(P<0.01)$ reduced methane production (9.56, 7.93 vs. $21.76 \mathrm{ml} / \mathrm{g} \mathrm{DM} ; 12.20,10.42$ vs. $25.76 \mathrm{ml} / \mathrm{g} \mathrm{DM} ; 15.49,12.33 \mathrm{vs} .26 .86 \mathrm{ml} / \mathrm{g} \mathrm{DM}$ ) in LC, MC and HC diets, respectively. Inclusion of nitrate at both the levels ( 5 and $10 \mathrm{mM})$ significantly $(P<0.05)$ reduced gas production in all the three diets, however IVTD was significantly reduced only in LC and MC diets. At higher level of sodium nitrate $(10 \mathrm{mM}), 7.5-11.8 \%$ of added nitrate was left unused and there was a significant accumulation of nitrite in the medium $(P<0.01)$. In order to eliminate residual nitrate and nitrite in the medium, another experiment was conducted where nitrate reducing bacteria isolated from Murrah buffalo adapted to sodium nitrate feeding were used as microbial feed additive. In this experiment, MC diet with 10 $\mathrm{mM}$ sodium nitrate was used along with buffalo rumen liquor as inoculum plus $3 \mathrm{ml}$ live or autoclaved culture of the isolates and incubated for $24 \mathrm{~h}$ at $39^{\circ} \mathrm{C}$. The treatments containing autoclaved cultures served as control for the respective isolates. With the live cultures of the isolates $(13,43,45,57,60,65$ and 75$)$ there was complete removal of nitrate and nitrite from the incubated medium and methane production was further reduced as compared to control treatment containing nitrate without any bacterial culture. There was no effect $(P>0.05)$ on IVTD of feed. The data indicated that nitrate reducing bacteria can be used as microbial feed additive when sodium nitrate is used to control methane emission from buffaloes to avoid nitrite accumulation in the rumen. 


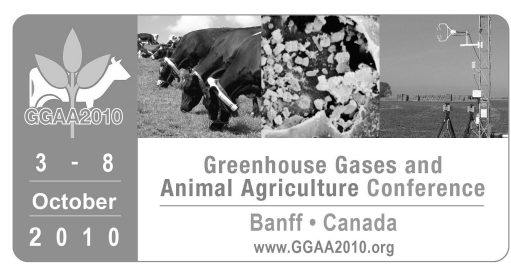

R22. Effect of cashew nut shell liquid on bacterial and archaeal community in the rumen of cattle

C. Su*, T. Shinkai*, M. Mitsumori*, O. Enishi, K. Nagashima, M. Mochizuki, S. Koike and Y. Kobayashi*

Cashew nut shell liquid (CNSL) has a potential to reduce methane production and to enhance propionate production in the rumen (Watanabe et al., Journal of Dairy Science, in press). However, the mechanisms involved in these favorable fermentation changes have not been fully characterized. The present study was aimed at clarifying a possible shift of microbiota with CNSL feeding by analyzing clone libraries of bacterial and archaeal genes expressed in the rumen of cattle fed a CNSL-supplemented diet. Three non-lactating Holstein cows were given a hay and concentrate diet (4:6) for 6 weeks. No supplementation was done for the first 4 weeks (control period), while CNSL supplemented the diet $\left(4{\mathrm{~g} 100 \mathrm{~kg}^{-1} \mathrm{BW} \mathrm{d}}^{-1}\right)$ for the last 2 weeks (CNSL period). Each cow was kept in a respiration chamber for the last 4 days of each period to monitor gas production and nutrient balance. Rumen content was collected before feeding on the last day of each period to analyze fermentation products and microbiota. The analysis of rumen microbiota was performed by sequencing CDNA libraries synthesized from mRNA of targeted bacterial and archaeal genes that are 16S rDNA and methyl coenzyme- $M$ reductase $A$ (mcrA), respectively. Methane production per dry matter intake was significantly reduced with CNSL feeding by $38 \%$ on average. Although CNSL supplementation did not significantly affect total VFA concentration in the rumen, it significantly enhanced molar proportion of propionate. Rumen protozoa showed no particular change with CNSL feeding. The CDNA library analysis clearly indicated that rumen bacterial and archaeal composition was dramatically changed with CNSL feeding (i.e., CNSL increased the detection frequency of Succinivibrio dextrinosolvens, Ruminobacter amylophilus and Prevotella spp.) that are known to be responsible for propionate production. For archaeal members, CNSL reduced the detection frequency of the known methanogenic species Methanobrevibacter smithii, Methanobrevibacter millerae and Methanobrevibacter gottschalkii, while it increased the detection frequency of uncultured methanogens. These results suggest that the reduction of methane with CNSL is strongly related to the shift of rumen microbiota.

\section{R23.Effect of level of roughage in the diet on the rumen microbial diversity in goat bucks} M. Wadhwa*, K. Kaur, J. S. Hundal, R. Kumar and M.P.S. Bakshi

The study was taken up to assess the effect of high and low roughage diet on the rumen microbial diversity in goat bucks. Two diets viz. low roughage-high concentrate (LR- HC) and high roughage-low concentrate (HR-LC) were prepared. The concentrate mixture contained maize 30 , mustard cake 30 , rice bran 13 , deoiled rice bran 24, mineral mixture 2 and common salt 1 part each. The roughage to concentrate ratio in LR-HC was 30:70, while in HR-LC it was 70:30. The roughage portion was made of wheat straw and green berseem (Trifolium alexandrium) in 80:20. The in vitro gas production studies revealed significantly $(P<0.01)$ higher net gas production (NGP), methane production both as percent of NGP as well as per $\mathrm{g}$ of DM and digestibility of OM from the LR-HC diet as compared to the HR-LC diet. The total volatile fatty acid production, acetate and ME availability from LR-HC was higher $(P<0.05)$ than the HR-LC diet. The in vivo studies conducted on 10 bucks divided into 2 equal groups, and offered either the LR-HC or HR-LC diet, revealed that the daily DM intake $(P<$ $0.05)$, digestibility of $\mathrm{DM}, \mathrm{OM}$ and hemicelluloses $(P<0.05)$ and $\mathrm{N}$-retention $(P>0.05)$ was higher in bucks fed the LR-HC as compared to the HR-LC diet. From the permanently fistulated bucks offered the LR-HC or HR-LC diet, 12 and 15 fibre degrading bacteria were isolated, respectively, by using specific media containing microcrystalline as the carbon source. The majority of the isolates were Gram positive with very few Gram negative bacteria. The isolates in the $\mathrm{HC}$ diet were curved/straight, thick (stumpy)/thin (filamentous) rods in 


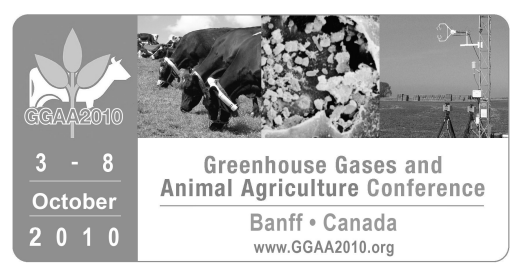

combinations, while the isolates from the goats fed the HR diet were cocci with variable chain length ranging from diplococci to 20 cells in groups/bunches. Twelve fibre degrading bacterial isolates from the rumen of goats fed the LR-HC diet were used as an inoculum to see their effect on the fermentation of wheat straw by in vitro gas production technique. The results revealed that bacterial isolates 1,2 and 3 improved $(P<0.05)$ the NGP and ME availability as compared to the control, without any significant effect on the digestibility of NDF and OM. However, isolate 8 improved $(P<0.05)$ digestibility of NDF and OM as compared to the control. The production of total and individual VFA was improved $(P<0.05)$ in isolate 3 as compared to the control. The relative proportion of VFAs revealed that the acetic acid was highest in isolates 8 and 3 , propionic acid in isolates 3,9 and 7 , while isobutyrate, butyrate, isolvalerate and valerate were improved $(P<0.01)$ over that of the control in isolate $1,2,4,5,6,10$ and 12 . The effect of 15 fibre degrading bacterial isolates from the rumen of goats fed the HR-LC diet on the fermentation of wheat straw revealed that isolates 1,14 and 15 improved NGP than that of the control group. The digestibility of NDF and OM was considerably higher in isolates 5, 6, 7, 8 and 9 as compared to the control. There was no significant effect on ME availability from the substrate. The total and individual VFA production from the substrate was higher $(P<0.01)$ in most of the isolates as compared to the control except 1,9 and 11 . The relative proportion of the acetic acid was depressed $(P<0.01)$ in all isolates, but that of propionate, butyrate and branched chain fatty acids were either improved $(P<0.01)$ or at par with that of the control. It was concluded that fiber degrading bacterial isolates 1, 2, 3 and 8 from the rumen of bucks fed the LR-HC diet and 5-9 from the rumen of bucks fed the HR-LC diet had an edge over other isolates.

\section{R24. Associated effects of three citrocompounds, pyromellitic diimide and 2- bromoethanesulphonate on methane production and rumen fermentation characteristics of starch- rich substrates in vitro}

H.J. Yang* and D. F. Zhang

Sixteen groups of experiments were conducted in a $\mathrm{L}_{16}\left(4^{5}\right)$ orthogonal experimental design to evaluate associative effects of five methanogenesis inhibitors at four dose levels: nitroethane (NE; 0, 5, 10 and $15 \mathrm{mM}$ ), 2-nitroethanol (NEOH; 0, 5, 10 and $15 \mathrm{mM}$ ), 2-nitro-1-propanol ( $\mathrm{NPOH} ; 0,5,10$ and $15 \mathrm{mM}$ ), pyromellitic diimide (PMDI; 0, 0.02, 0.05 and $0.07 \mathrm{mM}$ ) and 2-bromoethanesulphonate (BES; 0, 0.01, 0.03 and $0.05 \mathrm{mM}$ ) on in vitro ruminal methane production of the mixed substrate (Chinese wildrye hay: maize meal $=1: 4$ ) using a cumulative gas production technique. Results showed that in vitro dry matter disappearance (IVDMD) and total gas production $\left(\mathrm{GP}_{48}\right)$ were decreased by 10.1 to $24.0 \%$ and 14.5 to $37.4 \%$, respectively. Total volatile fatty acid production (VFA) was reduced by 1.3 to $28.9 \%$, while experiments 5 and 6 had preferable effect in that the total VFA productions were not different from that of control $(P>0.05)$. Acetate $(A C)$ increased while propionate $(\mathrm{Pr})$ and butyrate $(\mathrm{Bu})$ decreased $(\mathrm{P}<0.05)$ in all of the experiments with the addition of inhibitors. Hydrogen recovery $(2 \mathrm{Hrec})$ was decreased by 29.6 to $40.8 \%(\mathrm{P}<0.05)$. Methane concentration in gas $\left(\mathrm{CH}_{4}\right)$ was reduced by 95.5 to $99.6 \%$. Among these inhibitors, NEOH and NPOH had relatively higher efficiencies of the methane inhibition; and the rest were nearly equal effective to the methanogensis inhibition. An optimization analysis showed that these five inhibitors, at concentrations of 5, 5, 5, 0.02 and $0.03 \mathrm{mM}$, respectively, had the relatively higher associated methane inhibiting efficiency in that the in vitro methane could be reduced by greater than $95 \%$. 


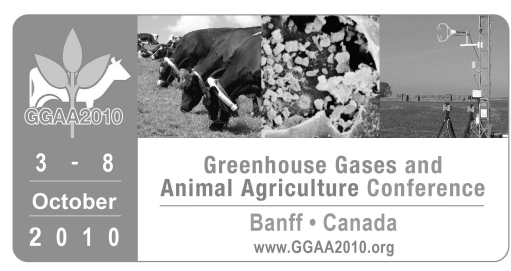

\title{
R25. Methane formation from four pure carbohydrates when fermented by three single protozoal species in vitro
}

\author{
J. O. Zeitz*, M. Kreuzer* and C. R. Soliva
}

Ruminal protozoa are involved in methanogenesis due to their role as hydrogen suppliers, and methanogens are associated with them endo- or ecto-symbiotically. Up to now this was mostly investigated using mixed rumen protozoal populations, often in comparison with defaunated ruminal fluid. Therefore, the role of single protozoal species is not well known. Due to different nutrient requirements of protozoal species, carbohydrates may play an important role. In the present study methanogenesis in cultures of Entodinium caudatum (EC), Epidinium ecaudatum (EE) and Eudiplodinium maggii (EM), isolated from sheep rumen together with bacteria and methanogens, was measured when fermenting cellulose, xylan, wheat starch and sucrose in vitro. Incubation took place in $100 \mathrm{ml}$ flasks for $24 \mathrm{~h}$ at $39^{\circ} \mathrm{C}(\mathrm{n}=4)$. Twenty milliliters each of protozoal culture and buffer were incubated alone (blank) or with $0.6 \mathrm{~g}$ of pure carbohydrate and $0.18 \mathrm{~g}$ of wheat gluten (protein source). At 4, 8, 20, and $24 \mathrm{~h}$, total gas and methane volumes produced were determined via glass syringes and gas chromatography (methane). Culture samples taken after $24 \mathrm{~h}$ were analyzed for $\mathrm{pH}$, ammonia, and counts of bacteria and protozoa. After incubation, counts $\mathrm{ml}^{-1}$ were 6193 for EC, 284 for EE and 402 for EM. There were no protozoal species differences, averaged over all carbohydrate types, in pH (5.17-5.29), ammonia (4.9$\left.6.0 \mathrm{mmol} \mathrm{I}^{-1}\right)$ and bacteria $\left(3.63-4.31 \times 10^{9} / \mathrm{ml}\right)$. Likewise, net gas production from EC, EE, and EM was similar. The same was true for the $\mathrm{CH}_{4} /$ total gas ratio with 0.062 (EC), 0.066 (EE) and 0.069 (EM). Across all protozoal species, the $\mathrm{CH}_{4} /$ gas ratio was highest for xylan (0.113) and cellulose (0.087), followed by starch (0.055), and was lowest for sucrose (0.020). This overall carbohydrate type effect was also obvious for each individual protozoal species. The methane formation kinetic was similar for EC, EE, and EM; the fermentation of sucrose and starch, with the lowest methane formation (0.9 and 2.0-3.1 ml, respectively), reached a plateau before 24 $\mathrm{h}$ passed, whereas the fermentation of xylan and cellulose produced up to $8.5 \mathrm{ml}$ methane, reaching no plateau even after $24 \mathrm{~h}$ of incubation. In conclusion, EC, EE, and EM seemed to have a similar effect on methane formation when incubating pure carbohydrates in vitro. This indicates that a selective inhibition of individual protozoal species for methane mitigation seems ineffective. The ranking found in methane from carbohydrates was as expected except for the clear difference between starch and sucrose.

\section{R26. Molecular identification of rumen methanogens: technologies, advantages and prospects M. Zhou*, T.A. McAllister* and L.L. Guan*}

Methanogenesis provides a means of hydrogen disposal and a mechanism to maintain low partial hydrogen pressure in the rumen, a perquisite for efficient ruminal fermentation. Methanogens possess stringent requirements for cultivation; accordingly, only a few species of methanogens have been successfully isolated from the rumen and cultured hitherto. Culture-independent molecular based approaches have provided new insight into the diversity, prevalence and role of methanogens within the overall rumen microbial community. In addition, recent developments in deep sequencing have enabled the ruminal microbial community to be investigated at a metagenomic level, providing information to explore the structure, functions and metabolic diversity of microbial communities. This review will summarize the existing molecular technologies utilized in the studies of ruminal methanogens by outlining their advantages and limitations, and introduce the future applications of deep sequencing approaches to study the ecology of ruminal methanogens. These approaches could provide new insight into the mechanisms of methanogenesis as well as the interactions of methanogens with other members of the rumen microbial community. An understanding of the fundamental role of 
Greenhouse Gases Animal Agriculture Conference Banff • Canada www.GGAA2010.org

methanogens in ruminal methane production could provide new insight into curtailing emissions of this important greenhouse gas from ruminants.

\section{NOTES}




\title{
SESSION 6: ORAL ABSTRACTS
}

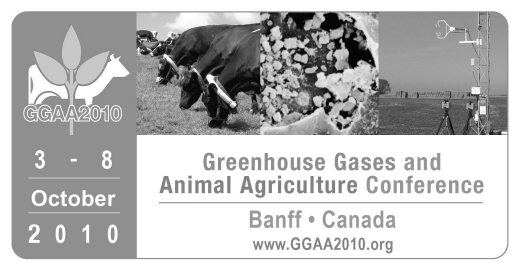

\section{PLEASE NOTE: Authors denoted with an asterisk are registered GGAA2010 delegates}

\author{
An assessment of whole farm models of greenhouse gas emissions as a means of improving \\ national and global inventories \\ P. Crosson*, L. Shalloo, P. Foley, D. O’Brien, G. Lanigan*, T. Boland* and D. Kenny
}

The IPCC reporting guidelines on greenhouse gas emissions specify the methodology and procedures to be followed for submitting consistent and comparable national emissions data on an annual basis in a timely, efficient and transparent manner (IPCC, 2006). The guidelines require that all potential sources of emissions and removals be assigned to six broad categories including Agriculture and LULUCF (land use, land use change and forestry). Whilst this approach is appropriate for reporting national or sectoral inventories, it is less suitable for calculating emissions from complex, multiple component systems. For example, emissions from livestock production systems arise from a number of sources within the farm-gate, in the production of farm inputs and from indirect emissions associated with ammonia volatilization and nitrate leaching. Furthermore, the interrelationships between soil, feed, manure and livestock emissions influence the magnitude and scope of total emissions. Farm systems modelling approaches have been used to investigate the GHG emissions from current and prototype agricultural production systems (Foley et al., 2010; O'Brien et al., 2010; Schils et al., 2007). Whole-farm systems modelling determines the GHG emissions associated with agricultural products by integrating the farm production profile with the relevant GHG conversion factors and converting the computed emissions to their global warming potential carbon dioxide $\left(\mathrm{CO}_{2}\right)$ equivalent. In this paper a number of studies which have quantified GHG emissions from Irish beef and dairy production systems are reviewed (Foley, 2009; Foley et al., 2010; O'Brien et al., 2010). Foley et al. (2010) and Foley (2009) modelled GHG emissions per unit area and per $\mathrm{kg}$ beef carcass from beef originating from suckler and dairy systems, respectively. Input data were generated using a bioeconomic model of beef production systems (Crosson, 2008) thus permitting concomitant financial analysis. This study found that, per kg beef carcass produced, reductions in GHG emissions of up to $30 \%$ could be achieved through the improved technological efficiency achieved on research units compared with average performance at farm level. The main drivers of this reduction in GHG emissions were level of animal performance and beef carcass output as well as efficiencies in utilization of grazed grass and inorganic fertilizers (Foley et al., 2010). Additionally, O Brien et al. (2010) linked a GHG model to a bioeconomic dairy systems model (Shalloo et al., 2004) to evaluate GHG emissions and technical and financial performance of dairy production systems and found that low levels of concentrate supplementation and genetic selection of cows for improved production as well as fertility traits resulted in lower GHG emissions per $\mathrm{kg}$ of milk solids. Given the prolificy of GHG farm systems models in the literature, a critique of the key methodologies will be outlined to identify the suitability of alternative approaches to: 1) enumerate total emissions association with agricultural production, 2) model the effect of the interactions of components within the system on total emissions, 3) investigate mitigation strategies for reducing total emissions from livestock production and, 4) evaluate the uncertainty associated with activity levels and emission factors. 


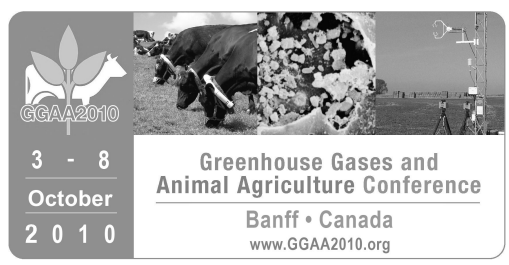

\section{Comparison of the global warming potential of meat production using Life Cycle Assessment: A review with reference to Australian research}

S. G. Wiedemann*

Greenhouse gas emissions from livestock are a subject of global significance, particularly when considered from a whole of supply chain perspective. Comprehensive, whole of supply chain research tools such as life cycle assessment (LCA) are increasingly being used to provide an estimate of livestock contributions to global warming, and to help identify management options to mitigate emissions. However, LCA research methods are variable and have been adopted for use in agriculture from less complex industrial applications, where emission estimation is generally less complex and variable than for livestock production. Considering the importance and proliferation of livestock LCA studies, this review was instigated to make a broad evaluation of studies for beef, lamb, pork and chicken meat. The review aimed to compare results within and across species using a standardized framework, with reference to the methodological approach used. The review identified sensitive management factors and emission sources for each species. Major differences between species were primarily related to production intensity and underlying physiological differences between species. Mean emissions intensity (on a liveweight basis) for the four species were $12.9 \mathrm{~kg} \mathrm{CO}_{2}$-e kg-1 (beef), $8.2 \mathrm{~kg} \mathrm{CO}_{2}$ - $\mathrm{e} \mathrm{kg}^{-1}$ (lamb), $3.7 \mathrm{~kg} \mathrm{CO}_{2}$-e kg-1 (pork) and $2.3 \mathrm{~kg} \mathrm{CO}_{2}-\mathrm{e} \mathrm{kg}^{-1}$ (chicken meat). The primary drivers for the differences between species are i) physiological differences in the digestive system which lead to lower direct animal emissions from monogastrics compared to ruminants, ii) the superior feed conversion ratio of monogastrics compared to ruminants and iii) the higher fecundity of monogastric species compared to ruminants. The author suggests that the strength of LCA is not primarily in detailed GHG assessment of individual emission sources, but as a tool to contextualize and prioritize the complex array of emission sources. Moreover, LCA studies have an important role in testing specific mitigation strategies to ensure that emissions are not simply shifted from one part of the production system to another.

\section{Rumen stoichiometric models and their contribution and challenges in predicting enteric methane production \\ E. Kebreab*}

The fermentation process in the rumen is a complex process involving microbial activities and degradable dietary components. Representation of this process using mathematical models is also complex. However, fermentation stoichiometry needs to be known in order to evaluate specific dietary components for the type of volatile fatty acid (VFA) produced during rumen fermentation. Accordingly, a number of VFA stoichiometric models have been developed and used in various rumen models to estimate VFA production and molar proportions. The approach depends on the assumption that molar proportions of VFA in the rumen fluid represent the proportions produced. Proper description of VFA stoichiometry ultimately determines the accuracy of methane prediction. Therefore, the objective of this study was to evaluate the three most commonly used VFA stoichiometric models: Murphy et al. (1982; MUR), Bannink et al. (2006; BAN) and Sveinbjörnsson et al. (2006; SVE) for their capacity to predict VFA and methane using independent data sources. Sixty eight treatments in rumen digestion studies on lactating dairy cows were collected from 23 published experiments in various journals. The experiments reported information on diet composition, true rumen substrate digestion, molar proportion of VFA and (only 3 experiments) enteric methane production. Mean square prediction error (MSPE) was used to assess the error of prediction. Volatile fatty acid molar proportions estimated using MUR model had higher root MSPE (RMSPE, \% observed mean) for acetate (14.8\%) 


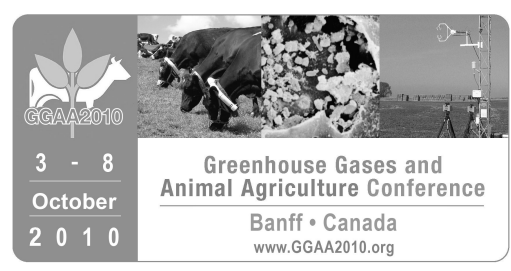

and propionate (17.0\%) and lower for butyrate (4.0\%), compared to BAN and SVE models, with 8.0, 34.6 and $10.6 \%$ of MSPE being random error, respectively. Molar proportion of VFA estimated using BAN model had lower RMSPE (7.4\%) for acetate and higher for butyrate (5.1\%) with 32.2 and 5.2\% MSPE being random error, respectively. Prediction using SVE model had intermediate RMSPE values for acetate but lower for propionate (11.7\%) and butyrate (2.0\%). The variations among the stoichiometric models in predicting VFA production rate had an effect on estimated methane production from predicted VFA production using a fermentation balance equation. In contrast to VFA predictions, predicted methane production using MUR resulted in lower RMSPE $(15.8 \%)$ compared to BAN (31.5\%) with 13.7 and 3.3\% of MSPE being random, respectively. Results indicate that variation among stoichiometric models in predicting VFA production rate and proportion influence the accuracy of estimating enteric methane production using rumen fermentation models. Further study is recommended to improve the VFA prediction potential of existing stoichiometric models.

\title{
Impact of distillers grains type and inclusion level on greenhouse gas reduction potential in the corn-ethanol-livestock life cycle
}

\author{
V. R. Bremer*, A. J. Liska, G. E. Erickson, K. G. Cassman, K. J. Hanford and T. J. Klopfenstein
}

New meta analysis equations of feedlot cattle performance when fed 0 to $50 \%$ of diet DM as corn wet (WDGS, $32 \% \mathrm{DM}$ ), modified (MDGS, partially dried WDGS, 46\% DM), or dry (DDGS, 90\% DM) distillers grains plus solubles replacing dry rolled and high moisture corn were incorporated into the Biofuel Energy Systems Simulator (BESS; www.bess.unl.edu) to evaluate the impact of DGS type and inclusion level on greenhouse gas (GHG) reduction potential in the corn-ethanol-livestock life cycle. Meta analyses of pen level performance for 19 trials feeding WDGS ( $n=338$ pens and 3,270 steers), 4 trials feeding MDGS ( $n=85$ pens and 680 steers, and 4 trials feeding DDGS ( $n=66$ pens and 581 steers) were conducted. All trials were conducted at University of Nebraska research feedlots. The feeding value of WDGS was 142 to $129 \%$ of the corn replaced in the diet from 20 to $40 \%$ of diet DM. Using the same approach, feeding values of MDGS were 125 to $117 \%$ and a constant $113 \%$ for DDGS. No performance response has been detected when DGS was fed to growing swine and dairy cows. Midwest corn-ethanol-livestock life cycle GHG reduction potential relative to gasoline $(97.7 \mathrm{~g}$ CO2e / MJ ethanol) was greatest for WDGS in feedlot diets and decreased from 61 to $57 \%$ for 20 to $40 \%$ of diet DM as WDGS. The GHG reduction potentials of MDGS and DDGS for feedlot cattle were 53 to $50 \%$ and 46 to $41 \%$, respectively. The life cycle GHG reduction potential of $10 \%$ of diet DM as WDGS, MDGS or DDGS for dairy cows was 53,48 and $43 \%$, respectively. The life cycle GHG reduction potential of $10 \%$ of diet DM as DDGS for swine was $42 \%$. These data indicate that ethanol plants in concentrated cattle feeding areas should produce WDGS to have the greatest GHG reduction potential regardless of co-product inclusion level. The GHG reduction potential of DDGS was lower than WDGS and MDGS for beef or dairy, but was comparable for all three livestock classes when fed DDGS. Partial drying (MDGS) or complete drying (DDGS) of DGS reduces both feeding value and GHG reduction potential relative to gasoline. Feeding WDGS to feedlot cattle is the optimum feed use of DGS based on feeding performance and GHG reduction potential.

\section{Benchmarking carbon footprints of dairy farms in $\mathbf{4 0}$ countries}

T. Hemme*, M. Hagemann, A. Ndambi, N. Sultana, O. Alqaisi

In the dairy chain the major share of greenhouse gas (GHG) emissions is generated on the dairy farm producing milk. As the dairy farming systems are very difference around the global it raise the question how much the 


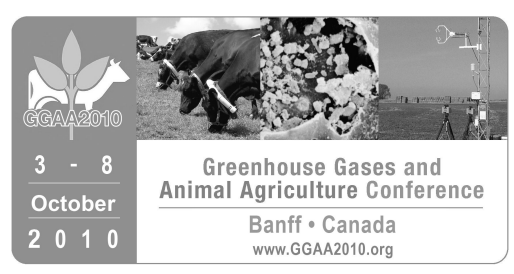

GHG emission differ between the different systems. The analysis is based on the IFCN concept of typical farms. The IFCN is a global research network of dairy economists from over 70 countries to create a better understanding of milk production. Besides farm economics comparisons the IFCN has done 08, a first step to analyse the GHG emissions in dairy farming systems. For this the farm economic software TIPICAL has been extended by a LCA model which was able to estimate the GHG emission on the farm data available. The analysis was applied for 46 typical dairy farms from 38 countries. The $\mathrm{GHG}$ emission in $\mathrm{kg} \mathrm{CO}_{2}$ equivalents per $100 \mathrm{~kg}$ milk range from 89 to 368 . The lowest emissions have been found for the typical farms in the countries USA, Israel, Netherlands, Spain and Italy. The highest emissions have been found for small scale dairy farming systems in Uganda, Cameroon, India, Pakistan, Bangladesh and China. A key driver for GHG emission was milk yield but even more the weight productivity which means the milk production per kg bodyweight of the cow. A look on GHG emission and cost of milk production leads to the hypothesis that farm types with low milk yields have low costs but high GHG emission. In contrary, it shows that farming systems with high milk yield have high costs and low GHG emission per kg milk.

\section{Impacts of future climate scenarios on the balance between productivity and total greenhouse gas emissions from pasture-based dairy systems in south east Australia \\ B. Cullen* and R. Eckard*}

The challenge for agriculture is to increase production in a warmer climate in order to meet the demands of an increasing global population, while also meeting targets for reduced greenhouse gas (GHG) emissions. The aim of this paper was to quantify the net effect of future climate scenarios on the productivity and GHG emissions from pasture-based dairy systems in four regions across southeast Australia using the biophysical model, DairyMod. A baseline climate (1971-2000) and three future climate scenarios representing increasingly warm and dry conditions were compared. At Kyabram (northern Victoria), summer irrigated perennial pastures were modelled in the baseline scenario, with supplementary irrigated annual pasture systems simulated in the baseline scenario for comparison and in the future scenarios. At Terang (southwest Victoria), Ellinbank (southeastern Victoria) and Elliott (northwestern Tasmania), dryland perennial pastures were modelled. In the simulations no supplementary feed was offered so that stocking rate and milk production reflected changes in the pattern of pasture production. In the dryland systems, increased production was modelled in all future scenarios for the cool temperate climate at Elliott, with reduced production in the 2070 mid and 2070 high scenarios at Ellinbank and Terang. At Kyabram, productivity of the annual system was lower than the perennial system in the baseline scenario, but was increased in future climates, assuming adequate irrigation water availability. Across the sites and climate scenarios average annual per cow GHG emissions were in the range 3.4 to $5.5 \mathrm{t} \mathrm{CO}_{2}$-e, with methane accounting for 63 to $89 \%$ of total emissions. Annual emissions per unit area ranged from 2.6 to $13.1 \mathrm{t} \mathrm{CO}_{2}$-e/ha across the sites and climate scenarios and generally reflected stocking rates. In the future scenarios, however, there were changes in nitrous oxide $\left(\mathrm{N}_{2} \mathrm{O}\right)$ emissions at dryland sites due to increasing direct $\mathrm{N}_{2} \mathrm{O}$ losses, with lo wer leaching and volatilisation. Average annual emission intensities ranged from 7.5 to $10.9 \mathrm{~g} \mathrm{CO}_{2}$-e/kg milk solids (MS) across the sites and climate scenarios. The lowest emissions intensity was at Elliott, which also showed little change in future climates. At Terang and Ellinbank, the emission intensity was $8.8 \mathrm{~g} \mathrm{CO}_{2}$-e/ $\mathrm{kg} \mathrm{MS}$ in the baseline climate, but this increased by more than $20 \%$ in the 2070 high scenario. On the basis of these results, pasture-based production systems can continue to be the basis of the dairy industry in northwest Tasmania but lower production and higher emission intensity at Terang and Ellinbank suggest that systems adaptations are required. 


\title{
SESSION 6: POSTER ABSTRACTS
}

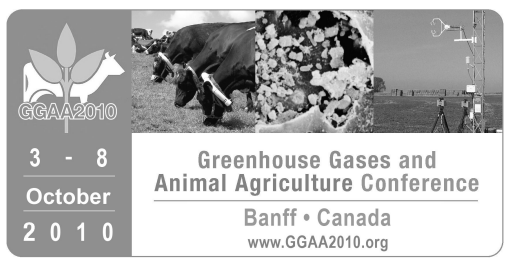

\section{PLEASE NOTE: Authors denoted with an asterisk are registered GGAA2010 delegates}

\author{
R27. Potential effects of animal management and genetic improvement on enteric methane \\ emissions, emissions intensity and productivity of Australian sheep production systems \\ D. J. Alcock* and R. S. Hegarty*
}

The efficacy of potential mitigation technologies for enteric methane emissions from ruminants are typically evaluated on individual animals, but little consideration has been given to likely changes in animal numbers, feed utilization, total productivity or emissions that will occur across the whole enterprise if such technologies are adopted. While impacts of the many rumen manipulations being studied are hard to anticipate, there is adequate information to assess the impact of farm management changes and potential animal genetic changes on whole farm productivity and enteric emissions. A long term simulation of the effects of a range of animal management, animal genetic and nutritional strategies on total enteric emissions and emission intensity of sheep enterprises in southern Australia was conducted using the GrassGro simulation model. It was assumed that graziers would alter stocking rates to achieve the sustainable economic optimum for each production system. Management options considered included choice of lambing time, joining maidens as lambs, and production-feeding of lambs to reduce time to slaughter. The potential for using selective animal breeding was also tested, with sheep physiological parameters being altered in GrassGro to represent genetic improvement in fecundity, liveweight gain, residual feed intake and methane yield. In general, the management choices delivering lowest emission intensity were also the most profitable within the sustainability constraints. Joining maiden ewes as lambs was only effective in reducing enterprise emissions intensity in self-replacing flocks. When stocking rates are at the sustainable economic optimum, the choice of enterprise or management had little influence on total enteric emissions from the enterprise. The optimal stocking rate was not sensitive to an emissions permit price of $\mathrm{AU} \$ 25 / \mathrm{tCO}_{2}$-e. If decisions are made solely on an economic basis, the grazier is likely to continue with similar levels of production (and emissions) until the carbon price rises to make the sheep enterprise unprofitable, or an alternative more profitable enterprise than sheep grazing emerges. Improving the genetic capacity for feed use efficiency or methane yield, offer modest opportunities for reducing enterprise emissions and emissions intensity but spread of genetics into the industries is expected to be slow.

\section{R28. Development of national methane emission inventory for domestic livestock in Saudi Arabia}

A. A. Aljaloud*, T. Yan and A. Abdukader

The objectives of the present study were to develop methane emission inventory for domestic livestock in each province and national total in Saudi Arabia from 2003 to 2007, and to identify the sources of variations in methane emissions during this period. Livestock animals in Saudi Arabia include dairy cattle, sheep, camels, goats, horses and chickens. There are two groups of animals for dairy cattle, sheep and chickens, i.e., modern high genetic merit group and traditional group. For example, high yielding cows produced an average milk yield of more than $8700 \mathrm{~kg} / \mathrm{yr}$ in 2007. The data used were obtained from national statistical databases, published information and farm surveys. The inventory for each species of animals was developed using Tier 1 methane emission factors for enteric fermentation and manure management of IPCC (2006). For dairy cattle, sheep and chickens, the inventories were separately developed for modern group and traditional group. In 2007, dairy cattle produced the highest methane output (38019 t/yr, of which $32117 \mathrm{t} / \mathrm{yr}$ were from high yielding group), 


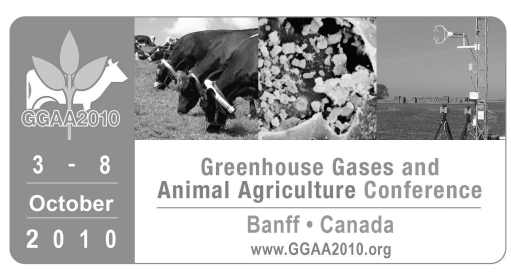

followed by sheep (35844 t/yr), camels (13565 t/yr) and goats (11549 t/yr), while chickens (1580 t/yr) and horses $(414 \mathrm{t} / \mathrm{yr})$ had the lowest methane emissions. The national methane emission inventory gradually increased from 2003 to 2007 (87069, 95750, 100058, 95713 and $100971 \mathrm{t} / \mathrm{yr}$, respectively). This is mainly derived from increased number of modern high yielding cows, with which total methane emissions increased from 22406 to 32117 t/yr from 2003 to 2007. For dairy cattle and sheep, Tier 2 methane emission factors were also developed for modern high genetic merit group and traditional group, using equations proposed by IPCC (2006). Dairy calves and pro-milking heifers were further divided into two subgroups ( $<1 \mathrm{yr}$ old and 1 to $2 \mathrm{yr}$ old). The results are different from those developed using Tier 1 method. For example, enteric methane emissions for young calves/heifer of $<1 \mathrm{yr}$ old for both modern and traditional groups were much lower with Tier 2 than Tier 1 method. Methane emissions from manure management were also lower with Tier 2 than Tier 1 method. For modern high yielding dairy cattle, this is because the majority of manure is managed with the drylot systems. Therefore, national methane inventory in 2007 developed for all domestic livestock with Tier 2 factors for dairy cattle and sheep and Tier 1 for other animals was lower than that with Tier 1 for all animals (98883 vs $100972 \mathrm{t} / \mathrm{yr}$ ).

\section{R29. A research model of enteric fermentation in dairy cows applied as Tier 3 to estimate methane emission for the Dutch National Inventory Report}

A. Bannink*, M. M. van Schijndel and J. Dijkstra*

In contrast to most other countries, the Dutch protocol for inventory of greenhouse gases includes a mechanistic model of digestion and fermentation processes as an advanced Tier 3 approach to estimate methane $\left(\mathrm{CH}_{4}\right)$ emission by dairy cows. The national $\mathrm{CH}_{4}$ emission is calculated based on annual national statistics on feed intake, diet composition and chemical composition of dietary ingredients as an input to the model. The model is dynamic and represents digestive as well as microbial fermentative processes responsible for methanogenesis both in the rumen and the large intestine. Three classes of micro-organisms are distinguished, viz. amylolytic bacteria, fibrolytic bacteria, and protozoa. The model differs from Tier 2 in that it predicts sources and sinks of hydrogen, and the elimination of excess hydrogen by methanogenesis. The model predicts the \% of gross energy intake emitted as $\mathrm{CH}_{4}$ in contrast to the constant \% assumed with Tier 2 . Calculations were made from 1990 to 2008. With the increase of dry matter intake and milk yield per cow, the $\mathrm{CH}_{4}$ emission per cow was calculated to increase relatively less rapidly. Hence, the amount of $\mathrm{CH}_{4}$ emitted per $\mathrm{kg}$ milk steadily decreased from about 17 to $15 \mathrm{~g} \mathrm{CH}_{4} / \mathrm{kg}$ fat and protein corrected milk. The $\mathrm{CH}_{4}$ conversion factor decreased from 6.1 to $5.9 \%$ of gross energy intake and, on average, exactly matches the 1996 IPCC Tier 2 default of $6.0 \%$. Regional differences (more maize silage in south-east versus more grass silage in north-west) resulted in substantial differences that were small when the Tier 2 method was applied. Uncertainty of predicted $\mathrm{CH}_{4}$ emission was evaluated by testing the effect of error in model inputs and internal model parameters. Total uncertainty is approximately $15 \%$, and most relevant are uncertainties in grass intake and in internal parameter values related to rumen acidity and production of volatile fatty acids. A recent update of the latter is thought to have improved explanation of $\mathrm{CH}_{4}$ emission in cows. Unlike the Tier 2 approach, the present Tier 3 approach enables the evaluation of dietary management decisions on $\mathrm{CH}_{4}$ emission. Its use in the Dutch inventory of greenhouse gases is hence combined with its use as a research tool to evaluate mitigation options. It is used to evaluate measures at various scales (diet, animal, farm management, region) and on various aspects other than $\mathrm{CH}_{4}$ emission (rumen function, feed digestion, cow performance, faeces and urine excretion). These applications are illustrated by recent studies. 


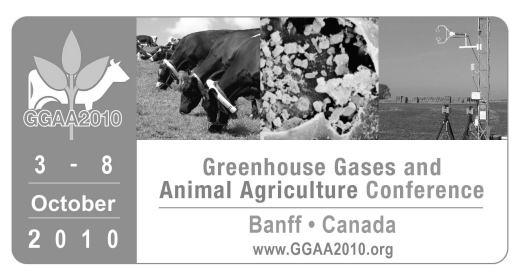

\section{R30. An empirical model to predict enteric methane production by cattle}

H. G. Bateman, J. M. Aldrich*, W. B. Fokkink, J. R. Newbold* and J. L. Firkins

A data set was constructed from published trials in which enteric methane was measured in cattle and from trials conducted at the Provimi Research and Innovation Center. The data set contained 160 treatment means from 38 trials. Treatment diets from the manuscripts were input to a Provimi North America proprietary feed formulation model to estimate nutrient contents. When available, feed analysis values from the default feed library were altered to reflect those in the published manuscript. Forage NDF and NFC degradability were empirically altered within a trial until the model predicted milk yields matched those of the published manuscript. Nutrient concentrations of experimental diets were used as inputs for regression analysis. Methane production $(\mathrm{g} / \mathrm{d})$ was evaluated as the dependant variable for the regressions. All data were weighted by the inverse of the SE squared. Dry matter intake was allowed to interact with nutrient contents to estimate nutrient intakes. Data were classified to groupings based on method of measuring methane, type of animal used for measurement, use of monensin in the diet, addition of fat to the diet, and addition of yeast or other rumen modifier. Backwards elimination multiple regressions were conducted using a mixed model with a random effect of trial. Terms least probable to differ from zero were removed sequentially from the model except when interactions terms appeared in the model,in which case their constituent terms remained irrespective of level of significance. The final model selected for predicting enteric methane production includes 19 parameters, has an $\mathrm{R}^{2}$ of 0.988 and a variance inflation factor of 89.6. The model indicates that increasing DMI, or ration content of effective NDF, non-fiber concentrate, rumen undegradable protein, or the ratio of lysine to methionine in the metabolizable protein increased enteric methane production. Increasing dietary content of $\mathrm{CP}$, fat, $\mathrm{ADF}$, starch, undegradable intake protein or the ruminal degradability of non-fiber carbohydrate decreased enteric methane production. Additionally, the presence of sodium monensin in the diet decreased enteric methane and there are adjustments necessary based on method used to measure methane. Altering dietary nutrient contents can be used to mitigate enteric methane production by cattle.

\section{R31. Accuracy and precision of empirical models for predicting enteric methane production by cattle and sensitivity of a proprietary model to dietary nutrient change}

H. G. Bateman, J. M. Aldrich*, W. B. Fokkink and J. R. Newbold*

A data set was constructed from published trials in which enteric methane was measured in cattle and from trials conducted at the Provimi Research and Innovation Center. The data set contained 160 treatment means from 38 trials. This dataset was used to construct an empirical model for prediction of enteric methane production by cattle (PNACH4). PNACH4 uses nutrient contents of diets to estimate enteric $\mathrm{CH}_{4}$ production by both lactating and non-lactating dairy cattle and for beef animals. Nutrient contents of experimental diets where enteric $\mathrm{CH}_{4}$ was measured were estimated using a feed formulation model that is proprietary to Provimi North America. These nutrient contents were used to predict enteric methane emissions using 6 published models and the PNACH4 model and were used to evaluate the prediction bias of the models. Individual nutrients were then increased 0.1 and predictions compared to that with the mean nutrient contents. Mean prediction of enteric $\mathrm{CH}_{4}$ by the PNACH4 model was $148.8 \mathrm{~g}^{2}$ animal ${ }^{-1} \mathrm{~d}^{-1}$. Sensitivity analysis (increasing individual nutrients 0.1) revealed that DMI increased $\mathrm{CH}_{4} 0.11, \mathrm{CP}$ decreased $\mathrm{CH}_{4} 0.06$, fat decreased $\mathrm{CH}_{4} 0.03$, ADF decreased $\mathrm{CH}_{4}$ 0.11, eNDF increased $\mathrm{CH}_{4}$ 0.04, NFC increased $\mathrm{CH}_{4}$ 0.12, starch decreased $\mathrm{CH}_{4} 0.07$, degradability of NFC decreased $\mathrm{CH}_{4} 0.12$, metabolizable RUP flow to the small intestine increased $\mathrm{CH}_{4} 0.11$, the ratio of lysine to methionine in the MP increased $\mathrm{CH}_{4} 0.11$, and UIP decreased $\mathrm{CH}_{4} 0.02$. 


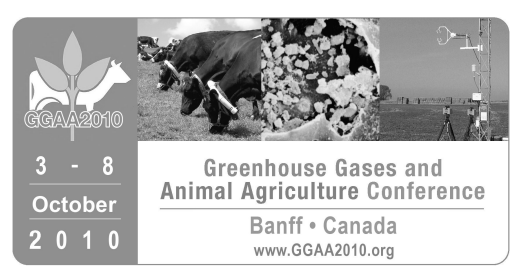

\begin{tabular}{|c|c|c|c|c|c|c|c|}
\hline Item & PNACH4 & $\begin{array}{l}\text { Moe \& } \\
\text { Tyrell } 1\end{array}$ & $\begin{array}{l}\text { Moe \& } \\
\text { Tyrell } 2\end{array}$ & Ellis 1 & Ellis 2 & Krebreab & Mills \\
\hline $\mathrm{R}^{2}$ & 0.7828 & 0.6087 & 0.5882 & 0.6918 & 0.7015 & 0.7181 & 0.6706 \\
\hline Linear Bias, \% & 21.02 & 37.43 & 39.16 & 63.49 & 64.40 & 68.92 & 47.29 \\
\hline Mean Bias, \% & 73.15 & 38.52 & 33.42 & 8.23 & 8.20 & 4.02 & 29.49 \\
\hline Dispersion, \% & 5.83 & 24.06 & 27.42 & 28.28 & 27.40 & 27.06 & 23.23 \\
\hline MSPE & 34592.5 & 6430.4 & 6702.4 & 3337.7 & 3229.5 & 3233.1 & 5481.8 \\
\hline RMSPE, g/d & 185.99 & 80.19 & 81.87 & 56.77 & 56.83 & 56.86 & 74.04 \\
\hline
\end{tabular}

The PNACH4 model had greater mean bias than other published models, possibly because it was constructed to function with inputs from both lactating and non-lactating cattle whereas other published models tend to concentrate on one animal class.

\section{R32. Mitigation of greenhouse gas emissions from beef production in Canada - Life cycle analysis using Holos \\ K. Beauchemin*, H. H. Janzen*, S. Little*, T. A. McAllister* and S. M. McGinn*}

Numerous mitigation strategies are proposed to reduce enteric $\mathrm{CH}_{4}$ from cattle. Before implementing such changes, it is critical to evaluate the net impact on the total farm greenhouse gas (GHG) emissions. A life cycle assessment (LCA) was conducted using HOLOS to estimate whole-farm GHG emissions from beef production in western Canada. HOLOS, is a whole-farm model developed by Agriculture and Agri-Food Canada for Canadian conditions based on Intergovernmental Panel on Climate Change methodology. Holos considers all significant $\mathrm{CH}_{4}, \mathrm{~N}_{2} \mathrm{O}$ and $\mathrm{CO}_{2}$ emissions and removals on the farm, as well as emissions from manufacture of fertilizer and herbicides and off-farm emissions of $\mathrm{N}_{2} \mathrm{O}$ derived from nitrogen applied on the farm. A simulation was first conducted to establish a baseline GHG emission intensity and mitigation practices were then applied to assess their impact on emission intensity. Mitigation practices included dietary modifications (increased and decreased use of forages, dietary supplementation with polyunsaturated lipids, use of corn distillers dried grains, improved forage quality) and improved animal husbandry (increased longevity of breeding stock, improved reproductive performance of the cow herd). The simulation consisted of a beef production operation comprised of 120 cows, 4 bulls, and their progeny, with the progeny fattened in a feedlot. The farm also included cropland and native prairie pasture for grazing to supply the feed required by the animals. The LCA was conducted over 8 years to fully account for the lifetime GHG emissions from breeding stock as well as the progeny raised for market. The baseline scenario estimated the GHG emission intensity of beef production at $22.73 \mathrm{~kg} \mathrm{CO}_{2}$ equivalent ( $\mathrm{kg}$ carcass) ${ }^{-1}$, with enteric $\mathrm{CH}_{4}$ accounting for $63 \%$ of total emissions. The strategies applied to the cow-calf herd individually reduced total farm GHG intensity by up to $8 \%$. Further reductions could be attained through additive effects by combining strategies. In comparison, strategies applied to the feedlot had only a small impact on overall GHG emissions because the feedlot accounted for only $20 \%$ of total GHG emissions. Mitigation strategies applied to the feedlot reduced total GHG intensity by less than $2 \%$ when applied individually or by $3-4 \%$ when applied in combination. Although the North American production system is highly efficient, our study shows that a number of mitigation strategies could be implemented to further lower the GHG emissions associated with producing beef. Greatest reductions in GHG emissions will be achieved if mitigation targets the breeding herd. 


\section{R33. Factors affecting dairy system methane emissions}

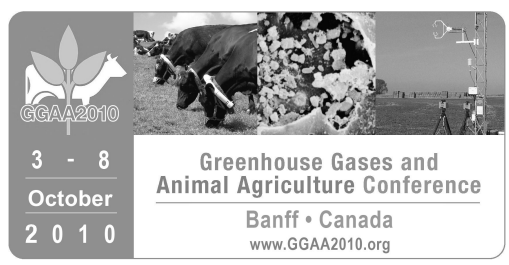

M. J. Bell*, E. Wall, G. Russell and G. Simm

Improving the productivity and efficiency of livestock production is seen as one of the most promising ways to reduce methane emissions. The aim of this study was to identify the key animal and system variables influencing total methane emissions from a dairy cow (emissions from enteric fermentation and manure) both within its lactation period and over its lifetime, and to suggest how modifying these variables could contribute to effective mitigation strategies. Predicted methane emissions for cows on different production systems were compared. Data from a total of 1,689 completed lactations from 834 cows, with predicted methane emissions from the Langhill Holstein Friesian dairy research herd, were available from January 1990 to June 2008. Cows were either on a Low or High Forage diet and either belonged to a genetic line selected for milk fat plus protein (Select) or were selected to remain close to the average genetic merit for milk fat plus protein production (Control) for Holstein Friesians evaluated in the UK. The association between different animal and systems variables and total methane emissions was investigated using Residual Maximum Likelihood (REML). The effect of lactation number, diet and genetic line were evaluated for total manure and enteric emissions before cows entered the milking herd and whilst in the milk herd (both per cow and per kilogram of milk). This study found that the main influential factors affecting total dairy systems methane emissions over a cow's lifetime were the number of milking herd offspring retained on the farm, the age at which a cow entered the milking herd, the average daily feed intake, a cow's lactation period length and lifespan. In addition to these factors, cows on a zero-grazing low forage system, selected for increased milk fat plus protein production, a greater proportion of their lactation period in milk and older animals were associated with higher total methane emissions during the lactation period. However, zero-grazing low forage fed cows selected for increased milk fat plus protein production will potentially result in the lowest methane emissions per unit product by about $3 \%$ compared to other production systems studied.

\section{R34. Impact of cold acclimatization on enteric methane emissions of beef cows fed protein deficient and sufficient forage-based diets}

J. Bernier*, K. Wittenberg*, K. Plaizier, M. Tenuta, D. Flaten, D. Krause, E. Kebreab* and K. Ominski*

The Canadian beef cow herd is exposed to long periods of cold temperatures and a range of forage qualities in the winter months. As low protein levels and cold acclimatization are suggested to influence enteric methane $\left(\mathrm{CH}_{4}\right)$ emissions, examination of these parameters is valuable in improving estimates of $\mathrm{CH}_{4}$ emissions from Canadian beef cattle. To accomplish this, thirty beef cows with an average body weight of $675.4+/-51.8 \mathrm{~kg}$ were divided into three treatment groups and fed diets consisting of $6 \%$ crude protein (CP) hay with no DDGS (control), 10\% DDGS (borderline sufficient nitrogen $(\mathrm{N}), 8.7 \% \mathrm{CP}$ ), or $20 \%$ DDGS (excess $\mathrm{N}, 11.5 \% \mathrm{CP}$ ). These diets were fed in thermal neutral (fall) and cold-stressed (winter) environments, with average, minimum and maximum temperatures of 7.3, 2.7 and 13.8 , and $-17.7,-23.5$ and $-11.0 \circ \mathrm{C}$ in fall and winter, respectively. Dry matter intake was not significantly different between diets or seasons. Available CP intake (ACPI), however, was significantly different $(P<0.0001)$ between diets with $576.7,918.9$ and $1349.6 \mathrm{~g} \mathrm{~d}^{-1}$ for control, $10 \%$ and $20 \%$ DDGS diets respectively, but did not differ between seasons. As expected, serum urea nitrogen (SUN) increased from 1.6 to 3.1 to $4.3 \mathrm{mmol} \mathrm{L}^{-1}$ as dietary ACPI increased across diets. Although cows consumed the same diets in winter, SUN differed between seasons $(P<0.0001)$ with 2.5 and $3.4 \mathrm{mmol} \mathrm{L}^{-1}$ in fall and winter, respectively. As a result of increasing dietary $\mathrm{CP}$ content, enteric $\mathrm{CH}_{4}$ emissions expressed as a percent of gross energy intake (\% GEl) were significantly different $(P=0.0128)$ between diets, with emissions of $6.5,6.8$, and $5.3 \% \mathrm{GEl}$ for control, $10 \%$ and $20 \%$ DDGS diets, respectively. When cold acclimatized, cows had significantly 


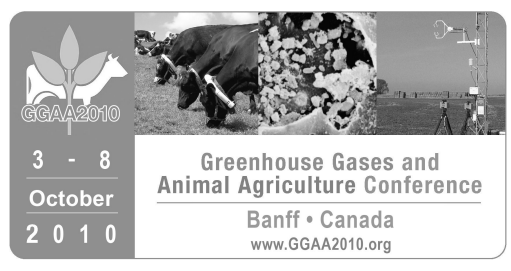

lower $(P<0.0001)$ emissions $(5.2 \% \mathrm{GEI})$ than when acclimatized to thermal neutral environments $(7.1 \% \mathrm{GEI})$. Enteric $\mathrm{CH}_{4}$ emissions (\% GEI) were reduced when increasing dietary $\mathrm{CP}$ was supplied in excess of animal requirements. Therefore, supplementation of low quality forage diets with $20 \%$ DDGS appears effective in reducing enteric $\mathrm{CH}_{4}$ emissions when expressed as \% GEl. Further, these results support the hypothesis that DDGS supplementation and cold acclimatization in cattle may reduce enteric $\mathrm{CH}_{4}$ emissions. Methane production in cold acclimatized cattle requires further exploration as these data suggests that the Canadian beef herd may produce less $\mathrm{CH}_{4}$ than previously predicted. Such information is essential for accurate model development and prediction of $\mathrm{CH}_{4}$ emissions from Canadian beef cattle.

\section{R35. Estimating greenhouse gas emissions from New Zealand dairy systems using a mechanistic whole farm model and inventory methodology \\ P. C. Beukes*, A. J. Romera and P. Gregorini}

In New Zealand (NZ), seasonally calving dairy cows are fed ryegrass-dominant pastures. Typically, all cows calve at the end of winter (July to September) and are milked for 8 to 9 months. Dairy farming is responsible for about $36 \%$ of agricultural GHG emissions in NZ. Milk solids (MS = fat + protein) production is increasing, partly as a result of land conversions from less profitable options. There is also concern that dairy industry GHG emissions will increase with the potential for large financial penalties if a carbon tax is imposed. The objective of this study was to use a mechanistic whole farm model (WFM) to evaluate the impact of currently available mitigation strategies on milk production and seasonal patterns of GHG emissions, and to compare the results with those predicted by an empirical model (Overseer ${ }^{\circ}$ ) that uses inventory methodology. The WFM, consisting of a framework that links a climate-driven pasture model with a mechanistic cow model (Molly), was used to simulate an "average" pasture-based dairy farm as the baseline. The baseline farm was then modified in the WFM by implementing different variations of five strategies: 1) a lower replacement rate, by improving reproductive performance; 2 ) a lower stocking rate, by improving production genetics of the cows; 3 ) capturing urinary $\mathrm{N}$, by keeping cows on a loafing pad in autumn; 4) feeding low protein forages grown on-farm, fertilised using captured effluent; and 5) less $\mathrm{N}$ fertiliser, partially replaced by nitrification inhibitors and a plant growth stimulator. The cow model in WFM predicts $\mathrm{CH}_{4}$ emissions on a daily basis from each individual cow on the farm, including replacements, but $\mathrm{N}_{2} \mathrm{O}$ emissions are currently not predicted. WFM results showed that an "average" NZ dairy farm has the potential to increase MS production by up to 14\% (from 1050 to $1200 \mathrm{~kg}$ $\mathrm{MS} / \mathrm{ha}$ per year) by implementing different variations of the above strategies. Modelling the same scenarios through Overseer showed that total GHG emissions could be reduced from a baseline $12 \mathrm{~kg} \mathrm{CO}$-eq/ $\mathrm{kg} \mathrm{MS}$ to between 8.5 and $9 \mathrm{~kg} \mathrm{CO}$-eq/ $\mathrm{kg} \mathrm{MS}$ in the improved systems. Animal $\mathrm{CH}_{4} / \mathrm{kg} \mathrm{MS}$ can be reduced by $20 \%$ (Overseer ${ }^{\circ}$ ) or $22 \%$ (WFM). WFM predictions of animal $\mathrm{CH}_{4} /$ ha per year were $15 \%$ higher compared with Overseer, but followed the same trend across the different farm systems. It is encouraging that a widely-used inventory tool (Overseer ${ }^{\circ}$ ) predicts the right trend for methane mitigation strategies. WFM predictions of daily $\mathrm{CH}_{4}$ emissions varied from 19 to $26 \mathrm{~g} \mathrm{CH}_{4} / \mathrm{kg}$ DM eaten over the year. 


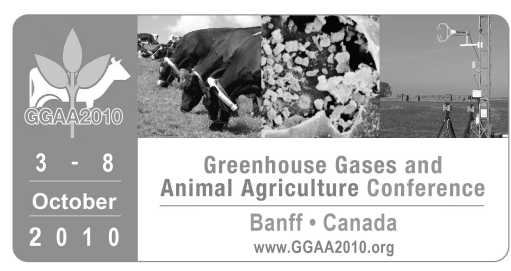

\section{R36. A comparative analysis of greenhouse gas emissions from agricultural enterprises in southeastern Australia}

N. A. Browne*, R. J. Eckard*, R. Behrendt and R. S. Kingwell

Agriculture in Australia contributes $16 \%$ of national greenhouse gas emissions, with enteric methane and nitrous oxide contributing 10.4 and $2.8 \%$ of national emissions, respectively. Understanding the relative emissions from different agricultural land uses and emissions per unit product is important, especially if agriculture is to face an emissions constrained future. Using the National Inventory methodology, whole-farm greenhouse gas emissions were calculated for different farm types in south eastern Australia. Sixteen case studies were examined that included Merino fine wool, prime lamb, cow/calf, steer, dairy, wheat and canola systems, with each represented firstly as an average farm and then as a top-producing farm. The aim was to develop a baseline of emissions produced by these enterprises and to examine farm emissions in relation to the amount of produce such as wool, meat, milk solids or grains. Biophysical models GrassGro and DairyMod were used to simulate the livestock systems and the models' outputs were then fed into an emissions calculator. This calculator used a yearly time frame and employed the International Panel on Climate Change methodology, as currently used in the Australian inventory. The calculator included $\mathrm{CH}_{4}$ and $\mathrm{N}_{2} \mathrm{O}$ on-farm emissions but excluded energy and transport emissions, which are not defined as agricultural emissions in the National Inventory. The dairy farms produced the highest emissions per hectare $\left(6.3-7.6 \mathrm{t} \mathrm{CO}_{2}\right.$-e ha $\left.{ }^{-1}\right)$, followed by beef (3.4-5.2 $\mathrm{t} \mathrm{CO}_{2}$-e ha $\left.{ }^{-1}\right)$, sheep (2.8-4.3 $\left.\mathrm{t} \mathrm{CO}_{2}-\mathrm{e} \mathrm{h}{ }^{-1}\right)$ and lastly grains $\left(0.2 \mathrm{t} \mathrm{CO}_{2}\right.$-e ha $\left.{ }^{-1}\right)$. When compared on an emissions intensity basis, wool emitted the most of all enterprises (61.7-64.8 $\mathrm{t} \mathrm{CO}_{2}$-e $\mathrm{t}^{-1}$ clean fleece) then cow/calf (31.1-33.0 t CO - e $\mathrm{t}^{-1}$ carcase weight), prime lamb (17.1-18.8 $\mathrm{t} \mathrm{CO}_{2}$-e $\mathrm{t}^{-1}$ carcase weight) dairy (9.3-10 $\mathrm{t}$ $\mathrm{CO}_{2}$-e $\mathrm{t}^{-1}$ milk solids) steers (6.2-6.7 $\mathrm{t} \mathrm{CO}_{2}$-e $\mathrm{t}^{-1}$ carcase weight) and finally grains $\left(0.03-0.11 \mathrm{t} \mathrm{CO}_{2}\right.$-e $\mathrm{t}^{-1}$ grain). The emissions intensities of top farms were not always less than average farms. Further research is required to define an equitable way of comparing emissions on an intensity and area basis between different farm types, as well as addressing the financial implications of an imposed carbon cost. Such a cost will alter the relative profitability of different production systems and thereby potentially affect future land use.

\section{R37. Comparing the environmental impact of the US beef industry in 1977 to 2007}

\section{J. L. Capper*}

Historical livestock production is commonly perceived to be inherently more environmentally sustainable than modern agricultural practices. This study modeled the environmental impact of the 1977 US beef industry, which produced 10.6 billion kg beef from 38.7 million head slaughtered, compared to that of 2007 (11.9 billion $\mathrm{kg}$ beef produced by 33.7 million head). The deterministic environmental impact model integrated resource inputs and waste outputs from animal nutrition and metabolism, herd population dynamics and cropping parameters using a modified life cycle assessment approach. Rations were formulated according to a scientifically and commercially-accepted animal nutrition model (AMTS Cattle.Pro) for growing animals (steers, heifers) and the supporting population (cows, bulls, herd replacements) according to production level (growth, pregnancy, lactation) at breed-appropriate bodyweights. System boundaries extended from the cow-calf operation to arrival at the slaughter plant, thus all operations and transport within these limits were included. Resource inputs included feedstuffs, water, land, fertilizers and fossil fuels. Waste outputs included manure and greenhouse gas emissions. The total animal population required to produce one billion $\mathrm{kg}$ of beef in 2007 was reduced by $31 \%$ compared to 1977 . This difference was conferred both by improved supporting population productivity over the time period and by dairy calves entering the beef production chain to be finished as slaughter animals, thus reducing the number of support animals required. A combination of the decrease in 


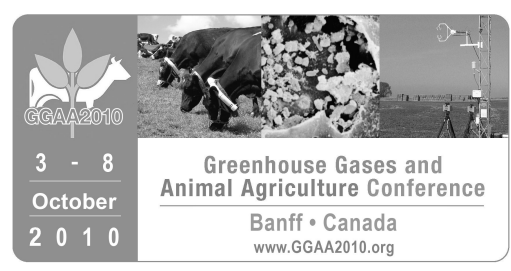

population size and improved productive efficiency between 1977 and 2007 conferred reductions in total feed energy and feedstuff use of 10 and 20\%, respectively. Total land area (pasture/rangeland and cropland) required to support beef production was reduced by $30 \%$. Water use per billion $\mathrm{kg}$ beef was reduced by $14 \%$ between 1977 and 2007. Compared to the 1977 beef industry, fossil fuel energy for beef production was reduced by $9 \%$ per unit in 2007. Methane and nitrous oxide emissions per billion kg beef produced in 2007 were reduced by 21 and $13 \%$, respectively. The total carbon footprint (expressed as $\mathrm{CO}_{2}$-equivalents per billion $\mathrm{kg}$ beef) was therefore reduced by $18 \%$ in 2007 compared with 1977. This analysis clearly demonstrates that advances in US beef industry productivity conferred by improvements in slaughter weight, growth rate, nutrition and management have considerably reduced the environmental impact of modern beef production, thus improving the sustainability of livestock production.

\section{R38. The environmental impact of conventional, natural and grass-fed beef production systems}

\section{J. L. Capper*}

Improving productivity demonstrably reduces the environmental impact of animal agriculture; yet extensive beef production systems are often cited as being more environmentally sustainable than conventional systems. This study modeled the environmental impact of three beef production systems: conventional (feedlot finishing system with $100 \%$ adoption of growth-enhancing technologies); natural (feedlot finishing system without growth-enhancing technologies); and grass-fed (all animals fed on a 100\% forage diet from birth to slaughter). Growth-enhancing technologies included ionophores, hormone implants, in-feed hormones and beta-agonists. The deterministic model integrated resource inputs and waste outputs from animal nutrition and metabolism, herd population dynamics and cropping parameters using a modified life cycle assessment approach with a functional unit of $363 \mathrm{~kg}$ beef carcass. Rations were formulated using a commercially-accepted animal nutrition model (AMTS Cattle.Pro) for growing animals (steers, heifers) and the supporting population (cows, bulls and herd replacements) according to bodyweight and production (growth, pregnancy and lactation). Animals were slaughtered after equivalent days on feed or once an appropriate slaughter weight was reached. System boundaries extended from the cow-calf operation to arrival at the slaughter plant, thus all operations and transport within these limits were included. Improved productivity within the conventional system resulted in a total of 4.07 animals (growing animals plus supporting population) required to produce one $363 \mathrm{~kg}$ carcass, compared to 4.56 animals in the natural system and 6.11 animals in the grass-fed system. A combination of the decrease in population size and improved productivity conferred by growth-enhancing technology use reduced total feedstuff use per $363 \mathrm{~kg}$ carcass in the conventional system by 1.58 metric $\mathrm{t}$ compared to natural beef production, and by 6.58 metric $t$ compared to grass-fed beef production. Total land area required per $363 \mathrm{~kg}$ carcass was lowest in the conventional system (1.95 ha), intermediate in the natural system ( $2.37 \mathrm{ha})$ and highest in the grass-fed system ( $3.58 \mathrm{ha})$. The conventional system used the equivalent of 0.44 US households' supply of water per carcass $(166,676 \mathrm{~L})$, while the natural and grass-fed systems used the equivalents of 0.51 and 1.85 US households' water supply. The carbon footprint of the conventional system was $11,248 \mathrm{~kg} \mathrm{CO}$-equivalents per carcass, equivalent to annual emissions from 2.22 average US cars, compared to 2.55 cars (natural system) and 3.80 cars (grass-fed system). The analysis clearly demonstrates that improved productivity conferred by growth-enhancing technology within intensive production systems considerably reduces natural resource use and the environmental impact of US beef production. 


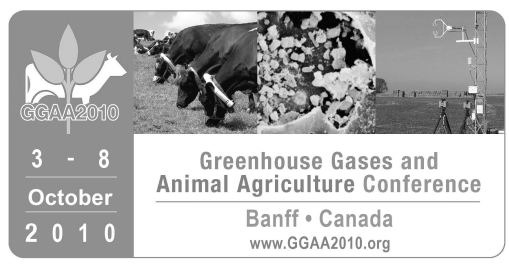

\section{R39. A point-in-time comparison of the environmental impact of Jersey vs. Holstein milk production J. L. Capper* and R. A. Cady*}

Improving productivity (milk yield per cow) reduces resource use and the environmental impact of dairy production, yet the interplay between milk yield, bodyweight and milk nutrient density has not previously been explored. This study investigated the environmental impact of producing 500,000 MT of cheddar cheese using either Jersey or Holstein cow populations. The model used 2009 DRMS DairyMetrics population data for milk yield and composition (Jersey: $20.9 \mathrm{~kg} \mathrm{~d}^{-1}, 4.8 \%$ fat, 3.7\% protein; Holstein: $29.1 \mathrm{~kg} \mathrm{~d}^{-1}, 3.8 \%$ fat, 3.1\% protein), age at first calving, calving interval, and culling rate. Each population contained lactating and dry cows, bulls and herd replacements for which rations were formulated according to AMTS Dairy.Pro at breed-appropriate bodyweights, with mature cows weighing $454 \mathrm{~kg}$ (Jersey) or $680 \mathrm{~kg}$ (Holstein). Resource inputs included feedstuffs, water, land, fertilizers and fossil fuels. Waste outputs included manure and greenhouse gas emissions. Cheese yield (kg) was calculated according to Van Slyke (1949). Production of 500,000 MT of cheese required 4.94 billion $\mathrm{kg}$ of Holstein milk compared to 3.98 billion $\mathrm{kg}$ of Jersey milk - a direct consequence of differences in milk nutrient density (fat and protein content) between the two populations. However, the reduced daily milk yield of Jersey cows increased the population size required to supply sufficient milk for cheese production by $9.3 \%$. The potential magnitude of the difference in population size was somewhat mitigated by the earlier age at first calving and shorter calving interval of Jersey cows. The differential in body weight between the Jersey and Holstein breed reduced the body mass of the Jersey population by $26 \%$. In consequence, population maintenance energy was reduced by $22 \%$, water use by $32 \%$ and cropland use by $11 \%$ per unit of cheese. Fossil fuel use was reduced by $18 \%$ per unit of cheese made using milk from the Jersey population. Methane and nitrous oxide emissions associated with cheese produced by the Jersey population were reduced by 22 and $9 \%$, respectively. The carbon footprint (total $\mathrm{CO}_{2}$-equivalents) was reduced by $20 \%$ per unit of cheese in Jerseys compared to Holsteins. It is clear that the interaction between milk nutrient density and body weight demonstrated by the Jersey population overcomes the reduced daily milk yield, thus reducing resource use and environmental impact. This reduction is achieved through two mechanisms: diluting population maintenance overhead through improved milk nutrient density; and reducing maintenance overhead through a reduction in productive and non-productive body mass within the population.

\section{R40. Prediction of ruminal methane of lactating dairy cows based on milk odd and branched chain fatty acids (OBCFA) profiles \\ J. Castro Montoya, A. Bhagwat, N. Peiren*, S. De Campeneere, B. De Baets and V. Fievez}

The IPCC guidelines for national greenhouse gases inventories suggests three approaches for the estimation of methane from livestock: Tier 1, based on default emission factors and Tier 2, based on more specific information of the whole production system; furthermore a method Tier 3, based on additional countryspecific information, is suggested for countries for which livestock emissions are particularly important. In addition, other models based mostly on feed composition have been proposed for estimating methane emissions from the farm. Molar rumen methane production also could be linked stoichiometrically to the molar production of rumen short-chain fatty acids (SCFA). Assuming a recovery of $90 \%$ of the metabolic hydrogen produced during fermentation of carbohydrates to pyruvate and acetyl CoA through the production of propionate, butyrate and methane, molar methane could be calculated as: $\mathrm{CH}_{4}=0.45^{*}$ Acetate $0.275 *$ Propionate $+0.4 *$ Butyrate [1]. Reliable rumen methane assessment is of utmost importance in evaluating mitigation strategies because their efficacy is often variable and dependent upon diverse factors e.g., basal diet and type of additive. Hence, on-farm methane estimation under practical conditions will be 


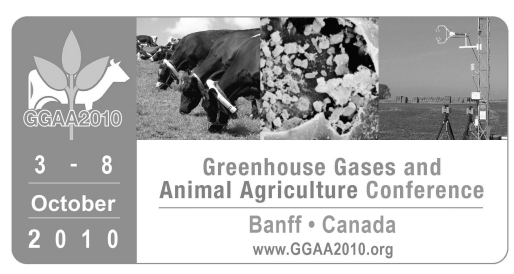

required to evaluate and compare those strategies accurately. As it has been shown that milk parameters reflect some information on the fermentation pattern of cows, milk could be the most feasible sample to link with methane production. For that reason, this study focuses on milk odd- and branched-chain fatty acids (OBCFA), which originate mainly from the rumen microbial membrane. Research at our laboratory showed the usefulness of OBCFA for predicting rumen acetate and propionate proportions. Multiple linear regression, partial least square and genetic algorithms were used for modelling purposes. The aim of the current experiment was to develop a model following the same approach, with methane calculated from average daily rumen acetate, propionate and butyrate proportions (Equation 1) measured in 44 fistulated cows fed on 26 different diets in 13 trials, which resulted in 224 coupled SCFA proportions and milk fatty acid (MFA) profiles. Modelling is currently ongoing and results will be compared with multiple linear regression developed by Vlaeminck et al. (2005). Although no direct methane measurements are available yet, the current experiment could give an idea of the usefulness of genetic algorithms for modelling methane as well as give some indication of the key MFA linked to rumen methane.

\section{R41. DGAS: Software for modeling and managing greenhouse gas emissions for Australian dairy farms \\ K. M. Christie*, R.P. Rawnsley*, R. Kildare and R.J. Eckard*}

The Dairy Greenhouse gas Abatement Strategy (DGAS) software was developed to model the carbon dioxide, methane and nitrous oxide emissions associated with dairying in Australia, using standard national inventory methods, algorithms and emission factors (DCC, 2008a). The user interface of the software includes two data entry pages; the farm and the herd. The farm data includes farm size, proportion of area rain-fed and irrigated, location, rainfall, tree plantings, manure management system, electricity, diesel, fertiliser and purchased feed inputs. The herd data includes milk production data and five livestock classes including animal numbers, liveweight and weight gain and dietary composition. The diet for the milking herd allows for seasonal variation, whereas the diets of other livestock classes are on an annual basis. The results are expressed as total farm greenhouse gas (GHG) emissions, broken down into four sub-totals (pre-farm embedded, carbon dioxide, methane and nitrous oxide). The results are also available as a comparative bar chart showing the 10 contributing sources of GHG emissions in addition to the potential sequestration of GHG emissions in tree plantings, expressed as tonnes of carbon dioxide equivalents per tonne of milksolids. Once the data have been entered for the farm, they can be copied to a hypothetical scenario, allowing users to compare the hypothetical farm or 'strategy' against the existing (baseline) farm, allowing for a range of potential abatement strategies to be explored. Comparative analysis between the existing farm and the hypothetical farm are presented on the results page. Should dairy GHG emissions be included as a liability or offset as part of a future emission reduction policy, two economics pages are included (baseline and hypothetical farm) to assess potential influences on farm income. The software requires very little data storage and as such has been developed using MS Excel. User forms provide a simple user-interface while the data storage and scenarios are stored in worksheets. DGAS analysis of 60 Tasmanian dairy farms found that on average 0.56 and 0.21 of total farm GHG emissions came from methane and nitrous oxide, respectively. Pre-farm embedded emissions and fuel and electricity emissions both accounted for 0.11 of total farm emissions (Christie et al., 2010). An assessment of the adoption of two GHG abatement strategies on the on-farm GHG emissions and emissions intensity of 60 Tasmanian dairy farms were explored using the functionalities of DGAS. 


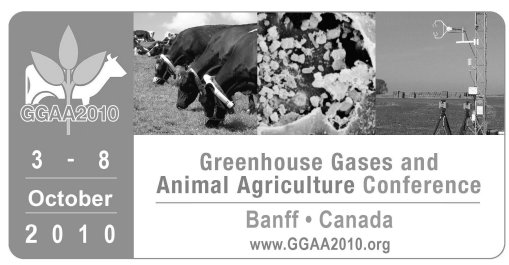

R42. A whole farm systems analysis of the greenhouse gas emissions of 60 Tasmanian dairy farms K. M. Christie*, R.P. Rawnsley* and R.J. Eckard*

The Australian dairy industry contributes approximately 0.02 of the nation's greenhouse gas (GHG) emissions, emitting an estimated 8.9 million tonnes of carbon dioxide equivalents per annum ( $\mathrm{CO}_{2} \mathrm{e} /$ annum; $\mathrm{DCC}, 2008$ ). This study examined the GHG emissions of 60 Tasmanian dairy farms using the Dairy Greenhouse gas Abatement Strategies calculator (DGAS), which incorporates the IPCC and Australian inventory methodologies, algorithms and emission factors (Christie et al., 2010). Sources of GHG emissions including the pre-farm embedded emissions associated with key farm inputs (grains/concentrates, fodder and fertilisers) and the onfarm emissions from carbon dioxide, methane and nitrous oxide were determined. The total farm GHG emissions ranged between 704 and 5,839 $\mathrm{t} \mathrm{CO}_{2} \mathrm{e}$ /annum, with a mean of 2,811 $\mathrm{t} \mathrm{CO}_{2} \mathrm{e}$ /annum. Dividing total farm emissions by annual milk production, milking herd size and farm area, the mean GHG emission intensities were $14.5 \mathrm{t} \mathrm{CO}_{2} \mathrm{e} / \mathrm{t}$ milksolids, $6.9 \mathrm{t} \mathrm{CO}_{2} \mathrm{e} / \mathrm{cow}$ and $12.6 \mathrm{t} \mathrm{CO}_{2} \mathrm{e} / \mathrm{ha}$. Linear regression analyses showed that 0.93 of the variation in total farm emissions could be explained by milk production (equation 1) while milking herd size (equation 2) and farm area (equation 3 ) were less indicative.

(1) Total emissions = Milksolids production*13.54 +151.69; $R^{2}=0.93$

(2) Total emissions $=$ Milking herd size $* 5.94+373.69 ; R^{2}=0.75$

(3) Total emissions $=$ Total farm area*7.68 $+993.90 ; R^{2}=0.41$

A stepwise multiple linear analysis showed that individual farm GHG emissions intensity could be explained using key farm indicators, expressed either on a per milksolids basis (equation 4), per cow basis (equation 5) or per hectare basis (equation 6):

(4) Milksolids intensity $\left(\mathrm{t} \mathrm{CO}_{2} \mathrm{e} / \mathrm{t}\right.$ milksolids $)=29.156+(-14.235 *$ feed conversion efficiency $)+(0.005 * \mathrm{~kg}$ nitrogen fertiliser/ha); $R^{2}=0.6$

(5) Cow intensity $\left(\mathrm{t} \mathrm{CO}_{2} \mathrm{e} / \mathrm{cow}\right)=-0.599+(1.228 *$ total dry matter intake $)+(0.002 * \mathrm{~kg}$ nitrogen fertiliser/ha); $R^{2}=0.87$

(6) Farm area intensity $\left(\mathrm{t} \mathrm{CO} \mathrm{CO}_{2} \mathrm{e} / \mathrm{ha}\right)=1.891+(0.011 * \mathrm{~kg}$ milksolids $/ \mathrm{ha})+(0.008 * \mathrm{~kg}$ nitrogen fertiliser/ha); $\mathrm{R}^{2}=0.94$

This study has shown that total GHG emissions of Tasmanian dairy farms can be accurately and most easily estimated by the farms total milk production. Feed conversion efficiency and nitrogen fertiliser inputs could explain 0.6 of the variation in the GHG emissions intensity of milk production for these pasture based dairy systems. This highlights these two factors as target areas for lowering the intensity of emissions associated with dairying in this environment.

\section{R43. Assessment of methane emissions from cattle as affected by different future scenarios in Argentina: A methodological proposal}

D. Colombatto*, M. del Rosario Moscoso and C.R. Feldkamp

Cattle production systems in Argentina are undergoing a transformation towards more intensive operations, with more participation of the feedlot articulated with the traditional grazing systems. This process will likely influence total beef production, but will also likely have different environmental impacts. It is well known that ruminant production systems can contribute substantially to total greenhouse gases emissions from agriculture, and among them, methane is one of the most important. The objective of the present work is to evaluate the methane emissions and beef production as affected by different future scenarios of the productive systems in Argentina. An assessment proposal is based on a simulation model that was developed 


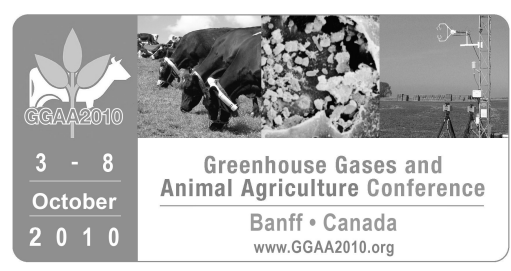

to study the impact of different future scenarios on the total beef production of the country. The model describes the national beef production through 64 "modal systems", assuming that each one of those represents a group of productive systems that have similar forage resources, produce the same type of animals and have similar management procedures. The aggregated production within each modal system is accomplished by simulating individual animals that represent homogeneous groups of animals, i.e., animals of similar age, live weight, breed and physiological status. Based on annual forage production curves, animal characteristics and management criteria, the dry matter, metabolizable energy and gross energy intake are estimated. Live weight, condition score, pregnancy, birth, death and/or sale are also simulated by the model on a dynamic fashion. The model was further modified to estimate the methane production, by assuming that the fraction of ingested gross energy lost as methane depends on the level of grain inclusion in the diet. Based on similar cow-calf systems, four different evolution scenarios of cattle finishing were simulated, using the 2010 situation as starting point ( $50 \%$ of the finished animals coming from feedlot): (1) Fattening on pastures, with supplementation with grain to animals weighing more than $420 \mathrm{~kg}$ live-weight at slaughter, and feedlot for animals from 320 to $400 \mathrm{~kg}$ live weight at slaughter; (2) an increase in the percentage of finished animals coming from feedlots (up to 80\%); (3) a decrease in the percentage of animals finished on feedlots (10\%); (4) an increase in the participation of the feedlot, but with increased live weights at slaughter (420-440 kg), including an additional backgrounding period at pasture.

\section{R44. Estimation of methane emissions by dairy cows on the basis of milk composition}

C. Delfosse*, E. Froidmont*, J. A. Fernández Pierna, C. Martin and F. Dehareng

The aim of this study was to estimate the relationship between dairy cows' methane $\left(\mathrm{CH}_{4}\right)$ emissions and their milk composition. The study was conducted using 8 lactating Holstein-Friesian cows in a replicated $2 \times 2$ Latin square design. In order to induce $\mathrm{CH}_{4}$ emission variation, two iso-DM and iso-NE diets, based on fresh grass and sugar beet pulp or maize silage and hay, were offered to animals. These diets were formulated for a daily production of $20 \mathrm{~L}$ milk/day and to target similar milk production among the groups. Each experimental period lasted 4 weeks. Milk fat from individual milk samples was extracted and analyzed by gas chromatography. Chromatographic data were expressed as fatty acid concentrations in milk fat ( $\mathrm{g} / 100 \mathrm{~g}$ of fat). Milk samples were also analyzed for $\mathrm{pH}$ and urea, lactose, protein, fat and $\mathrm{DM}$ contents. Individual $\mathrm{CH}_{4}$ emissions were measured daily over 7 consecutive days, using the $\mathrm{SF}_{6}$ methodology and, for each milking, was expressed proportionally to the amount of milk produced. The methane emission showed a wide range of variation. A multivariate calibration equation was built using the Partial Least Squares (PLS) method. This analysis allowed the establishment of a relationship between the methane emitted and the milk composition with a decent fit and error: $R^{2}=0.70, R M S E=61.78$. These results reflect the impact of rumen fermentation on both variables investigated: methane production and milk composition. The multivariate analysis revealed urea, C14:0, C16:0, C18:0 and C18:1-cis9 as the most important variables related to methane production. Further studies are necessary to confirm the results and increase the precision of determination of the coefficients. 


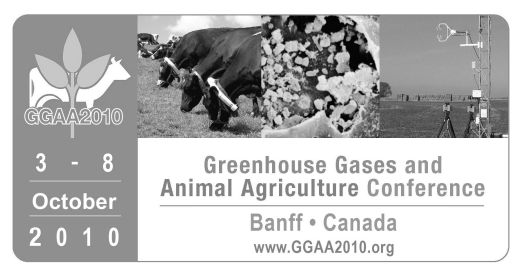

R45. Relationships of milk fatty acid profile with methane productionin dairy cattle

J. Dijkstra*, J. A. Apajalahti, A. Bannink*, W. J. J. Gerrits, J. R. Newbold*, H. B. Perdok*, S. M. van Zijderveld* and $\mathrm{H}$. Berends

The development of simple indicators to quantify methane production in cattle is of interest, both for research and for practical purposes on-farm. The profile of milk fatty acids (FA) may be related to methane production, given that diet composition affects rumen microbial metabolism and methanogenesis, as well as the supply of preformed FA and FA precursors to the mammary gland. The aim of this experiment was to evaluate the relationship of milk FA profile with methane production in dairy cattle. Data from three experiments with dairy cattle, encompassing 10 dietary treatments and 50 observations, were used. Dietary treatments included supplementation with calcium fumarate, diallyldisulfide, caprylic acid, capric acid, lauric acid, myristic acid, extruded linseed, linseed oil, and yucca powder. Methane was measured using open-circuit indirect respiration calorimetry chambers and expressed as g per $\mathrm{kg}$ dry matter intake (DMI). After extraction and methylation, milk FA were analyzed by gas chromatography and individual FA expressed as $\%$ of total FA. To determine the relationship between milk FA profile and methane production, mixed model regression techniques (PROC MIXED of SAS) were applied including a random experiment effect. A multivariate model was developed using a stepwise procedure (PROC GLMSELECT of SAS) with selection of FA based on the Schwarz Bayesian Information Criterion. Observations were weighted by the $\mathrm{n}$ of the experiment. Dry matter intake was $17.7 \pm 1.83 \mathrm{~kg} / \mathrm{d}$, milk production was $27.0 \pm 4.64 \mathrm{~kg} / \mathrm{d}$, and methane production was $376 \pm 55.7 \mathrm{~g} / \mathrm{d}$ (values expressed as means \pm $\mathrm{SD})$. Milk C10:0, C11:0, C14:0iso, C15:0iso, and C16:0 were positively related $(P<0.05)$ to methane $(\mathrm{g} / \mathrm{kg} \mathrm{DMI})$, whereas C17:0iso, C17:0anteiso, cis-9 C17:1, cis-9 C18:1, trans-10+11 C18:1, cis-11 C18:1, cis-12 C18:1 and trans-16+cis-14 C18:1 were negatively related $(P<0.05)$ to methane production. Multivariate analysis resulted in the equation (random experiment effect not presented): methane $=25.5 \pm 1.40+0.302 \pm 0.1123 \times \mathrm{C} 18: 0-$ $10.2 \pm 1.50 \times$ cis-11 C18:1 - 2.50 $\pm 0.441 \times$ trans $-10+11 C 18: 1\left(R^{2}=0.684\right.$ after correction for experiment effect; parameters significant at $P<0.02$ ). The present analysis confirmed the expected positive relationship between methane and C14:0iso and C15:0iso in milk FA, as well as the negative relationship between methane and various trans-intermediates, in particular trans-10+11 C18:1. In contrast with theoretical considerations, C15:0 and C17:0 were not related with methane production. More data, especially with diets that differ in forage quality and forage to concentrate proportion, are needed to confirm relationships between milk FA profile and methane production.

\section{R46. Impacts of future climate scenarios on nitrous oxide emissions from pasture-based dairy systems in south eastern Australia}

R. Eckard* and B. Cullen*

Nitrous oxide $\left(\mathrm{N}_{2} \mathrm{O}\right)$ emissions account for c. $10 \%$ of global GHG emissions, with the vast majority of these emissions (c. 90\%) derived from agriculture. The dairy industry in south eastern Australia is largely pasturebased relying on legumes, $\mathrm{N}$ fertiliser, imported feeds and effluent for adequate $\mathrm{N}$ nutrition of pastures. Total pasture $\mathrm{N}$ inputs can be in excess of $300 \mathrm{~kg} \mathrm{~N} \mathrm{ha}^{-1} \mathrm{yr}^{-1}$, with N surpluses $>200 \mathrm{~kg} \mathrm{~N} \mathrm{ha}^{-1} \mathrm{yr}^{-1}$, resulting in high emissions of $\mathrm{N}_{2} \mathrm{O}$. Climate change scenarios for south eastern Australia suggest increasing temperatures, declining rainfall and longer dry summer seasons, raising the question of the potential impact of future climate change scenarios on $\mathrm{N}_{2} \mathrm{O}$ emissions. The effect of four future climate change scenarios (measured baseline of 1971-2000, A1FI 2030 high emission scenario and 2070 mid (A1B) and high (A1FI) emission scenario) on $\mathrm{N}_{2} \mathrm{O}$ emissions were modelled, for four differing soil types, climates and systems (Elliott, Terang, Ellinbank and 


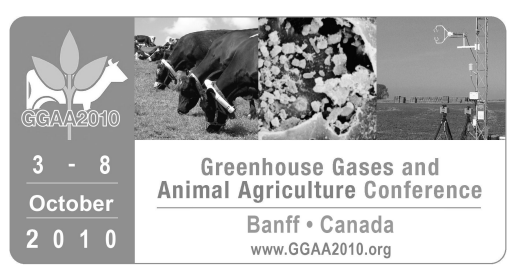

Kyabram) using DairyMod, a biophysical, mechanistic daily time-step, whole farm systems model. The model simulated a single heterogeneous grazed paddock to capture the dynamics of urine patches on $\mathrm{N}$ transformation in the soil. Urinary $\mathrm{N}$ was returned to $2 \%$ of the paddock area at each grazing, with the urine 'patch' moving sequentially around the paddock area, effectively covering $25 \%$ of the paddock area per year. The patterns of soil $\mathrm{NO}_{3}-\mathrm{N}$ and $\mathrm{N}_{2} \mathrm{O}$ emissions were dominated by the temporal variation in urine return, with soil $\mathrm{NO}_{3}-\mathrm{N}$ within a urine patch returning to pre-application levels within 12 months. Annual $\mathrm{N}_{2} \mathrm{O}$ emissions increased into the future projected climates at all sites except Elliott, where $\mathrm{N}_{2} \mathrm{O}$ emissions remained low due to a well drained soil. At Ellinbank, Terang and Kyabram the model showed an increase in number of days with soil water filed pore space (WFPS) of 60-80\% during the wetter colder months and less days with WFPS 60$80 \%$ during the drier, warmer months. Warmer soil temperatures, coupled with wet but less saturated soils, resulted in an increase opportunity for $\mathrm{N}_{2} \mathrm{O}$ production during the cooler months, while the potential for $\mathrm{N}_{2} \mathrm{O}$ production during the warmer months remained low. Emission factors (percentage of $\mathrm{N}$ inputs lost as $\mathrm{N}_{2} \mathrm{O}$ ) changed with a changing climate, emphasising the need for a more dynamic, mechanistic modelling approach in greenhouse gas inventories. The likelihood of increased $\mathrm{N}_{2} \mathrm{O}$ emissions from pasture-based dairy systems with the progression of climate change emphasises the need for targeted $\mathrm{N}_{2} \mathrm{O}$ abatement options.

\section{R47. A dairy goat dynamic simulation model to predict methane output \\ C. Fernández*, F. J. Espinós, M. C. López and E. Blas}

Ruminants may contribute to global warming through the release of methane $\left(\mathrm{CH}_{4}\right)$ gas by enteric fermentation. Most $\mathrm{CH}_{4}$ emissions from ruminants were estimated using simple regression equations. A dairy goat dynamic simulation model to predict methane output was constructed by using a computer-aided simulation via object-oriented modeling. The model was structured into three units; body weight, dry matter intake and milk yield. The model was developed for mixed ration and a group of 12 goats and 4 mixed diets were used to obtain some experimental inputs to the model construction. Twenty four goats in lactation were used to validate the model. Calorimetry system based on open circuit respiration mask was used for respiratory gas measurements. The average in vivo $\mathrm{CH}_{4}$ conversion rates obtained, as a percentage of gross energy intakes $(\mathrm{Ym})$, were $4.6 \%$ and $5.2 \%$ for the group of goats used to develop the model and the group of validation, respectively. The dynamic simulation model estimates $\mathrm{Ym}$ as an average value of $4.3 \%$. Based in our simulation for mixed diets, using IPCC (Intergovernmental Panel for Climate Change) values ( $\mathrm{Ym}=6.5$ ) can result in an overestimate for dairy goats.

\section{R48. Uncertainties and variation in carbon footprint for milk production in Sweden estimated by Monte Carlo simulation}

M. Henriksson*, A. Flysjö, C. Cederberg and J.E. Englund

Carbon Footprint (CF) for average Swedish milk ex farm gate (i.e. high yielding, mainly indoor production system with approx $50 \%$ concentrate feed in the diet) have here been examined in order to find; 1) the activities that most contribute to greenhouse gas (GHG) emissions in the milk production chain, 2) the impact of uncertainties in the emission factors (EF) used in CF calculations and 3) the impact of the variations in management practices and milk yield between individual farms. The basis of the study is a GHG emission estimate for the average Swedish milk production of 2005, performed following the ISO standards for Life Cycle Assessments. The impact of the uncertainty in EFs were analyzed with a Monte Carlo simulation using standard 


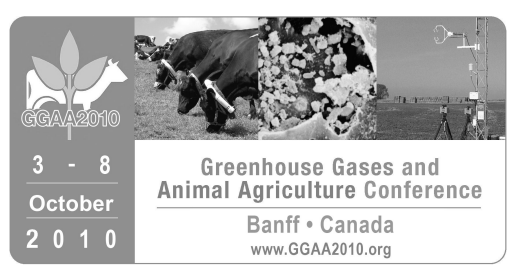

deviations for those EFs used in the calculations of $\mathrm{CH}_{4}$ from enteric fermentation, direct emissions of $\mathrm{N}_{2} \mathrm{O}$ from soil and indirect emissions of $\mathrm{N}_{2} \mathrm{O}$ from ammonia. Monte Carlo simulation was also used to estimate impact of the variation in milk yield, feed intake, $\mathrm{N}$-fertilizers and diesel on CF due to differences between farms. Standard deviations for these parameters were received from three different sources containing 1050 dairy farms for activity data concerting cows, e.g. milk yield and feed intake, 920 dairy farms for $\mathrm{N}$-fertilizer use and 46 dairy farms for diesel consumption on farm. In order of importance, $\mathrm{CH}_{4}$ from enteric fermentation, $\mathrm{N}_{2} \mathrm{O}$ direct from soil due to application of excreta, fertilizer and crop residues, $\mathrm{CO}_{2}$ from diesel used on farms, $\mathrm{N}_{2} \mathrm{O}$ and then $\mathrm{CO}_{2}$ from fertilizer production constituted to $85 \%$ of the total CF. Activity data that influence these emissions are feed intake, $\mathrm{N}$ in excreta, $\mathrm{N}$ fertilizer and diesel used. These parameters as well as milk yield showed large variations between farms, especially $\mathrm{N}$-fertilizers and diesel use. The impact of variations gave a total variation in $\mathrm{CF}\left(\mathrm{kg} \mathrm{CO}_{2}\right.$ eqivalent $\mathrm{kg}$ energy corrected milk $^{-1}$ ) that constituted $50 \%$ of the mean $\mathrm{CF}$. When uncertainties in the EFs were considered, the CF of milk varied in a range that constituted to more than $60 \%$ of the mean CF. The CF of milk is encumbered with large uncertainties due to insufficient knowledge to calculate emissions with high precision from the biological processes in milk production. Large variations among CF of individual farms can be expected due to differences in activity data. This variation reveals the potential to reduce GHG emission on both the farm and national level.

\section{R49. Feeding strategies play a key role for greenhouse gas emissions from Swedish dairy production M. Henriksson* and C. Swensson*}

The use and production of feed play a major role for greenhouse gas (GHG) emissions from milk production. In a previous study $1 / 3$ of the total GHG emissions from milk produced in Sweden were associated with feed production. The same study also stated that approximately $87 \%$ of the total GHG emissions were accounted for by considering only the production parameters milk yield, feed consumption, feed production (including fertilizer production), manure management and feed transportation. There is a large variation in feeding strategy among dairy farms in Sweden, which to some extent are due to the location. Swedish dairy farms are located between latitudes 550 and 68을 and in the northern part mainly grass and clover can be grown since the climate is not suitable for grain or protein crops. The aim with this study is to evaluate the impact of the composition of the feeding plan on the total GHG emissions per kg milk, when different feed components are used. The hypothesis is that milk from a dairy herd with a large share of home grown feed has a lower output of GHG emissions than milk produced on imported protein feed. The new software tool called Norfor, used in the Nordic countries for individual dairy cow diets, have been used to create a number of possible feeding plans for dairy farms located in diverse part of Sweden. Based on the content of nutrients in each feeding plan, methane from enteric fermentation is estimated in Norfor. Norfor also calculates nitrogen efficiency and content of nitrogen in excreta and urine. To estimate GHG emissions from the production of feed, a Swedish LCA-database for conventional feed components have been used. To balance the use of nitrogen fertilizer according to what is used for the various feed components in the LCA-feed database, nitrogen in excreta are considered for each feeding plan. Direct and indirect nitrous oxide emission from manure management is also calculated and taken into account as well as transports from feed industry. Presenting results will show the consequence of various feeding strategies in figures of GHG emissions per kg milk as well as the economical consequences expressed as daily or yearly feed costs. This will give important information for agriculture advisors, dairies and farmers in the aspect of reducing the impact of GHG from milk production in Sweden. 


\section{R50. Prediction of methane production from dairy cattle}

F. Hippenstiel*, M. Pries, W. Büscher* and K.-H. Südekum*

Techniques that allow direct measurements on animals to quantify methane emissions are costly and difficult to transfer to herd level. Mathematical approaches have been developed to predict methane emissions of cattle based on diet and intake characteristics which were calibrated against largely varying calorimetry data. In this study several methane prediction equations were applied to three typical Central European dairy cow diets in order to compare their applicability. The three diets differed with respect to forage proportion and type: Diet 1 consisted mainly of grass silage; Diet 2 was a mix of grass and maize silages; whereas Diet 3 comprised a maize silage-based diet. In a first attempt regression equations were selected containing easily accessible data such as dry matter intake (DMI, $\mathrm{kg} \mathrm{d}^{-1}$ ) and forage proportion (forage $\mathrm{DMI} \mathrm{DMl}{ }^{-1}$ ) that can be extracted also from on-farm datasets:

(1) Methane $\left(\mathrm{MJ} \mathrm{d}^{-1}\right)=8.56+0.14 \times$ forage $(\%)$

(2) Methane $\left(\mathrm{MJ} \mathrm{d}^{-1}\right)=3.23+0.81 \times \mathrm{DMI}$

(3) Methane $\left(\mathrm{MJ} \mathrm{d}^{-1}\right)=3.27+0.74 \times \mathrm{DMI}$

(Ellis et al., J Dairy Sci 2007, 90: 3456-3467)

(4) Methane $\left(\mathrm{kJ} \mathrm{kg}^{-1}\right.$ feed DM) $=1802-21.1 \times \mathrm{DMI}\left(\mathrm{g} \mathrm{kg}^{-1}\right.$ body weight)

(Jentsch et al.; Arch. Anim. Nutr. 2007, 61: 10-19)

(5) Methane $\left(\mathrm{MJ} \mathrm{d}^{-1}\right)=5.93+0.92 \times \mathrm{DMl}$ and

(6) Methane $\left(\mathrm{MJ} \mathrm{d}^{-1}\right)=1.06+10.27 \times$ forage proportion $+0.87 \times \mathrm{DMI}$

(Mills et al.; J. Anim. Sci. 2003, 81: 3141-3150)

Methane emissions ranged from 19.2 moles $\mathrm{d}^{-1}$ to 32.4 moles $\mathrm{d}^{-1}$ (Table 1). Differences between prediction equations were much greater than between diets within equation.

Table 1. Methane (moles/(cow $\times$ day))

Eq. Diet 1 Diet 2 Diet 3 Variables

(1) $22.1 \quad 19.2 \quad 22.6 \quad$ Forage

(2) $24.0 \quad 26.0 \quad 24.9 \quad \mathrm{DMI}$

(3) $22.3 \quad 24.2 \quad 23.1 \quad \mathrm{DMI}$

(4) $29.3 \quad 29.2 \quad 29.8 \quad \mathrm{DMI}$

(5) $30.1 \quad 32.4 \quad 31.1 \quad \mathrm{DMI}$

(6) $31.0 \quad 31.1 \quad 32.4 \quad$ Forage, DMI

SD (1-6) 3.744 .483 .92

SD (1-3) 0.862 .890 .97

SD (5-6) 0.450 .650 .68

Equations (1)-(3) yielded much lower methane values than equations (4)-(6). This may be due to differences in the databases the authors had used to generate the predictions and to differences in the calorimetry dataset. Utilizing equations with few but easily accessible data yielded largely differing methane emissions of cattle. Including other dietary variables in the prediction equations such as fibre fractions, starch, sugar and estimated nutrient digestibility may increase the precision of and consistency between models also on farm level. 


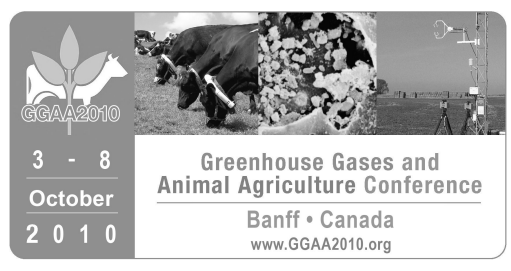

R51. Evaluation of enteric methane emissions from alternative cow-calf production systems

G. Legesse*, J. Small, S. Scott, E. Krebreab*, G. Crow, H. Block*, A. Alemu* and C. Robins

Beef cattle production in Canada contributes to the national pool of enteric methane emissions (EME). We used mechanistic and empirical models to determine the EME from alternative pasture and wintering feeding systems for cow-calf production in the Western Canadian Parkland. Animal performance and diet composition data were collected over five years (1998-2003) for different cow-calf production systems maintained with the herd at the Agriculture and Agri-Food Canada Research Centre, Brandon, MB, Canada. At turn-out (June), cowcalf pairs (288/yr including 72 primiparous heifers) grazed assigned summer pastures of either alfalfa-grass (AG) or grass (G) until weaning (September). Post-weaning (November) pregnant cows ( $n=240$ per yr) entered assigned winter systems of either extended-grazing (EG) of stockpiled forages and swathed crops, or one of three diets fed in a drylot (DL). Cows were given common diets between weaning and wintering, and precalving (from February until turn-out). The three diets in the DL were hay (HY), barley silage/oat straw (SS; 40:60, dry matter (DM) basis) and barley grain/oat straw (BS; 30:70 DM basis). Data were subjected to COWPOLL, MOLLY, IPCC Tier 2 and an empirical model (Ellis et al. 2009) to rank the different production systems according to the estimate of EME over $90 \mathrm{~d}$. The EME factors obtained from the mechanistic models (COWPOLL and MOLLY) varied from 5.66 to $8.62 \%$ of GEl, compared to a fixed EME factor for beef cows of $6.5 \%$ of Gross Energy Intake (GEI) recommended by IPCC. The EME estimated for AG and G were similar, although the AG had slightly higher values, because of a higher estimated feed intake. Rankings of EME by the mechanistic models, which took in detailed information on fibre, starch, $\mathrm{N}$ and volatile fatty acids, were the same for both feeding periods. The empirical model (based on the starch-to-ADF ratio and feed intake) determined lower volume of methane produced, but the ranking of feeding systems by EME was similar to results obtained from the mechanistic models. All the models except IPCC Tier 2 ranked the EME for winter systems from lowest to highest as SS, BS, EG and HY. The mechanistic models kept the same ranking when EME was calculated per kg of cow body weight maintained. The SS and BS diets were predicted to produce 3 to $36 \%$ less methane than the other diets. In conclusion, EME from cow-calf systems were lower when conserved feed for dry-pregnant cows contained barley silage or grain and straw rather than hay.

\title{
R52. Greenhouse gas emissions from integrated crop - beef finishing systems
}

\author{
E. J. Mc Geough*, P. Crosson*, D. A. Kenny and P. O'Kiely*
}

It is well established that significant amounts of greenhouse gases (GHG) are emitted from the processes involved in animal husbandry production systems. However, GHG mitigation strategies often focus on a single gas in isolation. Ultimately, it is essential that reducing emissions of one GHG does not result in increases in other GHG in different areas of the farm system. This study aimed to quantify the total GHG emissions associated with beef production systems utilizing maize and whole-crop wheat silages during the finishing phase and to rank these relative to grass silage and high concentrate-based finishing regimes. Furthermore, it aimed to identify farming systems which are most sustainable in terms of both GHG emissions and farm profit. A hybrid whole-farm systems modeling approach was taken in this study, encompassing a bioeconomic model and a GHG model. All on- and off-farm sources of methane, carbon dioxide and nitrous oxide were included in this analysis, with the GHG fluxes involved in land-use and land-use change also considered. Seven scenarios were modeled based on the inclusion of maize silages (MS) varying in harvest maturity (harvest date; 13 Sept and 23 Oct), whole-crop wheat silages (WCW) varying in grain content (11, 31 and 47\%), grass silage (GS) and ad libitum concentrates (ALC) in the diets of finishing beef cattle. Under the conditions of the present study, advancing maize maturity at harvest did not markedly increase total GHG emissions when expressed per 


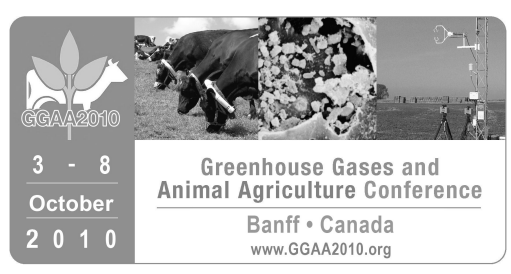

kilogram of beef carcass (17.62 vs. $17.79 \mathrm{~kg} \mathrm{CO} 2 \mathrm{e}$ ). Increasing the grain content of WCW silage reduced total GHG emissions (20.05, 18.25 and $16.45 \mathrm{~kg} \mathrm{CO}_{2} \mathrm{e} \mathrm{kg}^{-1}$ beef carcass, respectively); however, in general the WCW scenarios exhibited the higher GHG emissions and lower profitability overall. The total GHG emission per kilogram of beef carcass for ALC was $17.20 \mathrm{~kg} \mathrm{CO}_{2} \mathrm{e}$; however, the profitability of this scenario was lower than the MS and GS scenarios, thus limiting its attractiveness as a finishing option. Overall, GS exhibited the lowest GHG emissions per kilogram of beef carcass $\left(14.23 \mathrm{~kg} \mathrm{CO}_{2} \mathrm{e}\right)$ while providing the highest rate of financial return. Thus, it may be concluded that finishing beef cattle on grass silage-based diets may be most sustainable from a GHG and financial perspective.

\title{
R53. Regional inventory of methane and nitrous oxide emission from ruminant livestock in the Basque Country \\ P. Merino, E. Ramirez-Fanlo, H. Arriaga, M. V. Salazar*, O. Del Hierro, A. Artetxe and M. Pinto
}

Ruminant livestock systems contribute to global warming through the emission of methane $\left(\mathrm{CH}_{4}\right)$ and nitrous oxide $\left(\mathrm{N}_{2} \mathrm{O}\right)$. The quantification of greenhouse gas (GHG) emissions in Spain is reported annually in the National Emission Inventory. The objective of this study was to update the annual $\mathrm{CH}_{4}$ and $\mathrm{N}_{2} \mathrm{O}$ emissions by ruminant animals (dairy and beef cattle and dairy ewes) in the Basque Country (Northern Spain) according to the recommendations of IPCC 2006 (Tier 2) using farm management data of the region. Besides, a mathematical approach was used to assess the uncertainties of estimated emission factors (EFs). $\mathrm{CH}_{4} \mathrm{EF}$ from enteric fermentation averaged $107 \mathrm{~kg} \mathrm{CH}_{4}$ head ${ }^{-1}$ year ${ }^{-1}$ for dairy cattle for a mean milk yield of 7,870 kg milk head ${ }^{-1}$ year ${ }^{-1}$. The corresponding values for beef cows and dairy ewes were 60 and $8.4 \mathrm{~kg} \mathrm{CH}_{4}$ head $^{-1}$ year ${ }^{-1}$, respectively. Emission of $\mathrm{CH}_{4}$ from enteric fermentation accounted for $87 \%$ of total $\mathrm{CH}_{4}$ emission in ruminant production, with dairy and beef cattle being the main contributors. The contribution of beef cattle to enteric $\mathrm{CH}_{4}$ emission has turned important for the last few years, as many farmers have changed from dairy to beef cattle production. $\mathrm{CH}_{4} \mathrm{EF}$ (Tier 2) from manure management averaged 33.2, 2.0 and $0.3 \mathrm{~kg} \mathrm{CH}_{4}$ head $^{-1}$ year ${ }^{-1}$ for dairy cattle, beef cattle and dairy ewes, respectively. From 2005 onwards, many small dairy cow farms (<20 LU) have disappeared and manure management has turned mostly into liquid slurry, resulting therefore in higher $\mathrm{CH}_{4}$ emissions. EF of $\mathrm{N}_{2} \mathrm{O}$ from manure management was 1.0, 1.4 and $0.1 \mathrm{~kg} \mathrm{~N}_{2} \mathrm{O}$ head ${ }^{-1}$ year $^{-1}$ for dairy cattle, beef cattle and dairy ewes, respectively. EF values calculated as Tier 2 were higher than those from Tier 1 , except for dairy cattle's EF from enteric fermentation, since animals are mainly fed on concentrate high digestible diets, resulting in lower $\mathrm{CH}_{4}$ emissions. Improving livestock characterization, we obtained lower uncertainty for EFs calculated as Tier 2 than for default values from Tier 1. Emissions from manure management presented the largest uncertainty because of its high variability. The uncertainty of $\mathrm{N}_{2} \mathrm{O}$ EFs from manure management was higher than for enteric $\mathrm{CH}_{4} \mathrm{EFs}$, due to its high natural variability and poor knowledge of the phenomenon. The animal category with lowest uncertainty was dairy cattle, as more accurate data were available, due to be reared under intensified production systems.

\section{R54. Uruguayan Cattle GHG emissions: Modeling GHG emissions for different productive systems}

\author{
P. Modernel*, V. Picasso and L. Astigarraga
}

According to FAO report "Livestock's long shadow"; (2006) South America is one of the zones with most greenhouse gases (GHG) emissions generated from agriculture. Zooming in this continent, Brazil appears as the 


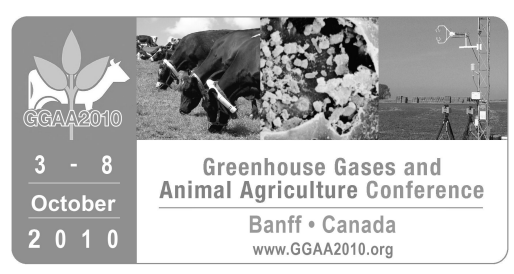

biggest contributor to GHG emissions from agriculture. The biggest proportion comes from the livestock sector, which is also the most important GHG emission in Uruguay (around 70\%). Livestock production is the most important activity in Uruguay in terms of occupied surface, number of farmers and country exports. Meat buyers (especially from EU) are concerned about emissions associated with meat production in Uruguay. In this regard, the country has started to calculate the carbon footprint on the livestock sector. In general, GHG emissions calculations do not take into account some differences among productive systems that would make a difference between Uruguay and his neighbours. For example, in Brazil there has been an increase land-use area for livestock production in the last 40 years. However, Uruguayan livestock has been producing meat based on native pastures for around 400 years which means that no natural ecosystems are being modified to make forage or grazing with the GHG emissions that this would cause. Another difference with the region is that cattle production is based on pastures and not on grains and supplements. Even though diets based on pasture have higher enteric fermentation emissions $\left(\mathrm{CH}_{4}\right)$ than diets with less fibre, they have less emissions generated from machinery for feed production $\left(\mathrm{CO}_{2}\right)$, fertilization $\left(\mathrm{N}_{2} \mathrm{O}\right.$ and $\left.\mathrm{CO}_{2}\right)$ and transport and feed distribution $\left(\mathrm{CO}_{2}\right)$. These make Uruguayan meat a different product for demanding markets that focus on environmental issues like the carbon footprint. This study evaluates different cattle fattening systems existing in Uruguay (feedlot vs. pasture) with a broad approach that includes: enteric fermentation $\left(\mathrm{CH}_{4}\right)$, manure management $\left(\mathrm{CH}_{4}\right.$ and $\left.\mathrm{N}_{2} \mathrm{O}\right)$, land-use area for livestock (for pastures and crops), on-farm operations and soils carbon fixation. Firstly, GHG emissions will be calculated using existing models with their associated emission factors; in a second stage a new model is developed with emission factors adapted to local livestock systems based on pastures.

\section{R55. Policy or the Environment? IPCC or LCA?}

\section{O'Brien, L. Shalloo, M. Wallace, F. Buckley, B. Horan and C. Grainger*}

The objective of this study was to compare two standard methodologies, Intergovernmental Panel on Climate Change (IPCC) method and life cycle analysis (LCA), for quantifying greenhouse gas (GHG) emissions from dairy farms. Both methods were applied to quantify the GHG emissions of dairy farms differing in strain of HolsteinFriesian cow and type of grass-based feed system. The strains of Holstein-Friesian cow used were; high milk production North American (HP), high fertility and survival (durability) North American (HD), and New Zealand (NZ). Three grass-based feed systems operated were; high grass allowance (HG, control); high stocking rate $(\mathrm{HS})$ and high concentrate supplementation $(\mathrm{HC})$. The dairy farms were modeled using an integrated economicGHG farm model. The model quantifies GHG emissions using the LCA approach and the IPCC method. The LCA approach was also used to distinguish direct (emissions on the farm site) from indirect (emissions from purchased inputs) GHG emissions. The study found that GHG emissions were always greater when calculated using the LCA method rather than the IPCC method and the ranking of dairy farms emissions per unit of product was not consistent under both methods. For example, the NZ strain achieved their lowest GHG emissions per unit of product in the HC system when the IPCC method was used. However, when the LCA approach was used their lowest emissions occurred in the HS system. The ranking was inconsistent because indirect emissions were included in the LCA approach. When indirect emissions were excluded from the LCA approach the ranking of emissions per unit of product was consistent. Both methods agreed that as cow strain changed from lower (HD and NZ) to higher genetic potential (HP) for milk production, the GHG emissions per unit of product increased. This was due to a decline in cow fertility that resulted in a higher number of nonproductive animals leading to a lower total farm milk solids production and an increase in emissions from nonproductive animals. The GHG emissions per ha increased for all strains moving from HG to HS to HC feed 


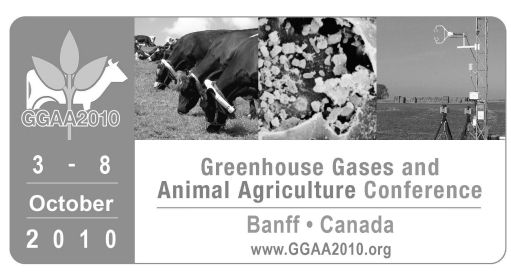

systems and this was associated with increases in herd feed intake. The most profitable combination was the NZ strain in the HS system and this combination also resulted in a $12 \%$ reduction in GHG emissions per ha compared with the NZ strain in the HC system, which produced the highest emissions. This demonstrates that grass-based systems can simultaneously achieve high profitability and decreased GHG emissions.

\section{R56. Minimizing Green House Gas emission through diet optimization}

M. S. Redshaw* and M. Binder

Numerous strategies have been developed to reduce the impact of animal agriculture on the production of greenhouse gases (GHG). This paper presents an approach based upon modelling the flow of contribution to the production of GHG in the diets of swine to minimize the impact at the animal level and thus contributing directly at an animal level to the efficiency and sustainability of meat production. Based on internationally recognized standards a tool was developed to model the flows of GHG leading to Global Warming Potential (GWP). These contributions are to calculate the impact of various feeding programs consisting of a range of raw materials drawn from those typically used in commercial production. This allows the producer to evaluate the GWP of varying feed formulation strategies. In addition to GWP the tool allows evaluation of the use of Primary Energy Demand (PED), Acidification and Eutrophication impact, and allowing a balanced view of often competing factors comparing three scenarios. This provides a new dimension to the daily business of optimizing diets allowing optimisation not only to be least cost but also finding solutions that are least impact. In this study three scenarios were evaluated using swine as a representative model to demonstrate the concept. These three scenarios were nutritionally equivalent, so that swine fed diets formulated for each scenario would be expected to achieve the same level of biological performance. The three scenarios were 'Standard' where soybean meal was the major protein source included in the diets, 'Rapeseed' where additionally rapeseed meal and oil were offered and 'Low Protein' where protein levels were lowered and compensated with addition of supplemental amino acids. The scenarios ran over three feeding phases 24-40, 40-70 and 70-105 kg, respectively. Results obtained in this study indicate that use of the Low Protein diet can reduce GHG emissions substantially, with reductions for PED, Acidification and Eutrophication compared to the Standard scenario. The scenario Rapeseed was intermediary to the treatments Standard and Low Protein for the parameters GWP and PED and close to the Standard scenario for the parameters Acidification and Eutrophication. This study demonstrates the potential of this model to allow meat producers to contribute significantly to reduction of GHG while still achieving the high level of animal performance required to be commercially competitive.

\section{R57. Software for evaluating greenhouse gas emissions and the carbon footprint of dairy production systems}

C. A. Rotz* and F. Montes

Dairy production, along with all other types of animal agriculture, is a recognized source of greenhouse gas (GHG) emissions, but little information exists on the net emissions from our farms. Component models for representing all important sources and sinks of $\mathrm{CH}_{4}, \mathrm{~N}_{2} \mathrm{O}$, and $\mathrm{CO}_{2}$ in dairy production were integrated in a software tool called the Dairy Greenhouse Gas Model or DairyGHG. This tool determines the farm-gate carbon footprint of a production system as the net exchange of all primary and secondary GHG emissions expressed in 


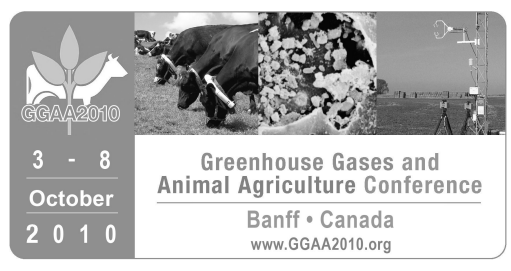

$\mathrm{CO}_{2}$ equivalent $\left(\mathrm{CO}_{2} \mathrm{e}\right)$ units per unit of energy corrected milk (ECM) produced. Primary emission sources include enteric fermentation, manure, cropland used in feed production, and the combustion of fuel in machinery used to produce feed and handle manure. Secondary emissions are those occurring during the production of resources used to produce milk, which can include fuel, electricity, machinery, fertilizer, pesticides, plastic, and purchased replacement animals. A long-term $C$ balance is assumed for the farm, which does not account for potential depletion or sequestration of soil $\mathrm{C}$. Evaluation of dairy farms of various sizes and production strategies has given farm-gate footprints of 0.37 to $0.75 \mathrm{~kg} \mathrm{CO}_{2} \mathrm{e}$ per $\mathrm{kg} \mathrm{ECM}$, depending upon milk production level and the feeding and manure handling strategies used. When biogenic sources and sinks of $\mathrm{CO}_{2}$ are ignored, this range increases to 0.67 to $0.95 \mathrm{~kg} \mathrm{CO} \mathrm{CO}_{2} \mathrm{e}$ per $\mathrm{kg} \mathrm{ECM}$. In a comparison to previous studies, DairyGHG predicted $C$ footprints similar to those reported when similar assumptions were made for feeding strategy, milk production, allocation method between milk and animal co-products, and sources of $\mathrm{CO}_{2}$ and secondary emissions. DairyGHG is available at http://www.ars.usda.gov/Main/docs.htm?docid=17355 for download and installation on computers using a Windows ${ }^{\circledR}$ operating system. This software provides a relatively simple tool for evaluating management effects on $n$ et GHG emissions and the overall $C$ footprint of dairy production systems. Graphical and tabular outputs provide estimates of all important GHG sources and sinks and a breakdown of the carbon footprint. A version of this GHG emission model is also included in the Integrated Farm System Model (IFSM). This comprehensive whole-farm simulation model predicts GHG emissions along with farm performance, economics, and other environmental impacts including ammonia emission, nitrate leaching, and phosphorus runoff. IFSM is available for download at http://www.ars.usda.gov/Main/docs.htm?docid=8519. IFSM provides a research tool for a more comprehensive evaluation and comparison of current and novel production strategies.

\section{R58. Modeling Greenhouse Gas Emissions from California Dairies: Manure-DNDC Model Development, Testing and Application}

W. Salas*, C. Li, and F. Mitloehner

In 2003, the National Academy of Sciences (NRC, 2003) found that EPA's current methodologies should be improved by using "process-based" models instead of an "emission factor" approach. Process-based models refer to models that are mechanistic and simulate biogeochemical processes. The measurement and monitoring of dairy-related air emissions and emission reductions is complex because the emission sources are dispersed and largely driven by biological activity with significant variability over time, space, and management practices. Emissions are further affected by local and regional meteorological and soil conditions. This complexity results from the interactions of a suite of biogeochemical processes such as decomposition, hydrolysis, nitrification, denitrification, fermentation, and ammonia volatilization. These microorganismmediated processes are highly sensitive to the quantity and quality of manure, which are controlled by feed sources, as well as the environmental factors (e.g., temperature, moisture, $\mathrm{pH}$, Eh etc.), which are driven by the local climate, soil and manure management measures. Over the past 20 years, the DNDC process-based model has been developed to predict impacts of various farming practices including fertilization and manure amendment on $\mathrm{C}$ and $\mathrm{N}$ biogeochemical cycles and trace gas emissions $\left(\mathrm{CH}_{4}\right.$ and $\left.\mathrm{N}_{2} \mathrm{O}\right)$ for the agro-ecosystems. A new version of DNDC (called Manure-DNDC) has been created for modeling GHG emissions from California dairies. A relatively complete suite of biogeochemical processes (e.g., mineralization, ammonification, ammonia volatilization, nitrification, denitrification, microbial assimilation etc.) have been parameterized and integrated into the Manure-DNDC model that enables the model to precisely track the life-cycle of manure. The model has been tested against observations in England, Scotland, Ireland and New Zealand where manure 


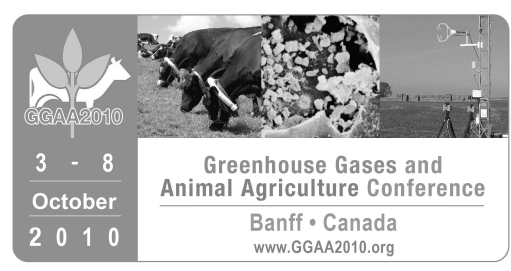

application is a dominant issue for agro-ecosystems. A number of on-going field or laboratory experiments are being conducted in California focusing on quantifying manure production and its impacts on ammonia, $\mathrm{N}_{2} \mathrm{O}$, $\mathrm{CH}_{4}$ and other gas emissions from dairy housing and drylots, manure treatments or processing, and field application. In addition, the environmental factors driving the manure life-cycle, such as climate, soil properties and farm management, have been incorporated in Manure-DNDC. This paper will present the theoretical basis of the Manure-DNDC model, results from recent model validation efforts and the modeling framework for compiling regional GHG emission inventories for animal agriculture.

\section{R59. Farm survey used to guide estimates of $\mathbf{N}$ intake and $\mathrm{NH}_{3}$ emissions, including early season grazing and piosphere effects}

S. Sheppard and S. Bittman*

National inventories of $\mathrm{N}$ emissions from cattle depend on reliable information about husbandry practices, with appropriate spatial and temporal resolution. A survey of $\sim 1400$ beef and $\sim 520$ dairy producers was used to quantify the prevalence of pasture and forage management practices that impact $\mathrm{N}$ intake and $\mathrm{NH}_{3}$ emissions. These data were coupled to a model to inventory $\mathrm{NH}_{3}$ emissions. The data allowed reconstruction of complete feed $\mathrm{N}$ by component to compare with reported total feed $\mathrm{N}$. The $\mathrm{N}$ intake from grazing is especially difficult to quantify. Early season grazing, when forages have elevated crude protein $(>30 \% \mathrm{CP})$, indicated potential for elevated emissions in May and June. Beef cattle were reported by producers to spend 17\% (range 7 to 30\%) of their time congregated, such as around waters or feed. This level of piosphere activity was attributed in the model to $20 \%$ increases in $\mathrm{NH}_{3}$ emissions relative to open pasture.

\section{R60. Methane production prediction of Thai native beef cattle}

K. Sommart*, K. Kongphitee, M. Otsuka, S. Udchachon and A. Takenaka*

The objective of this study was to establish methane prediction equations using a database from two energy feeding metabolism experiments (total 31 observations) in Thai native beef cattle. Methane production was measured using indirect calorimeter with a ventilated hood system at the Khon Kaen Animal Nutrition Research Center, Thailand. Simple and multiple regression techniques were used to examine the effect of animal and various dietary factors variables influencing methane production. Methane production $\left(L\right.$ day $\left.^{-1}\right)$ was highly $(P<$ $0.001)$ related to animal body weight $(\mathrm{BW}, \mathrm{kg})$, dry matter intake $\left(\mathrm{DMI}, \mathrm{kg} \mathrm{day}^{-1}\right)$ and gross energy intake $(\mathrm{GEl}$, $\mathrm{MJ}$ day $^{-1}$ ). The results from this study obtained by recommended equations are as follows: $\mathrm{CH}_{4}=0.035+0.627$ BW $\left(\mathrm{R}^{2}=0.52 ; P<0.001 ; \mathrm{RSD}=4.89 ; \mathrm{n}=31\right) ; \mathrm{CH}_{4}=69.088+22.497 \mathrm{DMI}\left(\mathrm{R}^{2}=0.35 ; P<0.001 ; \mathrm{RSD}=5.68 ; \mathrm{n}=\right.$ 31); $\mathrm{CH}_{4}=54.532+1.399 \mathrm{GEI}\left(\mathrm{R}^{2}=0.76 ; P<0.001 ; \mathrm{RSD}=3.45 ; \mathrm{n}=31\right) ; \mathrm{CH}_{4}=28.356+0.174 \mathrm{BW}+1.169 \mathrm{GEI}$ $\left(\mathrm{R}^{2}=0.78 ; P<0.001 ; \mathrm{RSD}=3.37 ; \mathrm{n}=31\right)$ and $\mathrm{CH}_{4}=49.209+2.863 \mathrm{DMl}+1.323 \mathrm{GEI}\left(\mathrm{R}^{2}=0.77 ; P<0.001 ; \mathrm{RSD}=\right.$ $3.49 ; n=31$. 


\section{R61. An LCA approach to assess GHG emissions from livestock production in Europe \\ F. Weiss and A. Leip*}

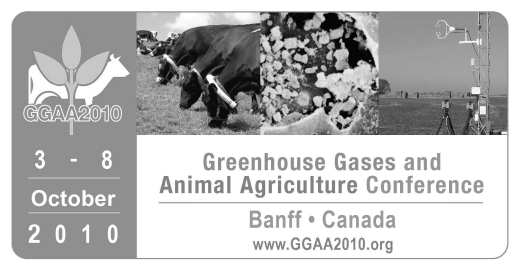

The contribution that the livestock sector makes to climate change has been on the front page of different media since the FAO published its report: "Livestock long shadow: environmental issues and options" at the end of 2006. The FAO report claims that livestock production is a major contributor to the world's environmental problems, including climate change. At the global level, the report estimates that livestock accounts for a significant share of greenhouse gas (GHG) emissions (about 18\% of total anthropogenic GHG emissions). However, GHG emissions from livestock production systems are highly variable across the world as are also the livestock production systems themselves. So, what is the carbon footprint of animal products made in Europe? And how does it relate to total GHG emissions from agriculture or total anthropogenic GHG emissions? To answer these questions, we have developed a food-chain approach in the framework of the project "Evaluation of the livestock sector's contribution to the EU greenhouse gas emissions" (GGELS), commissioned by the European Commission to its Joint Research Centre and running until December 2010. The quantification of greenhouse gas and ammonia emissions is carried out with the CAPRI model. CAPRI is a global economic model for agriculture with a regionalized focus for Europe. Its database comprises time series of mutually consistent national and regional data and covers market balances at the national scale. The quantification of methane emissions from enteric fermentation and manure management follows the IPCC 2006 guidelines, a Tier 2 approach for cattle activities and a Tier 1 approach for swine, poultry, sheep and goats. Nitrogen emissions are calculated according to a mass flow approach of the MITERRA-EUROPE model. It considers emissions sources as defined in the IPCC guidelines. Furthermore, we calculate GHG emissions from on-farm energy use including indirect emissions from machinery and buildings, pesticide usage and emissions from fertilizer production. Emissions from imported feeds are accounted for as well as emissions occurring during the transport of feed. Finally, we consider emissions from global land use changes induced by EU livestock production. Allocation of activity-based emissions to products is done on the basis of a physical/causal relationship: $\mathrm{CH}_{4}$ emissions from milk and meat production are distributed according to the energy requirement for lactation and growth and pregnancy, respectively. Other emissions are allocated according to the $\mathrm{N}$-content in the products. We present details of the methodology and first results of the calculations.

\section{R62. Operational requirements of a farm-specific greenhouse gas model - lessons from using OVERSEER in a regulatory framework}

D. M. Wheeler*, M. Shepherd and I. Power

OVERSEER ${ }^{\circ}$ nutrient budgets (Overseer) is a farm-specific model that provides nutrient budgets, environmental indices and greenhouse gas emission reports. Two important features of the model are that it uses inputs obtained easily from farmers, and it can model effects of a range of management and mitigation practices. The model is used extensively within New Zealand and is central to each farm producing a nutrient management plan. It is also increasingly being used as a tool in the implementation of regulatory policies for controlling $\mathrm{N}$ leaching and forms the basis for a cap and trade policy mechanism to control $\mathrm{N}$ leaching to Lake Taupo in Central North Island. Overseer is considered within NZ as a possible vehicle for calculating farm-specific greenhouse gas (GHG) emissions if a farm-specific trading scheme is adopted. Therefore, the role of Overseer in underpinning water quality policy serves as a useful case study in the operational challenges of using a farmscale model in an emissions trading scheme. The farm-specific estimates of GHG emissions requires inputs of (i) animal numbers and types and their diet to estimate $\mathrm{CH}_{4}$ emissions, (ii) fertiliser inputs and excreta urine to estimate nitrous oxide emissions, and (iii) fertiliser, supplements and fuel use to estimate embodied $\mathrm{CO}_{2}$ 


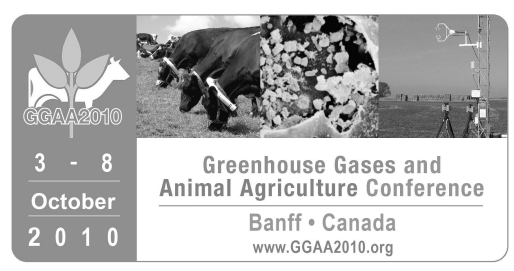

emissions. The inputs required to generate a farm GHG emissions report are essentially the same as those required for estimating $\mathrm{N}$ leaching. This paper uses Lake Taupo as a case study to highlight the challenges of using a nutrient management tool in a regulatory role, including 1 ) model description and examples of its use for GHG reporting, and 2) practical challenges in using the model in a regulatory role (model development, quality control and auditing training and accreditation of users). This paper will draw on the regulatory use of the Overseer model to indicate operational requirements for a farm-specific greenhouse gas model.

\section{R63. National methane emission inventory for domestic livestock in China \\ D. Wu*, T. Yan and B. Xue}

The present study aims to estimate methane emission inventories from enteric fermentation and manure management for domestic livestock in China, using Tier 1 methane emission factors of IPCC (2006) and national population of each species of domestic livestock in China in 2009. Animal species used include dairy cattle, beef cattle, buffalo, yak, mule, ass, camel, deer, horse, sheep, goat, rabbit, pig, chicken, turkey, goose and duck. The populations for growing/finishing animals and broiler poultry were adjusted for their life spans. As IPCC (2006) recommends no emission factors for yaks and rabbits, the factors for yaks were taken from those proposed for mules and asses because they have a similar range of live weight, while for rabbit, enteric factor was calculated from gross energy intake (GEI) and a ratio (3\%) of methane energy output as a proportion of GEI, and manure factor was estimated from organic matter excretion in feces and urine. Total methane emissions from enteric fermentation and manure management for domestic livestock in China in 2009 were estimated to be $8.345 \mathrm{Tg}$, with a carbon dioxide equivalent of $208.632 \mathrm{Tg}$ when assuming the global warming potential of methane being 25 times that of carbon dioxide. The majority of methane emission was derived from enteric fermentation (87.1\%). Beef cattle were the largest emitter ( $43.1 \%$ of total emission), followed by sheep (13.2\%), dairy cattle $(12.3 \%)$, pigs $(9.9 \%)$ and goats $(8.9 \%)$, while poultry $(2.8 \%$, including chickens, turkeys, geese and ducks), yaks $(1.8 \%)$, deer $(1.4 \%)$, horses $(1.4 \%)$, rabbits $(1.2 \%)$, mules and asses $(0.4 \%)$ and camels $(0,1 \%)$ had the lowest methane emissions. These results indicate that enteric fermentation of ruminant animals, especially for beef cattle, is the major area in research for development of mitigation strategies to reduce methane emissions from domestic livestock in China. Total methane emissions from domestic livestock, estimated from Tier 1 emission factors, in China in 2009 (8.345 $\left.\mathrm{Tg}_{\text {year }}{ }^{-1}\right)$ is much higher than that in Saudi Arabia in 2008 (0.101 Tg year $^{-1}$; Aljaoud et al., 2010) and Northern Ireland in 2005 (0.159 Tg year $^{-1}$; McCourt, 2007). However, when expressed as methane emission per human person or per km${ }^{2}$ of land, the value in China (6.3 kg person ${ }^{-1}$ or 895 $\mathrm{kg} \mathrm{km}^{2-1}$ ) was higher than that in Saudi Arabia (4.1 kg person ${ }^{-1}$ or $\left.45 \mathrm{~kg} \mathrm{~km}^{2-1}\right)$, but much lower than that in Northern Ireland $\left(93.7 \mathrm{~kg}\right.$ person ${ }^{-1}$ or $\left.11,508 \mathrm{~kg} \mathrm{~km}^{2-1}\right)$.

R64. Modelling the influence of increasing milk yield upon greenhouse gas emission and profitability considering different co-product allocation

M. Zehetmeier* and H. Hoffmann

A continuous increase in milk yields can be observed in many countries in the last decades. Besides economic advantages for farmers, improving milk yield is often considered an important method by which to decrease greenhouse gas (GHG) emissions per kilogram $(\mathrm{kg})$ of production. It should be considered that milk and beef production systems are often closely interlinked. Surplus calves and culled dairy cows play an important role in 


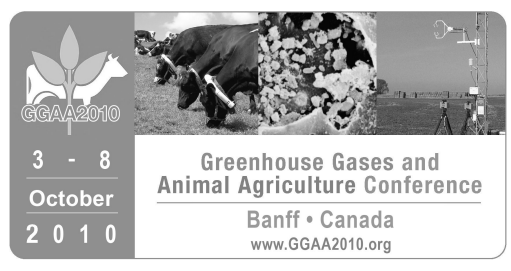

beef production in many countries. The aim of this study is to identify the influence of increasing milk yield of dairy cows on GHG emissions, beef production and economic parameters. Analyses of GHG emissions were undertaken using different methods of handling dairy co-products (surplus calves and meat from culled cows). Models were developed that incorporate several indoor dairy systems differing in milk yield and breed, bull fattening, heifer fattening and beef cow systems. The models simulate on-farm and off-farm emission sources of methane, nitrous oxide and carbon dioxide. The different methods for allocating GHG emissions to milk and co-products refer to the standard for life cycle inventory analysis - ISO 14041 of the International Organization for Standardization. Economic analysis includes different parameters such as profit per cow and return to labour. The study demonstrates that in general, profit per cow increases and the GHG efficiency of production improves with increasing milk yield. However, when GHG emissions (as $\mathrm{kg} \mathrm{CO}_{2} \mathrm{eq}$ ) of the dairy system are allocated to milk and co-products according to their economic value, the emission relative to farm profit displays only initial improvement in response to increased milk yield that does not persist in very high yield systems. In another system scenario, the fattening of surplus calves and beef breeding are added to the dairy system. This model enables comparison of various levels of milk production corrected to maintain a constant level of meat output. This system displays increasing GHG emissions with increasing milk yields. The profitability of this combined system only increases to a certain level of milk yield. This investigation demonstrates that the environmental (GHG) and economic evaluation of increasing milk yields in dairy farming differ depending upon the handling and value of co-products. The relative value of animal and beef co-products is related to the prevailing milk and beef price. It also has to be considered that quality of meat arising from dairy farm systems is often lower than quality of meat arising from beef farm systems.

\section{NOTES}


NOTES 


\title{
POST-CONFERENCE WORKSHOP ABSTRACTS
}

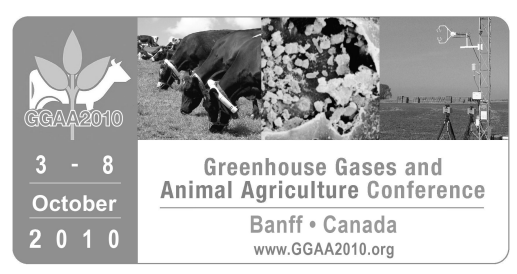

\section{Greenhouse Gases and Sustainable Animal Agriculture for Developing Countries}

\author{
Profile of methane by grazing ruminants and its mitigation strategies in China \\ R. J. Long*, J. D. Mi and X. D. Huang*
}

Enteric fermentation is one of the major contributors to the Greenhouse gas emission inventory in China. Methane emissions by grazing ruminants are serious due to the sharply increasing number. Therefore, this paper aims to introduce the situation of grazing ruminants and seek some effective ways to mitigate methane emissions in China. The data of number of grazing ruminants is based on China Animal Industry Yearbook $(2001,2008)$. The evaluation of methane emission by grazing ruminants is according to the following formula:

$$
\mathrm{CH}_{4 \text { livestock }} \sum_{i, j}\left(P_{i, j} \bullet E F_{i, j}\right) \text {. }
$$

Most of grazing ruminants are distributed around three areas: the Qinghai-Tibetan Plateau, Inner Mongolia Plateau and Xinjiang Area. In 2007, there were 27.47 million grazing cattle, 89.87 million grazing sheep and 36.17 million grazing goats which comprised of 25,63 and $25 \%$ of total national number of cattle, sheep and goat respectively. The number of grazing cattle, sheep and goat increased by $29 \%, 24 \%$ and $39 \%$ respectively, compared with the figures obtained in 2000. In 2007, methane emissions by grazing cattle, sheep, and goat were $0.96,0.45$ and $0.18 \mathrm{Tg}$ respectively which comprised of 20,57 and $20 \%$ of the total national methane production by those animals, respectively. From 2000 to 2007, methane production by grazing animals increased with the increment of the population of those three animal species. Mitigation strategies for grazing ruminants are found more difficult than indoor-feeding animals. Many methods have been proven to have positive impacts for reducing methane emission in research stage. Some policies have been taken by government, such as, "National Enclosure and Grazing Prohibition" Project which lead to a certain proportion of grazing livestock being kept for indoor feeding with grain supplementation. At present, Payment for Ecosystem Service (PES), also known as Payments for Environmental Services, is being utilized for improving rangeland ecosystem function through compensation of herd size reduction in individual households. Some applicable and effective approaches to mitigate methane emissions by grazing ruminants at farm level are also discussed such as 1) controlling or reducing the number of ruminants through increasing the slaughtering rate; 2) shortening the production cycle of grazing ruminant; 3) improving grazing management system such as concentrate supplementation. They have presented positive results, but more work is necessary for achieving long-term effect.

The effect of tea was on methane production in Ongole crossbred cattle

A. Purnomoadi*, M. F. Harlistyo, R. Adiwinarti, E. Rianto, O. Enishi* and M. Kurihara*

Please see abstract T104, Session 4: Mitigation Strategies for Enteric Methane, Page 149 


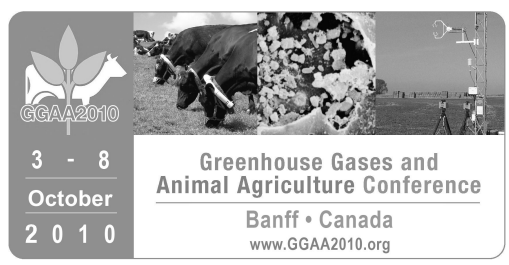

\author{
Methane production prediction of Thai native beef cattle \\ K. Sommart*, K. Kongphitee, M. Otsuka, S. Udchachon, and A. Takenaka*
}

The objective of this study was to establish methane prediction equations using a database from two energy feeding metabolism experiment (total 31 observations) in Thai native beef cattle. Methane production was mesured using indirect calorimeter with a ventilated hood system at Khon Kaen Animal Nutrition Research Center, Thailand. Simple and multiple regression technique were used to examine the effect of animal and various dietary factors variable influencing methane production. Methane production (L/day) was highly $(\mathrm{P}<0.001)$ relationship with animal body weight $(\mathrm{BW}, \mathrm{kg})$, dry matter intake(DMI,kg/day) and gross energy intake(GEI,MJ/day). The result from this study obtained recommended equations are as follows; $\mathrm{CH}_{4}=0.035+$ $0.627 \mathrm{BW}\left(\mathrm{R}^{2}=0.52 ; \mathrm{P}<0.001 ; \mathrm{RSD}=4.89 ; \mathrm{n}=31\right) ; \mathrm{CH}_{4}=69.088+22.497 \mathrm{DMI}\left(\mathrm{R}^{2}=0.35 ; \mathrm{P}<0.001 ; \mathrm{RSD}=5.68 ; \mathrm{n}=\right.$ 31); $\mathrm{CH}_{4}=54.532+1.399 \mathrm{GEI}\left(\mathrm{R}^{2}=0.76 ; \mathrm{P}<0.001 ; \mathrm{RSD}=3.45 ; \mathrm{n}=31\right) ; \mathrm{CH}_{4}=28.356+0.174 \mathrm{BW}+1.169 \mathrm{GEI}\left(\mathrm{R}^{2}=\right.$ $0.78 ; \mathrm{P}<0.001 ; \mathrm{RSD}=3.37 ; \mathrm{n}=31)$ and $\mathrm{CH}_{4}=49.209+2.863 \mathrm{DMI}+1.323 \mathrm{GEI}\left(\mathrm{R}^{2}=0.77 ; \mathrm{P}<0.001 ; \mathrm{RSD}=3.49 ; \mathrm{n}=\right.$ $31)$.

\title{
Effect of tannins on rumen fermentation, protozoa population and methanogenesis in vitro R. Bhatta*, M. Saravanan, L. Baruah, and K.T. Sampath
}

The present study was carried out to determine the effect of 13 tree leaves containing tannin on in vitro rumen fermentation, protozoa population and methanogenesis. Total phenol (TP) content in Azardirachta indica, Ficus bengalensis and Semaroba glauca was $>100 \mathrm{~g} / \mathrm{kg}$ DM. The TP was lowest in Jatropha curcus and Morus alba (12 $\mathrm{g} / \mathrm{kg} \mathrm{DM})$. The rumen fermentation and methane production were studied after $24 \mathrm{~h}$ incubation in the in vitro Hohenheim gas method. Activity of tannins, as represented by the increase in gas on addition of polyethylene glycol (PEG)-6000 ranged from 1.0 to 554 \%, with highest being in Ficus bengalensis (554\%) followed by Azardirachta indica (78.5 \%). The methane production reduction potential (MRP) was calculated by assuming net methane concentration for the control straw (Elusine coracana) as $100 \%$. The MRP of Autocarpus integrifolis, Sesbania grandiflora and Ficus religiosa was $>34.0$ percent The MRP of zero for Ficus bengalensis, Jatropha curcus and Morus alba meant that the methane concentration for this sample was the same as that of the control hay (Elusine coracana). Similarly, zero values of percent increase in methane on addition of PEG for Leucena leucocephala and Ficus bengalensis illustrate that the tannins in these samples do not contribute to methane concentration. The increase (\%) in protozoa population on addition of PEG was maximum in Ficus racemosa (50) followed by Glyricidia maculate (31.2), Ficus mysoriensis (29.9) and Ficus religiosa (27.5). The zero per cent increase in protozoa population indicated that the methane reduction observed in these samples was not due to defaunation effect caused by tannin. The increase in total volatile fatty acid concentration in samples when incubated with PEG-6000 ranged from 0.6 to $>69.8 \%$. The highest increase (\%) in $\mathrm{NH}_{3}-\mathrm{N}$ was recorded in Ficus mysoriensis (67.4) followed by Semaroba glauca (35.7) and Ficus religiosa (32.7) leaves reflecting the protein binding properties of phenolics in these leaves. Our results established that in vitro methanogenesis was not essentially related to the density of protozoa population and tree leaves studied containing tannins appear to have the potential to suppress methanogenesis. 


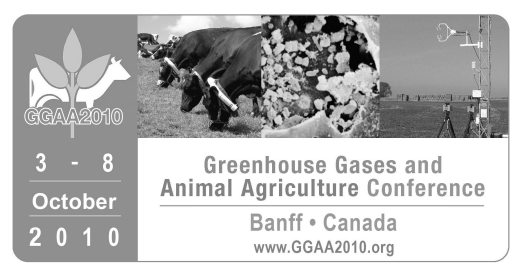

\section{A study of using different plant sources in association with pig manure for in vitro biogas production in the Mekong delta of Vietnam}

N. Van Thu*

Please see poster abstract M54 in Session 2: Nitrous Oxide and Methane Losses from Livestock Manure Atmospheric Emissions and Biogas Capture, Page 74

\section{Assessing Nitrogen excretion and gaseous Nitrogen loss during housing and storage of pig manure V.T. Khanh Van, V.C. Cuong*, T.M. Tien and S.G. Sommer*}

The assessment of the nitrogen cycle from feed via waste to the environment is an important process, as the excess of $\mathrm{N}$ lost can harm air, soil and groundwater quality. This paper focuses on estimating daily $\mathrm{N}$ excretion and losses during housing and composting under typical Vietnamese conditions. The feed-excretion experiment was carried out with three dietary treatments, which were high protein and low fibre $(\mathrm{H}-\mathrm{L})$, medium protein and medium fibre (M-M), and low protein and high fibre (L-H)) diets. Manure from feed-excretion experiment was used for compost and storage experiments. The solid fraction was composted for 70 days in insulated polystyrene boxes. The three composting methods used were in accordance with three additive combinations commonly used in Vietnam: adding straw only; adding straw $+2 \%$ lime and adding straw $+5 \%$ single superphosphate (SSP). The liquid fraction and slurry (mix liquid and solid) was storage in containers with and without tight PVC covers for 30 days and 90 days, respectively. Faecal $\mathrm{N}$ excretion, in contrast to urinary $\mathrm{N}$ excretion, was not significantly influenced by dietary content. The total $\mathrm{N}$ loss during housing estimated at $12 \%$ of the total $\mathrm{N}$ excretion. The total $\mathrm{N}$ loss for the uncovered method accounted for about $60 \%$ of original $\mathrm{N}$, while only approximately $30 \%$ was lost for the covered method. The composting method using SSP results in small $\mathrm{N}$ losses of approximately $30 \%$ of initial $\mathrm{N}$. In contrast, the $\mathrm{N}$ loss was rather high, at about $50 \%$ of initial $\mathrm{N}$ content retaining at post composting in composts with lime or straw. These results of $\mathrm{N}$ contents and losses are important for manure application so that $\mathrm{N}$ can be adjusted to ensure optimal nutritive value while at the same time minimizing environmental damage.

\section{Challenges of mitigating greenhouse gases from animal agriculture in third world countries}

\section{J.B. Liang*, Y. Wang, and M.F. Johromi}

Populations of both ruminant and non-ruminant livestock in Africa and Asia exceed those from Americas and Europe. The above suggests that the emission of greenhouse gases (GHG) and the mitigation of these gases deriving from animal agriculture are more critical in the African and Asian countries, making up the bulk of the developing countries in the world, than in the developed countries. The primary source of methane from animal agriculture is from the enteric fermentation of non-starch carbohydrates in ruminant livestock. Majority of the buffaloes, cattle, sheep and goats in the developing countries in Africa and Asia are fed with poor quality forages, crop residues and agro-industrial by-products, and thus further aggravate the above problem. The use of better quality feed including supplementation with high energy-protein concentrates has been proven to be an effective way to reduce methane production from ruminant livestock. However, such practice is beyond the ability of most farmers in the third world countries. Express emission of GHG from animal agriculture based on productivity, such as $\mathrm{g} \mathrm{GHG/kg} \mathrm{milk} \mathrm{or} \mathrm{meat} \mathrm{produced} \mathrm{is} \mathrm{idealistic} \mathrm{but} \mathrm{productivity} \mathrm{as} \mathrm{interpreted} \mathrm{by} \mathrm{the}$ developed world is not often applicable to many third world countries because, in the latter, owning livestock is an expression of the socio-economic status of the owners. In some countries, cattle and buffaloes are kept 
for religious and cultural reasons and thus economic productivity is not relevant to them. Release of methane and other GHG from livestock waste treatment systems is another source of GHG from livestock production. Unfortunately, livestock waste treatment is of low priority in most third world countries because producing bulk cheap animal protein to feed the accelerated increased human population is their priority. Current approaches taken by the developed countries to mitigate GHG from animal agriculture are of limited applications to the developing world, at least in the immediate and near future. Emphasis must therefore be given to search for a practical solution to mitigate the emission of GHG from animal agriculture in the third world countries in order to effectively mitigate global GHG emission from the livestock industry.

\section{NOTES}

